\title{
The Role of Aspirations \\ in Collective Action and Labor Markets
}

\author{
Thesis \\ in fulfillment of the \\ requirements for the degree of Dr. rer. pol \\ from the Faculty of Economics at \\ Georg-August-University Göttingen \\ submitted by \\ Christina Andrea Martini \\ born on November 10, 1988 in Frankfurt a.M.
}

Göttingen, October 2020 
1. Referee: Prof. Marcela Ibañez Diaz, Ph.D.

2. Referee: Prof. Dr. Meike Wollni

3. Referee: Prof. Dr. Menusch Khadjavi

Date of submission: October 8, 2020 


\section{Promotionsstudiengang „Wirtschaftswissenschaften“ \\ Versicherung bei Zulassung zur Promotionsprüfung}

Ich versichere,

1. dass ich die eingereichte Dissertation

selbstständig angefertigt habe und nicht die Hilfe Dritter in einer dem Prüfungsrecht und wissenschaftlicher Redlichkeit widersprechenden Weise in Anspruch genommen habe,

2. dass ich das Prüfungsrecht einschließlich der wissenschaftlichen Redlichkeit - hierzu gehört die strikte Beachtung des Zitiergebots, so dass die Übernahme fremden Gedankenguts in der Dissertation deutlich gekennzeichnet ist - beachtet habe,

3. dass beim vorliegenden Promotionsverfahren kein Vermittler gegen Entgelt eingeschaltet worden ist sowie im Zusammenhang mit dem Promotionsverfahren und seiner Vorbereitung

- $\quad$ kein Entgelt gezahlt oder entgeltgleiche Leistungen erbracht worden sind

- keine Dienste unentgeltlich in Anspruch genommen wurden, die dem Sinn und Zweck eines Prüfungsverfahrens widersprechen

4. dass ich eine entsprechende Promotion nicht anderweitig beantragt und hierbei die eingereichte Dissertation oder Teile daraus vorgelegt habe.

Mir ist bekannt, dass Unwahrheiten hinsichtlich der vorstehenden Versicherung die Zulassung zur Promotionsprüfung ausschließen und im Falle eines späteren Bekanntwerdens die Promotionsprüfung für ungültig erklärt werden oder der Doktorgrad aberkannt werden kann.

Datum Unterschrift 


\section{Overview of co-authors}

1. The papers "Community Aspirations and Collective Action" and "Community Aspirations and Cooperation: Prescriptive vs. Descriptive Role Models" are both coauthored with Marcela Ibañez Diaz and Menusch Khadjavi.

Marcela Ibañez Diaz and Christina Martini jointly developed the overall research idea and the conceptual framework. All authors contributed to the development of the research design and the instruments. Christina Martini prepared the literature review and the videos. Menusch Khadjavi organized the government permission to run the research in Zambia, and together with Christina Martini recruited the field research team, handled the logistics of the field work and implemented the pilot. Christina conducted the field work, the data cleaning, the data analysis, and wrote the first draft of the paper. Marcela Ibañez Diaz contributed to the data analysis as well as improved and extended the paper. Menusch Khadjavi provided feedback and helpful suggestions at all stages of writing the paper.

2. The paper "Can Role Model Videos Influence Female's Decision to Participate in the Labor Market? Evidence from a Field Experiment" is coauthored with Viviana Urueña.

Viviana Urueña and Christina Martini jointly developed the research idea, the experimental design and the instruments. They wrote the video script and produced the three videos used in the study. Viviana Urueña collected and cleaned the data. Christina Martini cleaned and analyzed the data and provided the initial literature review. Viviana Urueña contributed to the data analysis and the literature review. Both wrote the final draft of the paper.

Date, Signature 


\section{Acknowledgements}

I would like to express my gratitude to my first supervisor Prof. Marcela Ibañez Diaz, Ph.D. It was a great opportunity to learn from her. Her ideas and comments have encouraged me to think deeper and led me to broaden my mind. She always took the time to hear my questions and provided me with answers and advice that helped me advance. I am grateful for her commitment and effort that she put into the improvement of our papers. I appreciate all her ideas, time and funding that allowed me to write this thesis.

I thank Prof. Stephan Klasen, Ph.D. for his support being my second supervisor, especially for responding and helping me so quickly. I am glad to have been part of the Development Economics Group and the "Göttinger Schule" that he developed.

For introducing me to the field of experimental economics, proposing Zambia as a field site, assisting me with the preparation of the field experiments, and providing helpful comments, I am grateful to my third supervisor, Prof. Dr. Menusch Khadjavi. This was the first time for me to stay in Zambia and also the first time to conduct an experiment. I am therefore glad that Menusch introduced me to many people in Zambia, who have supported me during my stay.

I would like to thank Prof. Dr. Meike Wollni for commenting on our paper and providing helpful suggestions at the GlobalFood doctoral seminars and for joining the examination committee at such a short notice. For providing in-depth feedback on papers presented at the GlobalFood doctoral seminars, I also thank Prof. Dr. Holger A. Rau.

I am grateful to have been part of the RTG1666 GlobalFood and acknowledge the funding of the DFG. The RTG membership not only allowed me to conduct the many experiments, surveys, travels and hiring of research assistants, but also provided the opportunity to learn from other doctoral students and professors during the many seminars and meetings. I therefore thank the leadership and management for making this possible. I would also like to thank Dr. Friederike Lenel for the helpful comments on one of the papers and for her commitment in organizing the Development Economics and GlaD Seminar and various expert talks from which I learned a lot through participating.

This thesis is based on results from three experiments and several surveys that build on the collaboration of many people in the field. I express my gratitude to the numerous farmers and students in Zambia and Madagascar for taking the time to participate in our experiments and surveys. I thank all the research assistants - in Germany and Zambia for their work and commitment. A special thanks goes to Paul Malambo for being the best 
coordinator I could have hoped for. I am impressed with how much sensitivity, understanding and humor he was able to immediately gain the trust of the farmers. I would also like to thank Dr. Kacana Khadjavi, Charity and Muyambo Sipangule for their assistance prior and during the data collection. It was so much worth to have a place I could go if I needed help.

For welcoming me so warmly and always providing encouragement and help when needed, I would like to thank my colleagues from the Behavioral Development Economics Group: Dr. Pooja Balasubramanian, Dr. Alexia Gaudeul, Dr. Daniel Kromer, Tatiana Orozco Garcia, Prof. Dr. Gerhard Riener and Viviana Urueña. I thank Viviana for all the effort she has put into our joint project. I really appreciate our team work. I am indebted to Pooja for being the guardian of my plants and my flat. Viviana, Pooja and Tatiana - I am happy that the Economics Community has so wonderful young female researchers as you are.

I enjoyed the support of and gatherings with my GlobalFood colleagues at various seminars, retreats and coffee breaks. I especially thank Dr. Cansin Arslan, Nina Graßnick, Dr. Martin C. Parlasca, Dr. Anette Ruml and Dr. Liza von Grafenstein for making the time at the "HDW" so pleasant. I thank Nina, for her honest advice, moral support and the fun afterwork activities that we did together. Martin has been a great office mate, whom I thank for for his constant readiness to provide me with high quality comments when I needed feedback.

I am grateful to have the love, support and understanding of my husband, Peter. I cannot thank you enough for always being by my side and supporting me in every endeavor I undertake. My deepest gratitude also goes to my parents, Michaela and Klaus, for their support throughout the years and keen interest in my work; my sister, Tanja, who had to wait so long until I got to visit her; my parents-in-law, Pia and Achim, for providing a space to work and to rest.

Lastly, I am thankful for my friends outside Göttingen - for the laughter, good times and support in the last years: "Die Orscheler Mädels \& Jungs" Alina, Anne, Annika, Katrin \& Oliver, Lena and Sarah \& Chris; "Die Kieler" Alex, Eike, Gothlind, Helge, Nils, Lena and Urte; and "Die Bayern" Chrissi, Evi and Michi. 
"[E]xpectations about what people are able or unable to do all too often end up turning into self-fulfilling prophecies. Children give up on school when their teachers (and sometimes their parents) signal to them that they are not smart enough to master the curriculum; fruit sellers don't make the effort to repay their debt because they expect that they will fall back into debt very quickly; nurses stop coming to work because nobody expects them to be there; politicians whom no one expects to perform have no incentive to try improving people's lives. Changing expectations is not easy, but it is not impossible [...]."

Abhijit Banerjee and Esther Duflo (2011, p. 271) 


\section{Contents}

$\begin{array}{ll}\text { Acknowledgments } & \text { ix }\end{array}$

List of Tables $\quad$ xvii

List of Figures $\quad$ xix

List of Acronyms xxi

1 Introduction 1

1.1 Research Objectives and Contribution . . . . . . . . . . . . . . . . 1

1.2 Methods . . . . . . . . . . . . . . . . . . . . . . . 5

1.3 Summary of the Chapters . . . . . . . . . . . . . . . 5

1.3.1 Chapter 2 Community Aspirations and Collective Action . . . . . . . 6

1.3.2 Chapter 3 Community Aspirations and Cooperation: Prescriptive vs. Descriptive Role Models . . . . . . . . . . . . . . . . . . . 7

1.3.3 Chapter 4 Can Role Model Videos Influence Female's Decision to Participate in the Labor Market? . . . . . . . . . . . . . . . . . 8

2 Community Aspirations and Collective Action 11

2.1 Introduction . . . . . . . . . . . . . . . . . . . . . . . . 12

2.2 Conceptual Framework . . . . . . . . . . . . . . . . . . . . 15

2.2.1 Collective Action and Community Aspirations . . . . . . . . . . . . 17

2.2.2 Measurement of Community Aspirations . . . . . . . . . . . . . . 19

2.3 Empirical Strategy . . . . . . . . . . . . . . . . . . . . . . . 20

2.3.1 Experimental Design . . . . . . . . . . . . . . . . . . . 21

2.3.2 Treatment Videos . . . . . . . . . . . . . . . . . . . 22

2.3.3 Cooperation Measure . . . . . . . . . . . . . . . . . . . . 23

2.3.4 Hypotheses . . . . . . . . . . . . . . . . . . . 24

2.3.5 Experimental Procedures . . . . . . . . . . . . . . 25

2.4 Results . . . . . . . . . . . . . . . . . . . . 25

2.4 .1 Community Aspirations . . . . . . . . . . . . . . . . . 28 
2.4.2 Econometric Analysis . . . . . . . . . . . . . . . . . . . 30

2.4.3 Impact of Community Aspirations on Cooperation . . . . . . . . . . 31

2.4.4 Treatment Effects on Cooperation . . . . . . . . . . . . . 32

2.4.5 Treatment Effects on Aspirations and Beliefs . . . . . . . . . . . . 34

2.4 .6 Robustness . . . . . . . . . . . . . . . . . 36

2.5 Discussion . . . . . . . . . . . . . . . . . . 37

2.6 Conclusion . . . . . . . . . . . . . . . . . . . . . . . . 38

2.7 Appendix A - Tables . . . . . . . . . . . . . . . . . . . 41

2.8 Appendix B - Experimental Instructions and Surveys . . . . . . . . . . . . . 45

2.8.1 General Instructions . . . . . . . . . . . . . . . . . . . . 45

2.8 .2 Experimental Instructions . . . . . . . . . . . . . . . . . 46

2.8.3 Smallholder Survey . . . . . . . . . . . . . . . . . . . . . . . . . 48

2.8.4 Village Survey . . . . . . . . . . . . . . . . . . 57

2.9 Appendix C - Video Scripts . . . . . . . . . . . . . . . . . . . . . 62

2.9.1 Collective Action Video . . . . . . . . . . . . . . . . 62

2.9.2 Village Life Video . . . . . . . . . . . . . . . . . . 65

3 Community Aspirations and Cooperation: Prescriptive vs. Descriptive Role Models

3.1 Introduction . . . . . . . . . . . . . . . . . . . 70

3.2 Experimental Design . . . . . . . . . . . . . . . . . . . . . . 72

3.2 .1 Treatments . . . . . . . . . . . . . . 73

3.2 .2 Public Goods Game . . . . . . . . . . . . . . . . . . . 75

3.2 .3 Survey . . . . . . . . . . . . . . . . . . 76

3.2.4 Experimental Procedures . . . . . . . . . . . . . . . . 78

3.2 .5 Hypotheses . . . . . . . . . . . . . . . . . . . 78

3.2 .6 Empirical Strategy . . . . . . . . . . . . . . . . . . 80

3.3 Results . . . . . . . . . . . . . . . . . . . . . 80

3.3 .1 Descriptives . . . . . . . . . . . . . . . . . 80

3.3.2 Treatment Effects on Unconditional Cooperation . . . . . . . . . . . 82

3.3.3 Treatment Effects on Conditional Cooperation . . . . . . . . . . . . 84

3.3.4 Treatment Effects on Aspirations, Expectations and Beliefs . . . . 86 
3.4 Mechanism . . . . . . . . . . . . . . . . . . . 87

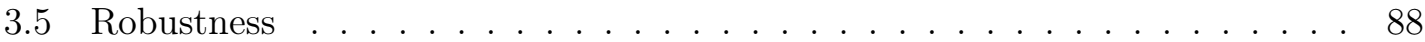

3.6 Discussion . . . . . . . . . . . . . . . . . . . . . . . . . . . . 89

3.7 Conclusion . . . . . . . . . . . . . . . . . . . . . . . . . . 91

3.8 Appendix A - Tables . . . . . . . . . . . . . . . . . . . . 93

3.9 Appendix B - Experimental Instructions and Surveys . . . . . . . . . . . . . 94

3.9 .1 General Instructions . . . . . . . . . . . . . . . . . . . . . 94

3.9.2 Experimental Instructions . . . . . . . . . . . . . . . . . . . 96

3.9 .3 Smallholder Survey . . . . . . . . . . . . . . . . . . . . . . . 104

3.9 .4 Village Survey . . . . . . . . . . . . . . . . . . . . 111

4 Can Role Model Videos Influence Female's Decision to Participate in the Labor Market?

4.1 Introduction . . . . . . . . . . . . . . . . . . . . . . . 116

4.2 Conceptual Framework . . . . . . . . . . . . . . . . . . . . . . . . . . 119

4.2.1 Role Models and Female Labor Market Outcomes . . . . . . . . . . . 119

4.2 .2 Hypotheses . . . . . . . . . . . . . . . . . . . . . . . . 120

4.3 Context, Experimental Design and Procedures . . . . . . . . . . . . . . . . 121

4.3 .1 Field Context . . . . . . . . . . . . . . . . . . . . . 121

4.3 .2 Experimental Design . . . . . . . . . . . . . . . . . . . 123

4.3.3 Experimental Procedures . . . . . . . . . . . . . . . . . 130

4.4 Empirical Strategy . . . . . . . . . . . . . . . . . . . . . . . . 132

4.5 Results . . . . . . . . . . . . . . . . . . . . . . . . 133

4.5.1 Descriptive Statistics and Randomization Checks . . . . . . . . . 133

4.5.2 Role Model Assessment . . . . . . . . . . . . . . . . . . . . . 135

4.5.3 Treatment Effects on Applications . . . . . . . . . . . . . . . . 136

4.6 Exploratory Analysis . . . . . . . . . . . . . . . . . . . . . . . 139

4.6.1 Descriptive Statistics of Mechanism Variables . . . . . . . . . . . 139

4.6.2 Treatment Effects on Mechanism Variables . . . . . . . . . . . . . . 140

4.6.3 Can the Mechanism Variables Explain Behavior in the Field Experiment? . . . . . . . . . . . . . . . . . . . . 143

4.7 Discussion . . . . . . . . . . . . . . . . . . . . . . . . 144 
4.8 Conclusion . . . . . . . . . . . . . . . . . . . . . . . . . . 146

4.9 Appendix A - Tables . . . . . . . . . . . . . . . . . . . . . . . . 148

4.10 Appendix B - Experimental Instructions and Survey . . . . . . . . . . . . 150

4.10 .1 General Instructions . . . . . . . . . . . . . . . . . . 150

4.10 .2 Lab-in-the-Field Instructions . . . . . . . . . . . . . . . . . 152

4.10 .3 Survey . . . . . . . . . . . . . . . . . . . . . 169

4.10.4 Field Experiment Instructions - Job Announcement . . . . . . . . . 177

4.10 .5 Job Application Form . . . . . . . . . . . . . . . . . . . 181

4.11 Appendix C - Video Scripts . . . . . . . . . . . . . . . . . . . . . 182

4.11 .1 Female Role Model Video . . . . . . . . . . . . . . . . . . . . . . . 182

4.11 .2 Male Role Model Video . . . . . . . . . . . . . . . . . . . . . 185

4.11 .3 Placebo Video . . . . . . . . . . . . . . . . . . . 188

5 Conclusion and Way Forward 191

$\begin{array}{ll}\text { Bibliography } & 207\end{array}$ 


\section{List of Tables}

2.1 Community Aspiration Indicators . . . . . . . . . . . . . . . . . . 20

2.2 Summary Statistics by Treatment . . . . . . . . . . . . . . . . . . . . 27

2.3 Current and Aspired Welfare . . . . . . . . . . . . . . . . 30

2.4 Aspiration and Cooperation in Collective Action . . . . . . . . . . . . . 32

2.5 Actual and Reported Contributions . . . . . . . . . . . . . . . . . 34

2.6 Treatment Effects on Aspirations and Beliefs _. . . . . . . . . . . 36

2.7 Correlates of Community und Individual Aspirations . . . . . . . . . . . . . 41

2.8 Treatment Effects on Community Aspirations Dimensions . . . . . . . . . . 41

2.9 Treatment Effects on Different Indices _. . . . . . . . . . . . . . . . 42

2.10 Variable Description . . . . . . . . . . . . . . . . . . . 43

2.11 Variable Description $2 \ldots \ldots \ldots \ldots \ldots$

3.1 Number of Participants Per Treatment . . . . . . . . . . . . . . . . . 73

3.2 Community Aspiration Dimensions . . . . . . . . . . . . . . 76

3.3 Summary Statistics . . . . . . . . . . . . . . . . . . . . . . . 81

3.4 Treatment Effects on Unconditional Contributions . . . . . . . . . . . . . . 84

3.5 Percentage of Participants Per Cooperation Behaviour in Each Treatment . 85

3.6 Treatment Effects on Conditional Contributions . . . . . . . . . . . . . . . 86

3.7 Treatment Effects on Aspirations, Expectations, Beliefs and Trust . . . . . . 87

3.8 Mechanism: Unconditional Contributions . . . . . . . . . . . . . . . . 88

3.9 Treatment Effects on Unconditional and Positive Unconditional Decisions Reduced Sample . . . . . . . . . . . . . . . . . . . . . . . 93

3.10 Treatment Effects on Conditional Contributions Reduced Sample . . . . . . 93

4.1 Summary Statistics . . . . . . . . . . . . . . . . . . . . . . 134

4.2 Rating of the Role Model . . . . . . . . . . . . . . . . . . . . . 136

4.3 Treatment Effects on Applications _. . . . . . . . . . . . . . . 138

4.4 Mechanism Variables in the Placebo Group . . . . . . . . . . . . . . . . . 139

4.5 Treatment Effects on Performance and Competitive Preferences . . . . . . . 142

4.6 Treatment Effects on Aspirations and Beliefs . . . . . . . . . . . . . . . 142 
4.7 Relation of Mechanism Variables to Complete Application . . . . . . . . . . 143

4.8 Relation of Mechanism Variables to Applications to the Coordinator Position 144

4.9 Aspirations in the Placebo Group by Gender . . . . . . . . . . . . . . . . . 148

4.10 Treatment Effects on Applications: Probit Model . . . . . . . . . . . . . . . 149

4.11 Multiple Hypothesis Testing ． . . . . . . . . . . . . . . . . . . . . . 149 


\section{List of Figures}

2.1 Conceptual Framework . . . . . . . . . . . . . . . . . . . . . . . . . . . 18

2.2 Location of Study _ . . . . . . . . . . . . . . . . . . . . . . . . 21

2.3 Experimental Design . . . . . . . . . . . . . . . . . . . . . . . . . 21

3.1 Proportion of Positive Contributors and Mean Unconditional Contributions 82

3.2 Poster $1 \ldots \ldots \ldots \ldots \ldots$

3.3 Poster $2 \ldots \ldots \ldots \ldots \ldots$

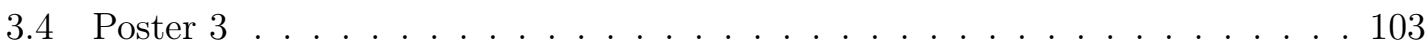

4.1 Structure Experimental Session . . . . . . . . . . . . . . . . . . . . 123

4.2 Example Task . . . . . . . . . . . . . . . . . . . . . . . . 128

4.3 Study Region . . . . . . . . . . . . . . . . . . . . . . . . 132

4.4 Applications to Assistant and Coordinator Position by Gender . . . . . . . . 137

4.5 Education Scale . . . . . . . . . . . . . . . . . . . . . . . . . 154

4.6 Income Scale . . . . . . . . . . . . . . . . . . . . . . . . 154

4.7 Social Status Ladder . . . . . . . . . . . . . . . . . . . . . . . . . 155

4.8 Asset Scale . . . . . . . . . . . . . . . . . . . . . . . 156 


\section{List of Acronyms}

ATT Average Treatment Effect on the Treated

CA Video Collective Action Video

CSO Central Statistical Office

CV Curriculum Vitae

DRC Democratic Republic of the Congo

FAO Food and Agriculture Organization of the United Nations

GPA Grade Point Average

GSE Generalized Self-Efficacy

HDI Human Development Index

ILO International Labour Organization

PGG Public Goods Game

MPI

Multidimensional Poverty Index

OLS

RCT

Ordinary Least Squares Estimation/Regression

SAVA Sambava-Antalaha-Vohemar-Andapa Region (Madagascar)

SDGs Sustainable Development Goals

SE Self-Efficacy

STEM Science, Technology, Engineering, and Mathematics

UNESCO United Nations Educational, Scientific and Cultural Organization

UNFPA United Nations Population Fund

UNICEF United Nations Children's Fund

USD US-Dollar

VL Video Village Life Video 


\section{Introduction}

"Failure to address the psychosocial determinants of human behaviour is often the weakest link in social policy initiatives. Simply providing access to resources does not mean that people will take advantage of them."

Albert Bandura (Talk for the British Psychological Society, The Psychologist 2009, p.505)

\subsection{Research Objectives and Contribution}

A growing literature in economics investigates explanations for why people remain poor. While earlier research in the context of development economics has focused on external constraints, such as credit, education or savings constraints, economists have recently come to explore behavioral - internal - constraints in poor people's decision processes (Mullainathan \& Thaler, 2000; Bertrand et al., 2004). ${ }^{1}$ One internal constraint that has received increased attention are aspirations. Aspirations are goals that lie in the distant future and motivate individuals to provide investments to attain them (Bernard et al., 2011; Lybbert \& Wydick, 2018). ${ }^{2}$ The lack of both hope and aspirations is one of the reasons why poor individuals forego investments that may help them to escape poverty (Banerjee \& Duflo, 2011; Duflo, 2012). Individuals may believe that a specific state, for example expanding a business, is unachievable and thus avoid necessary investments. The beliefs and ideas formed by individuals about themselves and the world, so-called mental models, influence which options people perceive and which actions they choose (World Bank, 2015). The belief that one is not able to succeed can lead to low aspirations for the future and reduces efforts to improve one's situation. Several studies suggest that low aspirations are

\footnotetext{
${ }^{1}$ See Dalton et al. (2018), Lybbert \& Wydick (2018) and La Ferrara (2019) for a more detailed description of internal constraints studied in development economics.

${ }^{2}$ In the utility framework, aspirations are modeled as reference points that provide increasing utility up to the aspiration threshold (Dalton et al., 2016; Genicot \& Ray, 2017; Lybbert \& Wydick, 2018). This differentiates the concept of aspirations from expectations, as expectations are the weights attached to the utility from uncertain events (Dalton et al., 2016).
} 
correlated with low levels of investments (Bernard et al., 2011; Janzen et al., 2017; Dalton et al., 2018). Small-scale entrepreneurs in Indonesia, for example, who have low aspirations are less likely to report to grow their business, to improve or implement record-keeping, or to develop a business plan (Dalton et al., 2018).

This thesis provides new insights into aspirations focusing on their role in several development outcomes as well as into their determinants. We consider how aspirations affect cooperation in collective action and investigate its impacts in labor market participation. Thereby, the thesis contributes to the literature on aspiration failures in various fields. It starts by considering aspirations that concern community welfare and whose attainment entails investments that benefit other community members. Just like an individual can aspire for higher individual welfare (such as more education, income, assets and status as in Bernard et al. (2014)), we argue that an individual can also aspire for higher community well-being. We refer to these long-term goals for the community as community aspirations. While there is a growing body of empirical research on individual aspirations (for overviews see e.g. La Ferrara (2016); Lybbert \& Wydick (2018); La Ferrara (2019)), community aspirations have not yet received attention as a determinant of investment decisions.

The first research objective of this thesis is to investigate whether community aspirations are an important determinant of collective action. We thereby extend the concept of aspirations to include aspirations for the community. In addition, we include a new concept into the analysis of pro-social behavior by considering the role of aspiring to higher community well-being, which is different from other concepts, such as the expectation of other people's behavior (Keser \& Winden, 2000; Fischbacher et al., 2001). As community aspirations have not yet been conceptualized to the best of our knowledge, also no empirical measures exist. Chapter 2 therefore starts with a conceptualization of community aspirations and presents empirical measures for community aspiration dimensions. The chapter then examines whether our proposed community aspiration measure is correlated with cooperation in collective action problems using reported and experimental measures of cooperation.

The second research objective concerns the determinants of community aspirations. The failure to make investments due to low aspirations has been coined aspiration failure (Ray, 2006). Aspiration failures are presumably prevalent among people living in poverty and can be a source of a poverty trap (Appadurai, 2004; Ray, 2006; Dalton et al., 2016). The potential role of aspirations for poverty traps is manifold. The first line of thought argues that the poor have a weak "capacity to aspire" (Appadurai, 2004). According to this view, the poor have fewer means to explore the future due to their resource constraints and limited access to information compared to the rich. Having less experiences of how aspirations and outcomes are connected, poor people are prone to have low aspirations that result in low take up of investment opportunities (Appadurai, 2004). A second line of thought proposes that poverty in conjunction with an economically polarized society results in aspiration failures among the poor (Ray, 2006). Ray introduced the concept of the "aspirations 
window", which denotes all those people which an individual can cognitively perceive and from whom an individual forms her aspirations. An aspiration failure consequently occurs, if there are no people in one's cognitive window who do better than oneself. As a result the gap between one's current and aspired outcome is too small to motivate effort. At the same time, there are also no investments, if affluent individuals are in a poor person's cognitive window resulting in an aspiration gap that is too large (Genicot \& Ray, 2017). Then aspirations seem unattainable, the cost of effort needed to achieve them is too high and expected benefits too low (Ray, 2006). This reasoning implies that aspirations and effort have an inverted U-shaped relationship and aspiration failures occur because of either too wide or too narrow aspiration gaps (Ray, 2006; Genicot \& Ray, 2017).

The third line of thought provides a different explanation for an aspiration based poverty trap that has to do with a behavioral bias in the aspiration formation. According to the model of Dalton et al. (2016) higher aspirations lead to more effort and aspirations are determined through the (private) outcomes achieved. ${ }^{3}$ The behavioral bias consists in failing to realize this feedback loop from outcomes to aspirations, which leads individuals to take aspirations as given. Poverty increases the negative effects of this bias, as poor people have lesser means and information and therefore experience lower outcomes compared to the rich. The behavioral bias can lead to a trap in which low efforts produce low aspirations, which then determine investments in the future (Dalton et al., 2016).

One potential policy intervention to help people break out of an aspiration based poverty trap is the exposure of people to role models to open their cognitive window (Duflo, 2012; World Bank, 2015). Role models can both change individuals' beliefs on what they can achieve as well as provide information on the connection between aspirations and outcomes (Bandura, 1977, 2004). Recent literature suggests that role models can have sizeable effects on individuals' behavior. Exposure to role models in television series, for example, is associated with low fertility, higher divorce and separation rates (Chong \& La Ferrara, 2009; La Ferrara et al., 2012). Empirical evidence also shows that role models can increase aspirations (Beaman et al., 2012; Bernard et al., 2014).

This thesis aims to explore whether role models can increase aspirations for one's community. The underlying hypothesis is, that there is an aspiration failure which inhibits individuals to make investments into their common future. The dissertation thus considers aspiration failures with respect to community aspirations. Similar to a behavioral poverty trap, we hypothesize that communities can be trapped in a situation with low collective action due to a community aspiration failure. We use the conceptualization of aspiration failures by Ray (2006) and Genicot \& Ray (2017) and consider that these failures are a consequence of poverty and emerge through a lack of successful examples that motivate individuals to set higher goals. Based on this hypothesis, chapter 2 and 3 examine the research question

\footnotetext{
${ }^{3}$ In the model of (Dalton et al., 2016) aspirations are only determined by private experiences and not through social outcomes as in the models of Bogliacino \& Ortoleva (2015) and Genicot \& Ray (2017).
} 
whether the provision of successful examples of collective action can change community aspirations and the level of cooperation. Both chapters report on results from randomized screenings of videos that show communities who successfully established village clubs. While we use a real public good to measure collective action after the video screening in chapter 2 , chapter 3 elicits unconditional and conditional cooperation with a public goods game measured in a lab-in-the-field experiment.

A third research objective is to understand how different designs of the role model videos and screenings alter community aspirations and collective action. In this regard, chapter 3 of this thesis examines two research questions. First, it assesses which type of information used to describe the role model is more effective in increasing community aspirations and unconditional and conditional contributions to a public good. To answer this question, we compare the two videos from chapter 2 that use different frames with a no video condition: The first video focuses on a descriptive picture of village life in communities that succeed at setting collective action mechanisms and the second video entails prescriptive messages promoting collective action.

The other research question pertains to the role of common knowledge of having seen the video in the decision to cooperate. We hypothesize that community aspirations only increase cooperative behavior if there is knowledge on shared higher community aspirations. To test this hypothesis we varied who of the participants in the group of two got to see a treatment video and assess their unconditional and conditional contributions in the public good game. The study presented in chapter 3 is the first to our knowledge to compare the effect of the framing in the literature on role models and aspirations. In addition, it extends research on the role of common knowledge to behavior in public goods settings.

While the first part of the thesis is dedicated to the study of community aspirations and its role in collective action, the remaining part of the dissertation examines the role of individual aspirations in the behavior on the labor market. The fourth research objective is thus to explore how exposure to role models influences adolescents' aspirations and decision to enter the labor market. Chapter 4 investigates the hypothesis that female adolescents in developing countries have low self-beliefs and aspirations for their future due to a lack of similar women who have become successful in entering the formal labor market and hold responsible and competitive positions. This can trap adolescents in a situation where low investments reinforce low aspirations. Previous research has demonstrated that role models can increase female's willingness to enter into competitive environments. We extend this line of research by investigating whether role models in videos can increase females' aspirations, labor market participation and their willingness to apply to more competitive positions. 


\subsection{Methods}

This thesis builds on results from field experiments. The use of field experiments in development economics has grown tremendously in the last decade and gained visibility across disciplines with last year's winners of the Nobel Memorial Prize in Economic Sciences (Abhijit Banerjee, Esther Duflo and Michael Kremer) for their experiment-based approach to alleviating poverty (The Nobel Prize, 2019). Randomized experiments provide a means to isolate causal effects of treatments and are useful to test assumptions and theories in settings where a counterfactual cannot be reliably established with other evaluation methods (Harrison \& List, 2004; Duflo et al., 2007). To answer whether role models can influence aspirations and behavior using non-experimental methods can present challenges for the identification due to self-selection and non-random variation of contextual factors. Providing a control group through randomization, experiments are argued to yield the most reliable counterfactual (Harrison \& List, 2004). By varying only one element (the video), we can receive an estimate of the average treatment effect that is internally valid (Banerjee \& Duflo, 2009). Experiments can also include a multiple of treatments that can provide answers to the underlying mechanisms and thus improve conceptual understanding (Banerjee \& Duflo, 2009).

To measure cooperative and competitive behavior, we use preference experiments which are validated method to measure social preferences (Cardenas \& Carpenter, 2008). In Chapter 2 and 3, we use public goods games to quantify the level of cooperation and in Chapter 4 we use the seminal design of Niederle \& Vesterlund (2007) to measure competitive preferences. To measure aspirations we follow established methods that use survey questions (Beaman et al., 2012; Bernard \& Taffesse, 2014). Since community aspirations have not been measured before, we developed indicators using the methodology of individual aspirations by Bernard \& Taffesse (2014). We also propose dimensions for community welfare that are relevant for the context of the study and are based on Amartya Sen's (2001) five types of freedoms that are essential for human development: political freedom, economic facilities, social opportunities, transparency guarantees, and protective security.

\subsection{Summary of the Chapters}

In the following, an outline of the papers presented in chapter 2,3 and 4 is provided. The last chapter, chapter 5, concludes with a summary of the findings with the aim of integrating the results of the different chapters and providing an outlook on possible future work in this field. 


\subsubsection{Chapter 2 Community Aspirations and Collective Action}

This chapter starts from the perspective that collective action is important for rural development as informal institutions can provide access to markets and enable the sustainable management of natural resources. Yet, some groups succeed to self-organize, while others fail. The literature on collective action has so far analyzed pro-social preferences (Fehr \& Fischbacher, 2003) and external constraints to behavior, such as group characteristics (Zelmer, 2003) and the institutional environment (Agrawal, 2001), as determinants of individuals' decision to cooperate. We instead focus on internal constraints. We propose that the decision to cooperate is determined by the aspirations for one's community and that one reason for low levels of cooperation among community members could lie in a community aspiration failure. The literature on aspirations has focused mainly on individual aspirations and individual outcomes (Beaman et al., 2012; Bernard \& Taffesse, 2014; Pasquier-Doumer \& Risso Brandon, 2015; Janzen et al., 2017; Riley, 2018; Lybbert \& Wydick, 2019; Serneels \& Dercon, 2020). We extend the concept of aspirations to include long-term goals that one has for the community. In this chapter we conceptualize community aspirations and develop measures that we validate by assessing its correlation with cooperation in a field experiment. In the second part of the chapter, we examine whether community aspirations and the level of cooperation can be raised by showing videos of successful collective action. We hypothesize that exposing individuals to role model communities can lead individuals to change their mental models on what communities can achieve and lead to a rise in aspirations.

To test our hypotheses we make use of a randomized controlled trial in which we randomized screenings of videos in 37 villages in Zambia in 2018. In treatment villages, participants watched one of two role model videos. Both videos feature villages in the Democratic Republic of the Congo who successfully organized themselves into village clubs. The difference between the videos lies in the presentation of the role models. Whereas one video does not explicitly mention that the welfare improvements shown in the video, for example improved income and nutrition, are due to successful collective action, the other video uses an explicit framing. After screening the video, we measured cooperation with a natural field experiment in which participants were asked for their contribution to a real public good: a savings group. We compare cooperation and aspirations of treated participants compared with participants from control villages.

We find some support for our hypothesis that community aspirations determine cooperation, as participants with higher aspirations are more likely to report to work for their village and make higher contributions to the public good. However, we also find that there is no or a negative relation of community aspirations to other reported cooperation measures such as contributions to the village treasury and general trust. In our role model intervention we find that the video describing village life increases contributions to the public good, while the video with the explicit messages on collective action has no significant effect on reported contributions, but on observed average contributions at the village level. 
Both videos have a negative effect on community aspirations and trust, while we find a positive effect on perceived participation beliefs. This result suggests that the mechanism could run though a change in the perceived norm of cooperation.

\subsubsection{Chapter 3 Community Aspirations and Cooperation: Prescriptive vs. Descriptive Role Models}

This paper also departs from the hypothesis that the reason for low levels of cooperation among community members is an aspiration failure caused by a lack of role models that motivate them to aspire higher. We advance from the study in Chapter 2 in several ways. First, we investigate the role of normative messages in role model videos. Recent research suggests that prescriptive and descriptive messages can have different effects on pro-social behavior (Cialdini, 2003; Moyer-Gusé, 2008; Paluck, 2009; La Ferrara, 2016; Blair et al., 2019). However, we are not aware of any entertainment education study that has varied the framing of the messages in the presentation of the role models in the same context. While the video of Chapter 2 displaying village life (village life video) without explicit reference to collective action contains descriptive norms only, the other video (collective action video) contains descriptive and prescriptive norms (what ought to be done).

We can thus compare which type of information is more effective in raising aspirations and cooperation. Our hypothesis is that the video with the salient message (collective action video) is more effective at increasing community aspirations and contributions to the public good. In addition, we examine the role of common knowledge in the decision to cooperate. Previous entertainment education studies have focused on the role of common knowledge in risky sexual and violent behavior (Arias, 2019; Banerjee et al., 2019). This study extends that research by focusing on the role of common knowledge in the decision to contribute to a public good. We expect that shared knowledge on increased aspirations increases contributions.

To answer these questions, we implemented a lab-in-the-field experiment with 358 individuals in eight villages in the same region as we conducted the randomized controlled trial in Chapter 2. We randomly assigned the participants to one of the three conditions: collective action video, village life video or no video. After the video screening we measured cooperative behavior with a two-person one-shot linear public goods game in which we asked for their unconditional and conditional contributions. To analyze the role of common knowledge, we varied who of the person in the game watched a video.

We find that the village life video effectively promotes cooperation: Unconditional contributions and non-zero contributions are higher in this treatment compared to the no video group. Unconditional contributions are even larger if both individuals watched this video. We also find a larger share of positive conditional cooperators in the village life video group. In addition, conditional contributions are higher in the village life video treatment compared 
to the control if both contributors watched the video. While community aspirations are not related to contribution decisions, we find that individual aspirations are correlated with unconditional contributions.

\subsubsection{Chapter 4 Can Role Model Videos Influence Female's Decision to Participate in the Labor Market?}

The paper included in chapter 4 presents the results of a framed field experiment conducted in Madagascar in 2018. Similar to other countries in the world, women in Madagascar are underrepresented in the formal labor market, earn lower wages and hold fewer leadership positions compared to men. We argue that one reason for the gender gap in labor market outcomes could be a lack of successful females that can serve as reference points. Analogous to the argumentation on behavioral poverty traps above, females could be trapped in a situation of low aspirations and low investments. In this chapter we test the hypothesis that role models in videos can increase female students' aspirations and willingness to apply to a (competitive) job. Previous literature has found that role models can increase female's willingness to enter into competitive environments focusing mainly on decisions in the lab or on the choice of studies (Stout et al., 2011; Breda et al., 2020; Ginther et al., 2020; Meier et al., 2020; Porter \& Serra, 2020; Schier, 2020). We extend this research by considering the decision of females to apply to competitive jobs.

We randomly assigned 336 students in their last year of secondary education to watch either a female role model, a male role model, or a placebo video. The role model videos are about a woman or man, who comes from the same region and background as the students. Each of them recounts how they succeeded in attaining their goal and the journey they embarked on in order to achieve it. In the placebo video both characters talk about the differences in the rural and urban life in the region. After the students watched the video, we measured students' aspirations and beliefs with survey questions and conducted a lab-in-the-field experiment to measure competitive preferences and performance. At the end of the experiment, we informed the students about two job openings in the research project of one of the principal investigators. The students could either apply for an assistant or a coordinator position. The latter involves more responsibilities and thus entails a higher wage. A week after the visit, when we distributed the earnings from the lab experiment, students could fill in an application form.

We find that the female role model is successful in motivating females as well as males to apply to one of the job. Interestingly, we find that the male role model reduces the gender gap in the applications to the coordinator position that is prevalent in the placebo group. Our results suggests that this is driven by increases in applications by females compared to the placebo. We examine possible mechanism by controlling for aspirations, beliefs and the decisions in the lab experiment. While competitive preferences can explain the decision to 
apply to the coordinator position in the male role model treatment, we find that aspirations and the current achievements can partly explain the motivation to apply to any position in the female role model treatment. 


\section{Community Aspirations and Collective Action ${ }^{1}$}

\footnotetext{
${ }^{1}$ We are grateful for the helpful comments and suggestions received by Kacana Khadjavi, Meike Wollni, Martin C. Parlasca, Jorge Luis Sellare as well as the participants from the GlobalFood doctoral seminar and from the 14th Nordic Conference on Behavioral and Experimental Economics. We thank Christiane Monsieu of the Dimitra Project for the permission to use their videos and Felix Betzenbichler for including the subtitles. We also thank Paul Malambo, Sarah Hanyama, Harriet Chibuta, Naomi Munthali, Nathanael Nsana, Emmanuel Juunza, Magdalene Trapp, Muyambo and Charity Sipangule for their excellent research assistance in the field and Malte Becker, Maximilian Köster, Merindah Lössel and Henrike Sternberg for their great data preparation and data cleaning support.
} 


\subsection{Introduction}

Collective action plays an essential role in development. Communities that manage to self-organize can avoid poverty traps and achieve sustainable development. For example, communities that set and enforce rules on the management of natural resources can avoid depleting natural resources, commonly referred to as the tragedy of commons (Ostrom, 1990; Vélez et al., 2020). Agricultural cooperatives can facilitate farmers' access to markets, decrease credit constraints, and facilitate the diffusion of new technologies (Valentinov, 2007; Wollni \& Zeller, 2007; Fischer \& Qaim, 2012). Despite the potential benefits of collective action, not all communities succeed in self-organizing and in establishing stable processes of collective action.

This paper puts forward a new explanation of why collective action fails. We propose that cooperative behavior depends on the goals and desires set for community well-being. We refer to those as community aspirations. Consistent with Sen's (2001) idea that freedom is both the end and a means to development, we conceptualize community aspirations as a multidimensional notion that includes five dimensions: political and economic freedoms, social opportunities, transparency and protective security. Our conjecture is that when individuals experience a low level of aspirations for the well-being of their community, they would lack incentives to cooperate in collective action problems.

Poverty can constrain aspirations (Appadurai, 2004; Dalton et al., 2016). Aspirations are formed by the lives and achievements of individuals that one can observe. Individuals living in poverty and a polarized society might lack the resources and examples to form higher aspirations (Appadurai, 2004; Ray, 2006). Low aspirations thus can lead to low cooperation, which can ultimately lead to pessimistic aspirations. Opening people's cognitive window by showing an alternative view of what they could achieve can help them escape the trap and achieve economic development (Ray, 2006).

The objective of this paper is twofold. First, we develop the concept of community aspiration and present an empirical measure. We assess the validity of the proposed measure by exploring its correlation with cooperation in the field. Second, we investigate whether giving examples of successful collective action cases can positively influence community aspirations and cooperation levels. Participants in the treatment group watched one of two videos depicting villages who cooperated successfully in collective action problems. The literature discusses distinct ways of presenting role models in order to foster behavioral change. While the literature on educational entertainment posits that the educational content should not be made too obvious (Bandura, 2004; La Ferrara, 2016), other studies have found that prescriptive messages are effective in behavioral campaigns (Cialdini, 2003). Our study compares two different ways of presenting role models. The first video used a narrative describing living conditions in organized communities; and the second a prescriptive frame explicitly explaining how organized communities can achieve better living conditions. We 
compare cooperation and community aspirations in the treatment videos with a control group that is not exposed to any video.

The analysis is based on survey and experimental data with 749 individuals living in 43 villages in Zambia. To capture the level of cooperation we allowed a sample of participants to make real contributions to a local public good that is common in Zambia. Participants could contribute part of their endowment of ten Kwacha (about 0.78 Euro $^{2}$ ) as seed capital for new savings groups. The amount contributed was doubled by us, generating a social dilemma in which collectively it was better to cooperate, but individually it was better to retain the endowment.

The results of our study indicate that individuals hold optimistic aspirations. Compared with the current level, participants aspire that community welfare will be six standard deviations higher. Confirming our hypothesis, we find that more optimistic participants report more frequent participation in collective workdays. Yet, no differences are found on other cooperation indicators such as contributions to the treasury or value spend in village activities. The field experiment results indicate that contributions to the savings group are higher among participants exposed to the narrative video than those in the control group. Yet, this does not seem to be due to changes in community aspirations. Robustness checks indicate that the results are consistent for some measures of community aspirations.

Our contribution to the literature is the following. To the best of our knowledge, we are the first to conceptualize community aspirations and develop an empirical measure that builds on Bernard et al. (2014) validated instruments on individual aspirations. Previous research on aspirations has focused mainly on the relation between individual aspirations and wealth (for an overview see La Ferrara (2016)). Second, we contribute to the literature on the determinants of collective action by analyzing the role of community aspirations in the decision to cooperate in a public goods setting. Earlier studies on aspirations considered how collective action influences individual aspirations (Ray, 2006; Mojo et al., 2016). ${ }^{3}$ Yet, these studies have not investigated how aspirations affect collective action. We contribute to the behavioral economics literature by including a new concept in the study of pro-social behavior. Empirical evidence largely supports the view that individuals behave as conditional cooperators increasing contributions as they expect higher contributions of the peers (Keser \& Winden, 2000; Fischbacher et al., 2001). Community aspirations refer instead to imagining and aiming at realizing higher communal welfare.

Our paper also relates to research considering how exposure to role models through media

\footnotetext{
${ }^{2}$ The exchange rate at the time of the experiment was around 12.81 Kwacha equivalent to one Euro.

${ }^{3}$ It has, for instance, been argued that groups can influence individual aspirations by their ability to (1) share information and experiences, (2) credibly share information to external agents and thereby induce social change, and (3) by their ability to coordinate actions (Ray, 2006). Empirical evidence shows that cooperative members have higher aspirations for income, education, and assets than non-members (Mojo et al., 2016).
} 
affects attitudes and economic behavior (Chong \& La Ferrara, 2009; Jensen \& Oster, 2009; Paluck, 2009; Paluck \& Green, 2009; La Ferrara et al., 2012; Banerjee et al., 2019). In particular, our paper closely relates to studies that have experimentally examined the effect of role models on aspirations and behavior. For instance, Beaman et al. (2012) showed how a random allocation of political positions reserved for women in Indian village councils reduced the gender gap in aspirations for young adolescents and their parents and eliminated the gender gap in educational outcomes. Showing videos of successful individuals from similar backgrounds to smallholders in Ethiopia was found to increase individual aspiration levels and changed the treated individuals' investment behavior compared with those in the control group half a year after the screening (Bernard et al., 2014). Another experimental study conducted with secondary school students in Uganda revealed that a role model movie changed educational outcomes (Riley, 2018). The author found that students from the treatment group were less likely to fail mathematics in the national exam than students from the control group. We extend that research to consider whether communities can serve as role models to promote cooperation.

Lastly, our paper also relates to literature in psychology on hope and utopian thinking and its role in collective action (Braithwaite, 2004; Greenaway et al., 2016; Fernando et al., 2018, 2019; Badaan et al., 2020). Greenaway et al. (2016), for instance, analyze whether hope, defined as a positive emotion directed at the future and the wish to change current states of the world, is related to intentions to engage in collective action to support people in an out-group. Using survey data they find that hope correlates with intentions to participate in political protest among respondents in the United States and in the Netherlands. The study by Fernando et al. (2018) provides evidence that utopian thinking - imagining ideal or better societies - is correlated with increased intentions to change the current situation. Imagination and a positive evaluation of an ecologically friendly future has also been shown to be associated with higher contributions to charity (Fernando et al., 2019). Compared to this literature we consider how the level of aspirations for one's community is related to experimental measures of collective action in a middle income country.

The paper is organized as follows: Section 2 introduces the conceptual framework explaining how community aspirations affect cooperation. We present our approach to measuring community aspirations. Section 3 explains the empirical strategy. In this section, we explain the experimental design and procedures used in data collection. The results are presented in Section 4. First, we give an overview of community aspirations and examine its relation with cooperation. We then present the results of our field experiment. Section 5 discusses the results and section 6 concludes. 


\subsection{Conceptual Framework}

Recent work in development economics focuses on aspirations. Aspirations are the set of goals that individuals hold for the future (Bernard et al., 2011). The common use of the concept of aspirations in economics entails several attributes. First, aspirations are goals that lie in the distant - and not in the near - future (Bernard et al., 2011). Second, aspirations are different from hope as the former require agency to accomplish the goals (Lybbert \& Wydick, 2018). Lastly, aspirations are different from expectations. Expectations refer to the belief in potential future outcomes, while aspirations are the preference for specific outcomes (Bernard et al., 2011).

In the theoretical models, aspirations are the relevant items in the choice set that motivate individuals' behavior (Bernard et al., 2014). A higher aspiration increases the expected benefit of an action promoting higher effort. Yet, if the difference in the standard of living that is aspired to and the standard of living that one already has is too small or too big, investment effort would be low (Ray, 2006).

The existing economic literature has focused on aspirations that entail personal goals such as income, education or social status. For instance, aspirations have been related to educational investment, educational attainment and school enrollment (Beaman et al., 2012; Bernard et al., 2014). Other studies found that aspirations predict savings, use of credit, investment and business expansion (Bernard et al., 2014; Macours \& Vakis, 2014; Janzen et al., 2017; Lybbert \& Wydick, 2018; Dalton et al., 2018). We propose that the concept of aspirations can be extended to account for preferences for goals that increase community well-being and have a public good nature. We refer to those preferences as community aspirations.

We adopt Sen (2001)'s conceptualization of development and consider that well-being depends on the freedoms that individuals enjoy. He proposes that freedom of choice is a multidimensional concept that includes five dimensions: political freedoms, economic facilities, social opportunities, transparency guarantees, and protective security. Political freedom is defined as the possibility to participate openly and without coercion in decisions that affect the community such that citizens enjoy the freedom of expression and are protected from abuse of power (Bollen, 1986). Decisions are guided by democratic principles where the majority of citizens participate in decision making. The most commonly used measure of political freedoms is the Index of Political Rights which accounts for freedom of speech, freedom of religion, individual economic choice, freedom of association, freedom of assembly, violence and crimes, freedom of movement, and women's rights (Krueger \& Malečková, 2003; Abadie, 2006). In our analysis, we capture political freedom by considering the aspirations regarding the right of assembly. The indicator variable that we use is the number of times per year that villagers would like to hold open meetings to discuss community issues. 
There is a well-established tradition in economics that associates welfare with freedom of choice. For any two choice sets that allow the individual to choose the most preferred element, the one containing more choices would receive a higher ranking (Gravel, 1994; Sen, 1991; Puppe, 1996; Pattanaik \& Xu, 1998). The dimension of economic facilities therefore has been operationalized as the possibility to live a decent life outside poverty and deprivation. While the Human Development Index (HDI) measures this dimension by income per-capita (Anand \& Sen, 1994), the Multidimensional Poverty Index (MPI) considers household standard of living (Alkire \& Santos, 2014). At the community level, this entails access to water, sanitary services, electricity and good quality of housing. We measure this dimension asking the aspirations regarding the number of households in the community with good housing conditions (made of red brick, burned brick or asbestos and with iron sheets on the roof) relative to the estimated number of households in 10 years.

Freedom of choice requires that individuals are capable of deciding. The economic opportunities and political liberties enhance this capability, but also access to public education and health services. The HDI, considers for example, the life expectancy at birth and expected and mean years of schooling (Anand \& Sen, 1994). The MPI, on the other hand focuses on child mortality, under-nutrition, school attendance and mean years of schooling. As it is difficult to imagine that households would want fellow community members to be deprived of any of this dimensions, we used an alternative measure that is likely to have more variability among respondents. We measure social opportunities as the number of minutes individuals aspire children to travel to reach primary school.

Transparency warranties refer to the possibility to live a secure life where individuals can trust the government and fellow citizens. The Index of Economic Freedom, measures this dimension as the degree of a country's legal protection of private property rights and degree of enforcement of those laws and the prevalence of corruption (Miller et al., 2016). Considering that a key component in providing security is the enforcement of norms, we proxy this dimension as preferences for access to police protection. We ask for the aspired number of security guards relative to the population in 10 years.

Access to protection from a social security net confers individuals the support and protection that wars, epidemics, and natural disasters can cause (Platteau, 1997; Dercon, 2005). We proxy the dimension of protective security as aspirations regarding the proportion of the population having access to support from the social network in case of need. Protective support is also manifested as contributions to community public goods. Therefore, we also consider a measure of aspired contributions to the village.

In a community context, attaining the five dimensions of freedom requires investment by individuals that ultimately benefit other people in the community: Political Freedom entails that each individual must invest time to hear the other's opinions and concerns. Further, the dimension Economic facilities has characteristics of a public good, as making 
resources available to the village network creates positive externalities (Coleman, 1988). Transparency and Protective support also have the properties of a public good since villagers (in Zambia) themselves are responsible for the organization of village security guards and solidarity networks. Further, (Zambian) villagers often provide labour and materials for the construction of the nearest school, benefiting (mostly) other villagers.

\subsubsection{Collective Action and Community Aspirations}

In a similar way in which aspirations for personal goals motivate effort, we advocate that cooperation depends on community aspirations - the goals for the common welfare-. The causal link between aspirations and cooperation is depicted in Figure 2.1.

There is a three stage process by which community aspirations affect cooperation in collective action comprising (1) imagination, (2) evaluation and (3) action. Imagination is the component in which community aspirations are formed (Appadurai, 2004). Cognitive and non-cognitive skills might influence the ability to imagine a different communal future. Recent research shows that intelligence, executive functions and automatic associative processes correlate with creative performance (Beaty et al., 2014; Benedek et al., 2014; Silvia, 2015). Aspirations can also be considered a social construct. Appadurai (2004) argues that aspirations are determined largely within a given community as a system of shared ideals. Previous experiences of oneself and others in our cognitive window can influence the propensity to aspire (Ray, 2006).

Non-cognitive factors such as income, political and social constraints can also affect the imagination. For example, Appadurai (2004) considers that poor and marginalized people are likely to have a weak capacity to aspire as they lack the resources and opportunities to train this capacity exploring how aspirations and outcomes are connected. Additionally, a large aspirations gap, the difference between the standard of living one aspires to and the present, can create disincentives to provide effort (Genicot \& Ray, 2020). Greater equality therefore, can yield higher aspirations, incentives to provide effort and growth (Bogliacino \& Ortoleva, 2015).

After an individual has formed a community aspiration and set goals for the community welfare, she goes over an evaluation stage in which a decision is taken on whether to act towards the imagined goals. In Stage 2: Evaluation, several factors determine the costs and benefits an individual attaches to following specific community aspirations. First, we consider that collective action entails a strategic interaction setting, as the decision to cooperate is based on the expectation of other's people behavior (Keser \& Winden, 2000; Fischbacher et al., 2001). The perceived norms on cooperation describe whether cooperative behavior is perceived to be valued in the community one lives in. Second, we propose that altruistic preferences will lead to a higher perceived benefit of investing resources to attain community aspirations. The third factor that affects the evaluation is beliefs in the efficacy 
of one's collective, so-called group efficacy beliefs increase the likelihood that an individual assesses the attainability of the aspiration.

The last component of our framework is called Action and denotes the actual investment of resources to attain the community aspiration. An action could take place at many points in time confronting the individual to decide whether to stick to pursuing the goal. Executive functions as the capacity to exert self-control and flexible thinking can determine whether the action is sustained over time and the goal is successfully reached. Finally, an individual assesses the attained state with the aspired one and is satisfied if the reference point was achieved and frustrated in case it was not met (Genicot \& Ray, 2017).

Community aspirations can be affected by exposing individuals to successful examples of collective action. Exposure to village role models directly affects imagination by expanding an individual's aspiration window. In addition, exposure to role models indirectly affects the evaluation by magnifying the perceived benefits and changing the perceived norms of cooperation (Tankard \& Paluck, 2016; Blair et al., 2019). Locus of control and group-efficacy beliefs can also be raised by successful experiences by others, such as by observing how a role model succeeds through his/her own work (Bandura, 2012). Exposure to village role models is therefore expected to increase cooperation.

Figure 2.1: Conceptual Framework

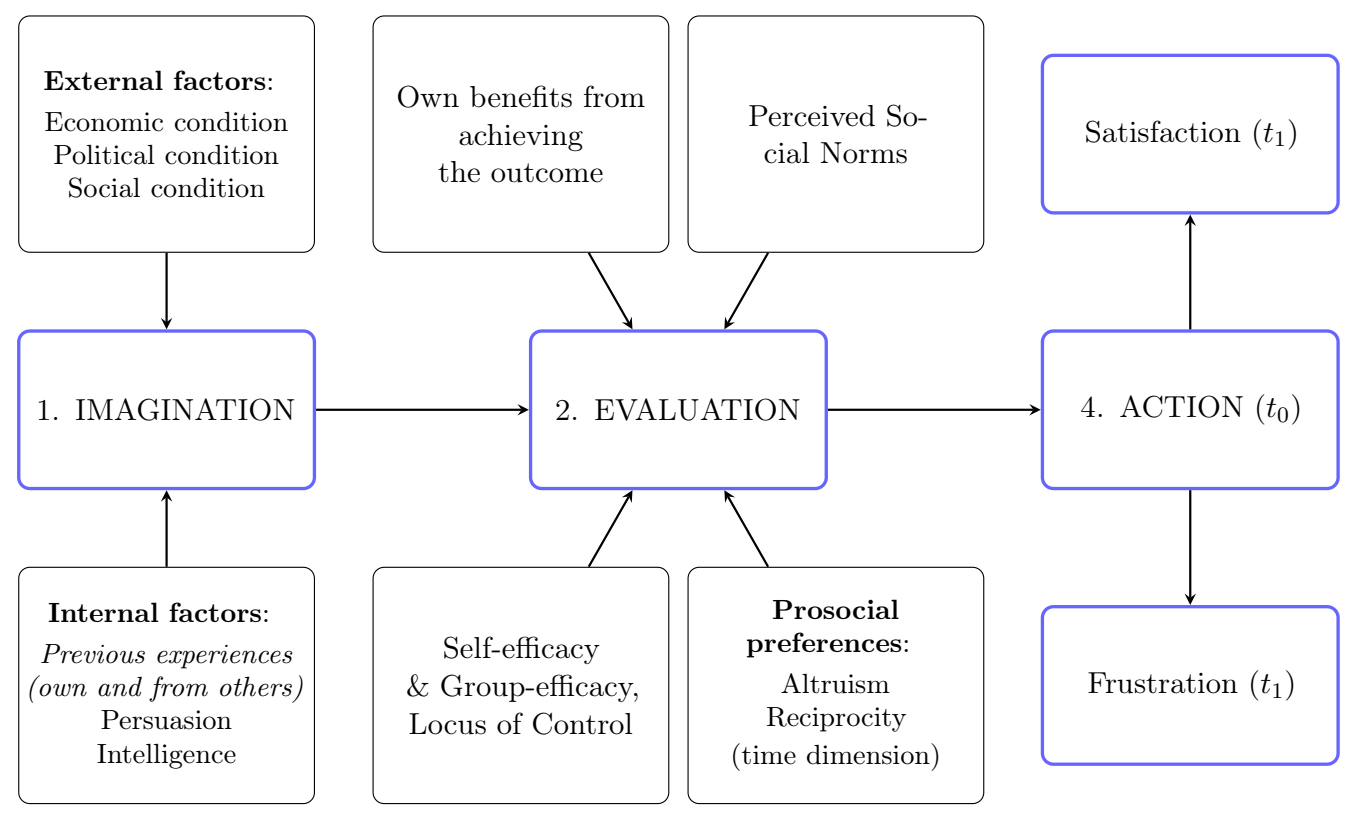




\subsubsection{Measurement of Community Aspirations}

Community aspirations have not been conceptualized and thus also have not been measured before. We therefore base our measurement strategy on existing instruments of individual aspirations. Distinct approaches to measuring individual aspirations have been proposed. For instance, aspirations are measured with questions on minimum income (Stutzer, 2004; Knight \& Gunatilaka, 2012), positive attitudes and depression (Macours \& Vakis, 2014), as well as on the desired education level, desired age of marriage and desired occupation (Beaman et al., 2012). We use a method similar to the ones applied in Beaman et al. (2012) and Bernard et al. (2014). The latter study used measures from Bernard \& Taffesse (2014), who tested the reliability and validity of the questions on individual aspirations in the field. We adapted the survey questions to fit community aspirations and to our field context.

Community aspirations entail five different dimensions. Table 1 presents the indicators we use for each of the dimensions. We selected the indicators based on the following criteria. First, they should be understood by the respondents and be feasible to compare across communities. We therefore chose indicators that can be found in the local context (derived through our pilot study) and where participants easily understand the best and the worst level. Further, we chose indicators based on whether they have sufficient variation. This excludes indicators where participants would always want 100 or 0 percent (such as life expectancy or infant mortality). Also, respondents should be able to modify them at the local level such as the number of village meetings instead of variables that determine political freedom at higher levels of authority (such as federal institutions). For each dimension, we first asked respondents about the current level so that individuals have a reference level of actual conditions in their community. Then, we asked the level they aspired to have in ten years. Finally, we asked for the level they expected to reach in this time window. To convert some of those measures into shares, we also asked for their population estimates in 10 years. ${ }^{4}$

For obtaining the community aspiration index, we standardize the responses for each dimension using the mean and the standard deviation of the control group and aggregated them giving equal weight to each dimension. Our community aspiration index $A_{s}$ is the following:

$$
A_{s}=\sum_{d}\left(\frac{a_{i}^{d}-\mu_{d c}}{\sigma_{d c}}\right)
$$

where $\sigma_{d c}$ is the standard deviation and $\mu_{d c}$ the sample mean from the control group $c$ for each aspiration question from dimension $d$.

To measure the individual aspirations index, $A_{i}$, we included questions on the level of education that they would like their youngest child to achieve, how many goats and cows

\footnotetext{
${ }^{4}$ Outliers in the population estimates were replaced with the mean values.
} 
they would like to have and how big they would like their plot to be in ten years.

As self-efficacy and locus of control are argued to be determinants of aspirations (Bandura, 1977) and have been found to correlate with individual aspirations in empirical studies (Wydick et al., 2013; Bernard et al., 2014), we also included a questions on locus of control and individual village efficacy belief. ${ }^{5}$

Table 2.1: Community Aspiration Indicators

\begin{tabular}{ll}
\hline Dimension & Description \\
\hline $\begin{array}{l}\text { Community aspirations } \\
\text { Political Freedoms }\end{array}$ & The number of times a month he/she would like villagers to join for a village meeting or celebrations \\
$\begin{array}{l}\text { Economic facilities } \\
\text { Social opportunities }\end{array}$ & $\begin{array}{l}\text { The share of households in the village he/she would like to have very good housing conditions } \\
\text { Transparency }\end{array}$ \\
$\begin{array}{l}\text { The share of the population they would like to have in their village as policemen/-women/voluntary guards } \\
\text { Protective security }\end{array}$ & $\begin{array}{l}\text { The Kwacha amount they would like each villager to contribute to village projects on average in a year } \\
\text { The share of households he/she would like to get supported in case of need }\end{array}$ \\
$\begin{array}{ll}\text { Individual aspirations } \\
\text { Education }\end{array}$ & $\begin{array}{l}\text { Level of education that they would like their youngest child to achieve } \\
\text { Wealth }\end{array}$ \\
& $\begin{array}{l}\text { Plot size } \\
\text { Number of cows }\end{array}$ \\
& Tumber of goats \\
Other dimensions & To be successful, above all one needs to work very hard \\
Village efficacy & People have influence in making this village a better place to live \\
\hline
\end{tabular}

\subsection{Empirical Strategy}

To assess the role of community aspirations in collective action, we collected survey and experimental data in rural Zambia in summer 2018. Two localities were selected for the study. The first locality are villages in Southern Province, where we collected lab-in-the-field data on cooperation. We use these villages to be part of our control group. The second locality comprises also villages in Southern Province located left and right of the main road (see map in Figure 2.2) in which we conducted our field experiment.

Below we present the experimental design, outcome measure of cooperation, hypotheses, and procedures.

\footnotetext{
${ }^{5}$ We took one of the question Bernard et al. (2011) use to measure locus of control: "Please tell me with which of the two statements you agree more: a) 'To be successful, above all one needs to work very hard.' b) 'To be successful, above all one needs to be lucky.'" (p. 7). Self-Efficacy is measure as "Do you think people like yourself have influence in making this village a better place to live?"
} 
Figure 2.2: Location of Study

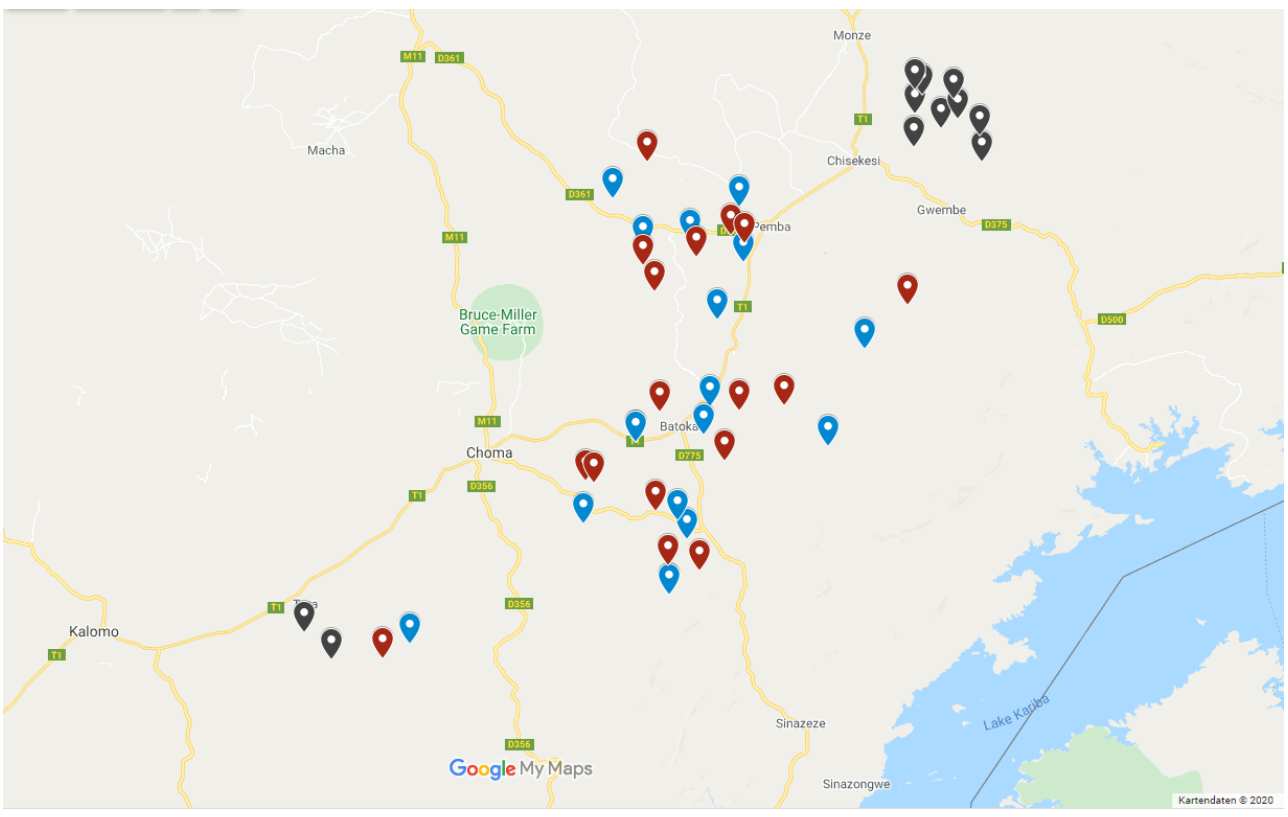

Note: The red and blue pins denote the location of the treatment villages. The grey pins show the control villages. Source: Own data.

\subsubsection{Experimental Design}

The stages of our intervention can be found in Figure 4.1. Our experiment uses two treatment conditions and one control group. In Stage 1 participants in the treatment group watched one of two videos showing examples of communities that were successful at self-organizing in the Democratic Republic of the Congo. In Stage 2, they decided how much they wanted to contribute to a real public good: a savings group. Participants in the control group did not watch any video and started directly in Stage 2. A sample of participants completed a survey where we measured aspirations and obtained information on socioeconomic characteristics (Stage 3). After completion of the survey, we paid the participants the survey fee and screened another video that explains how savings groups work. We describe the content of the treatment videos and design of the field experiment in more detail in the following.

Figure 2.3: Experimental Design

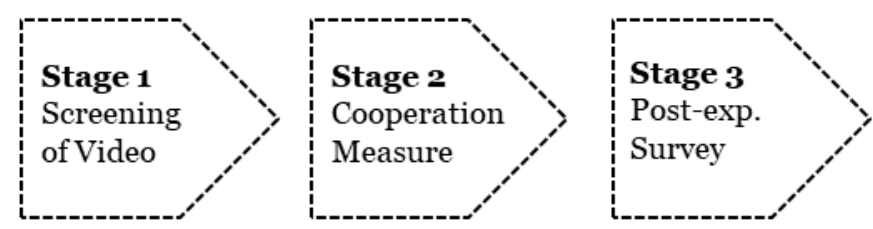




\subsubsection{Treatment Videos}

For the intervention we used already existing videos created within the Dimitra Project, a participatory communication project on gender and rural development from the Food and Agriculture Organization of the United Nations (FAO). The original versions are freely accessible via YouTube. ${ }^{1}$ We used sequences of two videos (Community Mobilization, Food Security and Nutrition) and edited a new video with a total duration of 11 minutes. Both treatment videos used the same images, but they used different scripts dubbed into the local Zambian language (Tonga) and displayed English subtitles. ${ }^{6}$ The screenings either took place at a house, a communal space or at a school in a village. We projected the videos onto a screen with a projector that was powered by a generator.

Participants in the treatment group watched a video depicting the positive outcomes of Dimitra Clubs in rural areas of the Democratic Republic of the Congo. We focus on the effects of the clubs on development and hence we substituted Dimitra Club with Village $C l u b .^{2}$ The village clubs comprise men and women who self-organized into groups to work actively in the development of their community.

The first video, village life video (VL video), is narrative and describes the life in rural communities in Congo. During the screening participants observe sequences where the villagers work together in road maintenance or hold community meetings. While the participants see improved living conditions in the area, the video does not provide information that these outcomes can be attributed to collective action. The narrator and characters only talk about villager's source of income, diet, and the geography and climate of the villages' locations.

The second video, collective action video (CA video), explicitly discusses how the community's living conditions can improve when the community cooperates in solving collective action problems. These true stories are told by a narrator and by the villagers themselves. The community members report their experiences of how the clubs positively influenced their lives (e.g., nutrition improved or their income increased). We showed images of villagers sitting in a club meeting, while the narrator explained how the groups facilitated collective action and increased social cohesion. It also includes a short sequence where a village chief expressed his satisfaction with the clubs and an agricultural inspector reports observing more active community participation.

The impacts of the intervention are measured as the difference in community aspirations and cooperation in a real public good between the treatment and control groups. Next, we explain the measure of cooperation we used.

\footnotetext{
${ }^{1}$ https://www youtube. com/playlist?list=PLzp5NgJ2-dK60BbZpPuTMn_7wSrclUE0I

${ }^{6}$ The video scripts can be found in the Appendix.

${ }^{2}$ The logo of the FAO was kept in the video.
} 


\subsubsection{Cooperation Measure}

To measure cooperation, we employ a one-shot n-public goods game. Each participant was handed out an envelope with ten Kwacha in ten one Kwacha coins. Subjects decide how much of this endowment they would like to invest in a real village project, where the amount contributed is multiplied by two.

The project was seed capital for all newly formed savings groups. Savings groups are common in rural Zambia, with 73 percent of our sampled villages having at least one savings group. The use of this public good has the advantage that it enables us to measure the video interventions' short-term (contributions) and long-term effects (savings group growth).

The participants were informed about the game structure in the experimental instructions, which were read out in the local language in front of the whole group (see the Appendix for the English version of the instructions). At the beginning of every session, a research assistant read out general instructions, which included, among other things, that participation is voluntary, decisions are anonymous, drop-out of the game is possible at any stage, questions can be asked to the research assistants in private and that there should not be any discussion in the group about the intervention and the game (see the Appendix for the English version of the general instructions).

After the experimental instructions were read out, participants were given the envelopes and were asked to wait at a pre-specified place (usually in a shaded area next to a building) until they were given further instructions. Participants were asked to put the Kwacha amount for the village project in a paper box that was installed behind another building. The rest was either put into their pocket or in their Chitenge (the traditional gown of women). The team of research assistants made sure that only one participant at a time was going behind the building in order to assure that the contribution decision was private. To rule out experimental demand effects, we also did not write ID numbers on the envelopes, so that the decisions were completely anonymous. The other participants, who were waiting to be called, were instructed not to communicate with each other during the waiting period to prevent consultation.

Once everybody made their contribution decision, a research assistant, village headman, village treasurer, village secretary (village committee) collected the box and counted the money invested in the village project. Village committee members were asked to be present for the counting for credibility reasons. Meanwhile, the rest of the research team already started some smallholder interviews. At the end of the interviews, the village treasurer announced the total contributions to the whole group. We added the same amount of money and reminded the group that the village treasurer would be distributing the money equally among the newly established groups. We proposed that they meet a week from our visit to discuss how many groups they would like to form. Even though savings groups are 
not uncommon in the region, it was expected that not everybody is aware of how savings groups work. Therefore, we showed another video which explained how savings groups are established before we continued the smallholder interviews. We further handed out three documents to the village leaders, including the same information shown in the video and some examples of accounting and templates for them to use later.

\subsubsection{Hypotheses}

We argue that community aspirations affect the incentives to cooperate in collective action problems. We expect that individuals who hold more optimistic aspirations will contribute more to the public good.

Hypothesis 1: Community aspirations are positively correlated with cooperation in collective action problems.

Community aspirations are expected to be influenced by an individual's cognitive window. We hypothesize that individuals in rural areas who have limited access to examples of villages who do "better" than themselves have low community aspirations for their village. By showing examples of communities that succeed at organizing collective action, a role model video can lead to a change in people's mindset on the possibilities that can arise by coordinated action and thus raise aspirations. This reasoning is in line with the argumentation of how a role model intervention could have changed individual aspiration and future oriented behavior in the study of Bernard et al. (2014). We expect that a video that shows examples of successful collective action (imagination stage: previous experience of others) will increase community aspirations, and perceived social norms on cooperation, as individuals generalize from the behavior of the role models to that of their village (Blair et al., 2019). We expect that the role model intervention also has an impact on actual collective behavior: By setting higher aspirations for one's community, individuals also invest more into collective action.

Hypothesis 2: The screening of a video that shows successful examples of collective action by similar individuals increases community aspirations, perceived norms of cooperation and increases cooperation.

We expect that the frame used to depict successful examples of collective action will influence the message's effectiveness at changing community aspirations and cooperation. It has been shown that messages that include prescriptive as well as descriptive content were more successful in fostering pro-social behavior compared to descriptive messages alone (Cialdini, 2003). We thus expect that prescriptive messages that explicitly highlight how cooperation can affect collective action will be more effective at changing community aspirations and promoting cooperation. 
Hypothesis 3: The collective action video that depicts how village groups can change community welfare is more effective at changing community aspirations and promoting cooperation than the village live video.

\subsubsection{Experimental Procedures}

For the randomization we made use of villages lists with information on the location, name and population size of the villages in Southern Province, given to us by the Zambian Central Statistical Office (CSO) in Lusaka. We selected villages with 70 to 270 adult inhabitants that were located within 20 kilometers (right and left) of the main road.

Before we conducted the intervention in every village, we visited each village's headman to ask for his permission. We informed him about our research project, without specifying the exact measures, and the time the study would take us in his village. A letter from a Zambian governmental agency that states their support to our research was also presented. Having the village headman's consent, we asked for his assistance in the recruitment of the villagers. We communicated that we need as many people as possible for our study. Setting no limit to the number of participants was important to reduce selection bias. Further, we emphasized that only people can participate in the study from the targeted village and are above the age of sixteen.

In total, we collected data from 45 villages: 8 control villages, 18 in the village life video condition and 17 in the collective action video. We formed village pairs that were within a five-kilometer radius. The pair of villages were visited on the same day, but were assigned to different treatments. ${ }^{7}$ On average, 40 villagers came to each session. The minimum group size was 18 and the maximum was 78 . In cases in which there was not enough space in the room, we did multiple rounds of screenings (maximum of three) to ensure that all participants in the session were exposed to the same treatment. Besides, in each session, we randomly chose twenty individuals to answer a survey. Participants in the survey received five Kwacha as an incentive. The survey contained several questions to measure individual and community aspirations and asked control questions on socio-economic characteristics of participants as well as perceived social capital in the village. The village headman answered a village survey on existing public goods in the village.

\subsection{Results}

Our data set comprises survey information from 749 individuals in three treatment conditions (145 participants in the control, 310 in VL Video and 294 in CA video). Out of the

\footnotetext{
${ }^{7}$ We have one village more in the village life video compared to the collective action video group as in one village appointment it turned out that the original village documented in the CSO data is now made up out of two.
} 
participants in the control group 38 reported their contributions to a real public good. The rest (101), participated in a public goods game in the lab.

The socioeconomic characteristics of our sample are presented in Panel A in Table 2.2. Participants are on average 38 to 44 years old, have completed 7 years of education, own 5-8 hectares of land and have lived in the village for 26 to 30 years. More than half of the surveyed participants are members of at least one group and use a mobile phone on a daily basis. Respondents participate in village work 3 to 5 times a year and report to have average spendings of 217 to 439 Kwacha for village activities in a year. General trust in fellow villagers is on average quite high with values between 3.12 and 3.34 (out of 4). The last column reports the p-value from a joint orthogonality test of the treatment arms. The results indicate that our randomization strategy worked for most of the variables. 
Table 2.2: Summary Statistics by Treatment

\begin{tabular}{|c|c|c|c|c|}
\hline & $\begin{array}{c}(1) \\
\text { Control }\end{array}$ & $\begin{array}{c}(2) \\
\text { Village } \\
\text { life }\end{array}$ & $\begin{array}{c}(3) \\
\text { Collective } \\
\text { action }\end{array}$ & $\begin{array}{c}\text { (4) } \\
\text { Orth. test } \\
\text { p-value }\end{array}$ \\
\hline \multicolumn{5}{|l|}{ Panel $A$} \\
\hline Age & $\begin{array}{l}38.72 \\
(1.22)\end{array}$ & $\begin{array}{l}42.54 \\
(0.86)\end{array}$ & $\begin{array}{l}44.17 \\
(0.89)\end{array}$ & 0.00 \\
\hline Female & $\begin{array}{c}0.54 \\
(0.04)\end{array}$ & $\begin{array}{c}0.47 \\
(0.03)\end{array}$ & $\begin{array}{c}0.48 \\
(0.03)\end{array}$ & 0.35 \\
\hline Highest grade & $\begin{array}{c}7.29 \\
(0.21)\end{array}$ & $\begin{array}{c}7.38 \\
(0.17)\end{array}$ & $\begin{array}{c}7.18 \\
(0.16)\end{array}$ & 0.69 \\
\hline Single & $\begin{array}{c}0.12 \\
(0.03)\end{array}$ & $\begin{array}{c}0.09 \\
(0.02)\end{array}$ & $\begin{array}{c}0.07 \\
(0.02)\end{array}$ & 0.34 \\
\hline Daily use of mobile phone & $\begin{array}{c}0.56 \\
(0.04)\end{array}$ & $\begin{array}{c}0.58 \\
(0.03)\end{array}$ & $\begin{array}{c}0.58 \\
(0.03)\end{array}$ & 0.84 \\
\hline Size of plot(s) & $\begin{array}{c}5.77 \\
(2.44)\end{array}$ & $\begin{array}{c}8.06 \\
(1.30)\end{array}$ & $\begin{array}{c}6.76 \\
(1.06)\end{array}$ & 0.57 \\
\hline Index herd size & $\begin{array}{l}-0.00 \\
(0.11)\end{array}$ & $\begin{array}{c}0.09 \\
(0.07)\end{array}$ & $\begin{array}{l}-0.05 \\
(0.06)\end{array}$ & 0.37 \\
\hline Group member & $\begin{array}{c}0.54 \\
(0.04)\end{array}$ & $\begin{array}{c}0.51 \\
(0.03)\end{array}$ & $\begin{array}{c}0.59 \\
(0.03)\end{array}$ & 0.18 \\
\hline Time lived in village & $\begin{array}{l}26.19 \\
(1.46)\end{array}$ & $\begin{array}{l}27.91 \\
(1.08)\end{array}$ & $\begin{array}{c}30.23 \\
(1.11)\end{array}$ & 0.08 \\
\hline Participation village work & $\begin{array}{c}2.66 \\
(0.38)\end{array}$ & $\begin{array}{c}4.85 \\
(0.87)\end{array}$ & $\begin{array}{c}4.97 \\
(1.15)\end{array}$ & 0.20 \\
\hline Spendings village & $\begin{array}{l}217.20 \\
(24.37)\end{array}$ & $\begin{array}{l}439.64 \\
(59.80)\end{array}$ & $\begin{array}{l}394.66 \\
(64.28)\end{array}$ & 0.07 \\
\hline Treasury contributions & $\begin{array}{c}8.11 \\
(0.52)\end{array}$ & $\begin{array}{l}29.50 \\
(1.75)\end{array}$ & $\begin{array}{l}15.33 \\
(0.68)\end{array}$ & 0.00 \\
\hline General trust & $\begin{array}{c}3.12 \\
(0.09)\end{array}$ & $\begin{array}{c}3.30 \\
(0.05)\end{array}$ & $\begin{array}{c}3.34 \\
(0.05)\end{array}$ & 0.05 \\
\hline Security group & $\begin{array}{c}0.63 \\
(0.04)\end{array}$ & $\begin{array}{c}0.79 \\
(0.02)\end{array}$ & $\begin{array}{c}0.82 \\
(0.02)\end{array}$ & 0.00 \\
\hline Reported amount sent & $\begin{array}{c}6.76 \\
(0.57)\end{array}$ & $\begin{array}{c}7.62 \\
(0.17)\end{array}$ & $\begin{array}{c}7.32 \\
(0.19)\end{array}$ & 0.20 \\
\hline Share of endowment sent & $\begin{array}{c}0.44 \\
(0.03)\end{array}$ & $\begin{array}{c}0.76 \\
(0.02)\end{array}$ & $\begin{array}{c}0.73 \\
(0.02)\end{array}$ & 0.00 \\
\hline$N$ & 145 & 310 & 294 & \\
\hline $\begin{array}{l}\text { Panel B } \\
\text { Actual amount sent }\end{array}$ & $\begin{array}{c}6.32 \\
(0.41) \\
\end{array}$ & $\begin{array}{c}6.52 \\
(0.24) \\
\end{array}$ & $\begin{array}{c}6.40 \\
(0.29) \\
\end{array}$ & 0.94 \\
\hline$N$ & 2 & 18 & 17 & \\
\hline
\end{tabular}




\subsubsection{Community Aspirations}

The summary statistics of the current and aspired dimensions of welfare are presented in Table 2.3. ${ }^{8}$ Aspirations reflect the level of welfare that individuals would like their community to achieve in ten years. Pairwise correlation of our community aspiration and current community index reveals a high and significantly positive correlation (Spearman $\rho=0.3435$ and $p$-value $<0.001)$. On average participants hold optimistic aspirations about the future, particularly with respect to individual welfare. We find that for all dimension of community aspirations, aspirations are significantly higher than the current level (two-sided $t$-test $p-$ value $<0.1$ ).

The Political Freedom dimension is measured as the preferred number of times villagers meet to discuss community issues or to celebrate together. Currently smallholders report to meet with their village on average 1.9 times per month and aspire to meet 3.4 times per month. For the dimension Protective Support we use two measures. First we consider how many households receive support in case of need. Smallholders aspire for 47 percent of the households in their village to get support in case of need compared with an estimate of 26 percent currently receiving support. The second measure is the amount of Kwacha they would like village members to contribute to finance village projects on average per year. Smallholders currently contribute 105 Kwacha (about 7 Euro) but aspire that villagers contribute 157 Kwacha in ten years (about 9.6 Euro). However, the standard deviation is very high and explains why the median is much lower compared to the mean, both for the current and aspired levels (40 and 50 Kwacha, respectively).

To quantify access to security, our proxy for the dimension Transparency, we asked the respondents for the number of policemen/women or voluntary guards they currently have and would like to have for their village and divided this number with the estimated amount of current or future number of households living in their village. The villagers would like to have on average 10 police/-women or voluntary guards for their village per 100 inhabitants; this is 4 more persons than they actually have (0.06).

Social Opportunities is our proxy for access to education and is measured as the minutes the smallholders would like students from their village to walk to a primary school. We inverted the measure so that higher numbers in the aspiration variables are always associated with better outcomes. ${ }^{9}$ On average, smallholders aspire that students only have to walk ten minutes $(1 / 0.10)$ or one third of the time they currently walk (33 minutes).

Our measure for the dimension Economic Facilities is the proportion of households that have very good housing conditions. Smallholders would like 81 percent of the households in

\footnotetext{
${ }^{8}$ We excluded outliers of the community aspiration index that are above 10 and replace missing observations in the dimensions with the mean value.

${ }^{9}$ However, one could argue that a certain number of policemen/women are optimal and above that they could also be decreasing individual and collective welfare.
} 
their village to have very good housing conditions. This is 34 percentage points more than the current estimate (47 percent).

We also report on the individual aspirations and current level. On average, smallholders aspire for 13.85 years of education for their youngest child ${ }^{10}$, while their current level of education amounts to 3.7 years. We measure wealth in terms of the size of their plot as well as the number of goats and cows an individual owns. We find that aspirations to have extreme values resulting in a high standard deviation. On average, smallholders report to own six goats, three cows and have 7.1 hectares of land. They aspire for 46 goats, 38 cows and 16 hectares of land.

The last two rows in Table 2.3 present the standardized measures of well-being. The values reported compare the difference with the control group. Column 1 reports the current welfare levels. It shows that mean index of community welfare is 0.96 standard deviations higher than in the control group and that individual welfare is 0.22 standard deviations higher. To account for these differences in wealth between treatment and control groups, we include controls of welfare levels in the analysis.

In the analysis we are interested in measuring how the treatment video changes aspirations. Column 2 in Table 2.3 reports the community and individual aspiration indices standardized by the control group. While the z-score for individual aspiration index is 16, this value is negative for community aspirations. This descriptive analysis indicates that the videos might have reduced community aspirations. In section 4 we do a formal test.

Table 2.7 in the Appendix reports the correlates of community and individual aspirations. We regress covariates at the individual level on the Community Aspiration Index in Column 1 and on the Individual Aspiration Index in Column 2. We find that the time respondents have lived in the village is positively related to community aspirations. Being female is associated with lower individual aspirations. This is in line with the study by Beaman et al. (2012) who find a gender gap in (educational and career) aspirations.

${ }^{10}$ For those who do not have children, we used the mean value. 
Table 2.3: Current and Aspired Welfare

\begin{tabular}{|c|c|c|c|c|c|}
\hline & \multicolumn{2}{|c|}{ Current level } & \multicolumn{2}{|c|}{ Aspirations } & \multirow[b]{2}{*}{$\begin{array}{c}\text { Diff. } \\
(5)\end{array}$} \\
\hline & $\begin{array}{c}\text { Mean } \\
(1)\end{array}$ & $\begin{array}{l}\text { SD } \\
(2)\end{array}$ & $\begin{array}{c}\text { Mean } \\
(3)\end{array}$ & $\begin{array}{l}\mathrm{SD} \\
(4)\end{array}$ & \\
\hline \multicolumn{6}{|c|}{ Panel A: Community aspirations } \\
\hline Number of meetings & 1.892 & 1.729 & 3.439 & 2.450 & $-1.547^{* * *}$ \\
\hline Share good housing & 0.468 & 0.354 & 0.814 & 0.968 & $-0.346^{* * *}$ \\
\hline School distance & 0.036 & 0.052 & 0.104 & 0.106 & $-0.068^{* * *}$ \\
\hline Security & 0.061 & 0.057 & 0.099 & 0.076 & $-0.038^{* * *}$ \\
\hline Share receiving support & 0.262 & 0.389 & 0.478 & 0.580 & $-0.216^{* * *}$ \\
\hline Contributions to village & 105.409 & 206.176 & 157.123 & 350.845 & $-51.714^{* * *}$ \\
\hline \multicolumn{6}{|c|}{ Panel B: Individual aspirations } \\
\hline Education child & 3.668 & 2.652 & 13.855 & 1.539 & $-10.187^{* * *}$ \\
\hline Plot size & 7.105 & 22.652 & 16.108 & 35.843 & $-9.003^{* * *}$ \\
\hline No. cows & 3.418 & 5.827 & 38.270 & 113.913 & $-34.852^{* * *}$ \\
\hline No. goats & 5.601 & 8.482 & 44.519 & 75.002 & $-38.919^{* * *}$ \\
\hline \multicolumn{6}{|l|}{ Panel $C:$ Indices } \\
\hline Community welfare & 0.969 & 3.543 & -0.812 & 1.294 & $1.781^{* * *}$ \\
\hline Individual welfare & 0.228 & 2.975 & 16.023 & 36.312 & $-15.795^{* * *}$ \\
\hline Observations & 749 & & 749 & & \\
\hline
\end{tabular}

\subsubsection{Econometric Analysis}

In the analysis we first consider the relation between community aspirations and collective action. For this we run the following regression:

$$
y_{i}=\alpha+\text { Aspirations }_{i}^{\prime} \beta+X_{i}^{\prime} \beta+\mu_{a}+\epsilon_{i}
$$

where $y_{i}$ is the vector of cooperation outcomes for individual $i$. We consider various self-reported measures of cooperation at the community level as participation in meetings, membership in community groups, contributions to the village. $X_{i}^{\prime}$ is a vector consisting of socioeconomic control variables at the individual level and $\epsilon_{i}$ is the error term. We also include area fixed effects, $\mu_{a}$, to control for unobserved differences in the villages. We use ordinary least squares (OLS) estimation and cluster the standard errors at the village level. Our main outcome of interest is Aspirations.

The second part of the analysis focuses on the impact of the village role model videos on cooperation and community aspirations. We estimate the average treatment effects running the following regression:

$$
y_{i}=\alpha+\delta T_{v}+X_{i}^{\prime} \beta+\mu_{a}+\epsilon_{v}
$$


where, $y_{i}$ denotes the outcome variable for individual $i$. We consider various outcome variables as reported contributions, community and individual aspiration index, and other psychological variables. $T_{v}$ is an indicator variable for the type of video that was presented (0 for control, 1 for VL video and 2 for $\mathrm{CA}$ video). All other variables have the same definition. The coefficient of interest is $\delta$ which captures the Average Treatment Effects on the Treated (ATT).

\subsubsection{Impact of Community Aspirations on Cooperation}

We propose that cooperation in collective action depends on community aspirations. To investigate this relation we estimate the model in Equation 2. Since exposure to the treatment videos could affect the self-reported cooperation in collective action problems, we estimate the model only for the sample of participants in the control group.

The indicator variables of cooperation that we use in the analysis are the following:

1. Group member: measured as an indicator variable equal to one if the participant is member of a group and zero otherwise,

2. Participation group: measure as the number of times per year that the individual participates in village work,

3. Spend village: measured as the value spent for village activities per year.

4. Contributions to the treasury in Kwacha.

5. Trust: generalized measure of trust,

6. Security group: indicator of whether the respondent participates in a policing group.

In the analysis we control for individual socioeconomic characteristics as age, gender, education and wealth level of the participant. In addition, we include control variables of village wealth measured as the number of households with access to water and perceived norm of cooperation measured as the level of perceived participation of other community members (low, average, high). The estimated coefficients for community aspirations are presented in Table 2.4. We find that community aspirations are positively and significantly correlated with participation, but negatively correlated with contributions to the treasury. We find that there is a negative and significant correlation of community aspiration and trust. We conclude that community aspirations explain cooperation in the form of networking, but have negative impact on monetary contributions.

Panel B in Table 2.4 presents the correlation of individual aspiration measures and collective action. We find that participation in security groups is positively correlated with individual 
aspirations. For the other indicators we find no significant correlation.

Table 2.4: Aspiration and Cooperation in Collective Action

\begin{tabular}{lcccccc}
\hline & $\begin{array}{c}\text { Group } \\
\text { member }\end{array}$ & $\begin{array}{c}\text { Partic. } \\
\text { work }\end{array}$ & $\begin{array}{c}\text { Spend } \\
\text { vill. }\end{array}$ & $\begin{array}{c}\text { Contr. } \\
\text { treasury }\end{array}$ & $\begin{array}{c}\text { General. } \\
\text { trust }\end{array}$ & $\begin{array}{c}\text { Security } \\
\text { group }\end{array}$ \\
\hline Panel A: & & & & & & \\
Community aspiration & 0.008 & $0.431^{* *}$ & 1.718 & $-0.622^{* *}$ & $-0.060^{* *}$ & 0.006 \\
& $(0.035)$ & $(0.172)$ & $(13.335)$ & $(0.246)$ & $(0.023)$ & $(0.035)$ \\
Constant & -0.137 & -3.766 & 359.294 & $22.654^{* * *}$ & $2.822^{* * *}$ & -0.094 \\
& $(0.338)$ & $(5.205)$ & $(241.585)$ & $(6.198)$ & $(0.737)$ & $(0.714)$ \\
& & & & & & \\
Panel B: & -0.001 & 0.004 & -0.392 & -0.016 & 0.000 & $0.003^{*}$ \\
Individual aspiration & $(0.002)$ & $(0.007)$ & $(1.559)$ & $(0.013)$ & $(0.006)$ & $(0.001)$ \\
& -0.116 & -3.647 & 370.937 & $22.773^{* * *}$ & $2.779^{* *}$ & -0.160 \\
Constant & $(0.355)$ & $(5.213)$ & $(247.032)$ & $(6.409)$ & $(0.838)$ & $(0.695)$ \\
\hline Observations & 145 & 145 & 145 & 145 & 145 & 145 \\
Fixed effects & No & No & No & No & No & No \\
Socioeconomic controls & Yes & Yes & Yes & Yes & Yes & Yes \\
\hline
\end{tabular}

Notes: Panel A presents regressions for community aspirations. Panel B present results for individual aspirations. Regressions include controls for: gender, age, relationship status, highest grade attained, size of the plot in hectares, herd size index, group membership, daily mobile phone usage, and area fixed effects. Missing values for mobile phone usage $(1 \mathrm{missing})$, participating in village work (8 missings) and generalized trust ( 1 missing) were replaced with mean values. Columns indicate the indicators of cooperation in collective action. Standard errors are clustered at the village level. *, ** and *** indicate significance at the $0.1,0.05$ and 0.01 level, respectively.

\subsubsection{Treatment Effects on Cooperation}

In this section we analyze the effect of the two videos on the decision to cooperate and community aspirations. We asked the smallholders several control questions on the videos to identify whether they rate the videos differently across treatments and to find out whether the role model intervention was successful. About 50 percent of the participants do not agree that the characters are similar to them. The answers point to the fact that they see the villages as more successful compared with their village and thus could potentially serve as role models. Only 30 percent of all participants state that they strongly agree that the characters are similar to them.

Using a two-sided Wilcoxon ranksum test we find no difference in the rating among VL and CA videos (p-value $=0.75)$. Further, participants from the VL and CA video intervention both equally agree to the question whether their village will be as successful as the ones depicted in the video (3.66 out of 4 ). These results point to the direction that the participants see role models in both videos. Participants in CA video agree to like the 
characters of the video more than those in VL video with the difference being statistically significant at the one percent level.

The outcome variables that we consider are Actual Contributions, which are the observed contributions in the experiment and Share of Endowment Sent, which is the share of contributions based on their endowment participants reported to have sent obtained in the post-experimental survey. We restrict our analysis to the 642 individuals that reported contributions in the public good.

We first examine Actual Contributions. Participants from CA video villages contribute on average $6.40 \mathrm{Kwacha}$ and participants from control villages $6.32 \mathrm{Kwacha}$. Using a two-sample $t$-test, we find that the difference is not statistically significant ( $\mathrm{p}$-value $=$ 0.930). Average contributions in the VL video treatment amount to $6.5 \mathrm{Kwacha}$, which is not significantly different from the average contributions in the other groups (p-values $\geq$ $0.754)$.

Reported contributions are significantly higher compared to actual contributions. Participants in the CA video group report on average to have contributed 7.45 Kwacha, compared with 7.66 Kwacha in the VL video group and 6.76 in the control group. The difference between actual and reported amounts in the video treatment groups is statistically significant $(\mathrm{p}$-values $=0.000) .{ }^{11}$ This shows that participants in both video treatment groups misreport their actual contributions in the smallholder survey. Yet, the bias in reporting is not different between the two treatment groups.

Participants in the CA video group report to have sent 73 percent of their endowment and participants in the control group 68 percent. Using a two-sided $t$-test, we find no significant difference. In the VL video treatment participants sent 73 percent of their endowment. This is not significantly different from the share in the CA video and the control group (two-sided $t$-test p-values $>0.105$ ).

In the following we use regression analysis to control for important covariates. In Table 2.5 we estimated two regressions on the village level for the outcome variable Average Actual Contribution, which is the model we specified in Equation 2. In both regressions we control for village level and session characteristics. Column 1 shows the results of OLS estimation. Since the p-value of the F-test for the overall significance of the model is not significant ( $\mathrm{p}$-value $=0.164$ ), Column 2 provides the estimates from robust regression analysis to account for outliers, which is not unsurprising with a small sample size of 37 observations. ${ }^{6}$ Controlling for village level observable characteristics, we find that the VL video and the CA video have a positive effect on average contributions at

\footnotetext{
${ }^{11}$ The sample size of the control villages is too small to conduct a two-sample $t$-test.

${ }^{6}$ We replaced the missing value for the variable Adults village and for the variable Already savings group for one village each in models in column 1 and 2 with the sample mean.
} 
the village level. Participants in the VL video contribute on average 1.18 Kwacha and participants in the CA video 1.54 Kwacha more compared to individuals in the control group.

Next we estimate OLS regressions for the outcome Share of Endowment Sent and control for individual observables. Columns 3 and 4 of Table 2.5 present the regression results using area fixed effects and clustering the standard error at the village level (Equation 3). In Column 5 we additionally control for community aspirations. The estimations partially confirm the results of the actual contributions regression above. The CA video treatment does not affect the share sent in the experiment at the individual level, but the VL video. Individuals in the VL video treatment contribute on average 9.4 percentage points more compared to individuals in the control group. If we further control for community aspirations in Column 5, the effect size increases to 10.4 percentage points. Community aspirations are positively related to the reported share sent.

Table 2.5: Actual and Reported Contributions

\begin{tabular}{|c|c|c|c|c|c|}
\hline & \multicolumn{2}{|c|}{ Average actual contributions } & \multicolumn{3}{|c|}{ Share of endowment sent } \\
\hline & (1) & $(2)$ & $(3)$ & $(4)$ & $(5)$ \\
\hline VL video & 0.739 & $1.183^{*}$ & $0.088^{*}$ & $0.094^{*}$ & $0.104^{*}$ \\
\hline & $(0.939)$ & $(0.589)$ & $(0.052)$ & $(0.052)$ & $(0.055)$ \\
\hline $\mathrm{CA}$ video & 0.388 & $1.539^{* *}$ & 0.060 & 0.066 & 0.078 \\
\hline & $(0.991)$ & $(0.622)$ & $(0.051)$ & $(0.053)$ & $(0.055)$ \\
\hline Comm. aspirations & & & & & $\begin{array}{c}0.021^{* *} \\
(0.009)\end{array}$ \\
\hline Constant & $\begin{array}{c}7.382^{* * *} \\
(1.297)\end{array}$ & $\begin{array}{c}7.197^{* * *} \\
(0.814)\end{array}$ & $\begin{array}{c}0.676^{* * *} \\
(0.001)\end{array}$ & $\begin{array}{c}0.585^{* * *} \\
(0.071)\end{array}$ & $\begin{array}{c}0.596^{* * *} \\
(0.070)\end{array}$ \\
\hline Observations & 37 & 37 & 642 & 642 & 642 \\
\hline$R^{2}$ & 0.356 & 0.703 & 0.056 & 0.075 & 0.080 \\
\hline Fixed effects & No & No & Yes & Yes & Yes \\
\hline Robust regression & No & Yes & No & No & No \\
\hline Controls & Yes & Yes & No & Yes & Yes \\
\hline
\end{tabular}

Notes: ${ }^{*} p<0.10,{ }^{* *} p<0.05,{ }^{* * *} p<0.01$. Column (1) and (2) report the results on regressing the treatments on average actual contributions at the village level. Regressions control for: adults village, already savings group, vehicles for transportation, frequency of meetings, treasury contributions, health group village, distance health facility ( $\mathrm{min}$ ) and availability medicine. Standard errors are in parentheses. Column (3), (4) and (5) report the results on regressing the treatments on the share of the endowment sent and include the individual-level control variables: gender, age, relationship status, highest grade attained, size of the plot in hectares, herd size index, group membership, daily mobile phone usage and area fixed effects. Standard errors clustered at the village level are in parentheses.

\subsubsection{Treatment Effects on Aspirations and Beliefs}

We hypothesize that the videos can change the reference point on what villages can achieve by working together and result in higher community aspirations. Further, we assume that the videos can lead to changes in individual aspirations, efficacy beliefs, trust and in perceived norms of cooperation. 
First, we examine the effect of the video on our community aspiration outcome variable, the community aspiration index. ${ }^{8} \mathrm{~A}$ two-sided Wilcoxon ranksum test does not yield a significant difference in the community aspiration index between CA video, VL video and control villagers ( $\mathrm{p}$-values $\geq 0.219$ ). In Table 2.6 Columns 1 to 3 we present OLS regression results with the dependent variable Community Aspiration Index. The regressions control for the same individual level controls as for the outcome Share of Endowment Sent and additionally for locus of control and village efficacy beliefs. We use area fixed effects and cluster the standard errors at the village level. We find that both the VL video as well as the CA video have a negative effect on reported community aspirations. Treated individuals have a 0.46 and 0.59 standard deviations lower aspiration index compared to participants in the control villages.

Next, we are testing whether the role model intervention has an effect on the level of individual aspirations. Using a two-sided Wilcoxon ranksum test, we find a no significant difference in the reported individual aspiration index between respondents from three treatment arms $(\mathrm{p}$-values $\geq 0.248)$. In Column 2 of Table 2.6 we present the regression results for the individual aspiration index. Controlling for the same covariates as in Column 1 , we find that the video treatments do not affect individual aspirations.

Since exposure to role models has been found to affect efficacy beliefs, we also test whether our role model intervention changes village efficacy. Column 3 of Table 2.6 shows that we do not find any treatment effects on participants' belief on the possibility to bring about positive change for their village. As discussed above in Section 2.2, exposure to the treatment videos could also affect the perceived social norm of cooperation. We test whether exposure to the CA and VL video treatment affect individuals' perceived participation in their village. The results are reported in Column 4. We find that individuals in the CA and VL video group report higher scores of perceived participation in their village compared to individuals in the control group. For reported trust we find that the treatments have a negative effect for participants in the VL and CA video group compared to individuals in the control group. This suggests that the two videos increase perceptions of the social norm of cooperation, while it crowds-out social capital.

\footnotetext{
${ }^{8}$ For our analysis we did not exclude outliers in the community and individual aspiration index.
} 
Table 2.6: Treatment Effects on Aspirations and Beliefs

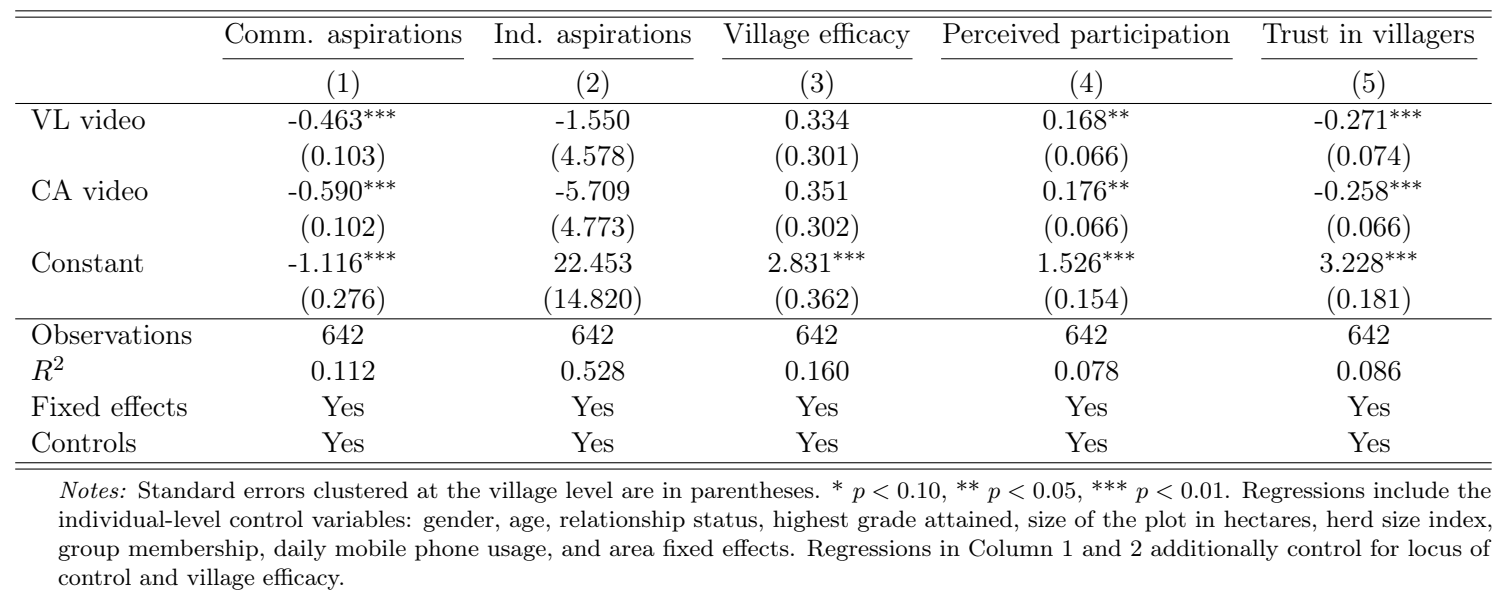

\subsubsection{Robustness}

In the following section we provide some robustness checks on our outcome measure of community aspirations. First, we analyze the effect of the videos on each community aspiration dimension separately. As can be seen in Table 2.8 in the Appendix, the negative treatment effect is driven by aspirations for village meetings. Participants in the VL and CA video treatment report 0.35 and 0.36 standard deviation lower aspirations for the number of community meetings. However, we also find that there is a positive effect of both videos on the dimension Economic Facilities, proxied with the share of population with good housing conditions, yet the effect size is small compared to the one for for village meeting aspirations. For all the other dimensions, we find no significant treatment effects. These results suggest that the videos do not consistently affect all dimensions of aspired community welfare.

As a second robustness check we test whether the negative treatment effects on the community aspiration index are robust to how the aspiration index is constructed. First, we consider whether the results change if we use different approaches of standardizing the measure. Table 2.9 Panel A shows four possibilities. Column 1 presents the index based on the method of Beaman et al. (2012) and Bernard et al. (2014) used in the analysis above, Column 2 presents the index with the same method but excluding the dimension Transparency, proxied by the share of security guards. Higher aspirations in this dimension can be interpreted in the way that an individual could expect more crime to happen, which is not associated with higher social welfare. We find that the results are robust to exclusion of this dimension. In Column 3 we constructed the index using the current level of achievements (from the control group) for the standardization. The negative treatment effect of the VL video disappears, while for the CA video the effect still remains. We find the same results, when we exclude the Transparency dimension from the index (Column 4). 
Another possibility to construct the index is using the growth rate or aspiration gap (see e.g. Janzen et al. (2017)). The growth rate denotes how far an individual aspires in relation to her current level $(\mathrm{g}=\mathrm{a}-\mathrm{c} / \mathrm{c}) .{ }^{12}$ We construct the growth rate for each dimension and take the mean to comprise the growth rate index. In Panel B of Table 2.9 Column 1 we find that using this measure as an outcome variable for community aspirations that there is no treatment effect - also, if we take out the dimension Transparency from the growth rate index. The growth rate can also be used to create a standardized measure of community aspirations. Using the current level for the standardized growth rate we again find a negative treatment effect of both of the videos, which persists if the Transparency dimension is not considered.

In summary, we find that the treatment videos have a negative effect on the level of community aspirations (when standardized with the aspirations of the control group), but no effect on the gap between their aspired and current level (growth rate).

\subsection{Discussion}

We find evidence that videos depicting successful examples of collective action can increase contributions to a real public good. At the village level we find that on average participants in the treatment villages contribute 12 to 15 percentage points more than participants from control villages. For reported contributions we only find a treatment effect of the village life video. While we exclude demand effects from not identifying individual decisions, we also acknowledge it is less credible compared to using observed measures of contributions in the experiment. Yet, the effect size is similar to the ones for actual contributions (10.4 percentage points). Further, our results are based on a control group that only includes few villages. Future research should therefore test whether the results are robust to using a control group with a larger sample size.

While the role model intervention was successful in increasing contributions to the public good, we find negative treatment effects on our preferred measure of community aspirations. Analyzing the effect on each community aspiration alone, we find that both videos have a positive effect on the dimension Economic facilities and a negative effect on Political Freedom proxied with the number of village meetings participants would like to have in a month. These results could suggest that role model videos could have different effects on distinct dimensions or that the number of village meetings is not a valid proxy. It could be that more village meetings are associated with higher opportunity costs of time. A similar argument could be made for our indicator of Transparency, measured as the share of security/police guards an individual aspires to have for her community. Above a certain threshold a security guard could also decrease community and/or individual welfare.

\footnotetext{
${ }^{12}$ For individuals who reported to have zero current level (e.g. no plots) the growth rate could not be calculated so that we increased all current levels by 0.1 .
} 
These results suggest that some indicators might be capturing aspirations for community welfare better than others. Future research should therefore test the validity of the different indicators for community welfare dimensions. While we find that the aspiration index is correlated with reported and experimental measures of cooperation, our paper does not provide a test of determinants of aspirations and correlates of aspirations with cooperation behavior for each dimension. Further, future projects should assess the external validity and reliability of the indicators by testing the questions in different settings, at different points in time and with variation in the order of measures and enumerators' experience in data collection (as done for individual aspirations in Bernard \& Taffesse (2014)).

Future work should also analyze the mechanism of the role model intervention on cooperation. While we only find inconclusive results for community aspirations, we find that the videos changed perceived participation beliefs of participants. This suggests that the effect could run through a change in expectations of other people's behavior. Yet, while we find positive effects on perceived norms of cooperation, we find a negative treatment effect on social capital, i.e. generalized trust in village members. This is contrary to the findings of Paluck (2009), who report that an radio edutainment intervention on the roots and consequences of violence changed descriptive and actual, but not prescriptive norms. To shed light on the mechanism of behavioral change, future projects could vary the degree to which groups are exposed to the video to analyze the role of expectations. ${ }^{13}$

Our study provides evidence that a 11 minute long video can modify aspirations, beliefs and cooperation levels directly after exposure. It is also important to consider the long-term effects, as reported in Bernard et al. (2014) for individual aspirations. In their study they find evidence of long-term effects, yet the effect size is smaller six months after the intervention. We provide the results of an evaluation one year after our intervention in a later study.

\subsection{Conclusion}

We provide a new explanation on why collective action fails: Individuals could lack aspirations for their community that prevent them from investing in collective action. Survey and experimental evidence presented in this paper provide some support for our hypothesis. Participants, who are more optimistic about the common welfare, engage more in participation and contribute more in the public good. Yet, community aspirations are also associated with lower contributions to the treasury and lower trust.

This finding suggests that changing community aspirations is crucial to promote cooperation. Based on this premise we implemented an field experiment in which community members

\footnotetext{
${ }^{13}$ In the study by Banerjee et al. (2019) analyzing the effect of a video series on HIV and risky sexual behavior, the authors do not find evidence that the positive treatment effects on health behavior can be explained by a change in perceived social norms.
} 
could contribute to finance a local public good: a savings group. We test whether expanding individuals' imagination by showing successful examples of cooperation induce cooperation. Our results show that a video that depicts communities that succeed at achieving higher welfare through collective action induce higher cooperation. Yet, using an explicit message to promote cooperation did not affect contributions to the public good. This finding suggests that examples and narratives are more effective at promoting cooperation.

The treatment videos had a negative effect on community aspirations compared with the control condition - yet, the effects are only robust to some ways of constructing the index. Instead, the videos changed perceived norms of cooperation. Treated smallholders report to perceive the participation of their fellow villagers in village activities higher compared to smallholders in the control group. However, we find a negative treatment effect on reported levels of trust.

We further examined the impact the treatment has on concepts related to aspirations. We do not find a treatment effect on locus of control or village efficacy beliefs. These results are different from Bernard et al. (2014), who found that their intervention not only changed individual aspirations, but also locus of control beliefs. However, the literature also argues that aspirations are more easily affected by outside interventions than self-efficacy or locus of control beliefs (Wuepper \& Lybbert, 2017).

A limitation of our study is that concept of community welfare that we use in our analysis, is not autochthonous. While this concept is acceptable by development practitioners and international organizations, local communities might have a very different idea of common welfare. Therefore, the indicator of community aspirations needs to be validated in the field. This exercise can also help to identify alternative or complementary indicators of welfare. The indicators could be developed using a participatory poverty assessment approach (Robb, 1998).

We find that community aspirations are positively correlated with some measures of cooperation but not others. More research is needed to understand how institutional factors interact with collective aspirations to promote cooperation. Future work should also asses the direction of the causality. In particular, participation in collective action could increase social aspirations. For example, Feigenberg et al. (2013) shows that more frequent meetings of saving groups are more likely to poor risk and less likely to default second loans. We recommend that self-reported cooperation measures are complemented with secondary information on actual participation.

We implemented the treatments at the village level and did not obtain individual measures on contributions to the public good. Further, this paper only included an analysis of the short-term effects of the video screening. A future extension is to consider the long-term effects of the intervention. While video interventions are cost-effective in reaching a large 
number of people, future work should examine whether alternative interventions can succeed at changing collective aspirations. 


\subsection{Appendix A - Tables}

Table 2.7: Correlates of Community und Individual Aspirations

\begin{tabular}{lcc}
\hline \hline & $(1)$ & $(2)$ \\
& Community aspiration index & Individual aspiration index \\
\hline Age & -0.004 & 0.250 \\
Female & $(0.008)$ & $(0.340)$ \\
& -0.109 & $-14.492^{* *}$ \\
Highest grade & $(0.293)$ & $(4.817)$ \\
& -0.064 & 0.490 \\
Single & $(0.078)$ & $(1.852)$ \\
& 0.074 & 16.039 \\
Use mobile phone & $(0.525)$ & $(11.601)$ \\
& 0.126 & -3.855 \\
Size of plot(s) & $(0.206)$ & $(5.667)$ \\
Index herd size & -0.003 & \\
& $(0.003)$ & 6.405 \\
Time lived in village & -0.073 & $(6.134)$ \\
Constant & $(0.086)$ & 0.165 \\
& $-0.016^{*}$ & $(0.250)$ \\
\hline Observations & $(0.008)$ & 6.444 \\
$R^{2}$ & 0.594 & $(30.022)$ \\
\hline \hline
\end{tabular}

Notes: Standard errors clustered at the village level are in parentheses. $* p<0.10, * * p<0.05$, *** $p<0.01$. Missing values for mobile phone usage $(1 \mathrm{missing})$, participating in village work $(8$ missings) and generalized trust (1 missing) were replaced with mean values.

Table 2.8: Treatment Effects on Community Aspirations Dimensions

\begin{tabular}{|c|c|c|c|c|c|}
\hline & Number of meetings & Share good housing & School distance & Contributions to village & Share receiving support \\
\hline & (1) & $(2)$ & (3) & (4) & (5) \\
\hline \multirow[t]{2}{*}{ VL video } & $-0.345^{* * *}$ & $0.060^{* * *}$ & -0.046 & -0.049 & -0.024 \\
\hline & $(0.055)$ & $(0.018)$ & $(0.073)$ & $(0.042)$ & $(0.031)$ \\
\hline \multirow[t]{2}{*}{ CA video } & $-0.358^{* * *}$ & $0.030^{*}$ & -0.089 & -0.072 & -0.021 \\
\hline & $(0.059)$ & $(0.017)$ & $(0.074)$ & $(0.044)$ & $(0.031)$ \\
\hline \multirow[t]{2}{*}{ Constant } & -0.197 & $-0.321^{* * *}$ & 0.173 & $-0.540^{* * *}$ & $-0.170^{* * *}$ \\
\hline & $(0.139)$ & $(0.094)$ & $(0.171)$ & $(0.098)$ & $(0.048)$ \\
\hline Observations & 642 & 642 & 642 & 642 & 642 \\
\hline$R^{2}$ & 0.127 & 0.067 & 0.043 & 0.143 & 0.052 \\
\hline Fixed effects & Yes & Yes & Yes & Yes & Yes \\
\hline Controls & Yes & Yes & Yes & Yes & Yes \\
\hline
\end{tabular}

Notes: Standard errors clustered at the village level are in parentheses. ${ }^{*} p<0.10,{ }^{* *} p<0.05,{ }^{* * *} p<0.01$. Regressions include the individual-level control variables: gender, age, relationship status, highest grade attained, size of the plot in hectares, herd size index, group membership, daily mobile phone usage, locus of control, village efficacy and area fixed effects. 
Table 2.9: Treatment Effects on Different Indices

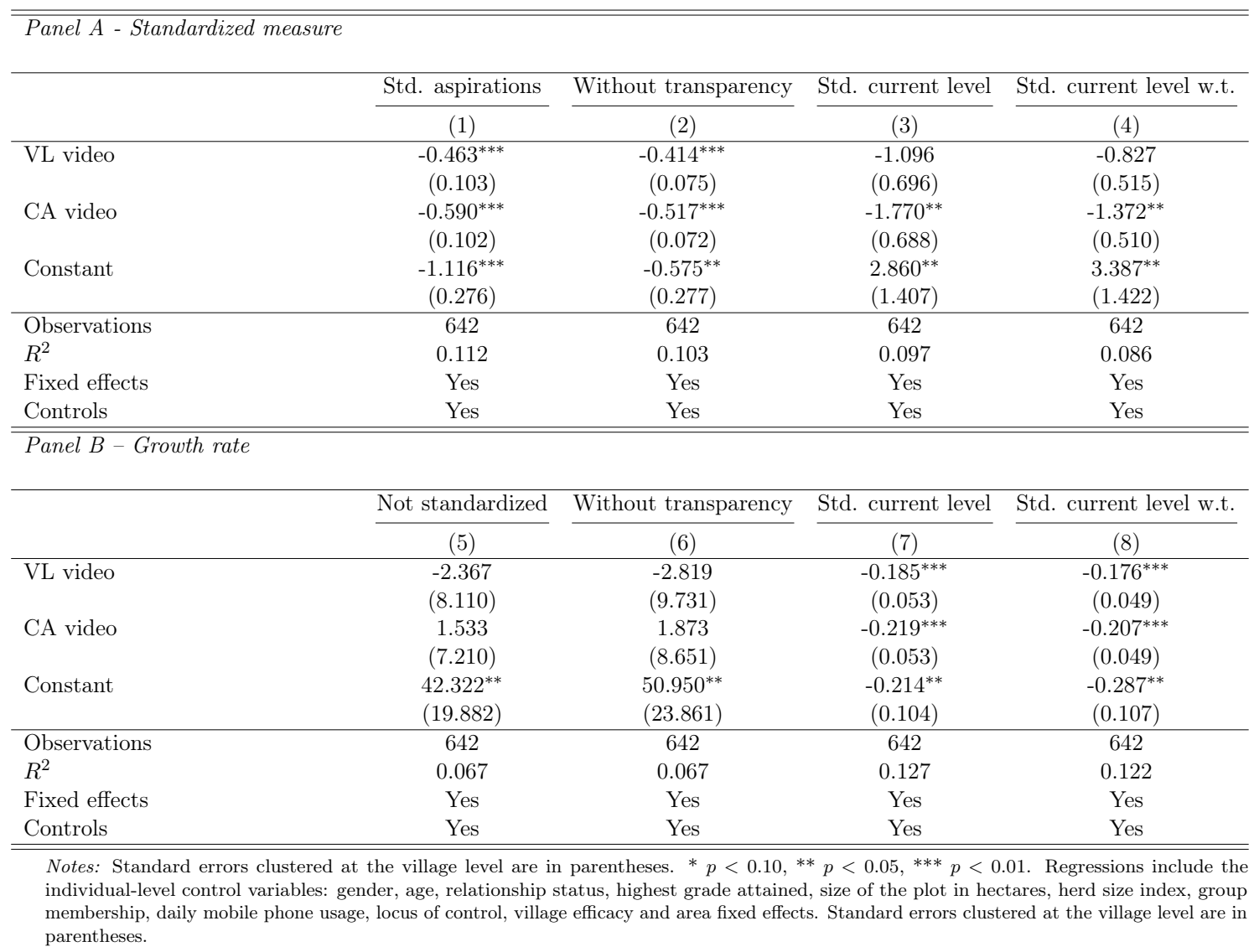


Table 2.10: Variable Description

\begin{tabular}{|c|c|}
\hline Variable & Explanation \\
\hline Adults village & Number of adults living in the village \\
\hline Age in years & Reported age in years \\
\hline Agree similar characters & $\begin{array}{l}\text { Whether the respondent disagrees/agrees that the video } \\
\text { characters are similar to themselves }(1=\text { yes, } 0=\text { no })\end{array}$ \\
\hline Average actual contributions & $\begin{array}{l}\text { Average contributions in the public goods game in each } \\
\text { village in Kwacha }\end{array}$ \\
\hline Average reported contributions & $\begin{array}{l}\text { Average reported contributions in the public goods } \\
\text { game in each village in Kwacha }\end{array}$ \\
\hline Community aspiration index & $\begin{array}{l}\text { Standardized index made up of five community aspira- } \\
\text { tion dimensions proxied by: economic welfare, access } \\
\text { to education, security, village contributions, mutual } \\
\text { support and village meetings }\end{array}$ \\
\hline Daily use of mobile phone & Respondent uses mobile phone daily $(1=$ yes, $0=$ no $)$ \\
\hline Distance health facility (min) & $\begin{array}{l}\text { Distance to the nearest health facility in walking min- } \\
\text { utes }\end{array}$ \\
\hline Frequency of meetings & $\begin{array}{l}\text { Frequency of village meetings }(1=\text { twice per year, } 2= \\
\text { once per month, } 3=\text { more than once per month })\end{array}$ \\
\hline General trust in villagers & $\begin{array}{l}\text { Trust in fellow villagers measured with the question: } \\
\text { "Do you think that most people in this village are basi- } \\
\text { cally honest and can be trusted?" ( } 1=\text { strongly disagree, } \\
2=\text { slightly disagree, } 3=\text { slightly agree, } 4=\text { strongly agree })\end{array}$ \\
\hline Group member & Respondent is a member of (a) group $(\mathrm{s})(1=$ yes, $0=$ no $)$ \\
\hline Highest grade & Highest grade of schooling attained in years \\
\hline Household has child(ren) & $\begin{array}{l}\text { Whether there are children in the age from } 6 \text { to } 18 \text { in } \\
\text { the respondent's family }(1=\text { yes, } 0=\text { no })\end{array}$ \\
\hline Individual aspiration index & $\begin{array}{l}\text { Standardized index made up of two individual aspira- } \\
\text { tion dimensions: education and assets }\end{array}$ \\
\hline Index herd size & $\begin{array}{l}\text { Index capturing the herd size derived with principal } \\
\text { component analysis }\end{array}$ \\
\hline Like character & $\begin{array}{l}\text { How strongly the respondent disagrees/agrees to like } \\
\text { the character }(1=\text { strongly disagree, } 4=\text { strongly agree }=)\end{array}$ \\
\hline Listens to radio daily & Respondent listens to radio daily $(1=$ yes, $0=$ no $)$ \\
\hline Locus of control & $\begin{array}{l}\text { If the respondent agrees to be successful: one needs to } \\
\text { work hard }=1 \text {, one needs to be lucky }=0\end{array}$ \\
\hline No. of goats & Number of goats the respondent owns currently \\
\hline
\end{tabular}


Table 2.11: Variable Description 2

\section{Variable}

No. of hh with access to safe water

No. of hh with good housing

Participation in village work per year

Perceived participation

Reported contributions

Security group

Share of endowment sent

Single

Size of plot(s)

Spendings village activities (individual/year)

Time lived in village

Treasury contributions (hh/year)

Village efficacy

\section{Explanation}

Number of households with access to safe drinking water (i.e. protected wells, boreholes, pumped water)

Number of households in the village with very good housing conditions (reported); good housing conditions: houses with walls made out of red brick, burnt brick or asbestos and/or with iron sheets on the roof

Number of times per year the respondent participates in village work such as road clearing, village clean up, insaka maintenance

How the respondent rates the spirit of participation in the village $(1=$ low, $2=$ average, $3=$ high $)$

The amount the respondent reported to have contributed to the village project in Kwacha

Security group exists in village $(1=$ yes, $0=$ no $)$

Amount of Kwacha that was sent in proportion to the endowment

Respondent is single $(1=$ yes, $0=$ no)

Size of the plot(s) the respondent owns currently in hectares

Respondent's average spending for village activities in a year in Kwacha

Time the person has lived in the village in years Households' contributions to the village treasury on average per year in Kwacha (reported by the village leadership)

Whether the respondents thinks that people like themselves have influence in making the village a better place to live $(1=$ agree, $0=$ disagree $)$ 


\subsection{Appendix B - Experimental Instructions and Surveys}

\subsubsection{General Instructions}

Good morning/afternoon. Thank you for taking the time to come to this activity today. We are a group of researchers from the University of Göttingen and the University of Kiel in Germany and from Zambia. We are conducting a study on socio-economic conditions in Zambia. In this activity, we will ask you to make decisions involving money and to complete a survey. You will get $10 \mathrm{Kwach}$ for an activity. The money you will get will be yours to keep and take home. The activities of this study are financed by the German Research Foundation. Before we start, we would like to tell you some important points.

Today's activities may take three hours. Before we begin we would like to make some general comments about what we are doing here today and explain the rules that we must follow. Participation in this study is completely voluntary. If at any time you do not want to participate, you are free to leave whether the activities have begun or not. In this case you will not receive the payment, though. Only people from this village are able to participate in this study. If you are not from this village, you can stay and watch, but not participate in the activities.

All decisions will be made in private. That means no one of the other participants will know how you have decided and what answers you have given. The information we collect will be saved in an anonymized manner. We will treat the information confidentially. If you have heard anything about these types of activities, you should try to forget about that because each activity can be completely different. That is why it is important that you listen as carefully as possible.

Before we explain the activities, each of you will draw a card from the bag with a number on it. This number is your ID number in our activity. We will show a video to all of you. If the number of participants is large, we will ask you to take turns to watch the video, beginning with lower numbers and going to larger numbers.. When all participants have watched the video, we will do an activity in the group which we will explain then. Afterwards, numbers 1 to 20 will also be asked to answer a survey. 


\subsubsection{Experimental Instructions}

Thank you for coming together. For this task you will receive 10 Kwacha. Here is a box in which you can put some, all or no money from the 10 Kwacha we give you. This money that is put to the box will be kept in your village. In addition to the money that you put into the box that belongs to your village, we will put the same amount of money which has been put to the village box on top of it. Thus, the total amount of money that you give to the village box will be doubled by us. Let us take an example. Suppose that the total amount of money that has been put into the village box is $60 \mathrm{Kwacha}$, so that the village has earned 60 Kwacha. This 60 Kwacha will be doubled by us, so that you will receive 60 Kwacha by us on top. In total you will have 120 Kwacha in the village box in the end.

The total amount of money in the village box will form the seed capital for new savings groups in your village. This means that village members can save money regularly and when in need of capital, they can borrow money for a private productive investment. Often the households lack access to capital to undertake productive investments. Therefore, setting a saving goal and having access to credit can facilitate the needed resources. This has been shown in the video, where the women in the village of Lilanda were able to buy household items together.

The suggestion that we have for you is that you form several savings groups in your village. Each saving group could consist of 8 to 15 households. Only newly established savings groups will be eligible to receive the money earned in this study today, not already existing groups. Members of already existing groups are free to also be a member of a newly formed savings group. Further, village members who have not been able to come to this study today will be able to be a member of the newly created savings groups. People from other villages, however, should not become members of the new groups. Similarly, the seed capital that you receive today cannot be send to saving groups with people from other villages.

The savings groups should meet regularly to collect the savings of group members. Once that the members have accumulated sufficient capital, members can borrow to finance productive investments such as buying seeds, animals, fertilizers or vaccinations, etc. Members of the group should repay the loan on periodic installments and on pre-determined dates. Do you understand the procedure? Control question: If the total amount of money given to the village box is 50 Kwacha. How much money will we give to you on top? How much money is then in the village box? We will now explain how you will make your decision. Please do not ask questions or talk while you are here in the group. This is very important. Please be sure that you obey this rule, because it is possible for one person to spoil the activities for everyone. If one person talks about the activities while others can hear it, we would not be able to carry out the activities today. 
We will call you one by one to come to a place where you will be given 10 Kwacha in $1 \mathrm{Kwach}$ coins in an envelope. We then ask you to go another place where you will wait in line until you will be called to come to the location where the box for the village box contributions is located. The box is located in such a way that nobody can see how much you contribute. You can put no coin, one, two, three, four, five, six, seven, eight, nine or ten Kwacha coins to the village box. If you have decided how much you want to put, you leave this amount in the envelope and place the envelope in the box. The money that you want to keep for yourself, you will take into your pocket. Please remember, nobody will get to know how much you put.

Once everybody has put their envelope into the box, we will take the box and open the envelopes to count the money that has been given to the village box together with the village treasurer. After we know the total amount that has been put into the box, we will double the total amount of coins. In the end we will give the total money, the money that you have given and that we have put on top, to the village treasurer. We would like to ask you to hold a village meeting in the next week. In this meeting you can set up the new saving groups. You will need to decide on who will be the leader of the group, the secretary and the treasurer. In addition you will decide on the individual productive use you want to give to the loan, as well as the conditions on the savings and loans. The money that you have contributed to the village box and the amount that we have put on top will be equally divided among the newly established saving groups by the village treasurer.

We will give you a booklet which shows how a saving group can be established. When you meet in the next week, you can discuss with each other how your village saving group should look like and determine the rules. The booklet also contains an accounting sheet with which you can keep track of the outgoing and ingoing money and the total amounts of money that has been borrowed and paid back by each individual in the saving group. Further, we kindly ask you to keep records of the meetings and the discussions. Please register who has taken part in the village meeting next week by each of you writing down your name on a form that can also be found in the booklet. We will give several booklets to the headman who will distribute them to each group. How many of you are already members of a savings group? Please raise your hands. Thank you.

You can now go to the car where our research assistants will hand out the envelopes with the 10 Kwacha coins to you. Please form two lines and do not speak while you are waiting in line. This is very important. 


\subsubsection{Smallholder Survey}

1. Name of the research assistant (First, Last)

2. Date of interview $(d d / \mathrm{mm} / \mathrm{yr})$

3. Village/Locality

4. Individual ID

5. First Name

6. Last Name

7. Mobile number(s)

8. Sex

9. Age (years)

10. Date of Birth $(d d / m m / y r)$

11. Marital Status

Single

Married

Divorced

Widowed

12. Relation to household head

13. What tribe are you?

14. How long have you lived in this village? (years)

15. What is the highest grade of schooling that you have completed? (Number of years)

16. How many 1 Kwacha coins did you leave in the envelope for the village treasury? Please be reminded, that this information will be kept private. Kwacha

17. What kind of change would you like to bring about in your village? Please tell me any desire/goal you want to achieve in your village in the future. [RECORD ANSWER]

___ Education:

_-_ Health:

___ Standard of living:

___ Safety: 
- Mutual support:

Participation:

(Please list the order in which the goals were mentioned)

18. How likely do you think you will be successful in bringing about these changes?

Very likely

Somewhat likely

Not likely

Very unlikely

19. Of all of these goals, which one is the most important one for you to change? (Specify goal)

Education

Health

Standard of living

Safety

$\square$ Mutual support

$\square$ Participation

Other, specify:

20. How many households in your village have very good housing conditions, i.e. houses with walls made out of red brick, burnt brick or asbestos and/or with iron sheets on the roof?

21. For how many households in your village would you like to have very good housing conditions in the future? (desire/goal)

22. How many households do you expect to actually have very good housing conditions in your village in ten years? (expectation)

22.1 If the expectation is higher than the desire/goal, why is this the case?

23. How many minutes do students from your village have to walk to get to a primary school?

24. How many minutes would you like students to walk to get to a primary school in the future? (desire/goal)

25. How many minutes do you expect students will actually have to walk to primary school in ten years? (expectation)

25.1 If the expectation is higher than the desire/goal, why is this the case? 
26. How many policemen/-women or voluntary guards does your village have?

27. How many policemen/-women or voluntary guards would you like your village to have in the future? (desire/goal)

28. How many policemen/-women or voluntary guards do you expect your village will actually have in ten years? (expectation)

28.1 If the expectation is higher than the desire/goal, why is this the case?

29. How much money do households in this village contribute to finance village projects in a year? (Kwacha/year)

30. How much money would you like that households in your village contribute annually to finance village projects in the future? (desire/goal) (Kwacha/year)

31. How much money do you expect households actually contribute annually to finance village projects in ten years? (expectation) (Kwacha/year)

31.1 If the expectation is higher than the desire/goal, why is this the case?

32. How many households in your village get support in case of need, such as suffering from economic loss due to crop failure?

33. How many households would you like to get support in case of need in the future? (desire/goal)

34. How many households do you expect to actually get support in case of need in ten years? (expectation)

34.1 If the expectation is higher than the desire/goal, why is this the case?

35. How many times do people in your village meet each other (for example for celebrations or village discussions) in a month?

36. How many times a month would you like people in your village to meet in the future? (desire/goal)

37. How many times a month do you expect people to actually meet in ten years? (expectation)

37.1 If the expectation is higher than the desire/goal, why is this the case?

38. Are there children in the age of 6 to 18 in your family?

Yes

No (Go to question 42)

39. What is the education level that the youngest child achieved until now? 
40. What is the level of education you would like this child to achieve in his/her life? (goal/desire)

41. What is the level of education you expect this child will to achieve in his/her life? (what they will probably achieve)

41.1 If the expectation is higher than the desire/goal, why is this the case?

42. Do you own land, cows and goats? How big is the size of your plot and how many cows and goats do you have?

Size of plot:

\# of cows:

\# of goats:

43. What is the size of your plot and number of cows and goats you would like to have in your life? (goal/desire)

Size of plot:

\# of cows:

\# of goats:

44. What is the size of your plot and number of cows and goats you expect to have in ten years? (expectation)

Size of plot:

\# of cows:

\# of goats:

44.1 If the expectation is higher than the desire/goal, why is this the case?

45. How many households live in this village? No. of households

46. How many households do you expect to live in this village in ten years? (no. of households)

47. Please tell me with which of the two statements you agree more:

Statement A: "To be successful, above all one needs to work very hard."

Statement B: "To be successful, above all one needs to be lucky."

I agree more with $\mathrm{A}$

I agree more with B

48. Do you think that women and men have equal rights in your village?

Yes 
if yes:

Strongly agree

$\square$ Moderately agree

No

if no:

Slightly disagree

Strongly disagree

49. Are you a member of any clubs, groups, organizations, committees or associations?

Yes

No (if no, go to question 64)

50. If yes, in which one(s):

Cooperative (fishing, agriculture, etc)

$\square$ Savings group/club

$\square$ Savings group/club

Neighborhood/village association/committee

$\square$ Water/waste group/club

$\square$ Health group/club

$\square$ Youth group/club

Women group/club

Sports group/club

Other (specify)

51. How often do you meet with your savings group?

Once a week

Twice a month

Once a month

Less than once a month

52. What is the name of your savings group?

53. How many members does your savings group have? (Open ended answer)

54. How many women are in the savings group?

55. How many men are in the savings group?

56. How long has the savings group been in existence? (in years) 
57. What is the goal of the savings group? (Open ended answer)

58. Does your group make regular deposits?

$\square$ Yes

$\square$ No (if no, go to question 60)

59. If yes, how much money does each member deposit every meeting?

Kwacha

60. How often does each member on average borrow money from the saving group in a year? (Open ended answer)

61. Would you say that the group is successful in achieving its group goal (such as providing loans for productive uses)?

Yes

if yes:

$\square$ Strongly agree

$\square$ Moderately agree

$\square$ no

if no:

Slightly disagree

$\square$ Strongly disagree

62. Did you have problem(s) in your saving groups?

$\square$ Yes

$\square$ No (if no, go to quesstion 64)

63. If yes, which ones? (Open ended answer)

64. Do you consider yourself to be active in the group(s), such as by attending meetings or volunteering your time in other ways, or are you relatively inactive?

Very active

$\square$ Somewhat active

$\square$ Not active

65. How many times a year do you participate in village work (such as road clearing, village clean up, insaka maintenance)?

-_- times per month

66. How much money do you spent on average for village activities or village problems in a year?

Kwacha/year 
67. How much money do you spend on schooling on average per school term?

-_- Kwacha/school term

68. Do you think that most people in this village are basically honest and can be trusted?

Yes

if yes:

$\square$ Strongly agree

$\square$ Moderately agree

No

if no:

Slightly disagree

$\square$ Strongly disagree

69. Do you think people like yourself have influence in making this village a better place to live?

Yes

If yes:

yes, a lot

$\square$ yes, a little bit

$\square$ No

70. Overall, how would you rate the spirit of participation in this village?

$\square$ High

$\square$ Average

Low

71. Do you have friends and/or family in the village ...?

$\square$ Yes

$\square$ No

72. How often do you visit the village ....? (Open ended answer)

73. How often do you use a mobile phone?

Every day

Once a week

Once a month

Once a year

Never 
74. How often do you listen to a radio?

Every day

Once a week

Once a month

Once a year

$\square$ Never

75. Do you like the characters of the video?

$\square$ Yes

if yes:

Strongly agree

$\square$ Moderately agree

No

if no:

Slightly disagree

Strongly disagree

76. Do you think that the people in the video are similar to you?

$\square$ Yes

if yes:

Strongly agree

$\square$ Moderately agree

$\square$ No

if no: why do you think that they are not similar?

77. Do you think your village can be as successful as the villages in the video within the next ten years?

$\square$ Yes

if yes:

Strongly agree

$\square$ Moderately agree

No

if no:

Slightly disagree

Strongly disagree 
78. Do you know the FAO, the Food and Agriculture Organization of the United Nations?

Yes

$\square$ No 


\subsubsection{Village Survey}

1. Name of the research assistant (First, Last)

2. Date of interview $(d d / m m / y r)$

3. Name of the interviewee (First, Last)

4. Role of the interviewee (e.g. headwoman/-man)

5. Village

6. How many households does your village have?

7. How many adults live in your village?

8. How many households in your village have access to safe drinking water (i.e. protected wells, boreholes, pumped water)?

9. On average how many minutes does it take a household to get access to safe drinking water?

10. What is the main market where villagers sell their products? (specify the name of the city where the main market is located)

11. How many kilometers away is the main market?

12. How many minutes does it take to reach the main market?

13. What is the state of the road leading to the market?

Good

if good:

very good

good

Poor

if poor:

$\square$ poor

$\square$ very poor

14. How many children in the village go to primary school?

15. How many children, who are in the age to go to primary school, do not attend primary school?

16. How far is the nearest health facility? distance (in walking minutes) 
17. Does the facility have medicine?

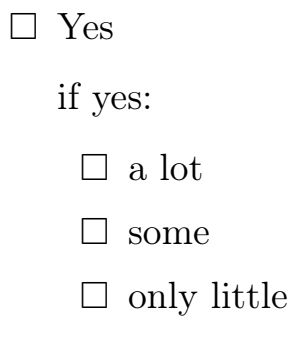

$\square$ No

18. Does the village have police or a neighborhood security committee?

Yes we have police

Yes we have neighborhood security committee

No

19. What type of transportation do people in this village use to go to neighboring villages?

Walking

Bicycle

Motorbike

Car

Public transport

Other

20. Do you have a resource that is used jointly such as a well or a village field/garden?

Yes

No (go to question 22)

21. If yes, which one(s)? (specify)

22. How often do the people come together for a village meeting?

More than once a month

Once a month

Twice a year

$\square$ Never happens

23. Which regular activities do the people in the village do together (such as the improvement of insaka, cleaning of roads and paths, maintenance of borehole)? (specify)

24. How often does the village meet per year? 
25. Do you document your village meetings and/or the regular activities (when they take part, what was done/spoken and how many people participate?)

26. In the last three years, has the village organized to address a need or a problem?

Yes

No (go to question 27)

a. Around which issue(s) did the village organize?

a)

b)

b. Was/were the initiative(s) successful?

a) Initiative $\# 1$

$\square$ Yes

$\square$ No

$\square$ Ongoing

b) Initiative \#2

$\square$ Yes

$\square$ No

$\square$ Ongoing

27. How many programs and institutions (such as WHO, UNICEF) assist your village?

a. What are the three assistance programs and the institutions that support them?

1. Program/institution:

2. Program/institution:

3. Program/institution:

28. Which of the following organizations, clubs, committees, or groups exist in this village?

Cooperative (fishing, agriculture, etc.)

Saving group/club

Neighborhood/village association/committee

Water/waste group/club

Health group/club

Youth group/club

$\square$ Women group/club

Sports group/club

Religious group/club

Other (specify) 
29. How many saving groups exist in this village?

a. How many people participate in the first savings group?

b. How many people participate in the second savings group?

c. How many people participate in the third savings group?

d. How many women in the village are members of a savings group?

e. How many men in the village are members of a savings group?

30. Do any persons or organizations (such as for example government, religious organizations, and businesses) help or support these village-based organizations?

Yes

No (go to question 31)

a. If yes, who/which one(s)? (specify)

31. Does this village have a village treasury?

Yes

No (go to question 32)

a. Who is in charge of the accounting of the village treasury? (specify)

b. Do you have accounting records?

$\square$ Yes

$\square$ No

c. How much money is in the village treasury at present?

d. How much money is in the village treasury on average in a year? - - - - - K Kwacha/year

e. How much money do people contribute to the village treasury on average per year?

- - - - - - Kwacha/year

f. Does the village treasury have other sources of money than financial contribution of people living in this village? (specify)

g. For what has the money in the village treasury spent in the last year? (specify)

32. How often do village members on average give money to a village member who is in need?

More than once a month

Once a month

Twice a year

Once a year 
$\square$ Never happens

33. What kinds of crimes (such as robberies, violent disputes, etc.) exist in this village? (specify)

34. How often do crimes happen in a year?

-

35. Are there members of this village who go to other places to work during certain periods of the year?

$\square$ Yes

$\square$ No 


\subsection{Appendix C - Video Scripts}

\subsubsection{Collective Action Video}

\section{Village Clubs: Community Mobilization}

Narrator: "In rural communities local development is everyone's business: men, women, youth and elders alike. Village clubs create quite a community dynamic. Each time a club is created people's participation and social cohesion are reinforced. At the entrance of the village of Iaosongi, in the heart of the Congo forest, the rehabilitation of the road was decided within the villagers in their village club. The clubs are used to facilitate dialogue and stimulate collective action. Village clubs are groups of people that meet regularly to discuss challenges, to find and implement solutions."

Woman: "Together, we decided to rehabilitate the road. Look how it looks now. First the men of the village enlarge the way and then women follow with their machetes."

Narrator: "It was a great challenge, indeed, as this route is the main one that leads to the village. Until recently it could only be used by bicycles and pedestrians. The road is not quite finished. Only a few hundred meters remain. But it is already having an impact."

Woman: "In the village, it is cheaper to buy cassava sticks than before. The price has dropped from 500 to 200, even to 150 Congolese Francs. And we manage to sell our fish for a higher price."

Villagers: "If you are afraid to be on the front-line, let us take your place and we will show you how to develop your environment."

Narrator: "In Lilanda, another village of the Tshopo Province it is harvest day and many people are here together as this is a community field. The traditional chief allocated land to the village clubs. The clubs then decided to use it for producing seeds and called upon the local union of producer organizations. Together they identified and adapted a variety of seeds and experimented with seldom used techniques such as line planting and double cropping. The partnership between producer organizations and the village clubs benefits the entire community. Production has increased and better quality seeds are now available. The whole population of Lilanda joins in and takes advantage of this new impetus. Taking its inspiration from the village clubs, 100 women producers created their own association spontaneously. Today they share the goods they have jointly acquired thanks to their individual contributions."

Woman: "We were inspired by the way the clubs operate and have decided that we too could be involved in the development of our community this is why we have created 
our association."

Village Clubs in DR Congo: Food Security and Nutrition

Narrator: "The Tshopo Province in the Northeast of the Democratic Republic of Congo is covered by rainforests and watered by the Congo River and its tributaries. On this huge territory fishing is a key economic activity that is traditionally controlled by men. Women bring occasional support. Therefore, in order to increase household incomes, why not allow women to fish? This question was raised during the discussions of the local village club in the fishing village of Isangi. The club was formed by the villagers. They have spaces in which rural men and women get organized, express themselves, and take collective action to improve their living conditions. Henry and Rebecca are husband and wife. They have been members of the village club for three years and have taken part in the discussions about fishing."

Man: "Men-women equality and the gender division of responsibility were discussed in our village club for the first time. We have realized that women can also play a proactive role in fishing activities."

Narrator: "Behaviors have gradually changed. It is now accepted for women to carry out tasks that were previously attributed to men. Rebecca, Henry's wife, fishes with a friend. The redefinition of women's roles has increased the households fish catches and increased their incomes as a result. At the same time the clubs have discussed and brought awareness to the issue of nutrition. The diet of the community is now more varied and balanced. People now eat vegetables, meat and, of course, fish. However, for Rebecca and her friends the benefits of this new gender division of tasks goes far beyond food and nutrition."

Woman: "Today, we pay school for five children. Three others are at home. We have also started to buy metal sheets to change the roof which currently leaks because it is in straw. Thanks to the club, we have increased our incomes and acquired new skills."

Narrator: "A few kilometers from Isangi, in Yalosuna, village clubs have encouraged communities to fight against food taboos and resulting malnutrition. Adama is busy preparing food for her family. On today's menu there is a variety of fish that, until recently, women were not allowed to eat."

Woman: "Traditions forbade us from eating catfish. People said that: "If you eat it, your eyes, belly and arms will swell, your hair will fall out and your body will be ripped in pieces."

Narrator: "Thanks to discussions and awareness activities in the village clubs, things have changed. Adama and the other women of the village are now allowed to eat forbidden food 
which represents a new source of protein and an important step towards gender equality. In this village, as well as in many other places, such changes have been possible thanks to the support of traditional chiefs."

Man: "I am so proud of this! It is an encouraging sign of trust with my people.I hope that in the future we will even improve this way of working."

Narrator: "In fact this is the very nature of the village clubs - to collaborate with all development stakeholders. The clubs also work closely with the local authorities."

Man: "I have seen the changes. Before when I visited the villages as an Agriculture Inspector, people used to ask me for machetes, seeds, ... But now they don't ask for everything. Instead they say 'come and see what we've done!'".

Narrator: "On the other bank of the Congo River, in the village of Bossokulu, the local village club has introduced a new crop, the soya bean, a legume that is highly rich in protein. Zhang is the leader of the local club that has played a key role in this change. After discussions in the club, members realized that the diets in the village in the province were not diversified enough; consisting mainly of cassava and banana. So they decided to introduce new varieties of crops."

Man: All this helps us for a good diet. Here, Fally takes care of his field where he has planted soya as a result of our discussion in our village club."

Narrator: "All of these experiences are worth being shared and it happens through a community radio. Each week the clubs discover what other clubs do, talk about it, and even build on these experiences. Thanks to their work and their networking, village clubs allow communities to redefine their daily life and to shape their future." 


\subsubsection{Village Life Video}

\section{Village Life in the Democratic Republic of the Congo: Farming}

Narrator: "In Sub-Saharan Africa, more than half of the population lives in the rural areas. For example in the Democratic Republic of Congo, almost $60 \%$ of the population live in rural areas. The village of Iaosongi is a good example of a traditional village in the Congo. [no speaking]. This village is located in the heart of the Congo forest. The village is very remote and it takes several hours to travel to the capital. The main access to the village is by an unpaved road. Regularly, it is necessary to do maintenance."

Woman: "I am Christine Sombotolea. I come from Iaosongi. This road connects us to other villages in the area. As it is no concrete road, it has to be maintained by machetes."

Narrator: "There are also other roads, which are smaller compared to the main one and that can only be used by bicycles and pedestrians. It is important for the village to be well connected to the other surrounding villages."

Woman: "Farmers from other villages come and sell their cassava sticks here. We get them for about 150 to 200 Congolese Francs. We mainly sell fresh fish."

Villagers: "If you are afraid to be on the front-line, let us take your place and we will show you how to develop your environment."

Narrator: "This is Lilanda, another village in the Democratic Republic of Congo. It is harvesting time. People here rely on farming. They grow a variety of crops. Among them are cassava, manioc, peanuts, corn, beans, rice and also bananas and pineapples. Drought is not a big problem here, as the village lies in an area with regular rainfall. The majority of people in the Democratic Republic of Congo work as subsistence farmers. Typically, farms are about four acres large and maintained by simple tools. Today, the women in Lilanda meet to share the goods that they have bought for their household: mattresses, pots and other household items they need for their living. They next bigger town is far away and people often lack transport possibilities."

Woman: "We do not have a car which we can use to drive to the next city, so we order our needed household items from a supplier who brings them to our village."

\section{Village Life in the Democratic Republic of the Congo: Fishing}

Narrator: "The Tshopo Province in the Northeast of the Democratic Republic of Congo is covered by rainforests and watered by the Congo River and its tributaries. On this huge territory fishing is a key economic activity that is traditionally controlled by men. Women 
bring occasional support in order to increase household incomes. For fishing, people here use traditional methods: Unmotorized canoes, seine nets, gill nets, hand lines and fish baskets. The fishing village of Isangi is meeting today to discuss their last week's catches and experiences. The fish are not easy to catch. Most of them only live in specific areas such as in channels and creeks with only little current. This is where the fish find their food. Henry and Rebecca are husband and wife. They have been living in Isangi for their whole life. They also depend on fishing for their living."

Man:"During the rainy season from September and October and also the time between April to June the fish are breeding. At these times there are a lot of small animals in the water the fish need for their growth."

Narrator: "In these periods there are not many fish that the fisher find in the Congo river. Catches are then the lowest in the whole year. Overall, however, the Congo river has a great diversity of fish such as the elephant fishes, cichlids and catfishes. Today, Rebecca is fishing with a friend. They hope to have fish for dinner. When they fish more than they can eat they sell their fish on the local market. The diet of the community is very varied and balanced. People eat vegetables, meat and, of course, fish. Rebecca and her friend have been successful. They are returning from fishing and are on their way to prepare dinner."

Woman: "We have five children who go to school. Three others are still at home. As everybody in the village, they will depend on fish. My husband takes them with him in his boat and teaches them how to fish. They learn how to locate the fish and how to throw the net into the river."

Narrator: "A few kilometers from Isangi, there is the village called Yalosuna. The woman, Adama is busy preparing food for her family. On today's menu there is a variety of fish that also come from the Congo river."

Woman: "I like to prepare catfish. It is cooked very fastly and it is very delicious, very nutritious. It is the favorite meal of my husband and my children."

Narrator: "Adama and her family eat the catfish cooked; with some oil and bread. It is a traditional meal in the village of Isangi due to the availability of catfish in the Congo river. The fish presents a source of protein which is an important step towards a good nutrition. The village of Isangi is governed by the grand traditional chief of the Kome Chiefdom Joseph Ngwangwa Onobaiso."

Man: "I have been the grand traditional chief for many years. The fish in my chiefdom are very important for the people. It presents a source of food and livelihood."

Narrator: "In Yalosuna people grow up with fishing. They learn it early on." 
Man: "I am also from the village Yalosuna. I am living here over 10 years now. Before I came here, I did not know how to fish. But since I learned it from the other men in the villages I earn my living with it."

Narrator: "On the other bank of the Congo River, in the village of Bossokulu, the inhabitants do not rely so much on fish, but instead on the soya bean, a legume that is highly rich in protein. So soya bean can replace animal products. The crop grows especially well in areas with a hot climate. Next to the soya bean, the diets in the village consists of mainly cassava and banana."

Man: "All this helps us for a good diet. Here, Fally takes care of his field where he has planted soya. He also sells the beans on the market."

Narrator: "After work, the village members meet to hear some radio or to talk about everyday life. Today they are celebrating a birthday of a village member. Celebrations are an important part of their culture." 


\section{Community Aspirations and Cooperation: Pre- scriptive vs. Descriptive Role Models ${ }^{1}$}

\footnotetext{
${ }^{1}$ We are grateful for the helpful comments and suggestions received by Kacana Khadjavi, Holger A. Rau, Martin C. Parlasca as well as the participants from the CollEcons seminar and the GlobalFood doctoral seminar. We thank Christiane Monsieu of the Dimitra Project for the permission to use their videos and Felix Betzenbichler for including the subtitles. We also thank Paul Malambo, Sarah Hanyama, Harriet Chibuta, Naomi Munthali, Magdalene Trapp, Muyambo and Charity Sipangule for their research assistance in the field as well as Maximilian Köster, Merindah Lössel and Henrike Sternberg for their data preparation and data cleaning support.
} 


\subsection{Introduction}

Cooperation among individuals in groups is essential for rural economic development, especially in countries where the state has limited capacity to provide local public goods (Cardenas \& Carpenter, 2008). Collective organization at the village level then provides an important substitute (Fafchamps, 2006). Villages characterized with high participation in village organization have been found to have higher incomes per capita compared to villages with low levels of participation (Narayan \& Pritchett, 2019). Yet, despite the potential benefits of collective action, there is considerable heterogeneity in the degree of self-organization (Ostrom, 2000). Understanding the factors that facilitate and constrain the evolution of collective action is thus of great importance.

In this paper we propose that collective action depends on the long term goals that individuals set for the community. The long term goals on what the society can become is what we call community aspirations. As discussed in Martini et al. (2020), we consider that community aspirations are multi-dimensional and depend on five main dimensions: political freedom, economic facilities, social opportunities, transparency guarantees, and protective security.

Our hypothesis is that there is an aspiration failure in that individuals lack reference to successful cases of collective action that inspire them to set higher communal goals. Based on this hypothesis, we test whether showing videos that depict living conditions in other communities can foster community aspirations and hence promote cooperation compared with a no video condition. We compare two types of videos. The first video depicts villages in which people have been successful in organizing themselves into village clubs. The characters talk about the positive outcomes of collective action, while the narrator presents information on the advantages of social organization. The second video does not include any messages that highlight the virtue of cooperation. It shows the same villages, but the characters instead talk about their living conditions and therefore, implicitly inform on why cooperation is advantageous. Our aim is to test which type of video is more effective at eliciting cooperation in a public goods game: the one which contains a descriptive and a prescriptive message promoting collective action (collective action video) or the descriptive one (village life video).

Ample empirical evidence demonstrates that individuals are conditional cooperators and contribute more to the public good when they expect others to contribute more (Keser \& Winden, 2000; Fischbacher et al., 2001; Kocher et al., 2008). Based on this premise, our hypothesis is that communal aspirations increase cooperation only when there are shared higher community aspirations. To test this hypothesis, we form groups with two participants and allow either one or both members of the group to watch the videos. This allows us to capture whether the videos are only successful in changing contributions if there is common knowledge on having seen the video. We further test the effect of the 
video on norms of conditional cooperation.

To test our hypotheses, we implemented a lab in the field experiment in which we randomly assigned 358 individuals in eight villages in Zambia into one of four treatment conditions or into a control group and subsequently measured cooperative behavior with a two-person one-shot linear public goods game. Similar to Fischbacher et al. (2001) we used the strategy method to obtain unconditional as well as conditional contribution decisions to the public good. After the experiment we obtained socio-economic information and measures for aspirations and beliefs using the method developed in Martini et al. (2020).

We find that the village life video is effective at facilitating cooperation. Compared to the no video group, unconditional contributions are higher in this treatment. If both players were exposed to the village life video, we find that unconditional contributions are even higher in magnitude and we also find a positive effect on conditional contributions. This points to the importance of social norms in the evolution of collective action. Further, there is a higher proportion of positive conditional cooperators and a higher proportion of positive unconditional contributions in this treatment. While the collective action video was not effective in increasing cooperative behavior, both videos have a positive effect on perceived norms of cooperation. Controlling for beliefs and aspirations, we find that our measure of individual aspirations, but not the measure of community aspirations, is significantly correlated with contribution decisions.

Our paper contributes to the literature on aspirations and poverty (Appadurai, 2004; Ray, 2006; Dalton et al., 2016). While there is extensive research on the role of individual aspirations on educational choices and investment decisions (Pasquier-Doumer \& Risso Brandon, 2015; Goux et al., 2017; Janzen et al., 2017; Lybbert \& Wydick, 2018; Serneels \& Dercon, 2020), there is no evidence on the role of aspirations in collective action. We extend the concept of aspirations to consider that individuals hold long term goals for the community. We propose that community aspirations affect cooperation. Martini et al. (2020) conceptualize community aspirations and propose an empirical measure. In this paper, we investigate the mechanism by which successful examples of collective action, in the form of videos, affect community aspirations and increase cooperation.

Our study experimentally analyzes whether the videos increase conditional cooperation or result in increased levels of unconditional contributions. In order to test the role of common knowledge in the decision to cooperate, we vary the number of participants in the group exposed to the videos. Other studies analyze the role of common knowledge in edutainment interventions with respect to attitudes and behavior related to AIDS/HIV and violence against women (Arias, 2019; Banerjee et al., 2019). We extend that notion given that in the setting of collective action, beliefs on the behavior of other people play a crucial role in cooperation (Fischbacher et al., 2001; La Ferrara, 2016). 
This paper also adds to the emerging experimental literature that aims at increasing aspirations through role models in the form of short videos or documentaries. For example, Bernard et al. (2014) randomly invited individuals in Ethiopia to either watch a placebo video or a treatment video that shows individuals who climbed out of poverty by setting up a business or being successful at farming. They find that six months after the screening treated individuals had higher aspirations, savings, use of credit and investment into education compared to the control group. In another study by Riley (2018) students were randomly shown either a placebo movie or a movie about a Ugandan girl from a poor neighborhood who aimed at becoming a chess master. Treated students in upper secondary school performed better and treated students from lower secondary school had higher math scores compared to untreated, which is driven by students failing math less often. Batista \& Seither (2019) combined random screenings of an aspirational video with training on business skills and goal setting among vendors in Mozambique. One year after the intervention they find that treated subjects had higher profits compared to the control group. Participants who additionally received training increased their profits even more. The study by Lubega et al. (2018) finds that HIV-positive women that were exposed to four four-minute role model videos throughout one year were more likely to start a business and increased their income compared to non-treated women. Lastly, Narciso et al. (2018) do not find evidence that role models in videos change behavior among ethnic minorities in Vietnam. Unlike those papers, we consider community role models, and screen examples of successful communities that help to inspire individuals on what the community can achieve by engaging in collective action. Further, we assess how a different framing of the video affects cooperation.

We chose to compare a video that is narrative and explains the advantages of village life to one that is salient on the value of cooperation. The empirical evidence shows that educational entertainment (edutainment) - entertainment media that entails educational messages with the intention to bring about desirable outcomes (Singhal \& Rogers, 2003) can increase pro-social behavior (Paluck, 2009; La Ferrara, 2016; Blair et al., 2019). Edutainment has been argued to be successful in changing individual behavior since the viewers show less resistance to narrative content compared to more explicit persuasive formats of communication (Moyer-Gusé, 2008). We test whether explicit appeals for collective action reduce cooperation. Other studies suggest that messages that use prescriptive and descriptive norms together are more successful Cialdini (2003). We test which type of message is more effective in the context of collective action.

\subsection{Experimental Design}

The experiment has three stages. In the first stage we randomly select participants to one of two conditions that vary whether the participants are exposed or not to one of two videos as explained in more detail below. Participants in the control treatment started directly in 
the second stage, where they participated in a two person public goods game (PGG). In the last stage participants completed an individual interview where we collected information on community aspirations and socioeconomic characteristics. Our primary outcomes of interest are contributions to PGG and community aspirations.

\subsubsection{Treatments}

Our experiment uses a between subject design to compare behavior in a control condition without video with four treatments that vary (1) the kind of video that the participants see and (2) whether or not the group member watched the same video. Table 3.1 presents the treatment design with the number of participants per-treatment arm. The rows indicate which type of video was screened in the groups: No video (Control), collective action video $(\mathrm{CA})$ or village life video $(\mathrm{V})$ while the columns indicate whether the partner watched the video.

Table 3.1: Number of Participants Per Treatment

\begin{tabular}{lccc}
\hline \hline & & \multicolumn{2}{c}{ The other person saw the video } \\
& & No & Yes \\
\hline No video & Control & $\cdot$ & $\cdot$ \\
\multirow{2}{*}{ Collective action video } & 130 & $\cdot$ & $\cdot$ \\
\multirow{2}{*}{ Village life video } & $\cdot$ & CA1 & CA2 \\
& $\cdot$ & 63 & 48 \\
& $\cdot$ & V1 & V2 \\
\hline \hline
\end{tabular}

Note: The numbers present the experimental observations.

The two videos have the same footage that is taken from a video series produced by the Dimitra Project, a participatory information and communication project from the Food and Agriculture Organization of the United Nations (FAO). The video series show the success of this participatory communication approach that consists of the creation of village clubs, named Dimitra Clubs. We used footage of two videos (Community Mobilization, Food Security and Nutrition) that show village clubs in the Democratic Republic of the Congo (DRC). The original videos can be accessed on YouTube. ${ }^{2}$ We edited the videos, created a new script and translated the content into the local Zambian language (Tonga). ${ }^{3}$ In addition, videos included English subtitles. The videos were synchronized to have a total length of 11 minutes. The footage of both videos is exactly the same. The only difference between the two treatment videos is the spoken content, which we will elaborate in the following.

\footnotetext{
${ }^{2}$ https://www youtube.com/playlist?list=PLzp5NgJ2-dK60BbZpPuTMn_7wSrclUE0I

${ }^{3}$ The video scripts can be found in Martini et al. (2020).
} 
The collective action video shows four villages in the North-East of the DRC which successfully established village clubs. ${ }^{4}$. These village clubs are people who formed groups with the aim of improving their lives and actively bringing about positive changes in their village. Together they meet regularly to discuss challenges they face, talk about solutions and take measures to implement them. The video demonstrates the positive outcomes that the village club generated. For example, the video shows how the villagers jointly built and maintain a road, till a community field and share goods that they have collectively acquired. The video also illustrates how through the discussion of villagers in the clubs, people introduced new crops, abolished food taboos and resolved gender division in tasks. The characters of the video talk about their motivation to engage in the clubs and how they feel that the clubs positively affected their lives; whether it is a higher dietary diversity or increases in households' income. Next to the village club members, the video also portrays a traditional chief and an agricultural inspector who report on increased trust and initiative they have observed since the establishment of the clubs. A narrator guides the viewer through the video, explains what village clubs are and that they increased collective action and thereby social cohesion. However, the narrator does not provide specific information on the steps that are necessary to build a village club and what makes them successful. Thus, as in Bernard et al. (2014), the video provides a vicarious experience in which participants were provided a different view on what is possible to achieve in their community by taking actions collectively.

The village life video tells a different story. The narrator and characters talk about life in four villages in the DRC: the villages' location and climate, villagers' source of income, diet and their social activities. The video contains general information about smallholders' livelihoods that was mainly shown in the video (without reference to collective action). The story of the video does not include reference to negative events and thus can be considered to describe an ideal village life. ${ }^{5}$ This can be explained by the fact that we used the same video footage of the collective action video that shows successful examples of villages that took part in the FAO Dimitra Project. It can thus be argued that the video also include role model villages without making the reason for their improved living conditions (successful collective action) salient. However, there are some parts that mention collective action activities that could not be rephrased since the pictures tell the story quite clearly. ${ }^{6}$ Any effects that we could observe between the collective action and village life video are thus on how explicitly the advantages of collective action are communicated.

\footnotetext{
${ }^{4}$ Instead of Dimitra Club we used Village Clubs, since we wanted to focus on the outcomes of the clubs and not talk about how and under which project they were formed.

${ }^{5}$ For instance, the video does not mention armed conflict and the resulting displacement that took place the DRC in the last 25 years (World Food Programme, 2020). The villages depicted in the videos are located in Tshopo Province, Northeast of DRC, and not in worst conflict affected provinces.

${ }^{6}$ The narrator mentions that the women of the village Lilanda meet to share goods that they have bought for their households (mattresses, pots) which were acquired from a supplier that came to their village. Also the narrator speaks about a meeting of a village, where the villagers discuss their last week's catches and experiences.
} 


\subsubsection{Public Goods Game}

In order to measure contribution to a public good we employ a two person one-shot linear public goods game. We form anonymous groups of two persons and give each an endowment of $40 \mathrm{Kwacha}$ (3.1 Euro at the time of the experiment ${ }^{7}$ ). Individuals make two type of decisions. First, they make an unconditional contribution decision and decide simultaneously how much money they would like to contribute to a group account. The amount deposited in the group account is multiplied by 1.6 and equally shared among group members. Participants could contribute any number multiple of 10 between zero and 40 Kwacha.

Second, participants made a conditional contribution decision. We provided them with a contribution table (see Appendix) in which we asked for their contribution for every possible contribution level of the other group member. To make the decision incentivecompatible, we employed the strategy method (Fischbacher et al., 2001) and for one participant in the group the unconditional decision was payment-relevant and for the other the conditional decision. After the experiment, one of the participants was asked to draw a card from a bag that determined for which of the two players the first decision was selected.

The payoff of each player $i$ is the following:

$$
\pi_{i}=40-g_{i}+0.8 \sum_{j=1}^{2} g_{j}
$$

where $g_{i}$ is the amount an individual contributes to the public account $g_{j}$. The dominant strategy is to contribute nothing to the group account $\left(g_{i}=0\right)$, whereas the Pareto-efficient outcome would be that both players contribute all their endowment $\left(g_{i}=40\right)$. We elicited beliefs on the contribution level of the other group member and incentivized correct answers by paying five Kwacha when the stated belief was equal to the actual contribution.

Since we asked respondents for their contributions for each level of possible contribution decisions of the other player, we can use their decisions to categorize them into different types of cooperation behavior. Following Fischbacher et al. (2001), we distinguish between six different types. We classify Free-riding behaviour as contributing non-positive amounts for all possible contribution levels of the other player. Unconditional cooperation is defined as always contributing the same positive amount. Decisions that display a monotonic function with at least one increase and that have a positive Spearman rank correlation that is significant at the one percent level are classified as Positive Conditional Cooperation. On the contrary, Negative Conditional Cooperation contains decisions that show a negative

\footnotetext{
${ }^{7}$ The exchange rate at the time of the experiment was around 12.81 Kwacha equivalent to one Euro. 40 Kwacha is a substantial amount of money for people living in rural Zambia. According to estimations of Central Statistical Office (2016) the monthly per capita income in the rural area in 2015 was 810 Kwacha.
} 
Spearman rank correlation that is significant at the one percent level and a monotonic decreasing function. Hump-shaped contributions are decisions that have monotonically increasing contributions until a maximum and thereafter monotonically decreasing contributions. ${ }^{8}$ All other remaining types of contributions are defined as Other.

The instructions for the PGG experiment were given in a group and then each participant was asked to come to a research assistant one by one to make his or her decision. If they had questions, each participant could ask the research assistant in private. To make sure they understood the questions, we asked them three control questions. After making their decisions, participants were asked to answer a survey. Only after the participants finished the survey, we paid the money they have earned in the public goods game and the survey fee of 5 Kwacha.

\subsubsection{Survey}

We randomly selected up to twenty participants to complete a survey after the experimental session. The random sampling (instead of surveying all subjects) was done due to time restrictions. The survey included questions on socio-economic information as well as on aspirations and beliefs.

We measure aspirations using an approach similar to Bernard \& Taffesse (2014) and Beaman et al. (2012). First we ask respondents for the aspirations or goals they want to achieve collectively and individually in different dimensions in ten years. As discussed in Martini et al. (2020), we propose that community aspirations are the preferences for goals that increase community well-being and have a public good nature. Following Sen (2001)'s conceptualization of well-being, we consider that community aspirations depend on five dimensions: 1) Political freedom, 2) Economic facilities, 3) Social opportunities, 4) Transparency guarantees, and 5) Protective security. Table 3.2, summarizes the measures used to proxy those dimension.

Table 3.2: Community Aspiration Dimensions

\begin{tabular}{lll}
\hline Community Aspiration Dimensions & Description \\
\hline 1 & Political freedom & The number of times a month he/she would like villagers to join for a village meeting \\
2 & Economic facilities & The proportion of households in the village he/she would like to have very good housing conditions \\
3 & Social opportunities & The number of minutes he/she wants students from their village to walk to a primary school \\
4 & Transparency warranties & Number of security guards relative to the population \\
5 & Protective security & The proportion of households he/she would like to get supported in case of need \\
& Amount they would like each villager to contribute to village projects on average in a year \\
\hline
\end{tabular}

To make the answers comparable across dimensions we took the following steps: First, we divided the answers to the aspiration questions that entail an assumption on the number of households in the village (questions of dimension 2, 4 and 5) with the participants' estimate on the number of households living in the village in ten years. For dimension 3

\footnotetext{
${ }^{8}$ Since we have only five decisions, we are not able to calculate the Spearman rank correlation after the maximum contribution and hence cannot use this criterion to define hump-shaped behavior.
} 
social opportunities, we inverted the measure so that higher values present higher aspired levels. Second, as Beaman et al. (2012), we standardize each dimension by using the sample mean and standard deviation of the control group. Afterwards we sum up the standardized answer to form the aspiration index. The community aspiration index is thus formalized in the following way:

$$
A_{s}=\sum_{d}\left(\frac{a_{i}^{d}-\mu_{d c}}{\sigma_{d c}}\right)
$$

where $\sigma_{d c}$ is the standard deviation and $\mu_{d c}$ the sample mean from the control group $c$ for each aspiration question from dimension $d$.

Similar to Bernard \& Taffesse (2014), before asking for their aspired level, we included questions on their current level of each dimension to facilitate finding answers. We use those answers and estimated an index of current social well-being (current index). This index is used in the regression analysis to control for the achieved level.

Further, we asked participants for their expected level, defined as what they believe the community would actually achieve. We constructed a community expectation index following the same approach as with the aspirations above..$^{9}$ Besides community aspirations, we collected information on individual aspirations by asking for (1) the size of the plot and (2) the number of cows and goats as well as the (3) the level of education they would like the youngest child in their family to have.

Since the treatment videos could also have an effect on participants' beliefs, we collected survey information on locus of control and village efficacy beliefs. We measured locus of control by asking the following question taken from Bernard et al. (2014): Please tell me with which of the two statements you agree more. Statement A: "To be successful, above all one needs to work very hard." Statement B: "To be successful, above all one needs to be lucky." This results in a binary variable that is one when the respondent agrees more with A (internal locus of control) and 0 if he/she agrees more with B (external locus of control). To obtain a measure of village efficacy beliefs, we asked the respondents whether they think people like themselves have influence in making the village a better place to live. We coded the variable with 0 if they answer "no", 1 if they state "yes".

Finally, we also use survey measures to capture participants' level of trust and perceived participation in the village to be able to analyze whether there is a shift in the answers influenced by the provision of other reference points. We measure trust with the question:

\footnotetext{
${ }^{9}$ Bernard \& Taffesse (2014) also ask for the maximum and minimum that can be achieved in their neighborhood to make sure that they do not report general wishes. Our pilot revealed that respondents had difficulties in answering these questions. Since our expectation index is significantly correlated with the aspiration index (correlation of 51 percent, significant at the one percent level), we believe that this was not detrimental to our measurement strategy.
} 
Do you think that most people in this village are basically honest and can be trusted? and coded the variable with 1 if participants strongly disagree, 2 if they slightly disagree, 3 if they slightly agree and 4 if they strongly agree. The variable Perceived Participation was coded with 1 if the respondent rates the spirit of participation in the village low, 2 if average and 3 if high.

\subsubsection{Experimental Procedures}

Our sample consists of eight villages in Southern Province that were selected from a village list which we obtained from the Zambian Central Statistical Office (CSO) in Lusaka. We randomly selected villages that have more than 100 and less than 300 inhabitants and that are located more than $2.5 \mathrm{~km}$ from each other. Several days before we conducted the experiment, we visited the headman to inform him about our study and ask for permission to collect data within his village. With his consent, we asked the village headman to assist us in inviting at least 30 persons per session. We expressed the need to have as many women as men participating in the sessions. Further, participants had to be at least sixteen years old and members of that particular village. In total we have experimental data for 358 and survey data for 242 individuals.

In each of the villages we conducted two sessions: one that started in the morning and one at midday. The procedure was the same for every session. When arriving in the village we introduced ourselves and the project. We read out the general instructions (see Appendix) which informed them about the confidentiality and anonymity of their decisions and answers as well as the possibility to always drop out of the activity. Then our research team asked the participants to draw a card from a bag that would determine their individual ID number and assigned treatment condition.

The pairs in the PGG were anonymous and participants did not receive feedback on the decision of the partner. There was no possibility for the partners to interact. Participants in the control treatment started with the PGG, while participants in the treatment groups first watched the video (village life/collective action). We did not tell the participants that the treatment group will watch a video. However, participants in the control group could infer as the other group stayed at the screening site, while they had to go to another place to start the PGG. When both participants watched the video, we did two screenings of the video, one for the treatment and one for the control group. We screened the video on two laptops at a common meeting place of a village.

\subsubsection{Hypotheses}

We would like to test the following. First, we are interested in the effect of the videos on cooperation in the PGG. We hypothesize that the two videos change the reference point on what is possible for their community to achieve, resulting in higher aspirations and thus 
higher contributions to the public good (Bernard et al., 2014).

Our hypothesis is that seeing people cooperating (village life video) or talking positively about cooperation (collective action video), changes the expected level of cooperativeness of their peers by generalizing from the behavior of people in the video to the behavior in their village (Blair et al., 2019). ${ }^{10}$ Therefore, we expect that the collective action and village life video increase conditional cooperation. Our first hypothesis is thus the following:

Hypothesis 1: The collective action and village life video lead to higher unconditional and conditional cooperation in the public goods game compared to the control group.

We expect that an individual will increase its contribution to the public good even more, if the other player has also watched the same video, since there is common knowledge. Knowing that the other person has also watched the same video, and also knowing that the other person knows that I know, can facilitate coordination (Arias, 2019). We thus compare decisions V2 and CA2 where two persons in the group are exposed to the treatment videos with the condition in which only one watched the video, V1 and CA1.

Hypothesis 2: Individuals who watched the collective action or village life video and their partner did as well, have higher (positive) unconditional and conditional contributions in the public goods game compared to individuals who saw the video and the partner did not.

Lastly, we believe that the content of the videos - the type of information provided matters. We thus compare the village life and the collective action videos. Studies reported in Cialdini (2003) have found that communication campaigns that use prescriptive and descriptive norms together are successful in facilitating pro-social behavior. We thus hypothesize that the collective action video, which could be argued to include prescriptive as well as descriptive norms ${ }^{11}$, leads to higher contributions to the public good compared to the village life video, which only contains descriptive norms.

Hypothesis 3: The collective action video leads to higher unconditional and conditional contributions in the public goods game compared to the village life video.

\footnotetext{
${ }^{10}$ Tankard \& Paluck (2016) analyze how a change in perception of behavior of other people (norms) can lead to social change. They argue that perceptions of norms are easier to change with role model interventions than attitudes.

${ }^{11}$ The video shows how people cooperate (descriptive norms) and how they approve the cooperative behavior (prescriptive norm).
} 


\subsubsection{Empirical Strategy}

To evaluate the effect of the treatments, we estimate the following model:

$$
y_{i}=\alpha+V_{s}^{\prime} \beta+X_{i}^{\prime} \gamma+\mu_{v}+\epsilon_{i}
$$

where $y_{i}$ is one of the outcome variables: unconditional contribution decision, the community or the individual aspiration index of individual $i . V_{s}^{\prime}$ is a vector consisting of four indicators representing the different treatments: $V 1$ (1) and $V 2$ (2), CA1 (3), and CA2 (4). The base is Control (0). $X_{i}^{\prime}$ is a vector including the following individual level control variables: gender, age, relationship status, highest grade attained, number of cows owned, size of the plot in hectares, children 6 to 18 in the family, daily mobile phone usage, daily listening to the radio, group membership, participation in village work per year and knowledge of the FAO. For the outcome Unconditional contributions we additionally include the belief in the other player's contribution. $\epsilon$ is the random error and $\mu_{v}$ village fixed effects to account for differences in the villages. The coefficient of interest is $\beta$.

For the conditional decision we include the possible contribution of the other player, $L_{i}$, into our models in equation (2). $L_{i}$ is the categorical variable Level which takes on the values $0,10,20,30$ and 40 . We run separate regressions for each treatment group (each indicator of the vector $V_{s}$ ) and employ a Wald test to test for differences in the coefficients in each of the treatment equations. The specification is the following:

$$
y_{i k}=\beta_{0}+X_{i k}^{\prime} \beta_{1}+\beta_{2} L_{i k}+\mu_{v}+\epsilon_{i}
$$

where $y_{i k}$ is the conditional decision of player i in treatment k. $X_{i}^{\prime}$ is a vector of individual level controls - the same as in equation (2) above. $\epsilon$ is a random error and $\mu_{v}$ village fixed effects. We employ ordinary least squares (OLS) regression for all outcome variables and calculate heteroscedasticity-robust standard errors.

\subsection{Results}

\subsubsection{Descriptives}

Table 4.1 reports the mean, standard errors as well as the p-value from a joint orthogonality test of treatment arms (F-test) for the main variables of our experiment. We find that there are only two variables which are significantly different from each other in the five treatment groups: highest grade attained and number of cows owned. We will include these as further controls in our analysis among other controls. 
Table 3.3: Summary Statistics

\begin{tabular}{|c|c|c|c|c|c|c|}
\hline & $\begin{array}{c}(1) \\
\text { Control }\end{array}$ & $\begin{array}{l}(2) \\
\text { V1 }\end{array}$ & $\begin{array}{l}\text { (3) } \\
\text { V2 }\end{array}$ & $\begin{array}{c}(4) \\
\text { CA1 }\end{array}$ & $\begin{array}{c}(5) \\
\text { CA2 }\end{array}$ & $\begin{array}{c}(6) \\
\text { p-value }\end{array}$ \\
\hline Female $(1=$ female, $0=$ male $)$ & $\begin{array}{c}0.505 \\
(0.048)\end{array}$ & $\begin{array}{c}0.559 \\
(0.065)\end{array}$ & $\begin{array}{c}0.800 \\
(0.200)\end{array}$ & $\begin{array}{c}0.533 \\
(0.075)\end{array}$ & $\begin{array}{c}0.292 \\
(0.095)\end{array}$ & 0.140 \\
\hline Age in years & $\begin{array}{l}36.954 \\
(1.381)\end{array}$ & $\begin{array}{l}36.678 \\
(1.679)\end{array}$ & $\begin{array}{l}43.200 \\
(3.367)\end{array}$ & $\begin{array}{l}38.356 \\
(2.508)\end{array}$ & $\begin{array}{l}40.125 \\
(3.539)\end{array}$ & 0.740 \\
\hline Single & $\begin{array}{c}0.119 \\
(0.031)\end{array}$ & $\begin{array}{c}0.119 \\
(0.042)\end{array}$ & $\begin{array}{c}0.000 \\
(0.000)\end{array}$ & $\begin{array}{c}0.156 \\
(0.055)\end{array}$ & $\begin{array}{c}0.125 \\
(0.069)\end{array}$ & 0.887 \\
\hline Highest grade & $\begin{array}{l}7.505 \\
(0.252)\end{array}$ & $\begin{array}{c}8.407 \\
(0.316)\end{array}$ & $\begin{array}{c}8.600 \\
(0.510)\end{array}$ & $\begin{array}{c}6.822 \\
(0.424)\end{array}$ & $\begin{array}{l}7.792 \\
(0.565)\end{array}$ & 0.036 \\
\hline No. of goats & $\begin{array}{c}3.826 \\
(0.655)\end{array}$ & $\begin{array}{c}3.169 \\
(0.454)\end{array}$ & $\begin{array}{c}3.000 \\
(1.265)\end{array}$ & $\begin{array}{c}2.444 \\
(0.679)\end{array}$ & $\begin{array}{c}4.792 \\
(1.273)\end{array}$ & 0.493 \\
\hline No. of cows & $\begin{array}{l}2.358 \\
(0.474)\end{array}$ & $\begin{array}{l}1.983 \\
(0.475)\end{array}$ & $\begin{array}{l}4.800 \\
(2.059)\end{array}$ & $\begin{array}{c}0.756 \\
(0.290)\end{array}$ & $\begin{array}{c}4.750 \\
(2.049)\end{array}$ & 0.024 \\
\hline Size of plot(s) & $\begin{array}{l}2.099 \\
(0.344)\end{array}$ & $\begin{array}{l}1.900 \\
(0.285)\end{array}$ & $\begin{array}{c}0.450 \\
(0.229)\end{array}$ & $\begin{array}{l}1.879 \\
(0.462)\end{array}$ & $\begin{array}{c}3.527 \\
(1.249)\end{array}$ & 0.255 \\
\hline Children $(1=$ yes, $0=$ no $)$ & $\begin{array}{c}0.807 \\
(0.038)\end{array}$ & $\begin{array}{c}0.746 \\
(0.057)\end{array}$ & $\begin{array}{c}1.000 \\
(0.000)\end{array}$ & $\begin{array}{c}0.778 \\
(0.063)\end{array}$ & $\begin{array}{c}0.583 \\
(0.103)\end{array}$ & 0.124 \\
\hline Daily use of mobile phone & $\begin{array}{c}0.505 \\
(0.048)\end{array}$ & $\begin{array}{c}0.593 \\
(0.065)\end{array}$ & $\begin{array}{c}0.800 \\
(0.200)\end{array}$ & $\begin{array}{c}0.422 \\
(0.074)\end{array}$ & $\begin{array}{c}0.417 \\
(0.103)\end{array}$ & 0.238 \\
\hline Listen to radio daily & $\begin{array}{c}0.688 \\
(0.045)\end{array}$ & $\begin{array}{c}0.729 \\
(0.058)\end{array}$ & $\begin{array}{c}0.800 \\
(0.200)\end{array}$ & $\begin{array}{c}0.600 \\
(0.074)\end{array}$ & $\begin{array}{c}0.583 \\
(0.103)\end{array}$ & 0.517 \\
\hline Group member $(1=$ yes, $0=$ no $)$ & $\begin{array}{c}0.661 \\
(0.046)\end{array}$ & $\begin{array}{c}0.729 \\
(0.058)\end{array}$ & $\begin{array}{c}0.600 \\
(0.245)\end{array}$ & $\begin{array}{c}0.644 \\
(0.072)\end{array}$ & $\begin{array}{c}0.625 \\
(0.101)\end{array}$ & 0.843 \\
\hline Participation in village work per year & $\begin{array}{c}3.147 \\
(0.489)\end{array}$ & $\begin{array}{c}2.780 \\
(0.375)\end{array}$ & $\begin{array}{c}1.400 \\
(0.748)\end{array}$ & $\begin{array}{c}3.822 \\
(0.600)\end{array}$ & $\begin{array}{c}1.583 \\
(0.288)\end{array}$ & 0.233 \\
\hline Knows the FAO $(1=$ yes, $0=$ no $)$ & $\begin{array}{c}0.450 \\
(0.048)\end{array}$ & $\begin{array}{c}0.559 \\
(0.065)\end{array}$ & $\begin{array}{c}0.600 \\
(0.245)\end{array}$ & $\begin{array}{c}0.467 \\
(0.075)\end{array}$ & $\begin{array}{c}0.542 \\
(0.104)\end{array}$ & 0.660 \\
\hline$N$ & 109 & 59 & 5 & 45 & 24 & \\
\hline
\end{tabular}

Note: Mean values are shown. Standard errors in parentheses. Column 6 shows the pvalues from a joint orthogonality test of the treatments. 


\subsubsection{Treatment Effects on Unconditional Cooperation}

First, we are interested in the effect of the two videos on unconditional contribution decisions. Figure 3.1 shows the fraction of participants in each of the treatment groups who contributed positive amounts to the public good. The highest amount of positive contributors with 89 percent can be found in the V1 treatment. In the control group 75 percent of the subjects have positive contributions. The difference in the proportion of positive contributors between $\mathrm{V} 1$ and control is significant at the five percent level (two-sample Wilcoxon rank-sum test $\mathrm{p}$-value $=0.03$ ). For treatments V2, CA1 and CA2 the graph bar suggests that the difference in the proportion of positive contributors is not significantly different compared to the control group. Employing a two-sample Wilcoxon rank-sum tests confirms the graphical inspection ( $\mathrm{p}$-values $>0.1$ ).

Figure 3.1 shows the mean in unconditional contributions for each treatment group. The bar graph indicates that participants in the V1 treatment make larger contributions to the PGG compared to participants in the other treatments. Whereas participants in the control group on average contributed 14.5 Kwacha, participants in the V1 treatment contributed 20.3 Kwacha. Using a two-sample Wilcoxon rank-sum test we find that the difference is significant at the one percent level $(\mathrm{p}$-value $=0.002)$. Participants in the CA1 treatment have a mean unconditional contribution of $13.8 \mathrm{Kwacha}$, which is not significantly different from the contributions in the control group (two-sample Wilcoxon rank-sum test p-value = 0.917). For the treatments V2 and CA2 where the two group members saw the video the bar graph suggest that there are no significant differences in the value contributed compared to the control group. The results of a two-sample Wilcoxon rank-sum test confirm that the difference is insignificant ( $\mathrm{p}$-values $=0.198 \& 0.263$ ).

Figure 3.1: Proportion of Positive Contributors and Mean Unconditional Contributions
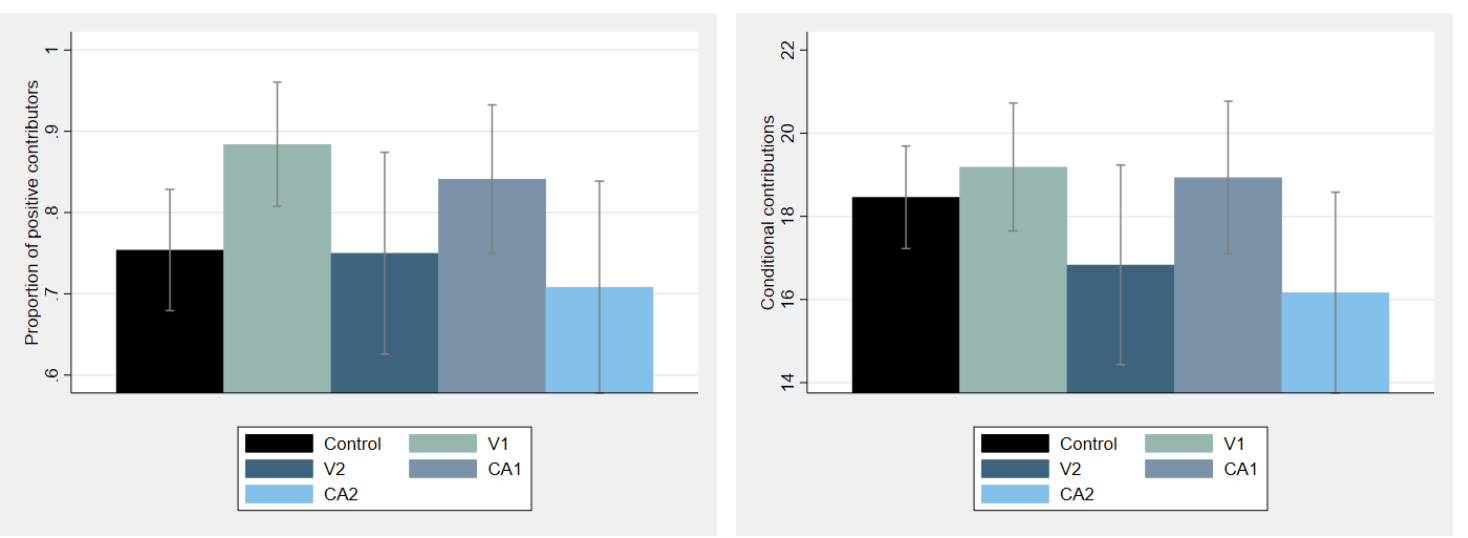

We estimate OLS regressions to control for important covariates and increase precision. The results can be found in Table 3.4. Column 1 reports the results of regressing the 
treatments on the outcome Positive unconditional contribution, which is one if a subject sent a positive amount and zero if not. Column 2 further controls for village fixed effects and additional individual level covariates. ${ }^{12}$ In each specification we find that the V1 treatment has a positive effect on the proportion of positive contributors. The likelihood of positive contributors is 16 percentage points higher in the V1 treatment compared to the control. For the other treatment arms, there are no significant differences in the amount of positive contributors compared with the control. Thus, we find evidence for supporting Hypothesis 1 for the village life video and participants exposed to the village life video contribute significantly more than participants in the control treatment. For the collective action video, the results do not support Hypothesis 1, which suggest that the form of communication plays an important role in promoting cooperation.

Our second hypothesis is that contributions to the public good increase more when both participants watched the video than when only one did so. To test this hypothesis, we compare the estimated coefficients for V1 and V2 treatments using our preferred specification that includes controls. The results of the Wald test indicate that there are no significant differences in the likelihood to contribute to the public good or the value contributed when participants watched the village life video alone compared when they watched it with the partner $(\mathrm{p}$-values $=0.4045$ and 0.3383$)$. Similarly, the comparison of the estimated coefficients for CA1 and CA2 indicate that the estimated coefficient is not significantly different (Wald test $\mathrm{p}$-values $=0.1789$ and 0.789 ). This evidence thus does not support Hypothesis 2 .

Lastly, the third hypothesis states that the video that combines a prescriptive and a descriptive message (collective action) is more effective at eliciting cooperation than the video that only has a descriptive message (village life). To test this hypothesis, we compare the estimated coefficients for V1 and CA1 and V2 and CA2. The results of the Wald test contradict Hypothesis 3 in that participants in V2 are significantly more likely to contribute than participants in C2 (Wald test p-value $=0.0245$ ), and participants in V1 contribute significantly larger amounts (0.0548). This finding suggest that narratives can be more effective at promoting collective action. ${ }^{13}$

\footnotetext{
${ }^{12}$ The number of observations for columns 2 is less than for the previous columns since we do not have survey information for every smallholder who participated in our experiment.

${ }^{13}$ Wald test for likelihood to contribute in V1 vs. CA1 p-value $=0.6724$ and for value of unconditional contributions between $\mathrm{V} 2$ and $\mathrm{CA} 2 \mathrm{p}$-value $=0.2035$.
} 
Table 3.4: Treatment Effects on Unconditional Contributions

\begin{tabular}{|c|c|c|c|c|}
\hline & $(1)$ & $(2)$ & $(3)$ & $(4)$ \\
\hline & Positive uncond. contr. & Positive uncond. contr. & Unconditional contribution & Unconditional contribution \\
\hline \multirow[t]{2}{*}{$\mathrm{V} 1$} & $0.130^{* *}$ & $0.164^{* *}$ & $5.751^{* * *}$ & $5.109^{* *}$ \\
\hline & $(0.054)$ & $(0.070)$ & $(1.860)$ & $(2.113)$ \\
\hline \multirow[t]{2}{*}{ V2 } & -0.004 & 0.357 & $-3.080^{*}$ & $12.005^{*}$ \\
\hline & $(0.074)$ & $(0.223)$ & $(1.796)$ & $(6.834)$ \\
\hline \multirow[t]{2}{*}{ CA1 } & 0.087 & 0.117 & -0.729 & -0.949 \\
\hline & $(0.060)$ & $(0.090)$ & $(1.721)$ & $(2.374)$ \\
\hline \multirow[t]{2}{*}{ CA2 } & -0.046 & 0.069 & -1.622 & 5.461 \\
\hline & $(0.076)$ & $(0.177)$ & $(2.213)$ & $(4.731)$ \\
\hline \multirow[t]{2}{*}{ Constant } & $0.754^{* * *}$ & $0.779^{* * *}$ & $14.538^{* * *}$ & 2.058 \\
\hline & $(0.038)$ & $(0.175)$ & $(1.096)$ & $(4.282)$ \\
\hline Observations & 358 & 242 & 358 & 242 \\
\hline$R^{2}$ & 0.022 & 0.115 & 0.053 & 0.208 \\
\hline Fixed effects & No & Yes & No & Yes \\
\hline Controls & No & Yes & No & Yes \\
\hline
\end{tabular}

\subsubsection{Treatment Effects on Conditional Cooperation}

Table 3.5 presents the proportion of participants per types of cooperation behavior for each treatment group. Unlike Fischbacher et al. (2001), we find that a large proportion of participants (48 percent) are classified in the category Other. This is similar to Martinsson et al. (2013) who find that in Vietnam 32 percent of the participants showed no standard cooperation types.

We are interested in testing if the treatment videos change the cooperative types. Overall, using a Pearson's $\chi^{2}$ test we find a statistically significant difference in the proportion of cooperation types across treatments $(\mathrm{p}$-value $=0.034$ ). Comparing the proportion of subjects who show free-riding behavior in each treatment group, we do not find significant differences using Pearson's $\chi^{2}$ test $(p$-value $=0.679$ ). For unconditional cooperation and positive conditional cooperation, however, we find that the difference is significant ( $\mathrm{p}$-value $=0.019$ and 0.008). For the other types, no significant differences are found.

Analyzing each treatment separately, we find that compared with the control group there is a significantly higher share of conditional cooperators in V2 (Proportion test p-value $=$ 0.001 ) and a lower share of hump-shaped cooperators (Proportion test p-value $=0.081$ ) In addition, for CA2 the share of unconditional positive cooperators is significantly higher than in the control group (Proportion test p-value $=0.004$ ), while the share of negative conditional cooperators is significantly lower compared to $\mathrm{C} 1$ (Proportion test p-value $0=$ 0.007). This suggests that the treatment videos have an effect on conditional cooperation, but only when there is shared knowledge. Indeed, the fraction of conditional cooperators is also significantly larger in V2 than in V1 (Proportion test p-value $=0.025$ ). The results therefore provide some support for Hypothesis 2 for the village video, but not for the collective action video.

Contrary to Hypothesis 3, we find that the village video is more effective at increasing 
coonditional cooperation than the collective action video.

Table 3.5: Percentage of Participants Per Cooperation Behaviour in Each Treatment

\begin{tabular}{lccccccc}
\hline \hline Types of cooperation behaviour & $\begin{array}{c}\text { Control } \\
\%\end{array}$ & $\begin{array}{c}\text { V1 } \\
\%\end{array}$ & $\begin{array}{c}\text { V2 } \\
\%\end{array}$ & $\begin{array}{c}\text { CA1 } \\
\%\end{array}$ & $\begin{array}{c}\text { CA2 } \\
\%\end{array}$ & $\begin{array}{c}\text { Total } \\
\%\end{array}$ & $\begin{array}{c}\text { Pearson's } \chi^{2} \\
\text { p-value }\end{array}$ \\
\hline Free-riding & 6.9 & 2.9 & 6.3 & 3.2 & 4.2 & 5.0 & 0.679 \\
Unconditional cooperation & 4.6 & 8.7 & 4.2 & 3.2 & 18.8 & 7.0 & 0.019 \\
Positive conditional cooperation & 15.4 & 18.8 & 37.5 & 15.9 & 20.8 & 19.8 & 0.008 \\
Negative conditional cooperation & 6.9 & 4.3 & 4.2 & 3.2 & 2.1 & 4.7 & 0.641 \\
Hump-shaped & 19.2 & 17.4 & 8.3 & 25.4 & 12.5 & 17.6 & 0.160 \\
Other & 46.9 & 47.8 & 39.6 & 49.2 & 41.7 & 45.8 & 0.817 \\
\hline Total & 100 & 100 & 100 & 100 & 100 & 100 & \\
N & 545 & 295 & 25 & 225 & 120 & 1210 & \\
Pearson's $\chi^{2}$ p-value $=0.034$ & & & & & & & \\
\hline \hline
\end{tabular}

Next, we perform regression analysis on the outcome variable Conditional Contributions and include the variable Level, which denotes the possible contribution of the other player. The results are presented in Table 3.6. We find participants in all treatments, except for treatments V2 and CA2, to contribute significantly non-zero amounts. Further, for all treatments we find that conditional contributions increase significantly with increases in the level of possible contributions by the other player.

To test whether the coefficients are significantly different for participants in each treatment, we use a Wald test. The results can be found in Table 3.6 below the regression results. Out of the four treatments we only find significant differences in the level of the V2 treatment compared to the control and compared to the V1 treatment. V2-treated participants give on average 0.46 Kwacha for every contribution level of the other player, while untreated subjects contribute on average 0.11 Kwacha. We thus conclude that there is evidence in favor of Hypothesis 1 for the V2 treatment, while the videos have no significant effect on conditional contributions for the other treatment arms compared with the control.

The results also support Hypothesis 2 for V2 as conditional contributions are significantly higher compared with V1 where subjects contributed on average $0.13 \mathrm{Kwacha}$ for one Kwacha contributed by the partner. Comparing village life and collective action video, the results suggest that there is no significant difference between those treatment arms in the degree of conditional cooperation neither in terms of changes in the intercept or of the slope. We find no support for Hypothesis 3. 
Table 3.6: Treatment Effects on Conditional Contributions

\begin{tabular}{|c|c|c|c|c|c|}
\hline & $(1)$ & $(2)$ & (3) & $(4)$ & $(5)$ \\
\hline & Control & V1 & $\mathrm{V} 2$ & CA1 & CA2 \\
\hline \multirow[t]{2}{*}{ Level } & $0.108^{* *}$ & $0.131^{* *}$ & $0.460^{* * *}$ & $0.162^{* *}$ & $0.242^{* * *}$ \\
\hline & $(0.044)$ & $(0.054)$ & $(0.137)$ & $(0.062)$ & $(0.082)$ \\
\hline \multirow[t]{2}{*}{ Constant } & $17.369^{* * *}$ & $18.953^{* * *}$ & -6.854 & $18.941^{* * *}$ & 16.905 \\
\hline & $(4.596)$ & $(6.533)$ & $(19.554)$ & $(6.349)$ & $(10.832)$ \\
\hline Observations & 545 & 295 & 25 & 225 & 120 \\
\hline$R^{2}$ & 0.050 & 0.096 & 0.589 & 0.172 & 0.208 \\
\hline Fixed effects & Yes & Yes & Yes & Yes & Yes \\
\hline Controls & Yes & Yes & Yes & Yes & Yes \\
\hline Level Control - Treat & & 0.763 & $0.013^{* *}$ & 0.498 & 0.153 \\
\hline Const. Control - Treat & & 0.825 & 0.116 & 0.838 & 0.969 \\
\hline Level V1 - V2 & & & $0.023^{* *}$ & & \\
\hline Constant V1 - V2 & & & 0.105 & & \\
\hline Level CA1 - CA2 & & & & & 0.444 \\
\hline Constant CA1 - CA2 & & & & & 0.874 \\
\hline Level V1 - CA1 & & & & 0.713 & \\
\hline Constant V1 - CA1 & & & & 0.999 & \\
\hline Level V2 - CA2 & & & & & 0.162 \\
\hline Constant V2 - CA2 & & & & & 0.200 \\
\hline
\end{tabular}

\subsubsection{Treatment Effects on Aspirations, Expectations and Beliefs}

We propose that the videos can help to expand participants cognitive window by displaying successful examples of cooperation. We expect that the videos would therefore result in a change in community aspirations.

In this section we analyze the effect of the collective action and village life video on our measure of aspirations, expectations and beliefs. The results of estimating Equation 1 for those outcome variables can be found in Table 3.7. The first and second row report the results of regressing the community aspiration index and the community expectation index on the treatment vector, the current index as well as on further covariates. We find that there is no treatment effect on community aspirations and expectations. For individual aspirations we find that the V2 treatment has a negative effect, while the CA1 treatment has a positive effect on individual expectations.

Concerning our belief measures we do not find evidence that the treatment videos increase locus of control beliefs. We do, however, find that treatments V1 and CA1 have a positive effect on village efficacy. The probability of reporting to have village efficacy belief increases by 13.4 (V1) and by 17.5 (CA1) percentage points. Further, treatments CA1 and CA2 have a positive effect on subjects' perceived participation in the village. Compared to untreated subjects, participants are 42 percentage points more likely to perceive the 
participation high if they have seen the collective action video alone and 60 percentage points if they have seen the collective action video and their partner watched it as well. Lastly, we find that all treatments, but V2, have a positive effect on the level of trust participants report to have towards their fellow villagers. If they watched the CA1 (V1) video subjects are 41 (31) percentage points more likely to report a higher level of trust. Participants in the CA2 treatment even report 79 percentage points higher levels of trust compared to the control group.

Table 3.7: Treatment Effects on Aspirations, Expectations, Beliefs and Trust

\begin{tabular}{|c|c|c|c|c|c|c|c|c|}
\hline & $\begin{array}{c}\text { (1) } \\
\text { Commun. } \\
\text { aspiratiom }\end{array}$ & $\begin{array}{c}(2) \\
\text { Commun. } \\
\text { expectation }\end{array}$ & $\begin{array}{c}(3) \\
\text { Indiv. } \\
\text { aspiration }\end{array}$ & $\begin{array}{c}(4) \\
\text { Indiv. } \\
\text { expectation }\end{array}$ & $\begin{array}{c}(5) \\
\text { Locus of } \\
\text { control }\end{array}$ & $\begin{array}{c}\text { (6) } \\
\text { Village } \\
\text { efficacy }\end{array}$ & $\begin{array}{c}(7) \\
\text { Perc. } \\
\text { particip. }\end{array}$ & $\begin{array}{c}(8) \\
\text { Trust }\end{array}$ \\
\hline V1 & $\begin{array}{l}-0.709 \\
(0.523)\end{array}$ & $\begin{array}{l}-0.878 \\
(0.576)\end{array}$ & $\begin{array}{c}0.955 \\
(0.857)\end{array}$ & $\begin{array}{c}0.098 \\
(0.413)\end{array}$ & $\begin{array}{l}-0.019 \\
(0.045)\end{array}$ & $\begin{array}{l}0.134^{* *} \\
(0.063)\end{array}$ & $\begin{array}{l}-0.001 \\
(0.126)\end{array}$ & $\begin{array}{l}0.306^{*} \\
(0.174)\end{array}$ \\
\hline V2 & $\begin{array}{l}-0.365 \\
(1.233)\end{array}$ & $\begin{array}{l}-0.091 \\
(1.796)\end{array}$ & $\begin{array}{l}-1.685^{*} \\
(0.984)\end{array}$ & $\begin{array}{l}-1.721 \\
(1.433)\end{array}$ & $\begin{array}{l}-0.217 \\
(0.211)\end{array}$ & $\begin{array}{c}0.099 \\
(0.279)\end{array}$ & $\begin{array}{c}0.638 \\
(0.422)\end{array}$ & $\begin{array}{c}0.669 \\
(0.716)\end{array}$ \\
\hline CA1 & $\begin{array}{l}-0.553 \\
(0.396)\end{array}$ & $\begin{array}{c}0.464 \\
(0.796)\end{array}$ & $\begin{array}{l}-0.017 \\
(0.844)\end{array}$ & $\begin{array}{l}1.712^{*} \\
(0.888)\end{array}$ & $\begin{array}{c}0.071 \\
(0.044)\end{array}$ & $\begin{array}{l}0.175^{* *} \\
(0.069)\end{array}$ & $\begin{array}{c}0.414^{* * *} \\
(0.134)\end{array}$ & $\begin{array}{l}0.406^{*} \\
(0.218)\end{array}$ \\
\hline $\mathrm{CA} 2$ & $\begin{array}{l}-1.155 \\
(0.971)\end{array}$ & $\begin{array}{c}0.418 \\
(1.046)\end{array}$ & $\begin{array}{l}-0.745 \\
(0.824)\end{array}$ & $\begin{array}{l}-0.243 \\
(0.856)\end{array}$ & $\begin{array}{c}0.017 \\
(0.089)\end{array}$ & $\begin{array}{c}0.137 \\
(0.169)\end{array}$ & $\begin{array}{c}0.601^{* * *} \\
(0.224)\end{array}$ & $\begin{array}{c}0.789^{*} \\
(0.433)\end{array}$ \\
\hline Constant & $\begin{array}{c}1.782^{* *} \\
(0.872)\end{array}$ & $\begin{array}{c}-0.017 \\
(1.374)\end{array}$ & $\begin{array}{l}-1.336 \\
(1.572)\end{array}$ & $\begin{array}{l}-1.693 \\
(1.228)\end{array}$ & $\begin{array}{c}0.953^{* * *} \\
(0.093)\end{array}$ & $\begin{array}{c}0.499^{* * *} \\
(0.132)\end{array}$ & $\begin{array}{c}1.888^{* * *} \\
(0.237)\end{array}$ & $\begin{array}{c}2.805^{* * *} \\
(0.393)\end{array}$ \\
\hline Observations & 242 & 242 & 242 & 242 & 242 & 242 & 242 & 242 \\
\hline$R^{2}$ & 0.236 & 0.303 & 0.161 & 0.323 & 0.113 & 0.181 & 0.198 & 0.222 \\
\hline Fixed effects & Yes & Yes & Yes & Yes & Yes & Yes & Yes & Yes \\
\hline Controls & Yes & Yes & Yes & Yes & Yes & Yes & Yes & Yes \\
\hline
\end{tabular}

\subsection{Mechanism}

In this section we analyze whether the positive effect of the V1 and V2 treatment on unconditional contribution decisions to the public good can be explained by a shift in aspirations and/or beliefs. Table 3.8 reports the results for regressing unconditional contributions on aspirations, expectations and beliefs variables. Columns 9 and 10 include all variables in one model. Column 9 includes community and individual aspirations and column 10 community and individual expectations separately, since aspirations and expectations are strongly correlated. Controlling for the above mentioned variables we find that the treatment effects of the village video treatments remain in all specifications. Individual Aspiration Index is the only variable that is (negatively) correlated with unconditional contributions. This suggests that community aspirations and community expectations as well as beliefs and trust do not seem to play a role in participants' unconditional contribution decision, but that individual aspirations can partly explain cooperative preferences. 
Table 3.8: Mechanism: Unconditional Contributions

\begin{tabular}{|c|c|c|c|c|c|c|c|c|c|c|}
\hline & \multicolumn{10}{|c|}{ "Unconditional contribution } \\
\hline & (1) & (2) & (3) & (4) & (5) & (6) & (7) & (8) & (9) & (10) \\
\hline V1 & $5.108^{* *}$ & $5.113^{* *}$ & $5.554^{* * *}$ & $5.092^{* *}$ & $5.101^{* *}$ & $5.076^{* *}$ & $5.114^{* *}$ & $5.148^{* *}$ & $5.528^{* * *}$ & $5.105^{* *}$ \\
\hline V2 & $\begin{array}{c}(2.117) \\
12.003^{*} \\
(6.849)\end{array}$ & $\begin{array}{l}(2.122) \\
12.024^{*} \\
(6.869)\end{array}$ & $\begin{array}{c}(2.076) \\
11.220^{*} \\
(6.777)\end{array}$ & $\begin{array}{l}(2.124) \\
12.322^{*} \\
(6.811)\end{array}$ & $\begin{array}{l}(2.124) \\
11.921^{*} \\
(6.968)\end{array}$ & $\begin{array}{l}(2.112) \\
11.983^{*} \\
(6.852)\end{array}$ & $\begin{array}{l}(2.124) \\
12.394^{*} \\
(6.868)\end{array}$ & $\begin{array}{l}(2.122) \\
12.093^{*} \\
(6.810)\end{array}$ & $\begin{array}{c}(2.106) \\
11.640^{*} \\
(6.902)\end{array}$ & $\begin{array}{l}(2.165) \\
12.772^{*} \\
(6.967)\end{array}$ \\
\hline CA1 & $\begin{array}{l}-0.951 \\
(2.387)\end{array}$ & $\begin{array}{l}-0.834 \\
(2.357)\end{array}$ & $\begin{array}{l}-0.965 \\
(2.386)\end{array}$ & $\begin{array}{l}-1.255 \\
(2.449)\end{array}$ & $\begin{array}{l}-0.922 \\
(2.420)\end{array}$ & $\begin{array}{l}-0.991 \\
(2.445)\end{array}$ & $\begin{array}{l}-0.688 \\
(2.425)\end{array}$ & $\begin{array}{l}-0.896 \\
(2.428)\end{array}$ & $\begin{array}{l}-0.658 \\
(2.591)\end{array}$ & $\begin{array}{l}-0.838 \\
(2.639)\end{array}$ \\
\hline CA2 & $\begin{array}{c}5.458 \\
(4.741)\end{array}$ & $\begin{array}{c}5.630 \\
(4.738)\end{array}$ & $\begin{array}{c}5.104 \\
(4.604)\end{array}$ & $\begin{array}{c}5.507 \\
(4.756)\end{array}$ & $\begin{array}{c}5.467 \\
(4.739)\end{array}$ & $\begin{array}{c}5.427 \\
(4.760)\end{array}$ & $\begin{array}{c}5.858 \\
(4.759)\end{array}$ & $\begin{array}{c}5.564 \\
(4.756)\end{array}$ & $\begin{array}{c}5.614 \\
(4.690)\end{array}$ & $\begin{array}{c}6.239 \\
(4.840)\end{array}$ \\
\hline Commun. aspiration & $\begin{array}{l}-0.007 \\
(0.277)\end{array}$ & & & & & & & & $\begin{array}{c}0.010 \\
(0.302)\end{array}$ & \\
\hline Commun. expectation & & $\begin{array}{l}-0.107 \\
(0.202)\end{array}$ & & & & & & & & $\begin{array}{l}-0.167 \\
(0.215)\end{array}$ \\
\hline Indiv. aspiration & & & $\begin{array}{c}-0.471^{* * *} \\
(0.174)\end{array}$ & & & & & & $\begin{array}{c}-0.488^{* * *} \\
(0.176)\end{array}$ & \\
\hline Indiv. expectation & & & & $\begin{array}{c}0.183 \\
(0.209)\end{array}$ & & & & & & $\begin{array}{c}0.217 \\
(0.225)\end{array}$ \\
\hline Locus of c. & & & & & $\begin{array}{c}-0.387 \\
(4.671)\end{array}$ & & & & $\begin{array}{l}-0.345 \\
(4.634)\end{array}$ & $\begin{array}{l}-0.367 \\
(4.729)\end{array}$ \\
\hline V. efficacy & & & & & & $\begin{array}{c}0.244 \\
(2.011)\end{array}$ & & & $\begin{array}{c}0.561 \\
(2.090)\end{array}$ & $\begin{array}{c}0.210 \\
(2.105)\end{array}$ \\
\hline Perc. particip. & & & & & & & $\begin{array}{c}-0.644 \\
(1.167)\end{array}$ & & $\begin{array}{l}-0.825 \\
(1.185)\end{array}$ & $\begin{array}{c}-0.618 \\
(1.193)\end{array}$ \\
\hline Trust & & & & & & & & $\begin{array}{l}-0.130 \\
(0.802)\end{array}$ & $\begin{array}{l}-0.106 \\
(0.847)\end{array}$ & $\begin{array}{l}-0.127 \\
(0.840)\end{array}$ \\
\hline Constant & $\begin{array}{c}2.071 \\
(4.358)\end{array}$ & $\begin{array}{c}2.127 \\
(4.274)\end{array}$ & $\begin{array}{c}1.362 \\
(4.349)\end{array}$ & $\begin{array}{c}2.454 \\
(4.355)\end{array}$ & $\begin{array}{c}2.430 \\
(5.984)\end{array}$ & $\begin{array}{c}1.946 \\
(4.349)\end{array}$ & $\begin{array}{c}3.184 \\
(4.740)\end{array}$ & $\begin{array}{l}2.427 \\
(5.144)\end{array}$ & $\begin{array}{c}3.134 \\
(6.909)\end{array}$ & $\begin{array}{c}4.331 \\
(6.985)\end{array}$ \\
\hline Observations & 242 & 242 & 242 & 242 & 242 & 242 & 242 & 242 & 242 & 242 \\
\hline$R^{2}$ & 0.208 & 0.209 & 0.222 & 0.210 & 0.208 & 0.208 & 0.209 & 0.208 & 0.224 & 0.213 \\
\hline Fixed effects & Yes & Yes & Yes & Yes & Yes & Yes & Yes & Yes & Yes & Yes \\
\hline Controls & Yes & Yes & Yes & Yes & Yes & Yes & Yes & Yes & Yes & Yes \\
\hline
\end{tabular}

\subsection{Robustness}

In the following we perform a robustness check by limiting the analysis to observations who correctly state whether the partner has also watched the video. This leads to a reduced sample of 209 survey observations. The results for the outcomes Unconditional Contribution and Positive Unconditional Contribution are reported in Appendix Table 3.9. The results are similar to the ones for the whole sample except that the treatment effects increase in magnitude and the significance of the V1 treatment changes from the five percent to the one percent level.

The regression results for conditional decisions with the reduced sample can be found in Appendix Table 3.10. Column 1 presents the results for the control, column 2 for treatment V1 and column 3 for treatment CA1. In the other treatments there have not been any false answers. Compared to the results for the whole sample we find that in V1 participants do not follow a strong norm of conditional cooperation as the variable Level is not significant in the specification. This suggests that shared knowledge is important to trigger cooperation norms. 


\subsection{Discussion}

Our results show that the village life video is successful in increasing unconditional contributions and promoting conditional cooperation compared to the control group. This seems to be explained by a change in perceived village self-efficacy and not by changes in community aspirations as we expected. This finding suggest that community aspirations are not easily changeable and that a short term intervention as the one that we implemented in the study is not sufficient to expand the cognitive window of what participants think is possible for their community to achieve. Further work should therefore explore whether longer exposition to positive examples of cooperation can affect cooperation (e.g. using soap operas) and whether those interventions have an effect on alternative measures of cooperation. The results suggest that the treatments increase self-reported level of generalized trust. Future work could explore the effect of the videos on incentivized measures of trust and altruism.

As discussed in Martini et al. (2020), we propose that a larger window of imagination of what the community can achieve could motivate individuals to cooperate. Yet, the window of imagination is only the first step. Thereafter, individuals engage in an evaluation stage where they consider whether their effort would result in higher community welfare. To act pro-socially, individuals need to perceive that others would do the same and that the collective effort would result in improved social welfare. Future work should explore how community aspirations, perceived norms of cooperation and self-efficacy interact in promoting cooperation.

We further find that the collective action video that presented successful examples of cooperation descriptively and prescriptively changed participants' perception of community self-efficacy, participation in their village and increased generalized trust. Yet, this treatment did not promote higher contributions to the public good or increase in conditional cooperation. How can this be explained? In the following we provide some possible reasons.

The village life video includes reference to positive outcomes of collective action, while it does not explicitly stress that the outcomes are attributed to successful cooperation. The village life video is thus descriptive in its content, whereas the collective action video can be considered to be more prescriptive since the collective action benefits are made salient throughout the video. Mentioning this explicitly could have crowded out intrinsic motivation for pro-social behavior. As discussed in Bowles \& Polanía-Reyes (2012), participants who are confronted with specific incentives - prescriptive messages in videos in our case could feel constrained in their autonomy by feeling they have to comply to the cooperative behavior mentioned in the videos. Moyer-Gusé (2008) proposes that persuasive messages can create the feeling of arousal that occurs when individuals perceive that their freedom is being threatened. This can lead to reactance, a motivation to reassert one's freedom in response to attempted influence (J. W. Brehm, 1966; S. S. Brehm \& Brehm, 1981). This hypothesis could be tested in future work by including measures of perceived intention to 
change behavior after the video.

It can also be the case that the information in the video is not new to the participants. Perhaps because they value cooperation already or because other actors have stressed the importance and benefits of cooperation and the participant can recall that information. It has been found that awareness raising of a charity decreases charitable giving among people who already know about the cause (Smith \& Schwarz, 2012). The information provided in the videos could also run against their own perception about the success of collective action endeavours (Tankard \& Paluck, 2016). We do not have baseline data on how participants value cooperation. Yet, we know that 66 percent of our subjects are members of some type of group (savings group, agricultural cooperative, health group, etc.). This could suggest that there is already awareness on the benefits (and costs) of collective action and thus providing them information about the benefits of social organization does not change behaviour. However, these conjectures cannot explain the success of the village life video.

Another reason why the collective action video did not increase unconditional contributions could lie in the fact that they do not consider the villages part of their reference group (Tankard \& Paluck, 2016). Aspirations are determined by the observation of similar individuals (Ray, 2006). In this case it could be that the screened villagers did not enter their cognitive window, because their behavior did not seem relevant to them. Participants could consider the level of cooperation in the video too far away compared to the experiences they have made. The answers that are stated most often by participants for why they think the characters are not similar to them is that they are more cooperative and more hard-working, which supports this hypothesis. However, 63 percent of the participants in the collective action video treatment state that the characters in the video are similar to them. Similarity can be defined on various dimensions like language, culture, income-generating activities, as well as village collaboration. This could reflect that for the majority of the dimensions they are perceived similar, for some not - which could be the dimension of social organization.

In order to shed light into this question, future research could collect baseline data on participants' knowledge about and perceived benefits of collective action and their rating of characters' success in terms of village level organization.

One potential limitation of our experimental design is that in the conditions where only one participant of the group watched the video (V1 and CA1) the partner took the decision on contributions to the PGG earlier. While we treat those participants as our control group, having to take the decision at a different moment could have affected their contribution decisions. For example, they could have felt anxious about waiting for a more entertaining activity or could have felt unfairly treated. While we cannot be sure if that is the case, we recommend that this group is allocated to watch a placebo video.

The measure of community aspirations that we use in the study is new, therefore more work 
is required to validate the understanding of the questions and the reliability of the questions to capture aspirations for communal well-being. We suggest that before implementing this measure, the researchers do focus sessions in the villages to identify which are the main dimension of community welfare that participants care for and how they interpret success in those indicators.

\subsection{Conclusion}

In this paper we investigate the assumption that for cooperation to be successful, individuals need to have goals for the community - so-called community aspirations. Poor communities might lack examples of successful collective action from which they could draw inspiration to set higher goals. We experimentally test whether two videos can affect the level of aspirations and increase collective action among individuals in rural Zambia. In one video we show villages that experienced positive outcomes through collective action, while in the other video we portray the same villages without the reference that their welfare has improved due to social organization. We randomly assigned individuals to either watch the collective action, the village life or no video and then measured cooperation with a two-person one-shot linear public goods game and assessed their aspirations and beliefs with survey questions.

We find that in the village life video treatment- and not in the collective action video treatment - unconditional contributions are higher compared to the no video condition. Also, there are more positive conditional cooperators and less humpshaped cooperators. Reciprocity is highest and the treatment effect on unconditional contribution increases when both players saw the village life video. This points to the importance of common knowledge in the decision to cooperate. Further, both videos have a positive effect on perceived norms of cooperation. Yet, the village life video has a negative effect on reported individual aspirations. We do not find that community aspirations explain higher contributions, but find that individual aspirations are negatively related to unconditional contributions.

The results are partly unexpected, since we have hypothesized that the collective action video would lead to higher cooperation compared to the village life video. We provide some possible explanations, which are (1) crowding out of intrinsic motivation due to the prescriptive content, (2) role models' level of cooperation is too far away from that of the participants' village, and (3) role model video does not provide new information. To be able to answer these conjectures reliably, future research should incorporate baseline data on perceived benefits of cooperation and on subjects' rating of the characters level of cooperation. Further, it would be interesting to see whether the results replicate using role models from the same context and who have only slightly better (perceived) levels of cooperation. 
Since we find that providing role models in terms of better living conditions in videos is successful in increasing contributions to the public good, this could lead to the policy recommendation of increasing visibility of success cases of collective action by presenting more information on the impacts that it has on community welfare rather than by explicitly promoting self-organization. Our study provides evidence on the effects of a one-time screening of videos with customized normative and descriptive content and not for television exposure in general. 


\subsection{Appendix A - Tables}

Table 3.9: Treatment Effects on Unconditional and Positive Unconditional Decisions Reduced Sample

\begin{tabular}{|c|c|c|c|c|}
\hline & $\begin{array}{c}(1) \\
\text { (1) }\end{array}$ & $\begin{array}{c}(2) \\
\text { (2) }\end{array}$ & $\begin{array}{c}(3) \\
\text { Positive }\end{array}$ & $\begin{array}{c}(4) \\
\text { Positive }\end{array}$ \\
\hline \multirow[t]{2}{*}{ V1 } & $6.646^{* * *}$ & $6.661^{* * *}$ & $0.154^{* * *}$ & $0.204^{* * *}$ \\
\hline & $(2.032)$ & $(2.387)$ & $(0.057)$ & $(0.075)$ \\
\hline \multirow[t]{2}{*}{ V2 } & -2.839 & $13.387^{*}$ & -0.002 & $0.402^{*}$ \\
\hline & $(1.821)$ & $(6.948)$ & $(0.074)$ & $(0.232)$ \\
\hline \multirow[t]{2}{*}{ CA1 } & -0.147 & 0.323 & 0.097 & 0.145 \\
\hline & $(1.868)$ & $(2.501)$ & $(0.063)$ & $(0.096)$ \\
\hline \multirow[t]{2}{*}{ CA2 } & -1.381 & 6.997 & -0.044 & 0.105 \\
\hline & $(2.233)$ & $(4.748)$ & $(0.077)$ & $(0.182)$ \\
\hline \multirow[t]{2}{*}{ Constant } & $14.298^{* * *}$ & 2.012 & $0.752^{* * *}$ & $0.789^{* * *}$ \\
\hline & $(1.135)$ & $(4.912)$ & $(0.040)$ & $(0.194)$ \\
\hline Observations & 323 & 209 & 323 & 209 \\
\hline$R^{2}$ & 0.057 & 0.210 & 0.027 & 0.132 \\
\hline Fixed effects & No & Yes & No & Yes \\
\hline Controls & No & Yes & No & Yes \\
\hline
\end{tabular}

Table 3.10: Treatment Effects on Conditional Contributions Reduced Sample

\begin{tabular}{lccc}
\hline \hline & $(1)$ & $(2)$ & $(3)$ \\
& $\begin{array}{c}\text { Control } \\
\text { Conditional decisions }\end{array}$ & V1 & Conditional decisions \\
& $0.114^{* *}$ & 0.102 & Conditional decisions \\
\hline Level & $(0.046)$ & $(0.063)$ & $0.131^{*}$ \\
& $18.872^{* * *}$ & $20.088^{* *}$ & $(0.070)$ \\
Constant & $(3.952)$ & $(9.195)$ & $(12.251)$ \\
& 500 & 225 & 175 \\
\hline Observations & 0.056 & 0.079 & 0.247 \\
$R^{2}$ & Yes & Yes & Yes \\
Fixed effects & Yes & Yes & 0.843 \\
Controls & & 0.884 & $0.089^{*}$ \\
\hline \hline P: Level Control - Treatment & & 0.899 & 0.766 \\
P: Constant Control - Treatment & & 0.178 \\
P: Level V1 - CA1 & & \\
P: Constant V1 - CA1 & & \\
\hline \hline
\end{tabular}




\subsection{Appendix B - Experimental Instructions and Surveys}

\subsubsection{General Instructions}

Good morning/afternoon. Thank you for taking the time to come to this study today.

We are a group of researchers from the University of Göttingen and the University of Kiel in Germany and from Zambia. We are conducting a study on socio-economic conditions in Zambia. In this study, we will ask you to make decisions and to complete a survey. You will have the opportunity to earn money. The amount you earn will depend on your decisions. The activities of this study are financed by the German Research Foundation. Before we start, we would like to tell you some important points.

Today's activities may take three hours. Before we begin we would like to make some general comments about what we are doing here today and explain the rules that we must follow.

Participation in this study is completely voluntary. If at any time you feel not comfortable, you are free to leave whether the activities have begun or not. In this case you will not receive the payment, though.

All decisions will be made in private. That means no one of the other participants will know how you have decided and what answers you have given. You will also receive the money in private at the end of the activities. Nobody but the researchers will know how much money you have received. The information we collect will be saved in an anonymized manner. We will treat the information confidentially.

You might have heard about these types of activities before. However, what we will do can be different so please pay attention to what I am going to explain you.

Please do not ask questions or talk while you are here in the group. This is very important. Please be sure that you follow this rule, because it is possible for one person to spoil the activities for everyone. Do not worry if you do not completely understand the rules as we go through them here in the group. Each of you will have a chance to ask questions in private to be sure that you understand how the activities work.

Before we explain the activities, we divide you into two groups, the Circle Group and the Triangle Group. For this purpose, each of you will draw a card from the bag. The symbol of your card will determine your group and the number is your ID number. The people who are in the Triangle Group will leave to another place, where they cannot see or hear the people in the Circle Group. In the meantime the Circle Group will stay at this place. 
In two hours we will do a similar activity with another group. Please do not interact with them, as this can spoil our study. 


\subsubsection{Experimental Instructions}

We will first describe the basic decision situation in this activity. Then we will provide you with examples.

At the beginning of the activity, we will form groups with two people. The group will consist of one person from the Triangle Group and one person from the Circle Group. Neither you, nor the other person will know who is in the group.

Both You and the Other Person will receive 40 Kwacha each [point to Poster1]. The task for each person is the same: Both, You and the Other Person have to decide independently how much money you want to put in the group account.

\section{How are your earnings calculated?}

Your income in this activity will be the sum of the amount you earn in the private and in the group account.

Your income from the Private Account [point to private account on Poster1]

Everything that you leave in the private account will be yours. Nobody else will benefit from the money you leave in the private account. If you have $10 \mathrm{Kwacha}$ in the private account, you receive 10 Kwacha from the private account.

Your income from the Group Account [point to private account on Poster1]

The amount of money that You and the Other Person put in the group account will be summed up [point to arrows "passed"]. This value will be multiplied by 1.6 [point to 1.6 in group account] and then will be equally divided among the two persons in the group [point to "group account divided by 2]. Therefore each one will receive 0.8 of the total value in the group account.

Both you and the Other Person will get the same money from the group account, independent of how much each of you has put in this account. Your income from the group account will thus not only consist in what you put yourself into the group account, but you will also earn money from what the Other Person has put into the group account. Also the Other Person will earn money from what you have put into the group account. The income from the group account will correspond to [group account and income from group account on Poster 1]:

Individual income from the group account $=[1.6 *$ (amount You passed + Amount the Other Person passed)] /2 


\section{Your Total Income}

In the end, the total income of each person will be the sum of the income of the private account and the income of the group account [point to the box next to total income]:

Total individual income $=$ Income from the private account + Income from the group account

We will provide you with some examples to show you how the total income is calculated.

Example 1[Poster 1, example]:

In this example, assume you keep $10 \mathrm{Kwacha}$ in the private account and put $30 \mathrm{Kwacha}$ in the group account. The Other Person puts $10 \mathrm{Kwacha}$ in the group account and keeps $30 \mathrm{Kwacha}$ in the private account. You now have $10 \mathrm{Kwacha}$ in the private account. The Other Person now has $30 \mathrm{Kwach}$ in the private account. The total amount of money in the group account amounts to 40 Kwacha [point to "total deposits group account"].

In the next step, the money that is in the group account will be multiplied by 1.6. In our example: 40 Kwacha*1.6 = 64 Kwacha. The total amount in the group account is 64 Kwacha [point to "value of the group account"]. Next, independently of what each person has put in the group account, the total amount will be equally divided among the two persons. In the example we have, the total amount was 64 Kwacha. Divided by 2 this makes 32 Kwacha. [Point to each cell in the row "Individual income from the group account"] So you and the Other Person will both get 32 Kwacha from the group account.

The total income is the sum of the income from the private account and the group account [Point to the respective cells of individual income of the private and the group account]. Your total income is $10 \mathrm{Kwach}$ from the private account plus $32 \mathrm{Kwach}$ from the group account, equal to 42 Kwacha. The Income for the Other Person is 30 Kwacha from the private account plus 32 Kwacha from the group account equal to 62 Kwacha [point to the respective cells].

On this poster [Show Poster2] we have already calculated the total income for you and the Other Person for every possible value put in the group account. Let me show you how to read this: On this poster, you can see "You" and five arrows with different numbers. This symbolizes the possible values you can put in the group account: Either 0 Kwacha, 10 Kwacha, 20 Kwacha, 30 Kwacha or 40 Kwacha [point to the arrows]. In the boxes you see the possible values that the Other Person can put, also shown by arrows with numbers. The Other Person can also put either 0 Kwacha, 10 Kwacha, 20 Kwacha, 30 Kwacha or 40 Kwacha in the group account. The numbers display the possible income 
you and the Other Person get [point to the payoffs]. The first numbers indicate your income for every possible value of the Other Person [show in every box]. And the second numbers indicate the income of the Other Person, given the value you put [show in every box].

In the example above, where "You" put 30 Kwacha and the "Other Person" 10 Kwacha, you can find the payoffs for both You and other Other Person here [show arrows of 30 Kwacha, 10 Kwacha and then the payoff of each person]: You put 30 Kwacha and the Other Person puts 10 Kwacha. You will earn a total income of 42 Kwacha and the Other Person will have a total income of 62 Kwacha.

\section{Example 2}

Let us look at other examples. Let us assume, you decide to put 0 Kwacha [point to arrows with the 0 ] and the Other Person also decides to put 0 Kwacha in the group account [point to arrows with the 0]. How much is your total income? Your total income will be [point to the payoffs of "You" at 40] 40 Kwacha and that of the Other Person also 40 Kwacha [point to the payoff of "Other" at 40].

\section{Example 3}

Assume you instead decide to put $20 \mathrm{Kwacha}$ [point to arrows with the 20/20] and the Other Person also decides to put $20 \mathrm{Kwach}$, you will both receive 52 Kwacha [point to the payoffs of "You" and "Other" at 20/20].

\section{Example 4}

Let us assume, you put 40 Kwacha and the Other Person also puts 40 Kwacha, you and the Other Person both will earn 64 Kwacha [point to the payoffs of "You" and "Other" at 40/40].

The total income increases for both of you the more You and Other Person put in the group account. Let us look how your total income behaves if one person puts more than the other.

\section{Example 5}

Assume you put 0 Kwacha in the group account and the Other Person puts 40 Kwacha [show the respective arrows]. Then you will receive 72 Kwacha and the Other Person 32 Kwacha [point to the payoffs of each participant].

What this shows is that if the Other Person puts more to the group account than you, he or she will have a lower total income in the end and you will benefit when the Other Person puts all the 40 Kwachas in the group account. 


\section{Example 6}

This holds for the other direction as well. Assume that you put all your endowment of 40 Kwacha in the group account and that the Other Person puts 0 Kwacha. Then the Poster will tell us that [point to the arrows and the payoffs] you will earn 32 Kwacha and the Other Person will have a total income of 72 Kwacha.

We will ask you later to decide for yourself how much of the 40 Kwacha you want to put in the group account. How much you put in the group account can be chosen freely, as long as it is in ten Kwacha units. Every amount that is not put into the group account will remain in the private account.

\section{Elicitation of decisions}

After having explained the general set-up of the decision-making situation and the resulting income, we will now explain how you will make your decisions in detail. We will call you one by one to a place far away enough so that you can give your decision in private. Nobody of you will know and get to know the identity of the person you are in a group with and you will also not know how he or she decided.

Once we call your ID number, we will ask you to come to our colleague. We will then ask you two types of decisions. In each decision, you have to choose how much of the 40 Kwacha you want to put in the group account. We ask you to mark your decision on the decision sheet that our research assistant will give to you. This decision sheet will look like the Poster we have showed you before [point to Poster2]. Here you will mark one of the possible value by making a cross at the respective box [show how to mark it with a non-permanent marker].

We have already described the first decision above. In the second type of decision, we will ask you to indicate how much money you want to put in the group account for every possible decision of the person in your group. Let us explain this in more detail with the following picture [show Poster3]. Here we provide you with a table that shows each possible value of the Other Person to the group account [point to the first column].

This time you will base your decision on every possible decision of the Other Person: We would like to know how much you want to put in the group account if the Other Person has put 0 Kwacha in the group account [point to cell next to 0 Kwacha and pretend to write a number]. We also want to know how much you will put in the group account if the other person puts in the group account 10 Kwacha [point to cell next to 10 Kwacha and pretend to write a number], 20 Kwacha [point to cell next to 20 Kwacha and mark it with an $x$ ], 30 Kwacha [point to cell next to 30 Kwacha and pretend to write a number] or 40 Kwacha [point to cell next to 40 Kwacha and pretend to write a number] to the group account. Thus this time we would like to have five answers from you: one for each possible value that 
the Other Person could put in the group account. You can condition the value you put in the group account on the value the other group member puts. Please fill each cell in this table.

After you have given an answer to each possible decision of the Other Person, we will ask you about your belief in how much the Other Person from your group has put in the group account [point to the part on the Poster3]. Please write down how much you think the Other Person has actually put in the account. If your belief is correct, you will receive 5 Kwacha more.

Each one of you made two decisions. First you selected one of the arrows and then you wrote a number in the table. For one participant in the group the first decision will determine earnings and for the other the second decision.

To determine which decision counts for whom, we will select either a Triangle or a Circle by asking one of you to draw a card of a bag. If this person selects a Triangle, the first decision will count for participants in the Group Triangle and in this case, the second decision will count for the Circle Group.

If the person selects a Circle, instead, then it will be the opposite, in this case for those in the Circle Group the first decision will count and for the Triangle Group the second decision. When you make the decisions both can count for the final payment. Therefore you will have to think carefully about each type of decision.

After you have written down your belief, you will have a break. Afterwards, we will ask you to complete a survey.

\section{Control Questions}

Please ask the following questions to each respondent and mark the answer with the respective ID on a piece of paper:

1. How much money can you put in the group account? 0,10,20,30,40 Kwacha

2. What is your total income if You put $30 \mathrm{Kwacha}$ in the group account and the Other Person puts 20 Kwacha? 50 Kwacha

3. What is the Other Person's total income? 60 Kwacha 
Figure 3.2: Poster 1

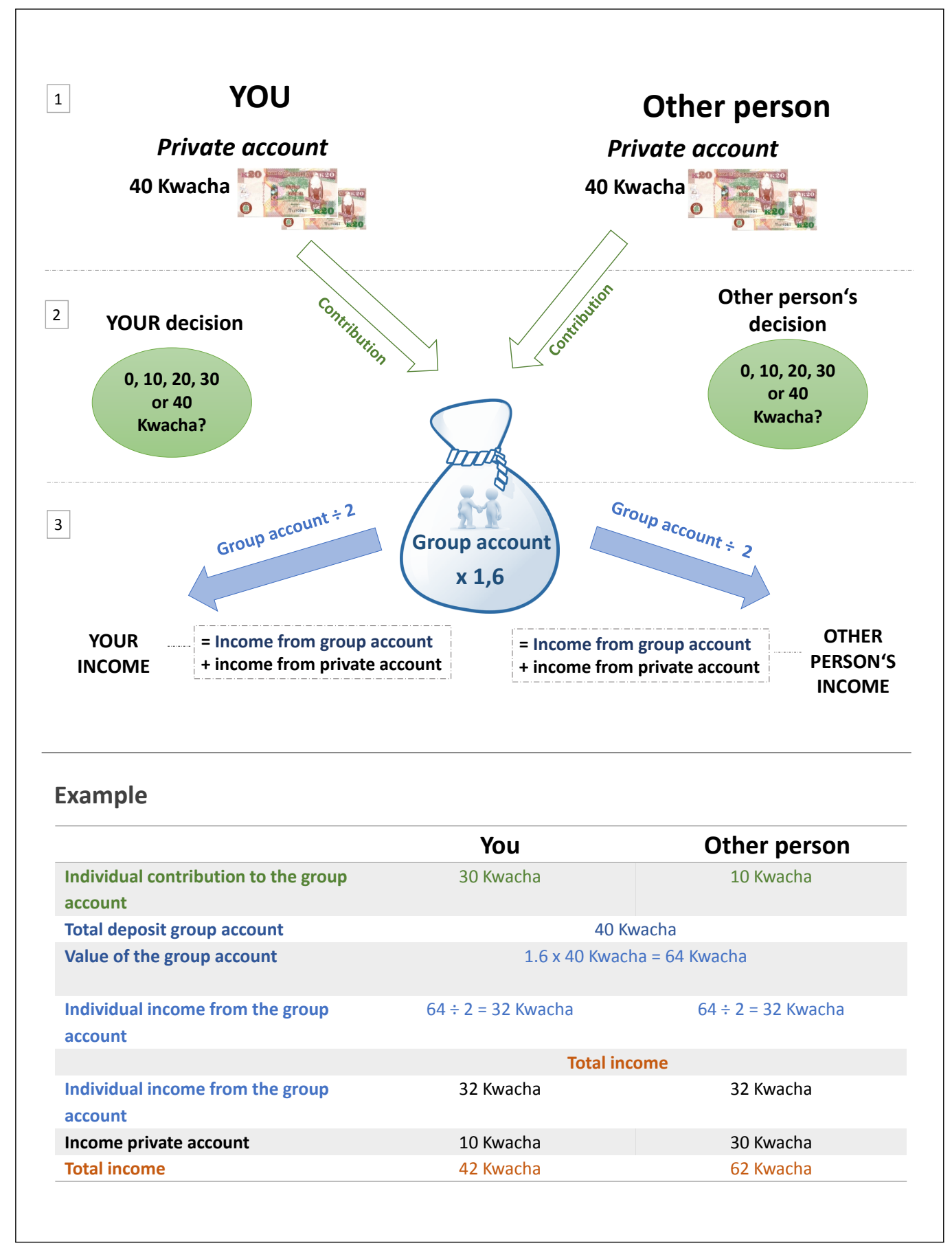


Figure 3.3: Poster 2

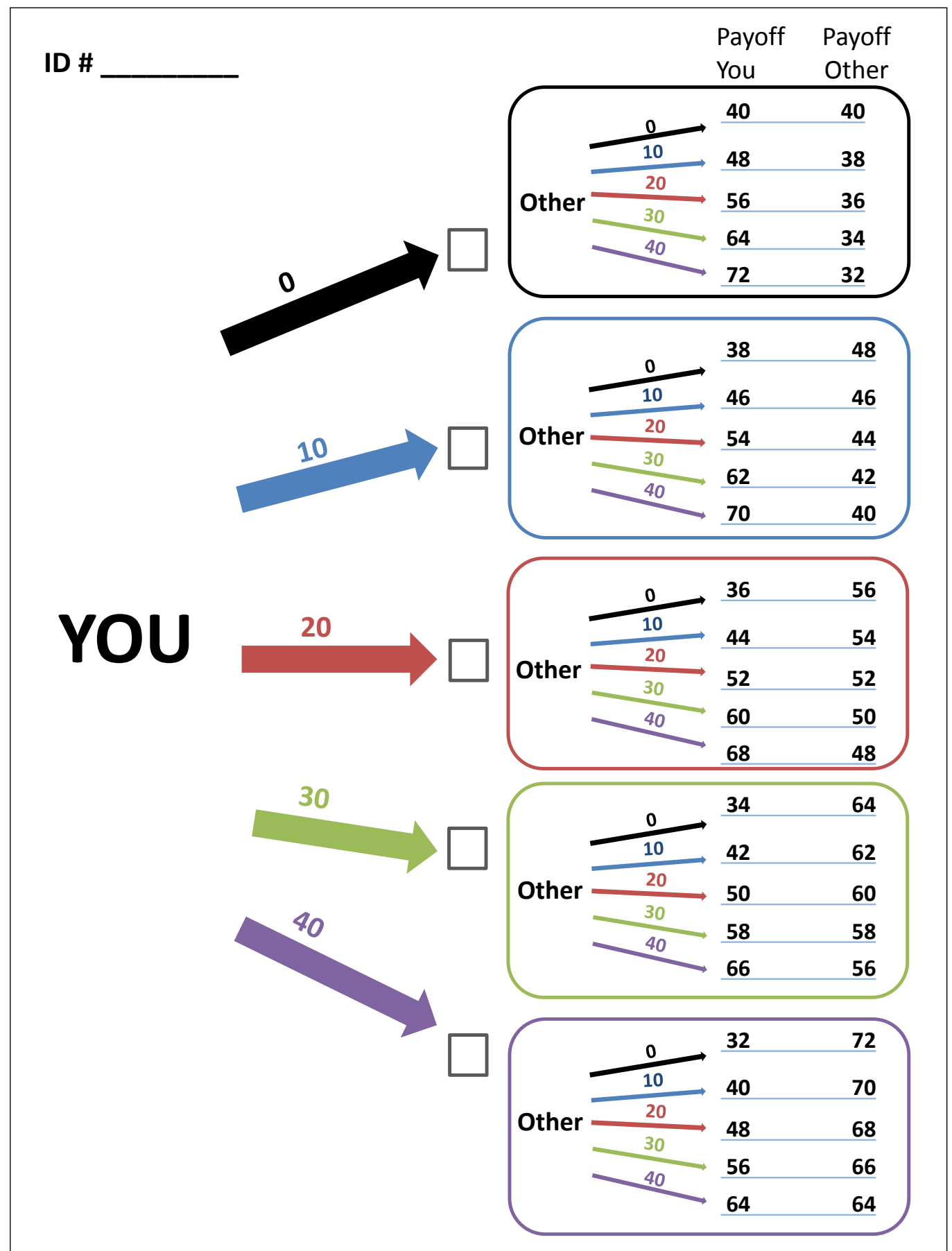


Figure 3.4: Poster 3

ID \#

\section{Contribution of the Other $\quad$ Your contribution to the \\ Person to the group group account is:}

account:

0

10

20

30

40

\section{YOUR BELIEF}

How much do you think did the person in the other group contribute? If you guess right, you will earn 5 Kwacha.

Kwacha 


\subsubsection{Smallholder Survey}

1. Name of the research assistant (First, Last)

2. Date of interview $(d d / m m / y r)$

3. Village/Locality

4. Individual ID

5. First Name

6. Last Name

7. Mobile number(s)

8. Sex

9. Age (years)

10. Date of Birth $(d d / m m / y r)$

11. Marital Status

12. Relation to household head

13. What tribe are you?

14. How long have you lived in this village? (years)

15. What is the highest grade of schooling that you have completed? (Insert grade, e.g. grade 12=12)

16. What kind of change would you like to bring about in your village? Please tell me any desire/goal you want to achieve in your village in the future. [RECORD ANSWER]

- - Education:

- - Health:

- - - Standard of living:

-_- Safety:

-_- Mutual support:

- - Participation:

(Please list the order in which the goals were mentioned)

17. How likely do you think you will be successful in bringing about these changes?

Very likely 
Somewhat likely

$\square$ Not likely

Very unlikely

18. Of all of these goals, which one is the most important one for you to change? (Specify goal)

19. How many households in your village have very good housing conditions, i.e. houses with walls made out of red brick, burnt brick or asbestos and/or with iron sheets on the roof?

20. For how many households in your village would you like to have very good housing conditions in the future? (desire/goal)

21. How many households do you expect to actually have very good housing conditions in your village in ten years? (expectation)

22. How many minutes do students from your village have to walk to get to a primary school?

23. How many minutes would you like students to walk to get to a primary school in the future? (desire/goal)

24. How many minutes do you expect students will actually have to walk to primary school in ten years? (expectation)

25. How many policemen/-women or voluntary guards does your village have?

26. How many policemen/-women or voluntary guards would you like your village to have in the future? (desire/goal)

27. How many policemen/-women or voluntary guards do you expect your village will actually have in ten years? (expectation)

28. How much money do households in this village contribute to finance village projects in a year?

29. How much money would you like that households in your village contribute annually to finance village projects in the future? (desire/goal)

30. How much money do you expect households actually contribute annually to finance village projects in ten years? (expectation)

31. How many books does a household have in your village?

32. How many books would you like a household to have in the future? (desire/goal)

33. How many books do you expect a household will actually have in ten years? (expectation) 
34. How many households in your village get support in case of need, such as suffering from economic loss due to crop failure?

35. How many households would you like to get support in case of need in the future? (desire/goal)

36. How many households do you expect to actually get support in case of need in ten years? (expectation)

37. How many times do people in your village meet each other (for example for celebrations or village discussions) in a month?

38. How many times a month would you like people in your village to meet in the future? (desire/goal)

39. How many times a month do you expect people to actually meet in ten years? (expectation)

40. Are there children in the age of 6 to 18 in your family?

Yes

No (Go to question 44)

41. What is the education level that the youngest child achieved until now?

42. What is the level of education you would like this child to achieve in his/her life? (goal/desire)

43. What is the level of education you expect this child will to achieve in his/her life? (what they will probably achieve)

44. Do you own land, cows and goats? How big is the size of your plot and how many cows and goats do you have?

Size of plot:

\# of cows:

\# of goats:

45. What is the size of your plot and number of cows and goats you would like to have in your life? (goal/desire)

Size of plot:

\# of cows:

\# of goats:

46. What is the size of your plot and number of cows and goats you expect to have in ten years? (expectation) 
Size of plot:

\# of cows:

\# of goats:

47. How many households live in this village?

48. Please tell me with which of the two statements you agree more:

Statement A: "To be successful, above all one needs to work very hard."

Statement B: "To be successful, above all one needs to be lucky."

I agree more with $\mathrm{A}$

I agree more with B

49. Do you think that women and men have equal rights in your village?

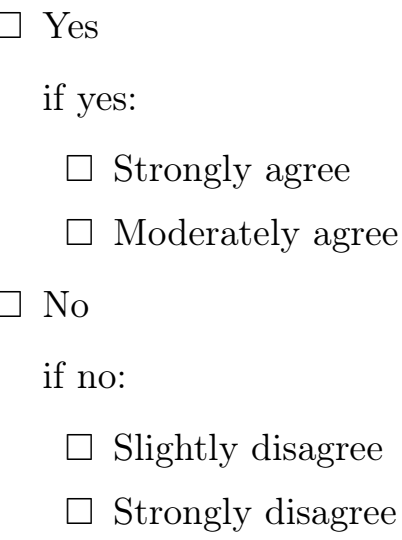

50. How often in the past year have you joined together with others in the village to address a common issue?

- - times

51. Are you a member of any clubs, groups, organizations, committees or associations?

$\square$ Yes

$\square$ No (if no, go to question 54)

52. If yes, in which one(s):

Cooperative (fishing, agriculture, etc)

Savings group/club

Savings group/club

Neighborhood/village association/committee

Water/waste group/club

$\square$ Health group/club 
$\square$ Youth group/club

$\square$ Women group/club

Sports group/club

Other (specify)

53. Do you consider yourself to be active in the group(s), such as by attending meetings or volunteering your time in other ways, or are you relatively inactive?

$\square$ Very active

$\square$ Somewhat active

Not active

54. How many times a year do you participate in village work (such as road clearing, village clean up, insaka maintenance)?

--_ days per month

55. How much money do you spent on average for village activities or village problems in a year?

-_- Kwacha/year

56. How much money do you spend on schooling on average per month?

-_- Kwacha/month

57. Do you think that most people in this village are basically honest and can be trusted?

$\square$ Yes

if yes:

Strongly agree

$\square$ Moderately agree

$\square$ No

if no:

Slightly disagree

Strongly disagree

58. Do you think people like yourself have influence in making this village a better place to live?

Yes

if yes:

Yes, a lot

$\square$ Yes, a little bit 
No

59. Overall, how would you rate the spirit of participation in this village?

$\square$ High

$\square$ Average

$\square$ Low

60. How often do you use a mobile phone?

Every day

Once a week

Once a month

Once a year

Never

61. How often do you listen to a radio?

Every day

$\square$ Once a week

$\square$ Once a month

$\checkmark$ Once a year

$\square$ Never

62. Did you watch a video today?

$\square$ Yes

$\square$ No

63. Do you like the characters of the video?

Yes

if yes:

Strongly agree

$\square$ Moderately agree

$\square$ No

if no:

Slightly disagree

$\square$ Strongly disagree

64. Do you think that the people in the video are similar to you?

Yes 


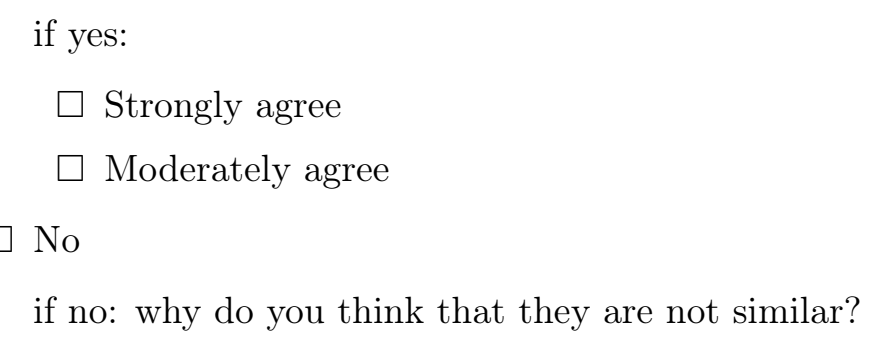

65. Do you think your village can be as successful as the villages in the video within the next ten years?

$\square$ Yes

if yes:

Strongly agree

$\square$ Moderately agree

No

if no:

Slightly disagree

Strongly disagree

66. Do you know the FAO, the Food and Agriculture Organization of the United Nations?

Yes

No

67. Do you think that the other group (Circle or Triangle) has watched the video?

Yes

$\square$ No 


\subsubsection{Village Survey}

1. Name of the research assistant (First, Last)

2. Date of interview $(d d / m m / y r)$

3. Name of the interviewee (First, Last)

4. Role of the interviewee (e.g. headwoman/-man)

5. Village

6. How many households in your village have access to safe drinking water (i.e. protected wells, boreholes, pumped water)?

7. On average how many minutes does it take a household to get access to safe drinking water?

8. What is the main market where villagers sell their products? (specify the name of the city where the main market is located)

9. How many kilometers away is the main market?

10. How many minutes does it take to reach the main market?

11. What is the state of the road leading to the market?

$\square$ Very good

$\square$ Good

$\square$ Average

$\square$ Poor

$\square$ Very poor

12. How many children in the village go to primary school?

13. How many children in the village are in the age to go to primary school?

14. How far is the nearest health facility? distance (in walking minutes)

15. Does the facility have medicine?

$$
\begin{aligned}
& \text { Yes } \\
& \text { if yes: } \\
& \square \text { Very good access } \\
& \square \text { Average access }
\end{aligned}
$$




\section{Poor access}

$\square$ No

16. Does the village have police or a neighborhood security committee?

Yes we have police

Yes we have neighborhood security committee

$\square$ No

17. What type of transportation do people in this village use to go to neighboring villages?

Walking

$\square$ Bicycle

Motorbike

Car

Public transport

Other

18. Do you have a resource that is used jointly such as a well or a village field/garden?

Yes

$\square$ No (go to question 20)

19. If yes, which one(s)? (specify)

20. How often do the people come together for a village meeting?

More than once a month

Once a month

Twice a year

Never happens

21. Which regular activities do the people in the village do together (such as the improvement of insaka, cleaning of roads and paths, maintenance of borehole)? (specify)

22. Do you document your village meetings and/or the regular activities (when they take part, what was done/spoken and how many people participate?)

23. In the last three years, has the village organized to address a need or a problem?

Yes

No (go to question 26) 
24. Around which issue(s) did the village organize?

a)

b)

25. Was/were the initiative(s) successful?

a) Initiative \#1

$\square$ Yes

$\square$ No

$\square$ Ongoing

b) Initiative $\# 2$

$\square$ Yes

$\square$ No

$\square$ Ongoing

26. Are there any specific assistance programs to this community?

$\square$ Yes

$\square$ No

27. What are the two main programs and the institutions that support them?

a) Program/institution:

b) Program/institution:

28. Which of the following organizations, clubs, committees, or groups exist in this village?

Cooperative (fishing, agriculture, etc.)

Saving group/club

Neighborhood/village association/committee

Water/waste group/club

Health group/club

$\square$ Youth group/club

$\square$ Women group/club

Sports group/club

$\square$ Other (specify)

29. Do any persons or organizations (such as for example government, religious organizations, and businesses) help or support these village-based organizations?

Yes 
$\square$ No (go to question $X X$ )

30. If yes, who/which one(s)? (specify)

31. Does this village have a village treasury?

Yes

No (go to question $X X$ )

32. Who is in charge of the accounting of the village treasury? (specify)

33. Do you have accounting records?

Yes

No

34. How much money is in the village treasury at present?

- - - - - - - Kwacha

35. How much money is in the village treasury on average in a year?

Kwacha/year

36. How much money do people contribute to the village treasury on average per year? Kwacha/year

37. Does the village treasury have other sources of money than financial contribution of people living in this village? (specify)

38. For what has the money in the village treasury spent in the last year? (specify)

39. How often do village members on average give money to a village member who is in need?

More than once a month

Once a month

Twice a year

Once a year

Never happens

40. What kinds of crimes (such as robberies, violent disputes, etc.) exist in this village? (specify)

41. How often do crimes happen in a year?

- - - - - - - times/year

42. Are there members of this village who go to other places to work during certain periods of the year?

Yes

No 


\section{Can Role Model Videos Influence Female's De- cision to Participate in the Labor Market? Evi- dence from a Field Experiment ${ }^{1}$}

\footnotetext{
${ }^{1}$ We are grateful for the comments and suggestions received from the participants at the 18th EUDN $\mathrm{PhD}$ Workshop and the GlobalFood Brownbag Seminar. We especially thank Marcela Ibañez, Friederike Lenel and Holger Rau for their feedback and helpful comments on our paper. All remaining errors are ours. Ana Maria Montañez, Magdalene Trapp and Marius Willmann provided great research assistance. Special thanks to the Diversity Turn team for their constant feedback and support in the field. This research was financed by the "Niedersaechsiches Vorab" of Volkswagen Foundation (grant number: 11-76251-99-35/13 (ZN3119)) and by the German Research Foundation (DFG) through the GlobalFood Program (RTG1666). We would like to thank all enumerators who participated in the data collection in Madagascar, and all the students that attended our experimental sessions. We would also like to thank the school directors that from the beginning showed great support for the project.
} 


\subsection{Introduction}

Compared to men, women are underrepresented in developing countries' formal labor markets. According to the International Labour Organization (ILO) indicators ${ }^{2}, 60$ percent of women in low-income countries are employed in the labor market compared to 75 percent of men. In addition, only 22 percent of corporate managers in these countries are female. The shortage of women participation in the formal labor market and the lack of women in leading positions - especially from those with higher education and ability -, generates an economic loss as there is a valuable share of labor force which is not being efficiently used (Niederle \& Vesterlund, 2011; Flory et al., 2015). Explanations for the gender difference in labor market outcomes are still being explored (Blau \& Kahn, 2017). Understanding the roots of the gender-gap and exploring solutions to close it is particularly relevant for achieving the Sustainable Development Goals (SDGs), especially for low income countries, where an important share of human capital could contribute to economic growth and long-term poverty reduction (Kolev \& Sirven, 2010). Further, gains in females' incomes can contribute to increases in bargaining power in the household and improvements in children's welfare (Duflo, 2003; Qian, 2008).

One reason for female's under-representation in the labor market could be the lack of successful examples of similar individuals that can serve as reference points they can learn from and form aspirations for a different future. The literature in psychology on social learning theory posits that individual's beliefs and behavior are shaped by the observation of experiences of other people (Bandura, 1977, 1986). Further, it is argued that an individual's aspirations are determined by the lives and achievements of other people in the individual's cognitive window (Ray, 2006). Poor people, however, often lack successful examples which prevent them to build aspirations and thus invest into a better future (Appadurai, 2004; Ray, 2006). As few women in developing countries are employed in the formal labor market, and even fewer are in leadership positions, women in these countries likely lack successful examples from which they can draw inspiration. Under these conditions, females can find themselves in a behavioral poverty trap, in which low aspirations produce low economic investments (Ray, 2006; Dalton et al., 2016; Genicot \& Ray, 2017). A possible route out of the behavioral trap is to provide successful examples of what similar individuals have achieved (Ray, 2006).

In this paper we experimentally test whether exposure to role model videos can motivate female high-school students to apply to competitive jobs. Observing how a similar person succeeds can lead individuals to revise their beliefs in the ability to achieve the same outcome - so called self-efficacy beliefs (Stout et al., 2011). Further, by observing how investments are connected to desired results can also increase individual's (internal) locus of control beliefs, i.e. the beliefs of how actions and outcomes are connected (Rotter,

\footnotetext{
${ }^{2}$ Data obtained from ILOSTAT Data explorer. Data reported corresponds to 2019 results.
} 
1966). Role models can also raise individuals' aspirations by changing their perceptions on the opportunities they have and thereby induce future-oriented behavior (Beaman et al., 2012; Bernard et al., 2014). Lastly, role models can also increase confidence and reduce negative effects in stereotype threat situations and thereby increase performance and willingness to enter into competition (Marx \& Roman, 2002; Meier et al., 2020). Based on this evidence we suggest that role models, who come from the same background, can lead female students to raise their aspirations, revise their beliefs about themselves and also on women's performance in competitive environments in general. Our study aims to answer the following research questions: Do female role models shown in videos increase the propensity of females to apply and choose a high responsibility position? Does the gender of the role model matter in female's decision to apply?

To shed light on our research questions, we conducted a field experiment in four secondary schools in Madagascar in 2018. Our study region is a relevant context to study, since Madagascar is one of the poorest nations in the world (World Bank, 2019), where paid jobs are scarce (Nordman et al., 2010), and where labor market participation of women, especially young women, is a real challenge (Herrera et al., 2019). We randomly assigned 336 female and male students to watch either a Female Role Model, a Male Role Model or a Placebo video. The treatment videos depict a female or male character who set a goal (becoming a teacher at a University) and shows how they achieved it despite the different challenges they encountered. These characters provide an example of successful individuals and come from a similar background as the participants. The PlaceBo video includes the same two characters, but discusses the differences of lifestyles between rural and urban areas. After video exposure, we measured students' aspirations, self-efficacy and locus of control beliefs. In addition, we conducted a lab-in-the-field experiment to measure participant's performance in a real-effort task and their preference to enter into competition. At the end of the session, we informed the students about the possibility to apply to one of two jobs in the research project of one of the principal investigators: assistant or coordinator. The main difference among the two real jobs is that the coordinator's position involves more responsibilities and thus has a higher remuneration. A week after the experiment we gave the students their earnings from the lab-in-the-field experiment and collected their job applications.

Our results show that the Female Role Model video, compared to the Placebo, encourages female participants as well as male participants to apply to one of the positions. We find a gender gap in applications to the coordinator position in the PLACEBO group, but find that it almost disappears in the Male Role Model group. Our results suggest that this is driven by an increase in the number of females applying compared to the PlaceBo. We test for four possible channels and find that competitive preferences, measured in our lab-in-the-field, can explain the increase in applications for the coordinator position in the Male Role Model treatment. We suggest that the Male Role Model character might credibly exhibit competitive traits that encourage competitive behavior among females. 
This result provides evidence that not only successful people from an in-group can be role models. In addition, we tests for a potential mechanism driving applications to any of the positions. We find that aspirations and the current level of achievements can partially explain the decision to apply. The latter is positively correlated with the decision to apply to one of the positions.

To our knowledge, our study is the first that investigates the effect of role model videos on the willingness to apply for a job. Previous studies have shown that female role models are effective in closing the gender gap and encouraging women to select into competitive environments (Stout et al., 2011; Breda et al., 2020; Ginther et al., 2020; Meier et al., 2020; Porter \& Serra, 2020; Schier, 2020). The study that is closest to ours is by Meier et al. (2020), which assesses whether role models in videos affect competitive preferences in an online experiment. Compared to their study, we focus on the decision to apply to a job in a development context. Also, there is empirical evidence that role models shown in media or videos are effective in altering the opportunities people perceive, the goals they set for themselves as well as the investments they make (Chong \& La Ferrara, 2009; Jensen \& Oster, 2009; Beaman et al., 2012; La Ferrara et al., 2012; Bernard et al., 2014; Riley, 2018). For example, Lubega et al. (2018) conducted a randomized controlled trial (RCT) in which they screened role model videos to woman with HIV in Uganda and find that treated females were more likely to start a business, have higher income and savings as well as improved health outcomes. Yet, the above studies have not investigated the effect of exposure to role models in videos on female's decision to apply to a job.

We contribute to three other important strands of literature. First, as we show a positive effect of role models on job applications, our paper is related to the literature that explores different strategies to incentivize women to participate in the labor market. For example, Jensen (2012) finds that providing recruiting services to young women in India is an effective tool to increase labor market participation. Further, Ibañez \& Riener (2018) show how affirmative action in a field experiment attracts women to apply to jobs in Colombia. In similar lines, McKelway (2020) conducts a RCT in India, where she offered women a psycho social program, followed by a job promotion video from the hiring company screened to participants and family members. The intervention increased women's generalized self-efficacy (GSE) and their labor market participation.

Second, by showing that information on role models mitigates the gap in the willingness to select into competition found by Niederle \& Vesterlund (2007), we extend the experimental knowledge on incentives that close the gender difference in competition (Wozniak et al., 2014; Meier et al., 2020). The study of Meier et al. (2020) also provides evidence that the gender gap in competition decreases when females receive information from role models. However, the kind of information and the type of role models are different to our study: Our intervention shows successful individuals, from a similar background to those of the participants, who talk about their aspirations and the way how they achieved 
them, while Meier et al. (2020) chose public figures who highlight the important role of competition in their careers.

Third, our paper contributes to the rich literature on competitive preferences by bridging lab evidence and field outcomes. Even though there is a large share of experimental literature on gender differences in the selection into competition and its potential effects on labor market outcomes (Croson \& Gneezy, 2009; Niederle \& Vesterlund, 2011), to our knowledge, the link between selection into competition in the lab and experimental measures on job selection in the field has not yet been studied. ${ }^{3}$

\subsection{Conceptual Framework}

\subsubsection{Role Models and Female Labor Market Outcomes}

The link between exposure to the role model videos and the decision to enter the labor market can be through several channels. We test for four channels: aspirations, competitive preferences, self-efficacy and locus of control beliefs. ${ }^{4}$

First, role models can increase female's aspirations. Aspirations are defined as distant goals that motivate individuals to provide investments in order to attain them (Bernard et al., 2011; Lybbert \& Wydick, 2018). Experiences of successful individuals can help women to imagine a different future and expand the opportunities they perceive for themselves. Further, observing a woman or a man succeeding by setting high goals and following them, females might feel inspired by the outcomes they have achieved and also set high goals for themselves. Aspirations have been found to correlate with educational and employment attainment of female adolescents (Roy et al., 2018) and with outcomes of peers with higher status (Janzen et al., 2017). Several experimental studies have shown that aspirations can be increased by role models (Beaman et al., 2012; Jensen, 2012; Bernard et al., 2014; Riley, 2018). Having higher aspirations can lead females to apply to one of the advertised positions and even apply to more competitive jobs, as they can imagine a different future for themselves.

Second, role models can also have an effect on labor market outcomes through competitive preferences. The gender difference in competition has been largely studied through laboratory and field experiments (Gneezy et al., 2003; Niederle \& Vesterlund, 2007; Carpenter et al., 2018). The common finding is that women are less willing to enter into competition in comparison to men (Niederle \& Vesterlund, 2011). A lower preference for competition

\footnotetext{
${ }^{3}$ Buser et al. (2020) show how competitiveness relates to survey measures on achieved education, choice of study and occupation, and income. Buser et al. (2014, 2017) investigate the relationship of competitiveness and choice of academic track with data from secondary schools.

${ }^{4}$ We do not test for other potential mechanisms such as mitigation of stereotype threats and discrimination.
} 
has been related to gender segregation in career choices (Kleinjans, 2009), women's lower presence in leadership positions (Gneezy et al., 2003; Booth, 2009; Niederle \& Vesterlund, 2011) and women's lower willingness to engage in more competitive compensation schemes (Flory et al., 2015; Kamas \& Preston, 2015). By observing a successful and similar example, women can become more ambitious and thus compete more (Schier, 2020). Role models can also lead women to update their priors that in turn could weaken gender stereotype threats (Meier et al., 2020; Schier, 2020). Exposing female students to a successful female of a similar background, who set a goal and achieved it, can make them more competitive and thus willing to apply for the coordinator position.

Third, the mechanism could also run through changes in self-efficacy beliefs, which refer to an individual's belief in his/her capacity to achieve an outcome (Bandura, 1977, 1997). Self-efficacy is a key predictor of female educational and employment aspirations (Roy et al., 2018) and, as aspirations, can also be increased through social comparison with role models and peers. Individuals, who observe how similar people succeed, can come to trust their own abilities more (Bandura, 1977, 2004). For instance, Stout et al. (2011) find that exposing female experts in science, technology, engineering, and mathematics (STEM) to female students increased their self-efficacy in STEM and made them more willing to pursue a career path in that field. We assume that individuals, who believe more in their abilities due to the role model intervention, are more willing to complete an application and apply to the coordinator position.

Lastly, role models can also lead to a change in locus of control beliefs. Locus of control refers to the beliefs an individual has regarding the control she or he has over own life outcomes. Individuals are said to have an internal locus of control if they believe that the outcomes are determined by their action, whereas individuals with external locus of control beliefs attribute outcomes to external forces (luck, fate, powerful others) (Rotter, 1966). Having an internal locus of control belief has been associated with several labor market outcomes (Cobb-Clark, 2015). There is also evidence that locus of control is malleable. Gottschalk (2005) analyzed a project in which long-term welfare recipients were randomly offered earnings subsidies once they took up work (reduce external constraints). The author finds that the longer recipients were employed the more likely they reported an internal locus of control belief. In our case, we suggest that seeing similar individuals succeed can also lead to a change in locus of control beliefs. The information provided in the videos could lead students to revise their beliefs on how behavior and outcomes are connected and thus on what is possible to achieve in their context, making them more willing to exert effort and apply to a (competitive) job.

\subsubsection{Hypotheses}

Based on the above empirical evidence, we argue that being exposed to either of the role model increases applications of the participants. Our first hypothesis thus is: 
Hypothesis 1. Participants will be more likely to apply to the job positions in the Female Role Model video and Male Role Model video treatment compared to participants in the Placebo group.

In addition, we believe that showing a successful female character will encourage female students to apply for the more competitive job - the coordinator position. Our second hypothesis is:

Hypothesis 2. Female students will be more willing to apply to the coordinator position when they are exposed to the female role model.

As other studies have shown, we believe that a female role model can close the gender gap that has been found in competitive environments (Niederle \& Vesterlund, 2011). Our third hypothesis is:

Hypothesis 3. There is no gender gap in the selection to the coordinator position in the female treatment.

\subsection{Context, Experimental Design and Procedures}

\subsubsection{Field Context}

To study the effects of a role model intervention on the decision to apply to a job, we chose Madagascar as our study region. Madagascar is one of the poorest nations in the world with around 77.6 percent of its population living under USD 1.90 per day (2011 Purchasing Power Parity) (World Bank, 2019). As a large share of the population is involved in agriculture, most of Madagascar's labor force is working in unpaid jobs or in the informal sector (Nordman et al., 2010). Paid jobs are scarce, which makes the formal labor market very competitive and difficult to access (Stifel \& Rakotomanana, 2007). In 2018, 83.3 percent of females were estimated to be in the labor force compared to 89 percent of the males (ILO, 2020). However, the largest share of the female workforce is involved in agricultural activities or is employed in the informal sector and thus receives lower wages compared to men (Nordman et al., 2010). Similar to other countries in the world, women are not only underrepresented in the formal labor market, but also in private and public leadership positions compared to men (Kolev \& Sirven, 2010). For instance, according to the data reported by World Economic Forum (2019), 28 percent of top managers in Madagascar are women and 19 percent of seats in parliament are held by women.

Madagascar has an increasing and large share of youth population, representing 21 percent of the total population (UNESCO, 2020), who are in the process of forming their aspirations. 
However, the youth in Madagascar face high barriers to access tertiary education (World Bank, 2019) and are more likely to enter the informal labor market compared to older cohorts (Stifel \& Rakotomanana, 2007). This goes hand-in-hand with information gaps regarding the returns of higher education, which disincentives students to apply and to continue on building up a career (Nguyen, 2008). We focus our interest on the student population finishing their last year of high school because these young men and women are at the stage to decide what to do next. On average, only 5 percent of the high school graduates decide to continue their education (UNESCO, 2020), and the rest is likely to enter the informal labor market. Because our study region is located at north-east part of the country where most of the vanilla production and commercialization takes place, the incentive to opt for informal jobs is high. Therefore, it is relevant to provide students with successful examples that allow them to aspire higher and encourage them to enter the formal market.

There is also a gender-gap in the formal labor market for young cohorts (Stifel \& Rakotomanana, 2007) and, although less prominent, in tertiary education enrollment rates (UNESCO, 2020). While there is no evidence of cognitive ability differences between female and male students (Herrera Almanza et al., 2017), one reason that explains the presence of these gaps is the prevalence of child marriage and early pregnancies (Glick et al., 2015; UNFPA, 2015; Herrera et al., 2019). 41 percent of women aged 20-24 years are married or in union before the age of 18 (UNICEF Madagascar, 2018) and 35.6 percent gave birth before that age (UNICEF, 2020). Postponing marriage and child bearing to pursue higher education or a professional career usually goes against family norms, which expect young women to marry and continue with the hereditary line (Skjortnes \& Zachariassen, 2010). In addition, given that a minority of the Malagasy population have access to wage jobs and pursued secondary or tertiary education, there is a lack of financial but also moral support from parents and family members to encourage young girls to pursue higher education (Skjortnes \& Zachariassen, 2010).

In addition to the difficult economic conditions that are present in Madagascar, social norms - and the gender-gaps they generate - result in the exclusion of women from politics and economic development. As a consequence most female students who are currently in secondary school, lack successful examples of women who continued with their education, accessed the formal labor market, and achieved top and competitive jobs. Because of these reasons, we suggest that Madagascar is an example of a country where women are likely to experience a behavioral poverty trap where low aspirations produce low investments. An intervention that provides examples of similar successful individuals could help women to imagine a different future, form higher aspirations and be more willing to enter a competitive formal labor market.

Female labor market participation can increase female's and her household's welfare in different dimensions. Todd (2013) analyzed programs directed at improving women's access 
to employment and quality of work, such as providing training and job search services to unemployed, and finds evidence that programs can increase female's wages and incomes. According to the theory of change proposed in Ibañez et al. (2017) (found in Balasubramanian et al. (2019)) increases in household's income through female's participation in the labor market can also influence household's welfare indirectly through increases in bargaining power and decreases in fertility. In the meta-analysis undertaken by the authors, they find that interventions aimed at increasing female economic empowerment at the community level, which considers interventions that increase female's access to employment, among others, lead to a moderate increase in household's economic situation and educational outcomes for the children (Ibañez et al., 2017). However, they find no significant effect on health and no changes in attitudes towards women.

\subsubsection{Experimental Design}

We conducted our study in north-eastern Madagascar with female and male students from the main public high-schools. Our experimental design comprised six stages (see Fig. 4.1). In the first two stages, we screened one of the treatment videos (FEmale Role Model, Male Role Model) or a Placebo video, followed by a short survey about the perceptions of participants regarding the main character(s) of the videos. In addition, we measured student's aspirations using a similar approach as in Bernard et al. (2014) and Bernard \& Taffesse (2014). In the third stage we measured inter- and intrapersonal competition preferences by following the experimental design of Niederle \& Vesterlund (2007) and Carpenter et al. (2018). In stage 4 we collected attitudinal and socioeconomic information. Stages 5 and 6 assessed the willingness of students to enter the labor market. In stage 5, we advertised two different job offers and students could express their interest in the positions. Stages 1 to 5 took place on the same day. One week after, we met the students again to distribute the experimental earnings and collect the job applications. This corresponds to stage 6 of our experimental design. In the following sections, we explain each of the stages in detail.

Figure 4.1: Structure Experimental Session

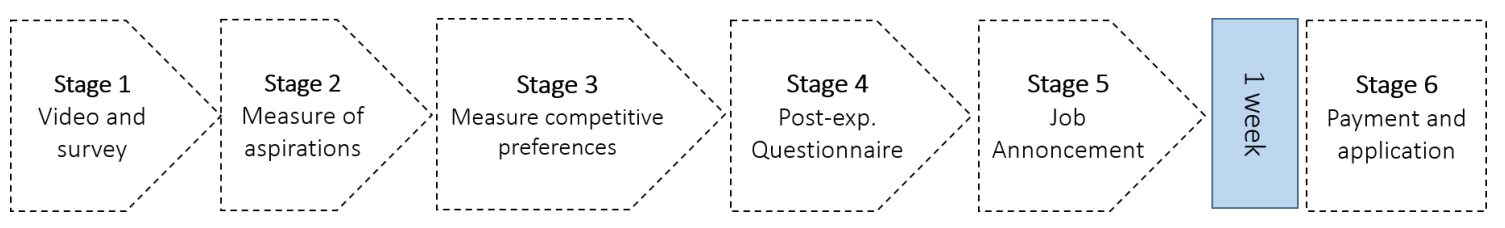

\section{Stage 1: Video and control survey}

In the first stage, we introduced our treatments by showing students one of three 10 minute videos in their local language. Students could either watch: a Female Role Model, a Male Role Model or a Placebo. In the first two videos, each role model introduces him/herself and narrates how he/she succeeded in achieving an important goal they set for 
themselves (becoming a teacher at a University) despite the hardships they faced (lack of financial resources, lack of confidence and lack of successful examples). They describe the steps they went through in order to achieve their goal and how they felt once they achieved it. In addition, the video narrates how some people from their network admire them for imagining and achieving a different future, but also how they face criticism from others in their village, who hold a more traditional view on life and on what people should aspire and achieve.

To increase the connection with the students' background, each role model shows the place they were raised (rural areas) and the school they attended. At the end, a family member, a friend and a colleague of each of the role models expresses how they perceive him or her and the image they have in the community they live in. The role model videos end with each of the characters achieving their goal and the videos close with the following sentence from the narrator: "The story of Marie-Rolande (Fulgence) shows that if one aims at doing something and works towards it, it is possible to achieve it. She (He) imagined a different life than most of her (his) friends and family have, and even though the journey was long and with many obstacles, she (he) was able to make that imagination a reality." The main factor changing between the two videos is gender. We chose both role models coming from a poor background, similar to our participants, as there is evidence that the role model's background matters to increase the identification with the character. None of the treatment videos provide information to the students on how to behave in the subsequent experimental stages and the role models do not refer to competition or the decision to enter the labor market. This allows us to exclude potential demand effects.

In the PlaceBo video both characters appear, present themselves (similar to the other two videos) and talk about the differences between the life in rural and urban areas. We consider this topic neutral as we refer to differences in lifestyles, clothing, climate, ethnicity, traditional ceremonies and types of schools that exist. We chose this topic because it is easy to understand and it is known by students. In this video we do not provide new information to students or a different perspective of their life. Furthermore, we did not present the characters as role models nor mentioned their achievements. The video just compares two different lifestyles and thus should not have an effect on our outcome variables. Different to Meier et al. (2020), we decided not to use a video with nature as PlaceBo, but to have an additional video with the same characters to make the results comparable and avoid potential noise coming from foreign music, images, etc. The PlaceBo video closes with the following sentence from the narrator: "Living in the city has advantages and disadvantages, same as in the rural area. However, this diversity makes the SAVA region a beautiful place to live."

Following the screening, students had to report their perceptions towards the character(s) of the video. In particular, we asked them if they liked the character, the degree to which they identify with him or her, and their perceptions of the role models' success and risk-taking. In the survey we also asked participants whether they knew the character. 


\section{Stage 2: Measure of aspirations}

Our measurement of aspirations is taken from Bernard et al. (2014) and Bernard \& Taffesse (2014). Each of our participants had to answer a set of questions on four specific dimensions: education, income, social status and assets. In each of the dimensions, students had to report the level they currently possess, the level they would like to achieve (aspirations) and the level they think they will be able to reach (expectations). Furthermore, we include questions on the maximum and the minimum levels students think an average person from the place they come from can achieve in each dimension. This is important as it assists them in finding answers and to make sure they do not report mere wishes (Bernard \& Taffesse, 2014). After the students have completed the survey, they had to distribute 20 points according to the importance they attach to each dimension. Based on these indicators we constructed the aspiration index according to the one in Bernard et al. (2014):

$$
A=\sum_{d} w^{d}\left(\frac{a_{i}^{d}-\mu^{d}}{\sigma^{d}}\right)
$$

where $\sigma_{d}$ is the standard deviation of the PlaceBo group, $\mu^{d}$ the mean of the Placebo group for each aspiration question from dimension $d$ and $w^{d}$ is the average weight students in the PlaCEBo group attached to each dimension.

To control for differences in students' achievements, we constructed a current index using the above procedure. Instead of aspirations, we use the level of each dimension that the participants have already achieved.

\section{Stage 3: Measure of competitive preferences}

To measure interpersonal competitive preferences, we used a laboratory experiment and followed the design by Niederle \& Vesterlund (2007) with small variations. In addition to the four tasks that are included in their study, we introduce a fifth task to measure intrapersonal competition preferences. We included this task following a similar structure as in Carpenter et al. (2018).

In the laboratory, participants were seated in rows of four people and were informed that they were forming a group with the people sitting in the same row. To avoid negative externalities from gender imbalances in each group, we sat two female and two male students in each row when possible. During the experiment we did not make the gender of the group participants salient. Since they could see the other group members, they could as well determine their gender. As students were allocated in each classroom randomly, we expect to reduce noise created by previous beliefs about the group's ability. Yet, we acknowledge that knowing other people in the group could have potential effects on the behavior. To control for this we asked students how many people of the group they are friends with in the post-experimental survey. 
Before starting with the real-effort task, participants received an explanation from the instructor, who by using a poster showed an example on how the task should be performed, the time for performing the task, and what would be taken as a correct and incorrect answer. The instructor did not continue with the explanation until the task was clear for all students. Instead of using a math task as in Niederle \& Vesterlund (2007), our real-effort task consisted in counting and reporting the number of 1's that are in a $8 \times 8$ matrix (see example Fig. 4.2). The task is solved correctly when the participant reports the correct number of 1's. We chose a gender neutral task, as tasks that are associated with stereotypes impact the decision to select into competition (Grosse et al., 2014). At this point participants were told that they would be asked to complete five tasks but that one of them would be relevant for payment, if this stage would randomly be chosen for payment at the end of the experiment.

This stage consisted of five tasks in which the compensation varies. In the following, we describe each of the tasks in detail. In Task-1 each participant received an individual payment of 500 Ariary $(\approx 0.13$ Euro) for each correct answer in the real-effort task (piece-rate payment). The amount earned is independent of the performance of others. In Task-2, participants entered into a 'winner takes it all' tournament, where they competed against the other group members. The task was the same as before with the difference that their earnings depend on their performance in comparison to the performance of others in the group. The winner earns 2,000 Ariary (0.512 Euro) per correct matrix solved and the losers earn nothing. In case of ties, the winner was chosen randomly.

In Task-3, participants had the opportunity to choose the compensation scheme they would like to have in case this task is randomly selected for payment. They could decide to have the individual pay rate of 500 Ariary for each matrix they solve correctly, or to enter into the 'winner takes it all' tournament against the people in their group. If the participant chose to enter into tournament, he or she competed with the performance in task 3 with the performance of the other group members in Task-2. All participants had to perform Task-3, therefore if the participant decided not to compete, he or she received the earnings according to their performance in this Task-3 (piece-rate payment). The payment scheme associated to the tournament is the same as in Task-2. This means that if a participant chose to compete and solved more matrices in this Task- 3 compared to the performance his or her group partners had in Task-2, the participant received 2.000 Ariary per correct matrix. If the participant solved less number of matrices then he or she received nothing. In case of a tie, the decision whether the participant wins or not was chosen randomly. In this Task-3, the decision each student made on whether to compete or not, did not affect the earnings of other group members or their decisions to compete or not.

In Task-4, participants did not have to solve matrices. Instead of performing the realeffort task, participants in Task-4 were asked to choose which compensation scheme they would like to apply for their past performance in Task-1: piece-rate vs. 'winner takes it 
all' tournament pay. If the participant chose to enter into tournament, then he or she was competing against the performance of other group members in Task-1. If his or her performance is the highest in comparison to others in the group, then he/she was declared winner and earned 2,000 Ariary per correct matrix solved (0.512 Euro) in Task-1. As in Tasks-2 and 3, in case of ties, the winner was chosen randomly. If the participant chose the piece-rate scheme, then the earnings would be the same as in Task-1. Before making their choice, we reminded each participant about the number of matrices they believed to have solved correctly in Task-1. Furthermore, like in the previous tasks, the decision each student made is individual and thus does not affect the earnings of other group members or their decision on whether to compete or not. Since we do not condition participants' earnings on a future performance, Task- 4 allows doing a comparison with the decision taken in Task-3 on whether to compete or not. In particular, we can observe whether factors such as risk aversion play a role in participant' preferences for interpersonal competition.

In addition to the design by Niederle \& Vesterlund (2007), we included an extra task to measure intrapersonal competitive preferences. In Task-5, we observed whether participants rather opt for piece-rate or in a 'winner takes it all' tournament with themselves. If they decided to compete, they had to outperform the number of matrices that they solved correctly in Task-2. We use Task-2 as comparison because students were framed in a competitive environment and thus more likely to exert a higher effort. If participants decided not to compete, they performed this Task- 5 and were paid with the piece-rate compensation scheme. Before performing the task, participants were informed about the beliefs they had about their performance in Task- 2 . We provided this information to participants in order to avoid random decisions due to information gaps.

In each of the tasks where participants had to solve matrices, they had a total of three minutes time to solve up to ten matrices. The difficulty of the matrices remained constant for all tasks. In contrast to Niederle \& Vesterlund (2007), we did not provide participants with information on their absolute performance after each task to avoid possible differences in feedback aversion across gender. Instead we use an incentivized question to ask subjects for their belief on their absolute performance after every task. In addition, at the end of Task-5 participants were asked to provide their beliefs regarding their relative rank within their group for Tasks-1 and 2, the average performance of all participants in the session, and the number of people from the group that decided to compete in Task-3. For each correct answer, participants received an additional 1,000 Ariary (0.25 Euro). 
Figure 4.2: Example Task

\section{Matrix 1}

$\left[\begin{array}{lllllllll}1 & 1 & 0 & 0 & 1 & 0 & 0 & 1 \\ 0 & 0 & 1 & 0 & 0 & 1 & 0 & 1 \\ 0 & 1 & 0 & 1 & 1 & 1 & 1 & 0 \\ 0 & 0 & 1 & 1 & 0 & 0 & 0 & 0 \\ 1 & 1 & 1 & 0 & 1 & 0 & 0 & 0 \\ 1 & 1 & 1 & 0 & 1 & 0 & 0 & 0 \\ 0 & 0 & 1 & 0 & 0 & 0 & 0 & 0 \\ 0 & 1 & 1 & 1 & 1 & 0 & 1 & 1\end{array}\right]$

How many 1's are in this picture?

\section{Stage 4: Post-experimental questionnaire}

Before starting with the post-experimental questionnaire, one participant per session randomly chosen - came to the front to select the activity that will be relevant for payment. After the activity was selected, students started to fill the questionnaire. At this point participants did not know their experimental earnings and this information was provided only when students came to collect their earnings, a week after the experimental session.

In the questionnaire, participants were asked about their socioeconomic situation, if they have any role models, time and risk preferences and about the education of their parents. Lastly, we included a set of questions to measure our additional outcome variables: locus of control, academic self-efficacy and generalized self-efficacy. We explain below the measurement of these outcome variables. The post-experimental questionnaire can be found in the Appendix.

- Locus of control: To measure this variable, a subset of six statements pairs were selected from the twenty-nine pairs that comprise the 'Internal versus External Scale' from (Rotter, 1966). The selection was done by taking into account students' context to enhance comprehension and reduce noise in the answers. In this part of the questionnaire, each student is provided with pairs of two statements, A and B. The task of the students is to mark the pair to which statement they agree the most on a 1-4 scale (from "I agree much more with A" to "I agree much more with B"). A and B-statements present situations where people reflect an external or internal control of the corresponding outcomes. The final score is calculated according to the total number of internal control choices the student answered. This means, that the higher the score, the higher the locus of control beliefs. 
- Academic self-efficacy: Students had to rate their degree of confidence in learning different subjects, for instance mathematics, biology or a foreign language, by writing down a number from 1 to 10, where 1 means "Cannot do at all" and 10 means "Highly certain can do". This question comprised seven different subjects and to obtain the measure we sum up the answers in each subject. The measurement of this variable is similar to the one described by Bandura (2006), with the difference that we do not take a scale from 1 to 100 but from 1 to 10 to increase comprehension.

- Generalized self-efficacy (GSE): It is calculated by taking the sum of 10 statements where students had to decide whether the statement says something that is "Not true of myself", which takes the value of (1), or whether it is "True of myself" which takes the value of (5). Higher values reflect larger GSE. Examples of the statements are the following: "I can always manage to solve difficult problems if I try hard enough"; "I can solve most problems if I invest the necessary effort'; "If I am in trouble, I can usually think of a solution". This measure is the Jerusalem \& Schwarzer (1995) scale with two slight modifications. First, we rephrased the scale in first person, meaning that instead of having the option of "Not true at all", the participant read "Not true of myself". Second, instead of having a 1-4 scale, we used a 1-5, to add a category in the middle representing "Half true of myself".

\section{Stage 5: Real job announcement ${ }^{5}$}

After the students finished the questionnaire, the experimenter casually entered the room to tell the students about a job opportunity. The students could apply for a job as an assistant or as a coordinator in a research project in Madagascar of one of the principal investigators. We only gave them the opportunity to apply to one job to mimic a situation where they have to decide between a more or less competitive environment. ${ }^{6}$ The experimenter told the students that the research project works with vanilla farmers in the SAVA region and that she is looking for assistants and a coordinator to help her with the organization of the workshops with vanilla farmers. Independent of the treatment group, all students who took part in the experiment received the exact same information. After the job was announced, each participant received a paper sheet with more information about the positions. The information provided include that the job of the assistant consists in helping with the organization of the workshops and to fill in questionnaires with different farmers, while the job of the coordinator is to visit the villages and plan workshops in advance with the village chief. The main difference between the two job offers was that the coordinator position

\footnotetext{
${ }^{5}$ We introduced two further treatments in this stage: Public and private sub-treatments to test whether social norms or social stigma may discourage female students to apply for the jobs. In each session, one group of students had to express their interest in the job privately and in the other publicly. This was known by the students before they made the decisions. Different to the private treatment, in the public treatment the participants in the room knew to which positions other participants have applied to. Due to power issues, the paper does not focus on these treatments and to report the results we pooled the decisions taken in the two sub-treatments.

${ }^{6}$ The job was to take place during the months of October to December 2018 for the experimental sessions conducted in July, or during the months of May to June 2019 for the experimental sessions conducted in November. The dates were chosen according to the school calendar.
} 
had more responsibilities and hence a higher salary (13 percent higher) compared to the assistant position. In addition, we required that candidates for each position should be motivated to work in rural areas, be good team members and have good communications skills.

In this stage, students first had to decide whether they are interested in applying for a position or not. If they were interested, they had to select which one of the two positions they are interested in applying to, assistant or coordinator. After students have made their decisions and gave the corresponding decision sheet to the experimenter, they were told that to be considered as a potential candidate for any position, they must bring a recent photograph in one week time. We added this requirement to make the application process somewhat demanding for the students. Once students received the information they were told to leave one by one and at the door each of them received a participation fee of 2,000 Ariary from the experimenter. This bonus payment was independent of their experimental earnings, which was given one week after each session.

\section{Stage 6: Payment and job application}

A week after the experiment, we met the students again at each of the schools to distribute their earnings from the experiment and hand the application forms to interested students. The use of this type of forms, which provides the same information as a curriculum vitae $(\mathrm{CV})$, is a standard format that companies in Madagascar and in other developing countries receive and accept for their hiring process. Hence, we also adopted this standard procedure for our hiring process.

One of our main outcome variables is the number of complete applications received. To be considered as a complete application, each student should have filled the form with their personal information and included a recent photograph. We will thus consider students who have applied as those who have handed in a complete application form. Participants were informed about the photo requirement during stage 5 of the experiment, and each of them received one private call or message with a reminder during the week in between the experimental session and the earnings distribution. The application is valid for the position students expressed interest in stage $5 .^{7}$

\subsubsection{Experimental Procedures}

We conducted our study in the four biggest public high-schools of the Sambava-AntalahaVohemar-Andapa (SAVA) region in north-eastern Madagascar between July and November 2018 (See Figure 4.3). We selected only public schools because students in those schools are more likely to face income constraints and thus experience an aspiration failure. ${ }^{8}$ To conduct

\footnotetext{
${ }^{7}$ We chose this procedure since it reduces potential spillover effects in the decision to apply to a position.

${ }^{8}$ While in private schools fees reach on average 240,000 Ariary (approx. 61.5 Euro) for a complete school year, in public schools the fees are on average 50,000 Ariary (approx. 12.8 Euro).
} 
our experimental sessions, we invited students who were in their last year of secondary education. We consider this group particularly relevant to study as students are at the point of life to decide what to do after graduation.

To select the participants, we visited the public high-schools several days before the experiments were taking place and invited students to take part in a workshop. During the lunch break we registered interested students and gave further information about the venue. With the students' information we could allocate each of them in one of the treatment groups, making sure that we have the same number of females and males in each treatment (stratified random sampling). However, due to a school strike that started right before we scheduled our data collection, we could not effectively use this previous allocation in two of the schools. ${ }^{9}$ Thus, there are groups of four where we do not have the same number of male and female participants. To control for this, we included the variable Gender imbalance group in our analysis, which takes the value of one if the group of four is not balanced and zero otherwise.

In total, 336 students took part in our $3 \times 2$ between-subject experiment. During each experimental session communication between students was not allowed. The sessions lasted on average two and a half hours including the post-experimental survey and the job announcement. On average students earned 7,700 Ariary $\left(2\right.$ Euro $\left.^{10}\right)$ plus a bonus payment for participation of 2,000 Ariary (0.51 Euro). The potential earnings are similar to the average wage for a working day in a farm (approx. 3 Euro). Participants had the possibility to earn money in Stage 3 and additionally in two activities that are not included in the present study, yet only one was randomly selected for payment. In cases were Stage 3 was randomly selected for payment, the earnings of only one of the five tasks -chosen randomlywere paid out.

\footnotetext{
${ }^{9}$ In these schools very few participants and more males than females came to the meeting point. We therefore used the following procedure: We divided the students by gender and told them to make a line. One by one we sent each student to one of the three rooms (one room for each treatment and control group), being careful to keep a similar share of female and male participants.

${ }^{10}$ Exchange rate at the time of the experiments was around 3.900 Ariary equivalent to 1 Euro.
} 


\section{Figure 4.3: Study Region}

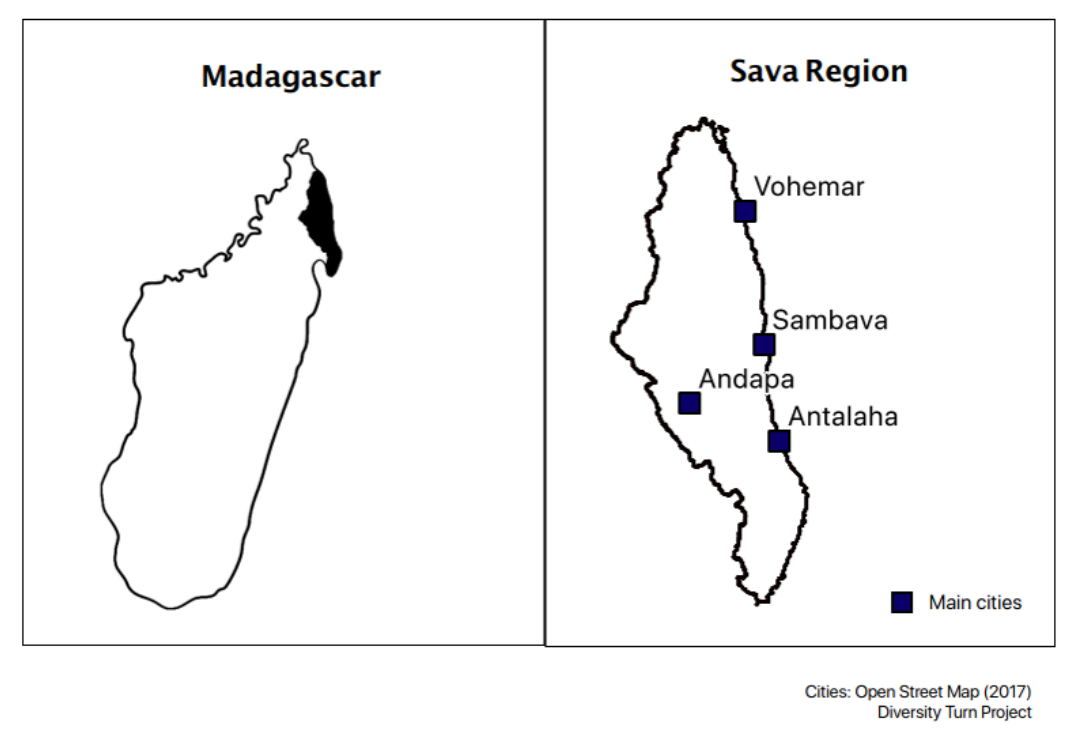

\subsection{Empirical Strategy}

To study the effects of our role model intervention on the decision to apply to one of the advertised position, we estimate the following model:

$$
L_{i}=\alpha+\delta T_{i}+\lambda F_{i}+\beta\left(T_{i} \cdot F_{i}\right)+X_{i}^{\prime} \gamma+\mu_{s}+\epsilon_{i}
$$

where $L_{i}$ represents one of our two main outcome variables: (1) Complete Application that takes the values: $0=$ Not applied, $1=$ Applied to one of the advertised positions, (2) Coordinator Position that takes the values: $0=$ Applied to Assistant Position, $1=$ Applied to Coordinator Position. $T_{i}$ denotes the treatment variable that takes the values: $0=$ Placebo video, $1=$ Female Role Model video and $2=$ Male Role Model video. $F_{i}$ is an indicator variable equal to one when the participant is female and zero if male. $X_{i}^{\prime}$ is a vector of individual characteristics, such as number of brothers, whether their family cultivates vanilla, the frequency individuals meet outsiders, the frequency they used their smartphone and their mother's highest degree. $\mu_{s}$ are school fixed effects and $\epsilon_{i}$ is the random error. We estimate an ordinary least squares model (OLS) to facilitate the interpretation of the interactions and calculate robust standard errors. ${ }^{11}$

\footnotetext{
${ }^{11}$ See Gomila (2020) for why using linear regression analysis should be preferred over logistic regression analysis in experimental studies.
} 


\subsection{Results}

In this section we outline the results from our field experiment. Section 5.1 includes descriptive statistics and randomization checks. In section 5.2 we show participants' rating of the role models and in section 5.3 we present the results of the role model intervention on job applications.

\subsubsection{Descriptive Statistics and Randomization Checks}

Table 4.1 presents the means and p-values of balance tests for individual variables in the three treatment groups. There are no significant differences in the proportion of females, the age of the participants, their chosen focus in secondary school, the economic status, their job situation, whether their family is involved in the vanilla business, whether they were raised in the city or in the rural area and the highest degree achieved by the mother. We find significant differences in the frequency of smartphone usage, the frequency of meeting people who are not from their school or their family as well as whether there were any friends in their group of four. To account for these differences, we will control for these variables in the analysis. 
Table 4.1: Summary Statistics

\begin{tabular}{lcccc}
\hline \hline & $(1)$ & $(2)$ & $(3)$ & $(4)$ \\
& Placebo & Woman video & Man video & p-value \\
\hline Female & 0.400 & 0.450 & 0.455 & 0.655 \\
Age in years & $(0.046)$ & $(0.047)$ & $(0.048)$ & \\
& 19.192 & 18.968 & 18.884 & 0.420 \\
Science focus & $(0.180)$ & $(0.160)$ & $(0.175)$ & \\
& 0.557 & 0.577 & 0.509 & 0.587 \\
Number of brothers & $(0.047)$ & $(0.047)$ & $(0.048)$ & \\
& 2.339 & 2.180 & 1.973 & 0.156 \\
Economic status & $(0.134)$ & $(0.149)$ & $(0.119)$ & \\
& 2.652 & 2.748 & 2.609 & 0.429 \\
Job at present & $(0.070)$ & $(0.082)$ & $(0.078)$ & \\
& 0.061 & 0.117 & 0.109 & 0.297 \\
Vanilla family & $(0.022)$ & $(0.031)$ & $(0.030)$ & \\
Friends group & 0.713 & 0.658 & 0.700 & 0.646 \\
Frequency meeting outsiders & $(0.042)$ & $(0.045)$ & $(0.044)$ & \\
& 0.835 & 1.090 & 1.418 & 0.000 \\
Frequency smartphone usage & $(0.088)$ & $(0.102)$ & $(0.088)$ & \\
& 4.200 & 4.667 & 4.600 & 0.000 \\
Raised in city & $(0.097)$ & $(0.083)$ & $(0.071)$ & \\
& 2.670 & 4.135 & 3.855 & 0.000 \\
Highest degree mother & $(0.164)$ & $(0.137)$ & $(0.156)$ & \\
& 0.513 & 0.545 & 0.545 & 0.854 \\
& $(0.047)$ & $(0.048)$ & $(0.048)$ & \\
$N$ & 1.545 & 1.640 & 1.736 & 0.126 \\
& $(0.074)$ & $(0.052)$ & $(0.070)$ & \\
& 115 & 111 & 110 &
\end{tabular}

\begin{tabular}{lccc}
$N$ & 115 & 111 & 110 \\
\hline
\end{tabular} Notes: Column 4 reports the p-value from joint orthogonality test of treatment arms. Mean values are
shown. Standard errors in parentheses. Variable description: Female: 1 if the student is female and 0 otherwise; Age in years: Age of participant calculated from the year participants were born; Science focus: 1 if the student chose the science focus and 0 if he/she instead chose the language focus; Number of brothers: Number of brothers (not siblings) participants reported; Economic status: Takes the values from 1 (poor) to 5 (wealthy) according to the economic situation reported by the student; Job at present: 1 if the participant has a job at the moment of the experiment, 0 otherwise: Vanilla family: 1 if the participant comes from a family that is in the vanilla business, 0 otherwise; Friends group: Number of friends the participant reported to be in his/her group of four, takes the values from 1 to 3 ; Frequency meeting outsiders: takes values from 1 to 5 , where 1 indicates that students never meet outsiders and 5 indicates they meet every day with outsiders; Frequency smartphone usage: takes values from 1 to 5 , where 1 indicates students never have used an smartphone and 5 indicates they use it every day; Raised in city: 1 if the participant was raised in an urban area, 0 otherwise; Highest degree mother: $0=$ no education, $1=$ primary education, $2=$ secondary education, $3=$ university degree. 


\subsubsection{Role Model Assessment}

After the video screening, we asked the students about their perceptions on the video and the main character(s). ${ }^{12}$ Table 4.2 shows the means and the two-sided $t$-tests p-values from the answers reported by female and male participants to five questions. Each question could be answered with the following scale: strongly disagree (1), disagree (2), neither agree nor disagree (3), agree (4), strongly agree (5).

Both female and male participants agree quite strongly that the main characters in the Female Role Model video and in the Male Role Model video are not afraid of taking risks. The ratings are significantly different compared to the ratings of participants who watched the PlaceBo video. Further, we find that females and males identify with the role models. However, male students report to equally identify with the Female Role Model and the Male Role Model, while female students identify much more with the Female Role Model. Participants also agree quite strongly to the question whether they like the characters. Females and males significantly like the Female Role Model character more compared to the Placebo. Interestingly, females in the Female Role Model treatment report to be quite certain to be as successful as the main character (4.3 out of 5 ), whereas in the Male Role Model treatment females report lower scores (3.96 out of 5; p-value = 0.099).

The analysis shows that the selection of role models in terms of their similarity to female participants has been successful, as females identify with the main character of the Female Role Model video and even with the main character of the Male Role Model video. However, we find that the character's success is not rated significantly different across females in the different treatment groups. This can be explained by the fact that both role model characters were also the main characters of the PLACEBO video and their profession was mentioned. This implies that a potential treatment effect could be underestimated. Yet, both female and male students in the two treatment video groups agree more strongly to the question whether they have been motivated by the video compared to female and male students in the PLACEBO group (two-sided $t$-test p-values $\leq 0.026$ ), such that the characters may serve as role models in showing how they achieved a goal.

\footnotetext{
${ }^{12}$ One limitation of our study design is that we have both characters of the Female Role Model and the Male Role Model video in the Placebo video. The ratings of the Placebo video thus refer to both characters.
} 
Table 4.2: Rating of the Role Model

\begin{tabular}{|c|c|c|c|c|c|c|}
\hline & $\begin{array}{c}(1) \\
\text { Placebo video }\end{array}$ & $\begin{array}{c}(2) \\
\text { Woman video }\end{array}$ & $\begin{array}{c}(3) \\
\text { Man video }\end{array}$ & $\begin{array}{c}(4) \\
\text { (1) vs. (2), } \\
\text { p-value }\end{array}$ & $\begin{array}{c}(5) \\
\text { (1) vs. (3), } \\
\text { p-value }\end{array}$ & $\begin{array}{c}(6) \\
\text { (2) vs. (3), } \\
\text { p-value }\end{array}$ \\
\hline \multicolumn{7}{|l|}{ Panel $A$ - Female participants } \\
\hline Character is not afraid of risks & $\begin{array}{c}3.935 \\
(0.160)\end{array}$ & $\begin{array}{c}4.740 \\
(0.069)\end{array}$ & $\begin{array}{c}4.740 \\
(0.063)\end{array}$ & 0.000 & 0.000 & 1.000 \\
\hline Character is successful & $\begin{array}{c}4.457 \\
(0.102)\end{array}$ & $\begin{array}{c}4.640 \\
(0.102)\end{array}$ & $\begin{array}{c}4.620 \\
(0.094)\end{array}$ & 0.207 & 0.241 & 0.886 \\
\hline Participant likes character & $\begin{array}{c}4.326 \\
(0.099)\end{array}$ & $\begin{array}{c}4.700 \\
(0.065)\end{array}$ & $\begin{array}{c}4.520 \\
(0.087)\end{array}$ & 0.002 & 0.142 & 0.101 \\
\hline Identifies with character & $\begin{array}{c}3.565 \\
(0.186)\end{array}$ & $\begin{array}{c}4.700 \\
(0.077)\end{array}$ & $\begin{array}{c}4.280 \\
(0.125)\end{array}$ & 0.000 & 0.002 & 0.005 \\
\hline Can be as successful as character & $\begin{array}{c}4.283 \\
(0.111)\end{array}$ & $\begin{array}{c}4.260 \\
(0.124)\end{array}$ & $\begin{array}{c}3.960 \\
(0.131)\end{array}$ & 0.893 & 0.065 & 0.099 \\
\hline$N$ & 46 & 50 & 50 & & & \\
\hline \multicolumn{7}{|l|}{ Panel B - Male participants } \\
\hline Character is not afraid of risks & $\begin{array}{c}4.101 \\
(0.124)\end{array}$ & $\begin{array}{c}4.787 \\
(0.053)\end{array}$ & $\begin{array}{c}4.700 \\
(0.060)\end{array}$ & 0.000 & 0.000 & 0.277 \\
\hline Character is successful & $\begin{array}{c}4.377 \\
(0.095)\end{array}$ & $\begin{array}{c}4.574 \\
(0.092)\end{array}$ & $\begin{array}{c}4.467 \\
(0.087)\end{array}$ & 0.141 & 0.492 & 0.400 \\
\hline Participant likes character & $\begin{array}{c}4.333 \\
(0.076)\end{array}$ & $\begin{array}{c}4.754 \\
(0.056)\end{array}$ & $\begin{array}{c}4.467 \\
(0.084)\end{array}$ & 0.000 & 0.241 & 0.005 \\
\hline Identifies with character & $\begin{array}{c}3.913 \\
(0.113)\end{array}$ & $\begin{array}{c}4.426 \\
(0.098)\end{array}$ & $\begin{array}{c}4.433 \\
(0.093)\end{array}$ & 0.001 & 0.001 & 0.958 \\
\hline Can be as successful as character & $\begin{array}{c}4.188 \\
(0.091)\end{array}$ & $\begin{array}{c}4.377 \\
(0.094)\end{array}$ & $\begin{array}{c}4.100 \\
(0.113)\end{array}$ & 0.152 & 0.539 & 0.062 \\
\hline$N$ & 69 & 61 & 60 & & & \\
\hline
\end{tabular}

\subsubsection{Treatment Effects on Applications}

In total we received complete applications from more than half of the participants (186 out of 336 students). In the Female Role Model group 63 percent of the students applied, while in the PlaceBo group 48 percent completed an application. A two-sample Fisher's exact test reveals that the difference is significant at the five percent level (p-value $=0.023$ ). In the Male Role Model group 55 percent of the students applied, which is not significantly different from the PLACEBO group (A two-sample Fisher's exact test p-value $=0.287)$. Using a two-sided Fisher's exact test we find no gender differences in each of the treatments for the outcome Complete Application (all test p-values $\geq 0.846$ ).

Figure 4.4 displays the percentage of applications for the assistant and figure 4.4 for the coordinator position by gender in each treatment group (shares conditional on all participants who applied). The highest percentage of applications for the assistant position among both female and male students can be found in the Female Role Model group. 44 percent of the females applied in the Female Role Model group compared to 28 percent in the PlaceBo group (two-sample Fisher's exact test p-value $=0.139$ ). In the Female Role Model treatment 31 percent of the males applied to the assistant position, whereas only 16 percent of the male students applied in the PlaceBo group. The difference is significant at the ten percent level (two-sample Fisher's exact test p-value $=0.060$ ). For the coordinator position we find that the proportion of applications by female students is highest in the Male Role Model video. 28 percent of the females applied in this treatment, compared to 17 percent in the Placebo and 18 percent in the Female Role 
MODEL group. Yet, female applications are not significantly different across treatment groups (all Fisher's exact tests p-values $\geq 236$ ). Applications to the coordinator position among males are equally high in each of the treatments: 33 percent of the males applied in the Placebo and in the Female Role Model group, and 30 percent in the Male Role Model group (all Fisher's exact tests p-values $\geq 845$ ). We find a gender difference in the proportion of applicants for the coordinator position in the PLACEBO and in the Female Role Model (two-sided Fisher's exact test p-values $=0.085 \& 0.087$ ), but not in the Male Role Model group (two-sided Fisher's exact test p-value $=0.836$ ).

Figure 4.4: Applications to Assistant and Coordinator Position by Gender
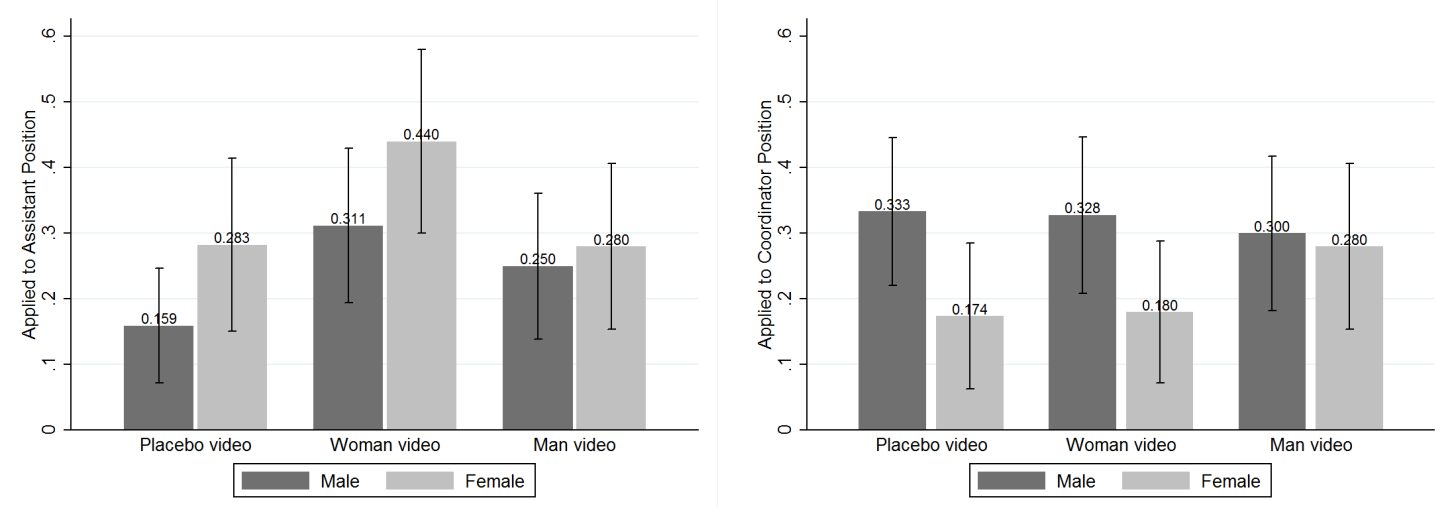

In the following we use regression analysis to control for the effects of subject heterogeneity. In table 4.3 column 1 we regress Completed Application on the treatments and include school fixed effects. The model in column 2 contains further controls. The above results remain: The Female Role Model video treatment has a positive effect on participants' decision to apply to one of the jobs, while the MALE Role Model video has no effect. Also, as can be seen from column 3, we find no gender difference in the propensity to apply to the positions. We find a significant difference in the probability of females to apply in the Female Role Model video group compared to females in the PlaceBo group. We also find that male students are more likely to apply for one of the positions in the Female Role Model treatment compared to male students in the Placebo group. Thus, our results provide evidence in favor of Hypothesis $\mathbf{1}$ for the Female Role Model treatment and lack evidence for the Male Role Model treatment.

Columns 4 to 6 in table 4.3 include the results on the outcome Coordinator Position. Controlling for further covariates in column 5, we find that there is no average treatment effect of the Female Role Model or Male Role Model video on the choice of position. However, we find that female participants are less likely to apply to the coordinator position than males in the Placebo condition. In the model in column 6, we find that there is no gender difference in applications to the coordinator position in the MALE ROLE MODEL video treatment. Our results suggest that this is driven by an increase in females applying 
to the competitive position compared to the PlaceBo. Further, compared to the PlaceBo condition, we find that the treatments do not have an effect on males' decision to apply to the coordinator position. Our results thus do not provide evidence in favor of Hypothesis 2.

In column 6 we again include an interaction term to assess whether the treatment had differential effects on female and male students. We find that the gender gap, which is found in the Placebo group, is not prevalent in the Male Role Model but in the Female Role Model treatment group. Thus, we do not find support in favor of Hypothesis 3.

In summary, we find that the Female Role Model was successful in encouraging female as well as male students to apply for one of the advertised positions. In addition, we find that the MALE Role Model almost closes the gender gap in the coordinator position that is present in the Placebo group, whereas it still exists in the Female Role Model treatment. These results indicate that only a MALE Role Model encourages applications among females to more competitive jobs. These results hold if we instead estimate a probit model and after controlling for multiple hypothesis testing (See Table 4.10 and 4.11 in the Appendix).

Table 4.3: Treatment Effects on Applications

\begin{tabular}{|c|c|c|c|c|c|c|}
\hline & \multicolumn{3}{|c|}{ Complete application } & \multicolumn{3}{|c|}{ Coordinator position } \\
\hline & (1) & $(2)$ & $(3)$ & $(4)$ & (5) & (6) \\
\hline \multirow[t]{2}{*}{ Woman video } & $0.155^{* *}$ & $0.205^{* * *}$ & $0.173^{* *}$ & $-0.149^{*}$ & -0.102 & -0.108 \\
\hline & $(0.065)$ & $(0.068)$ & $(0.085)$ & $(0.089)$ & $(0.102)$ & $(0.126)$ \\
\hline \multirow[t]{2}{*}{ Man video } & 0.077 & 0.096 & 0.086 & -0.021 & 0.047 & -0.087 \\
\hline & $(0.064)$ & $(0.070)$ & $(0.086)$ & $(0.095)$ & $(0.107)$ & $(0.130)$ \\
\hline \multirow[t]{2}{*}{ Female } & & 0.068 & 0.036 & & $-0.240^{* * *}$ & $-0.363^{* * *}$ \\
\hline & & $(0.059)$ & $(0.100)$ & & $(0.082)$ & $(0.139)$ \\
\hline \multirow[t]{2}{*}{ Woman video $\times$ Female } & & & 0.075 & & & 0.043 \\
\hline & & & $(0.132)$ & & & $(0.182)$ \\
\hline \multirow[t]{2}{*}{ Man video $\times$ Female } & & & 0.025 & & & $0.327^{*}$ \\
\hline & & & $(0.134)$ & & & $(0.198)$ \\
\hline \multirow[t]{2}{*}{ Constant } & $0.630^{* * *}$ & -0.380 & -0.392 & $0.490^{* * *}$ & $1.223^{* *}$ & $1.160^{* *}$ \\
\hline & $(0.057)$ & $(0.437)$ & $(0.438)$ & $(0.079)$ & $(0.595)$ & $(0.578)$ \\
\hline Observations & 336 & 336 & 336 & 186 & 186 & 186 \\
\hline Fixed effects & Yes & Yes & Yes & Yes & Yes & Yes \\
\hline Controls & No & Yes & Yes & No & Yes & Yes \\
\hline \multicolumn{7}{|c|}{$\begin{array}{l}\text { Notes: Robust standard errors in parentheses. }{ }^{*} p<0.10,{ }^{*} p<0.05,{ }^{*} * *<0.01 \text {. Control variables: } \\
\text { Age in years: Age of participant calculated from the year participants were born; Science focus: } 1 \text { if the } \\
\text { student chose the science focus and } 0 \text { if he/she instead chose the language focus; Number of brothers: } \\
\text { Number of brothers (not siblings) participants reported; Economic status: Takes the values from } 1 \\
\text { (poor) to } 5 \text { (wealthy) according to the economic situation reported by the student; Job at present: } 1 \\
\text { if the participant has a job at the moment of the experiment, } 0 \text { otherwise; Vanilla family: } 1 \text { if the } \\
\text { participant comes from a family that is in the vanilla business, } 0 \text { otherwise; Friends group: Number of } \\
\text { friends the participant reported to be in his/her group of four, takes the values from } 1 \text { to } 3 \text {; Frequency } \\
\text { meeting outsiders: takes values from } 1 \text { to } 5 \text {, where } 1 \text { indicates that students never meet outsiders and } 5 \\
\text { indicates they meet every day with outsiders; Frequency smartphone usage: takes values from } 1 \text { to } 5 \text {, } \\
\text { where } 1 \text { indicates students never have used an smartphone and } 5 \text { indicates they use it every day; Gender } \\
\text { imbalance group: } 1 \text { if there is an uneven number of female and males in the group of four, } 0 \text { if there } \\
\text { is a balance; Highest degree mother: } 0=\text { no education, } 1 \text { =primary education, } 2=\text { secondary education, } \\
3=\text { university degree. }\end{array}$} \\
\hline
\end{tabular}




\subsection{Exploratory Analysis}

In this chapter we perform an exploratory analysis to assess whether the treatment effects can be explained by changes in the measures obtained from the lab experiment. As a first step we report descriptive statistics on the variables that we obtained in the lab-in-the-field experiment for the PlACEBO group. We then analyze whether our role model intervention affects behavior in the lab, before we control for the lab measures in our main outcome regression.

\subsubsection{Descriptive Statistics of Mechanism Variables}

Table 4.4 shows the descriptive statistics for each of our mechanism variables in the PLACEBO group. On average students solve 4.42 mazes in task 1 and 5.69 in task 2. Only about a third of the students (31 percent) chose tournament pay in task 3 and 24 percent chose intra-competition in task 5. Concerning our aspiration measures, we find that our sample includes observations with very high levels of income and asset aspirations, as can be seen from the maximum levels reported and the difference in the mean and median. The median aspired income is 2,000,000 Ariary (about 464 Euro) and the median aspired level of assets is 150,000,000 Ariary (about 34,780 Euro). Given that the minimum wage per month in Madagascar is of about 34 Euro ("Caisse Nationale de Prévoyance Sociale Madagascar", 2015), students' aspire quite high. Also student's education and social status aspirations are high with students on average aspiring to achieve 19.43 years of schooling and a social status of 9.16. We also test for differences in aspirations across gender reported in table 4.9 in the Appendix, but find that there are no significant differences. Further, students in the PlaceBo group on average report a general self-efficacy score of 36.47 (out of 55) and an academic self-efficacy score of 41.08 , which is quite low given that the highest score is

70. Lastly, students in the PlACEBO group on average report to have 3.92 locus of control beliefs (out of 6 ).

Table 4.4: Mechanism Variables in the Placebo Group

\begin{tabular}{lcccccc}
\hline & Mean & Median & SD & Min & Max & N \\
\hline Performance task 1 & 4.42 & 5.00 & 1.65 & 0.00 & 8.00 & 115.00 \\
Performance task 2 & 5.69 & 6.00 & 1.68 & 0.00 & 9.00 & 115.00 \\
Compete in task 3 & 0.31 & 0.00 & 0.47 & 0.00 & 1.00 & 115.00 \\
Compete in task 5 & 0.24 & 0.00 & 0.43 & 0.00 & 1.00 & 115.00 \\
Income goal (in 1000 Ariary) & $966,752.57$ & $2,000.00$ & $9,353,898.46$ & 10.00 & $100,000,000.00$ & 115.00 \\
Asset goal (in 1000 Ariary) & $3,292,051.96$ & $150,000.00$ & $15,604,268.64$ & 25.00 & $100,000,000.00$ & 115.00 \\
Education goal & 19.43 & 22.00 & 2.80 & 12.50 & 22.00 & 115.00 \\
Social status goal & 9.16 & 8.00 & 11.00 & 1.00 & 100.00 & 115.00 \\
Locus of control & 3.92 & 4.00 & 0.99 & 0.00 & 6.00 & 115.00 \\
General self-efficacy & 36.47 & 37.00 & 6.38 & 21.00 & 48.00 & 115.00 \\
Academic self-efficacy & 41.08 & 40.97 & 9.29 & 11.00 & 61.00 & 115.00 \\
\hline
\end{tabular}




\subsubsection{Treatment Effects on Mechanism Variables}

In table 4.5 we present the results of estimating ordinary least squares (OLS) regressions on performance and competitive preferences. First, we assess whether the treatments have an effect on performance in the real-effort task as it might influence the decision to compete. In Columns 1 to 4 we regress the number of correctly solved mazes in task 1 and task 2 on the treatment variable, gender, an interaction of treatment and gender, school fixed effects and further controls specified in the table notes. We find that female students perform better in task 1 and task 2 compared to males in all but one case (performance in task 1 in the Male Role Model video treatment). Female students on average solve 4.8 mazes out of 10 in the Placebo group, 5.7 mazes in the Female Role Model group and 6.5 in the Male Role Model group. Overall, we find that the Female Role Model and the Male Role Model video have a positive effect on female and male students' task 1 and task 2 performance. If we look at the performance increases in the two treatment groups compared to the Placebo, we find that especially the Male Role Model drove effort provision, not only among male, but also among female students. Females in the MALE Role Model group solve 1.6 (1.8) mazes more in task 1 (task 2) compared to females in the Placebo group, whereas males in the Male Role Model group solve 1.8 (1.9) more mazes correctly in task 1 (task 2) compared to males in the PlaceBo condition.

In a next step we assess the effects the role model videos on students' decision to enter into competition with other students in their group of four people. We find that only 17 percent of the female students in the PlACEBO group chose tournament pay, 24 percent in the Female Role Model video and 28 percent in the Male Role Model video treatment. We employ OLS regressions to control for differences in performance in the previous tasks and other covariates that could potentially effect the decision to compete. The estimations are shown in table 4.5 in columns 5 and 6 . The dependent variable takes on the value of 1 if the student chose tournament compensation or 0 if he or she decided for piece rate.

Our results show that female students in the PlACEBO condition are 26 percentage points less likely to enter into competition compared to male students. However, we find no gender difference in the choice to compete in the two treatment groups. This can be explained by a decrease in the propensity of male students to enter into competition in the two treatment groups compared to the PlaCEBo condition. Only 25 percent of the male students decide for tournament compensation in the Female Role Model video group and 28 percent in the Male Role Model group compared to 41 percent in the Placebo condition. Compared to Meier et al. (2020), we used a placebo video that we also produced in Madagascar and that showed the same characters and surroundings as the treatment videos. In retrospective we assumed that this placebo video was neutral, but our results suggest that it could have encouraged competitive behavior due to the mentioning of decreasing land availability in the rural areas and that many young people search for income in the cities. 
Next, we analyze whether the role model intervention has an effect on the propensity of students to enter into intra-competition with their past performance in task 2 . The results can also be found in table 4.5 in columns 7 and 8 . Compared to inter-competition we find no gender differences in the Placebo group. Also, we find that there are no treatment effects on the propensity to enter into intra-competition among female and male students. On average 22 percent of the females in the PlaceBo group competed against their own past performance, 36 percent in the Female Role Model and 38 percent in the Male Role Model treatment. For the male sample we find that 26 percent chose intra-competition in the Placebo group, 25 percent in the Female Role Model and 52 percent in the MALE ROLE MOdEL treatment.

The results of the OLS regressions on the aspiration index, locus of control and selfefficacy beliefs are reported in table 4.6. In columns 1 and 2 we regress the aspiration index on the treatmment variable, gender, an interaction of treatment and gender, school fixed effects, the current index and further individual level controls. ${ }^{13}$ We find that the female students in the Female Role Model video treatment report an aspiration index that 20 percent of a standard deviation higher compared to females in the PLACEBO group. The Male Role Model also has a positive effect on females' aspiration index. Treated female students have a 21 percent of a standard deviation higher index compared to females in the Placebo group. We find that the treatments have no effects on males.

In columns 3 and 4 we regress the same controls on the outcome Locus of control (except for the current index). We find no treatment effect for each of the role model treatments. While our role model treatments did not increase General self-efficacy beliefs (columns 5 and 6), we find that the Female Role Model video has a positive effect on females' Academic self-efficacy beliefs(columns 7 and 8). Treated female students report a 3.85 higher score compared to females in the PLACEBO condition.

\footnotetext{
${ }^{13}$ For the analysis on aspirations we drop observations that have extreme high aspiration index values by trimming the sample to the 95 percentile, which results in 17 observations less compared to the whole sample. We find no treatment effects without dropping the outliers.
} 
Table 4.5: Treatment Effects on Performance and Competitive Preferences

\begin{tabular}{lcccccccc}
\hline \hline & $(1)$ & $(2)$ & $(3)$ & $(4)$ & $(5)$ & $(6)$ & $(7)$ & $(8)$ \\
& Perf. 1 & Perf. 1 & Perf. 2 & Perf. 2 & Compete 3 & $\begin{array}{c}(6) \\
\text { Compete 3 }\end{array}$ & $\begin{array}{c}\text { Compete 5 } \\
\text { Compete 5 }\end{array}$ \\
\hline Woman video & $0.965^{* * *}$ & $0.827^{* * *}$ & $1.219^{* * *}$ & $0.980^{* * *}$ & $-0.174^{* *}$ & $-0.223^{* * *}$ & -0.027 & -0.039 \\
& $(0.283)$ & $(0.306)$ & $(0.279)$ & $(0.282)$ & $(0.075)$ & $(0.074)$ & $(0.072)$ & $(0.081)$ \\
Man video & $1.977^{* * *}$ & $1.881^{* * *}$ & $2.204^{* * *}$ & $2.014^{* * *}$ & -0.129 & $-0.234^{* * *}$ & $0.250^{* * *}$ & 0.171 \\
& $(0.285)$ & $(0.301)$ & $(0.308)$ & $(0.271)$ & $(0.086)$ & $(0.089)$ & $(0.087)$ & $(0.104)$ \\
Female & $0.635^{* *}$ & $0.546^{*}$ & $0.554^{*}$ & $0.471^{*}$ & $-0.208^{* * *}$ & $-0.260^{* * *}$ & -0.025 & -0.044 \\
& $(0.291)$ & $(0.305)$ & $(0.295)$ & $(0.272)$ & $(0.079)$ & $(0.074)$ & $(0.080)$ & $(0.078)$ \\
Woman video $\times$ Female & -0.168 & -0.060 & 0.400 & 0.177 & $0.230^{* *}$ & $0.215^{* *}$ & 0.162 & 0.154 \\
& $(0.396)$ & $(0.407)$ & $(0.376)$ & $(0.345)$ & $(0.107)$ & $(0.102)$ & $(0.113)$ & $(0.112)$ \\
Man video $\times$ Female & -0.300 & -0.317 & -0.175 & -0.320 & $0.235^{* *}$ & $0.220^{* *}$ & -0.085 & -0.094 \\
& $(0.425)$ & $(0.431)$ & $(0.437)$ & $(0.365)$ & $(0.117)$ & $(0.107)$ & $(0.125)$ & $(0.123)$ \\
Constant & $4.037^{* * *}$ & $5.135^{* * *}$ & $5.661^{* * *}$ & $7.519^{* * *}$ & $0.367^{* * *}$ & $0.990^{* *}$ & $0.217^{* * *}$ & 0.249 \\
& $(0.246)$ & $(1.445)$ & $(0.240)$ & $(1.136)$ & $(0.067)$ & $(0.395)$ & $(0.065)$ & $(0.387)$ \\
\hline Observations & 336 & 336 & 336 & 336 & 336 & 336 & 336 & 336 \\
$R^{2}$ & 0.281 & 0.325 & 0.304 & 0.524 & 0.127 & 0.280 & 0.109 & 0.191 \\
Fixed effects & Yes & Yes & Yes & Yes & Yes & Yes & Yes & Yes \\
Controls & No & Yes & No & Yes & No & Yes & No & Yes \\
\hline \hline
\end{tabular}

Notes: Robust standard errors in parentheses. ${ }^{*} p<0.10,{ }^{* *} p<0.05,{ }^{* * *} p<0.01$. Control variables: Age in years: Age of participant calculated from the year participants were born; Science focus: 1 if the student chose the science focus and 0 if he/she instead chose the language focus; Number of brothers: Number of brothers (not siblings) participants reported; Economic status: Takes the values from 1 (poor) to 5 (wealthy) according to the economic situation reported by the student; Vanilla family: 1 if the participant comes from a family that is in the vanilla business, 0 otherwise; Friends group: Number of friends the participant reported to be in his/her group of four, takes the values from 1 to 3; Frequency meeting outsiders: takes values from 1 to 5 , where 1 indicates that students never meet outsiders and 5 indicates they meet every day with outsiders; Frequency smartphone usage: takes values from 1 to 5 , where 1 indicates students never have used an smartphone and 5 indicates they use it every day; Gender imbalance group: 1 if there is an uneven number of female and males in the group of four, 0 if there is a balance. Column 4 further includes Performance difference 2-1: the difference in performance between task 1 and task 2; column 6 additional controls for Belief rank 2: Participant's belief in his rank (1=highest, 4=lowest) in the group and column 8 instead of Belief rank 2 controls for Belief performance task 2.

Table 4.6: Treatment Effects on Aspirations and Beliefs

\begin{tabular}{|c|c|c|c|c|c|c|c|c|}
\hline & $\begin{array}{c}\text { (1) } \\
\text { Asp }\end{array}$ & $\begin{array}{c}(2) \\
\end{array}$ & (3) & (4) & $\begin{array}{c}(5) \\
\end{array}$ & $\begin{array}{c}(6) \\
\text { (6) }\end{array}$ & $\begin{array}{c}(7) \\
\text { A }\end{array}$ & $\begin{array}{c}(8) \\
\text { A }\end{array}$ \\
\hline \multirow[t]{2}{*}{ Woman video } & 0.044 & 0.016 & -0.104 & -0.067 & 0.662 & 0.270 & $4.061^{* *}$ & 2.528 \\
\hline & $(0.078)$ & $(0.081)$ & $(0.169)$ & $(0.192)$ & $(1.032)$ & $(1.120)$ & $(1.657)$ & $(1.722)$ \\
\hline \multirow[t]{2}{*}{ Man video } & 0.072 & 0.073 & -0.091 & -0.039 & 1.309 & 1.197 & 1.897 & 0.868 \\
\hline & $(0.070)$ & $(0.073)$ & $(0.172)$ & (0.187) & (0.918) & (1.004) & $(1.824)$ & $(1.836)$ \\
\hline \multirow[t]{2}{*}{ Female } & -0.092 & -0.086 & -0.220 & -0.218 & -1.540 & -1.602 & -2.719 & -2.654 \\
\hline & $(0.073)$ & $(0.074)$ & $(0.188)$ & $(0.181)$ & $(1.249)$ & $(1.295)$ & $(1.720)$ & $(1.797)$ \\
\hline \multirow[t]{2}{*}{ Woman video $\times$ Female } & $0.205^{*}$ & $0.186^{*}$ & $0.437^{*}$ & 0.354 & 1.256 & 1.493 & 0.423 & 1.319 \\
\hline & $(0.110)$ & $(0.110)$ & $(0.264)$ & $(0.264)$ & $(1.703)$ & $(1.747)$ & $(2.568)$ & $(2.603)$ \\
\hline \multirow[t]{2}{*}{ Man video $\times$ Female } & 0.200 & 0.155 & 0.202 & 0.145 & 1.863 & 1.823 & 1.410 & 1.402 \\
\hline & $(0.124)$ & $(0.121)$ & $(0.240)$ & $(0.243)$ & $(1.558)$ & $(1.635)$ & $(2.734)$ & $(2.844)$ \\
\hline \multirow[t]{2}{*}{ Constant } & -0.051 & 0.113 & $3.898^{* * *}$ & $5.247^{* * *}$ & $36.949^{* * *}$ & $33.043^{* * *}$ & $43.091^{* * *}$ & $32.869^{* * *}$ \\
\hline & $(0.056)$ & $(0.392)$ & $(0.136)$ & $(0.942)$ & $(0.747)$ & $(5.028)$ & $(1.342)$ & $(9.107)$ \\
\hline Observations & 319 & 319 & 336 & 336 & 336 & 336 & 336 & 336 \\
\hline$R^{2}$ & 0.117 & 0.194 & 0.031 & 0.048 & 0.062 & 0.087 & 0.048 & 0.092 \\
\hline Fixed effects & Yes & Yes & Yes & Yes & Yes & Yes & Yes & Yes \\
\hline Controls & No & Yes & No & Yes & No & Yes & No & Yes \\
\hline
\end{tabular}

Notes: Robust standard errors in parentheses. ${ }^{*} p<0.10,{ }^{* *} p<0.05,{ }^{* * *} p<0.01$. Control variables: Age in years: Age of participant calculated from the year participants were born; Science focus: 1 if the student chose the science focus and 0 if he/she instead chose the language focus; Economic status: Takes the values from 1 (poor) to 5 (wealthy) according to the economic situation reported by the student; Job at present: 1 if the participant has a job at the moment of the experiment, 0 otherwise; Vanilla family: 1 if the participant comes from a family that is in the vanilla business, 0 otherwise; Friends group: Number of friends the participant reported to be in his/her group of four, takes the values from 1 to 3 ; Frequency meeting outsiders: takes values from 1 to 5 , where 1 indicates that students never meet outsiders and 5 indicates they meet every day with outsiders; Frequency smartphone usage: takes values from 1 to 5 , where 1 indicates students never have used an smartphone and 5 indicates they use it every day; Gender imbalance group: 1 if there is an uneven number of female and males in the group of four, 0 if there is a balance; Highest degree mother: $0=$ no education, $1=$ primary education, $2=$ secondary education, $3=$ university degree, Current index. 


\subsubsection{Can the Mechanism Variables Explain Behavior in the Field Ex- periment?}

The above analysis revealed that the treatment videos have an effect on some of our mechanism variables. In the following section we include these variables into our main outcome regressions to assess whether any of these variables can explain the treatment effects on completed applications and the choice of position. In table 4.7 we present the results of the OLS estimation for our outcome Complete Application controlling for performance in task 1 and in task 2, decision to compete in task 3, the aspiration and current index, and academic self-efficacy beliefs. Controlling for the mechanism variables we find that the significance level of the Female Role Model treatment effect reduces to the 10 percent level when we control for the aspiration and current index (columns 4 and 6). Further, we find that the current index is significantly and positively related to the outcome variable (yet very small in magnitude).

Table 4.8 presents the results for the outcome Coordinator Position including the same mechanism variables as above. We find that by controlling for the variables, except for performance in task 1, the interaction Man video $x$ Female becomes insignificant. Further, we find that the decision to compete is significantly and positively related to the decision to apply to the coordinator position. The results remain if all mechanism variables are included into one model (column 6). This suggests that the willingness to enter into competition can partly explain the decision to apply to the more competitive job. All other variables do not correlate with the outcome variable.

Table 4.7: Relation of Mechanism Variables to Complete Application

\begin{tabular}{|c|c|c|c|c|c|c|}
\hline & $\begin{array}{c}\text { (1) } \\
\text { Commplete application }\end{array}$ & $\begin{array}{c}(2) \\
\text { Complete application }\end{array}$ & $\begin{array}{c}\text { (3) } \\
\text { Complete application }\end{array}$ & $\begin{array}{c}(4) \\
\text { Complete application }\end{array}$ & $\begin{array}{c}\text { (5) } \\
\text { Complete application }\end{array}$ & $\begin{array}{c}(6) \\
\text { Complete application }\end{array}$ \\
\hline Woman video & $\begin{array}{l}0.182^{* *} \\
(0.085)\end{array}$ & $\begin{array}{l}0.189^{* *} \\
(0.086)\end{array}$ & $\begin{array}{l}0.171^{* *} \\
(0.087)\end{array}$ & $\begin{array}{l}0.149^{*} \\
(0.086)\end{array}$ & $\begin{array}{l}0.176^{* *} \\
(0.085)\end{array}$ & $\begin{array}{l}0.164^{*} \\
(0.091)\end{array}$ \\
\hline Man video & $\begin{array}{c}0.105 \\
(0.092)\end{array}$ & $\begin{array}{c}0.115 \\
(0.090)\end{array}$ & $\begin{array}{c}0.084 \\
(0.087)\end{array}$ & $\begin{array}{c}0.072 \\
(0.091)\end{array}$ & $\begin{array}{c}0.087 \\
(0.086)\end{array}$ & $\begin{array}{c}0.093 \\
(0.098)\end{array}$ \\
\hline Female & $\begin{array}{c}0.042 \\
(0.100)\end{array}$ & $\begin{array}{c}0.043 \\
(0.100)\end{array}$ & $\begin{array}{c}0.033 \\
(0.100)\end{array}$ & $\begin{array}{c}0.032 \\
(0.100)\end{array}$ & $\begin{array}{c}0.033 \\
(0.100)\end{array}$ & $\begin{array}{c}0.034 \\
(0.103)\end{array}$ \\
\hline Woman video $\times$ Female & $\begin{array}{c}0.074 \\
(0.132)\end{array}$ & $\begin{array}{c}0.080 \\
(0.132)\end{array}$ & $\begin{array}{c}0.077 \\
(0.134)\end{array}$ & $\begin{array}{c}0.096 \\
(0.133)\end{array}$ & $\begin{array}{c}0.076 \\
(0.132)\end{array}$ & $\begin{array}{c}0.099 \\
(0.137)\end{array}$ \\
\hline Man video $\times$ Female & $\begin{array}{c}0.022 \\
(0.134)\end{array}$ & $\begin{array}{c}0.021 \\
(0.134)\end{array}$ & $\begin{array}{c}0.028 \\
(0.135)\end{array}$ & $\begin{array}{c}0.030 \\
(0.139)\end{array}$ & $\begin{array}{c}0.027 \\
(0.135)\end{array}$ & $\begin{array}{c}0.029 \\
(0.141)\end{array}$ \\
\hline Perf. 1 & $\begin{array}{l}-0.010 \\
(0.017)\end{array}$ & & & & & $\begin{array}{l}-0.002 \\
(0.022)\end{array}$ \\
\hline Perf. 2 & & $\begin{array}{l}-0.014 \\
(0.017)\end{array}$ & & & & $\begin{array}{l}-0.007 \\
(0.021)\end{array}$ \\
\hline Compete 3 & & & $\begin{array}{l}-0.013 \\
(0.064)\end{array}$ & & & $\begin{array}{c}0.007 \\
(0.070)\end{array}$ \\
\hline Asp. index & & & & $\begin{array}{c}0.082 \\
(0.064)\end{array}$ & & $\begin{array}{c}0.087 \\
(0.065)\end{array}$ \\
\hline Current index & & & & $\begin{array}{l}0.006^{* *} \\
(0.003)\end{array}$ & & $\begin{array}{l}0.006^{* *} \\
(0.003)\end{array}$ \\
\hline Academic SE & & & & & $\begin{array}{l}-0.001 \\
(0.003)\end{array}$ & $\begin{array}{l}-0.001 \\
(0.003)\end{array}$ \\
\hline Constant & $\begin{array}{l}-0.329 \\
(0.448)\end{array}$ & $\begin{array}{l}-0.246 \\
(0.476)\end{array}$ & $\begin{array}{l}-0.378 \\
(0.440)\end{array}$ & $\begin{array}{l}-0.406 \\
(0.440)\end{array}$ & $\begin{array}{l}-0.356 \\
(0.452)\end{array}$ & $\begin{array}{l}-0.278 \\
(0.495)\end{array}$ \\
\hline Observations & 336 & 336 & 336 & 319 & 336 & 319 \\
\hline Fixed effects & Yes & Yes & Yes & Yes & Yes & Yes \\
\hline Controls & Yes & Yes & Yes & Yes & Yes & Yes \\
\hline
\end{tabular}

Notes: Robust standard errors in parentheses. ${ }^{*} p<0.10,{ }^{* *} p<0.05,{ }^{* * *} p<0.01$. Control variables: Age in years: Age of participant calculated from the year participants were born; Science focus: 1 if the student chose the science focus and 0 if he/she instead chose the language focus; Number of brothers: Number of brothers (not siblings) participants reported; Economic status: Takes the value
from 1 (poor) to 5 (wealthy) according to the economic situation reported by the student; Job at present: 1 if the participant has a job at the moment of the experiment, 0 otherwise; Vanilla family: if the participant comes from a family that is in the vanilla business, 0 otherwise; Friends group: Number of friends the participant reported to be in his/her group of four, takes the values from 1 to 3 Frequency meeting outsiders: takes values from 1 to 5 , where 1 indicates that students never meet outsiders and 5 indicates they meet every day with outsiders; Frequency smartphone usage: takes values from 1 to 5 , where 1 indicates students never have used an smartphone and 5 indicates they use it every day; Gender imbalance group: 1 if there is an uneven number of female and males in the group of four, 0 if there is a balance; Highest degree mother: $0=$ no education, $1=$ primary education, $2=$ secondary education, $3=$ university degree. 
Table 4.8: Relation of Mechanism Variables to Applications to the Coordinator Position

\begin{tabular}{|c|c|c|c|c|c|c|}
\hline & $\begin{array}{c}(1) \\
\text { Coordinator position } \\
\end{array}$ & $\begin{array}{c}(2) \\
\text { Coordinator position } \\
\end{array}$ & $\begin{array}{c}\text { (3) } \\
\text { Coordinator position } \\
\end{array}$ & $\begin{array}{c}(4) \\
\text { Coordinator position } \\
\end{array}$ & $\begin{array}{c}(5) \\
\text { Coordinator position } \\
\end{array}$ & $\begin{array}{c}(6) \\
\text { Coordinator position } \\
\end{array}$ \\
\hline Woman video & $\begin{array}{l}-0.107 \\
(0.127)\end{array}$ & $\begin{array}{l}-0.113 \\
(0.127)\end{array}$ & $\begin{array}{l}-0.061 \\
(0.127)\end{array}$ & $\begin{array}{c}-0.114 \\
(0.129)\end{array}$ & $\begin{array}{l}-0.115 \\
(0.125)\end{array}$ & $\begin{array}{l}-0.062 \\
(0.133)\end{array}$ \\
\hline Man video & $\begin{array}{l}-0.082 \\
(0.134)\end{array}$ & $\begin{array}{l}-0.104 \\
(0.138)\end{array}$ & $\begin{array}{l}-0.051 \\
(0.131)\end{array}$ & $\begin{array}{l}-0.113 \\
(0.134)\end{array}$ & $\begin{array}{l}-0.090 \\
(0.129)\end{array}$ & $\begin{array}{l}-0.059 \\
(0.143)\end{array}$ \\
\hline Female & $\begin{array}{c}-0.364^{* * *} \\
(0.138)\end{array}$ & $\begin{array}{c}-0.363^{* *} \\
(0.141)\end{array}$ & $\begin{array}{c}-0.331^{* *} \\
(0.140)\end{array}$ & $\begin{array}{c}-0.338^{* *} \\
(0.142)\end{array}$ & $\begin{array}{c}-0.354^{* *} \\
(0.142)\end{array}$ & $\begin{array}{c}-0.290^{* *} \\
(0.147)\end{array}$ \\
\hline Woman video $\times$ Female & $\begin{array}{c}0.048 \\
(0.182)\end{array}$ & $\begin{array}{c}0.029 \\
(0.183)\end{array}$ & $\begin{array}{l}-0.012 \\
(0.179)\end{array}$ & $\begin{array}{c}0.007 \\
(0.191)\end{array}$ & $\begin{array}{c}0.031 \\
(0.186)\end{array}$ & $\begin{array}{l}-0.064 \\
(0.193)\end{array}$ \\
\hline Man video $\times$ Female & $\begin{array}{l}0.333^{*} \\
(0.196)\end{array}$ & $\begin{array}{c}0.325 \\
(0.199)\end{array}$ & $\begin{array}{c}0.268 \\
(0.200)\end{array}$ & $\begin{array}{c}0.326 \\
(0.206)\end{array}$ & $\begin{array}{c}0.318 \\
(0.200)\end{array}$ & $\begin{array}{c}0.256 \\
(0.208)\end{array}$ \\
\hline Perf. 1 & $\begin{array}{l}-0.005 \\
(0.025)\end{array}$ & & & & & $\begin{array}{l}-0.005 \\
(0.034)\end{array}$ \\
\hline Perf. 2 & & $\begin{array}{c}0.012 \\
(0.026)\end{array}$ & & & & $\begin{array}{l}-0.007 \\
(0.036)\end{array}$ \\
\hline Compete 3 & & & $\begin{array}{l}0.186^{* *} \\
(0.085)\end{array}$ & & & $\begin{array}{l}0.213^{* *} \\
(0.091)\end{array}$ \\
\hline Asp. index & & & & $\begin{array}{c}0.030 \\
(0.094)\end{array}$ & & $\begin{array}{c}0.042 \\
(0.091)\end{array}$ \\
\hline Current index & & & & $\begin{array}{c}0.002 \\
(0.003)\end{array}$ & & $\begin{array}{c}0.004 \\
(0.004)\end{array}$ \\
\hline Academic SE & & & & & $\begin{array}{c}0.002 \\
(0.004)\end{array}$ & $\begin{array}{c}0.003 \\
(0.004)\end{array}$ \\
\hline Constant & $\begin{array}{l}1.197^{*} \\
(0.618)\end{array}$ & $\begin{array}{c}1.024 \\
(0.646)\end{array}$ & $\begin{array}{l}1.107^{* *} \\
(0.558)\end{array}$ & $\begin{array}{l}1.262^{* *} \\
(0.592)\end{array}$ & $\begin{array}{l}1.067^{*} \\
(0.605)\end{array}$ & $\begin{array}{l}1.175^{*} \\
(0.640)\end{array}$ \\
\hline Observations & 186 & 186 & 186 & 180 & 186 & 180 \\
\hline Fixed effects & Yes & Yes & Yes & Yes & Yes & Yes \\
\hline Controls & Yes & Yes & Yes & Yes & Yes & Yes \\
\hline
\end{tabular}

Notes: Robust standard errors in parentheses. ${ }^{*} p<0.10,{ }^{* *} p<0.05,{ }^{* * *} p<0.01$. Control variables: Age in years: Age of participant calculated from the year participants were born; Science Takes the values from 1 (poor) to 5 (wealthy) according to the economic situation reported by the student; Job at present: 1 if the participant has a job at the moment of the experiment, 0 otherwise; Vanilla family: 1 if the participant comes from a family that is in the vanilla business, 0 otherwise; Friends group: Number of friends the participant reported to be in his/her group of four, takes the values from 1 to 3 ; Frequency meeting outsiders: takes values from 1 to 5 , where 1 indicates that students never meet outsiders and 5 indicates they meet every day with outsiders; Frequency smartphone usage: takes values from 1 to 5 , where 1 indicates students never have used an smartphone and 5 indicates they use it every day; Gender imbalance group: 1 if there is an uneven number of female and males in the group of four, 0 if there is a balance; Highest degree mother: $0=$ no education, $1=$ primary education, $2=$ secondary education, $3=$ university degree

\subsection{Discussion}

Our research finds that providing information of a role model through a video has a positive impact on their willingness to apply for the jobs we advertised (assistant and coordinator). In particular, Female Role Model increases applications to one of the two positions offered; while the MALE Role Model increases the chances that female students apply to the coordinator position compared to the PlaceBo condition. The proportion of females applying to the coordinator position increases by 10 percentage points in the MALE ROLE Model video compared to the Female Role Model and Placebo group. As a consequence, the gender-gap in applications to the coordinator position that is present in the PlACEBO group shrinks.

Our exploratory analysis suggests that the mechanism could run through competitive preferences, as we find that the decision to apply to the coordinator position is positively correlated with the decision to enter into competition in Task-3 and the treatment effect of the Male Role Model disappears. This suggests that our Male Role Model is more successful in encouraging competitive behavior which translates into real world decisions such as applying for more competitive and better paid jobs. The literature studying the effects of role models on social behavior has been suggesting that same-sex interactions are successful (Stout et al., 2011; Beaman et al., 2012; Meier et al., 2020). However, the results of our study suggest that it is important to consider the traits that the different genders represent. In general, males are perceived to be more competitive than females (Blau \& Kahn, 2017). Hence, one way to explain our results is, that videos with a male 
character could nudge females towards more competitive behavior since males could appear more competitive compared to females. Compared to previous studies, which find that this competitive image of males discourages females to enter into competition, our role models come from similar backgrounds and have goals that are attainable for them as well. One could also argue that females' decision to apply for a competitive job after seeing a Male Role Model, could be driven by a 'defiance' response of females to stop replicating stereotypes that are embedded in social norms (Schier, 2020). Interestingly the MALE Role Model did not encourage competitive behavior among male participants. A potential reason why males did not react to the Male Role Model compared to the Placebo could lie in the content of the Placebo video. Future research could use different Placebo videos as well as different characters to test this conjecture.

Our results also show that exposing individuals to role models, that talk about aspirations and the way to achieve them, is effective in driving students to apply without the need to make competition salient as done in other studies (Meier et al., 2020). We can also rule out that our observed treatment effects are driven by demand effects, since our videos do not refer to the labor market or gave information about the announced positions. Further, the experimenter advertised the positions at the end of the session in a casual way and provided the same information to all groups without raising hopes about future outcomes.

We also find treatment effects on aspirations. Female students in the Female Role Model and the Male Role Model video report higher aspirations compared to females in the PlaCEBo group. Yet, important to consider is also the effect of unsuccessful applications on the level of aspirations and beliefs (McKelway, 2020). Unfortunately, we were not able to hire any of the applicants due to low communication skills. ${ }^{14}$ If aspirations are not realized this can lead to frustration and to a decrease in investments (Genicot \& Ray, 2017). A possible remedy could be to increase exposure to successful experiences of others (role models) or to decrease the barriers of attaining a job.

Our paper does not address other potential mechanisms that could play a role in determining females' willingness to participate in the labor market such as discrimination or stereotype threats, which could have been affected by the video. Also, we have not collected information on the ability of the students at school (such as the grade point

\footnotetext{
${ }^{14}$ After receiving the job applications we went through the screening process. We checked each application taking into account the following points: 1) Check names in database to make sure applicants participated in the sessions; 2) Check for the position applied; 3) Check the English and French level reported. At least one has to be rated as "good". After the screening, we selected 33 candidates for the personal interviews. Since we collected all personal information of candidates it was possible to reach all of them after the sessions. The interviews took place in November 2018 and July 2019 in each of the different cities the experiments took place. Unfortunately, none of the candidates we interviewed was eligible for the assistant or coordinator positions as they were very shy towards the researcher and translator and hence it was difficult to communicate with them. Thus, even though they had the formal requirements they lacked the confidence that probably develops through previous work experiences.
} 
average (GPA)). Thus, we cannot tell which one of the females applied more to one of the positions in terms of their ability which is also important to consider when exposed to competitive environments.

\subsection{Conclusion}

In this paper we analyze the effect of a role model intervention on female's as well as male's decision to participate in the labor market. We implemented a field and lab-in-the-field experiment with secondary school students in Madagascar in which we either screened a Female Role Model, a Male Role Model or a Placebo video to the students. The female and the male video told the story of two individuals who succeeded in becoming a teacher at a University, while the placebo video was about life in rural and urban Madagascar. After video exposure we measured competitive preferences using a lab-in-the-field experiment adapted from Niederle \& Vesterlund (2007) and obtained students' aspirations and beliefs through survey questions. At the end of the session, we offered students the opportunity to apply for two jobs in our research team. They could either apply to be an assistant or a coordinator. The coordinator involves task with more responsibility and thus has a higher compensation.

We find that the Female Role Model video, compared to the Placebo, has a positive effect on the decision to apply to any of the two positions for both female and male students. There is a gender gap in applications to the coordinator position in the PLACEBO group. However, the gap almost disappears in the MALE RoLE MODEL video treatment group as almost an equal share of females and males apply to the coordinator position. Our results suggest that is driven by more females applying to the more competitive position compared to the Placebo. We use the measures obtained in the lab-in-the-field experiment and the post-experimental survey to analyze possible mechanism and find that the decision to apply to any of the two positions can partly be explained by participant's aspirations and current level of achievements. Further, we find that the decision to enter into competition in the lab can explain the decision to apply for the coordinator position in the MALE ROLE MODEL treatment group.

Hence, our study provides evidence that for role models to be successful, they do not have to be of the same sex, but suggest that the character's traits matter. Further, the novelty of our study lies in relating the decisions from the lab experiment with the decisions students took in the field experiment. Therefore, unlike other studies that assume a link between competitive preferences and labor market outcomes, we are able to show that competitive preferences can explain the decision to apply for the coordinator position in the Male Role Model treatment.

It is likely that the results obtained in Madagascar can be similar to other contexts, 
in which female students experience a behavioral poverty trap. Our study shows that video interventions about successful individuals provide a low-cost alternative in contexts where there is a lack of role models that are similar and geographically close. Other examples of policy measures that could be implemented are to increase the share of female role models through affirmative action such as quotas (Beaman et al., 2012; Niederle et al., 2013; Ibañez \& Riener, 2018). These measures should go hand in hand with lifting external constraints such as discrimination and barriers to tertiary enrollment. 


\subsection{Appendix A - Tables}

Table 4.9: Aspirations in the Placebo Group by Gender

\begin{tabular}{lccc}
\hline \hline & $(1)$ & $(2)$ & $(3)$ \\
& Male & Female & p-value \\
\hline Education & 19.196 & 19.135 & 0.911 \\
& $(0.349)$ & $(0.408)$ & \\
Income & 23685.652 & 11196.563 & 0.457 \\
& $(13566.069)$ & $(4675.124)$ & \\
Status & 9.304 & 9.063 & 0.907 \\
& $(1.055)$ & $(1.966)$ & \\
Assets & 687011.123 & 431542.188 & 0.353 \\
& $(177387.262)$ & $(207055.172)$ & \\
\hline$N$ & 69 & 48 & \\
\hline
\end{tabular}

Notes: Column 3 reports the p-value from joint orthogonality test of treatment arms. Standard errors in parentheses. Comparisons of income and asset goals are based on a $95 \%$ reduced sample. 
Table 4.10: Treatment Effects on Applications: Probit Model

\begin{tabular}{lccccccc}
\hline \hline & \multicolumn{3}{c}{ Complete application } & & \multicolumn{3}{c}{ Coordinator position } \\
\cline { 2 - 3 } \cline { 7 - 8 } & $(1)$ & $(2)$ & $(3)$ & & $(4)$ & $(5)$ & $(6)$ \\
\hline Woman video & $0.155^{* *}$ & $0.213^{* * *}$ & $0.183^{* *}$ & & $-0.149^{*}$ & -0.107 & -0.105 \\
& $(0.063)$ & $(0.065)$ & $(0.084)$ & & $(0.088)$ & $(0.096)$ & $(0.116)$ \\
Man video & 0.077 & 0.096 & 0.090 & -0.021 & 0.041 & -0.092 \\
& $(0.063)$ & $(0.067)$ & $(0.083)$ & & $(0.093)$ & $(0.095)$ & $(0.117)$ \\
Female & & 0.064 & 0.065 & & $-0.242^{* * *}$ & $-0.240^{* * *}$ \\
& & $(0.055)$ & $(0.055)$ & & & $(0.076)$ & $(0.074)$ \\
Woman videon $\times$ Female & & & 0.059 & & & 0.033 \\
& & & $(0.121)$ & & & $(0.161)$ \\
Man video $\times$ Female & & & 0.015 & & & $0.321^{*}$ \\
& & & $(0.126)$ & & & $(0.177)$ \\
\hline Observations & 336 & 336 & 336 & & 186 & 186 & 186 \\
Fixed effects & Yes & Yes & Yes & & Yes & Yes & Yes \\
Controls & No & Yes & Yes & No & Yes & Yes \\
\hline \hline
\end{tabular}

Notes: Robust standard errors in parentheses. Coefficient present marginal effects evaluated at a man. ${ }^{*} p<0.10,{ }^{* *} p<0.05,{ }^{* * *} p<0.01$. Control variables: Age in years: Age of participant calculated from the year participants were born; Science focus: 1 if the student chose the science focus and 0 if he/she instead chose the language focus; Number of brothers: Number of brothers (not siblings) participants reported; Economic status: Takes the values from 1 (poor) to 5 (wealthy) according to the economic situation reported by the student; Job at present: 1 if the participant has a job at the moment of the experiment, 0 otherwise; Vanilla family: 1 if the participant comes from a family that is in the vanilla business, 0 otherwise; Friends group: Number of friends the participant reported to be in his/her group of four, takes the values from 1 to 3 ; Frequency meeting outsiders: takes values from 1 to 5 , where 1 indicates that students never meet outsiders and 5 indicates they meet everyday with outsiders; Frequency smartphone usage: takes values from 1 to 5 , where 1 indicates students never have used an smartphone and 5 indicates they use it everyday; Gender imbalance group: 1 if there is an uneven number of female and males in the group of four, 0 if there is a balance; Highest degree mother: $0=$ no education, $1=$ primary education, $2=$ secondary education, $3=$ university degree.

Table 4.11: Multiple Hypothesis Testing

\begin{tabular}{|c|c|c|c|c|c|}
\hline Outcome variable & Treatment & Subgroup & Difference & p-value not adjusted & p-value adjusted (B-H) \\
\hline Complete Application & Female Video vs. Control & Female & 0.248 & 0.020 & 0.070 \\
\hline Complete Application & Male Video vs. Control & Female & 0.111 & 0.308 & 0.451 \\
\hline Complete Application & Female Video vs. Control & Male & 0.173 & 0.041 & 0.096 \\
\hline Complete Application & Male Video vs. Control & Male & 0.086 & 0.322 & 0.451 \\
\hline Coordinator Position & Female Video vs. Control & Female & -0.065 & 0.659 & 0.769 \\
\hline Coordinator Position & Female Video & Female vs. Male & -0.320 & 0.010 & 0.070 \\
\hline Coordinator Position & Male Video & Female vs. Male & -0.036 & 0.799 & 0.799 \\
\hline
\end{tabular}

Notes: For the multiple hypothesis testing we use the Benjamini-Hochberg method as it has been shown to be less conservative, especially with low power samples, than the Bonferroni correction. 


\subsection{Appendix B - Experimental Instructions and Survey}

\subsubsection{General Instructions}

\section{Dear participant, welcome to our workshop!}

We are part of a research group called Diversity Turn. This is a project from the University of Göttingen. The objective of our project is to study vanilla production and the decisions students make under different incentive schemes in the SAVA region.

\section{What are you doing today?}

Today you will be participating in a workshop in which you will have the opportunity to earn money. Just for your participation you will receive a bonus of 2,000 Ariary at the end of the workshop. In addition, you can increase that amount by earning money in the different activities of the workshop. The amount of money that you earn will depend on your decisions and the decisions taken by people from other communities in the SAVA region. To calculate your earnings, we first need to finish the workshops in the other communities. Therefore, we will pay you in the next week once we have finished the workshops in the region.

This workshop has two parts. The first part will last approximately 1 hour and consist of four different activities. Thereafter, there will be a survey. Once you have finished both parts you will receive the 2,000 Ariary as a bonus of your participation and you will receive the additional earnings next week.

If at any time you feel uncomfortable, you are free to leave the room whether we have started the workshop or not. However, in that case you will not earn money.

Maybe you might have heard about this workshop before, yet what we will be doing today might be different. In order to do the activities correctly, please read carefully and pay attention when I explain them.

I would like to thank you for taking the time to come to this workshop. The results of each of the activities that we will be doing today will be very helpful for the research project. We appreciate your help very much.

I would also like to clarify that your identity will be kept anonymous along the workshop. This means that except from my colleagues and me, nobody will know your identity. We are only interested in the decisions that you take today and not in your identity. We will identify your decisions with the number that is on your table.

From now on, if you have questions, please quietly raise your hand and one of my colleagues will come to you to clarify your questions. Please do not talk to other participants in the 
workshop. This is very important.

\section{How is this workshop organized? ${ }^{15}$}

Now we will start the first part of the workshop. As I explained before in this part of the workshop you will have the opportunity to earn money. We will do four activities, which we will refer to as Activity Triangle, Activity Circle, Activity Square, and Activity Rhombus. In each of these activities, except of Activity Square, you have the possibility to earn money. Yet, only one of the activities would be selected for the final payment.

At the end of the session one of the activities will be chosen randomly for payment and your earnings will be calculated according to the results of this activity. This means that each activity can get potentially relevant for your payoff, so please make careful decisions in each activity. Some of the activities that we will be doing today are very similar that is why we ask you to read carefully each of them and follow the instructions accordingly.

\footnotetext{
${ }^{15}$ The instructions included omit the first two activities (Activity Triangle, Activity Circle) as they are part of another study. The activities were the same for all treatment and control groups.
} 


\subsubsection{Lab-in-the-Field Instructions}

Instructor: Now we will prepare our next activity. In the meantime we will show you a video. Please remain in your seat and be quiet. Please pay attention, after the video has finished you we will be asked some questions about the video and yourself.

[Individuals were randomly allocated into 3 different rooms, in each room they either watched a video of a female, male role model or a placebo video about the life in rural vs. urban areas]

Please answer the following questions. Circle the answer that best applies to what you think or feel:

1. Do you know the person in the video? $\square$ Yes $\square$ No

If your answer is "YES" please continue with question 2

If your answer is "NO" please continue with question 3

2. On a scale from 1 to 5 , where 1 is not close at all and 5 is very close, how you rate the relationship you have with the main character[s] shown in the video?

\begin{tabular}{|c|c|c|c|c|}
\hline $\begin{array}{c}1 \\
\text { Not close at all }\end{array}$ & 2 & 3 & 4 & 5 \\
Very close \\
\hline
\end{tabular}

3. On a scale from 1 to 5 where 1 means "I strongly disagree" and 5 means "I strongly agree", how much do you agree or disagree with the following statements? Please circle your answer.

3.1. "I feel motivated by the video I have just seen"

\begin{tabular}{|c|c|c|c|c|}
\hline 1 & 2 & 3 & 4 & 5 \\
Strongly disagree & Disagree & Neither agree nor disagree & Agree & Strongly agree \\
\hline
\end{tabular}

3.2. "I like the main character(s) of the video"

\begin{tabular}{|c|c|c|c|c|}
\hline 1 & 2 & 3 & 4 & 5 \\
Strongly disagree & Disagree & Neither agree nor disagree & Agree & Strongly agree \\
\hline
\end{tabular}

3.3. "I can identify with the main character(s) of the video"

\begin{tabular}{|c|c|c|c|c|}
\hline 1 & 2 & 3 & 4 & 5 \\
Strongly disagree & Disagree & Neither agree nor disagree & Agree & Strongly agree \\
\hline
\end{tabular}


3.4. "The main character(s) of the video is successful in his/her life"

\begin{tabular}{|c|c|c|c|c|}
\hline 1 & 2 & 3 & 4 & 5 \\
Strongly disagree & Disagree & Neither agree nor disagree & Agree & Strongly agree \\
\hline
\end{tabular}

3.5. "The main character(s) of the video is a person who is not afraid of taking risks."

\begin{tabular}{|c|c|c|c|c|}
\hline 1 & 2 & 3 & 4 & 5 \\
Strongly disagree & Disagree & Neither agree nor disagree & Agree & Strongly agree \\
\hline
\end{tabular}

3.6. "I think I can be as successful as the main character(s) of the video within the next ten years."

\begin{tabular}{|c|c|c|c|c|}
\hline 1 & 2 & 3 & 4 & 5 \\
Strongly disagree & Disagree & Neither agree nor disagree & Agree & Strongly agree \\
\hline
\end{tabular}

\section{Activity Square}

Instructor: Now, we will start with a new activity. We will ask you some questions on the categories: education, income, social status and assets. For every category we will provide you with a scale to help you answer the questions. You can also report higher levels than those that we suggest in the scales. Please be careful in answering the questions. Consider that when we ask you for what you would like to achieve, we aim to understand your desires, your goals; and with the question on what do you expect to achieve we would like to know the level that you think you will probably achieve.

The answers you will provide here are completely anonymous and will only be used for academic purposes. This means that neither your name, nor any other names, will be mentioned at any time. Nobody will be able to identify that you gave this information. This is not a test; therefore there are no right or wrong answers. You should answer the questions according to your opinion and current situation.

If you still do not understand the difference between what would you like to achieve and what do you expect to achieve please mark the "I still don't understand the difference" box below. If you have understood the difference please mark the "I understand the difference" box below.

I still do not understand the differences

I understand the difference 


\section{Categories Questions}

Category 1. Education:

1. To answer the following questions, please consider the scale below. You are free to report higher levels than those suggested. If you have questions please raise your hand.

Figure 4.5: Education Scale

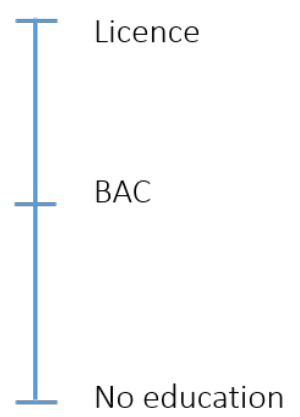

(a) What is the maximum level of education an average person in the city or village that you come from can have?

(b) What is the minimum level of education that an average person in the city or village that you come from can have?

(c) What is the education level that you have achieved until now?

(d) What is the level of education you would like to achieve in your life? (goal/desire)

(e) What is the level of education you expect to achieve in your life? (what you will probably achieve)

Category 2. Income:

1. To answer the following questions, please consider the scale below. You are free to report higher levels than those suggested. If you have questions please raise your hand.

Figure 4.6: Income Scale

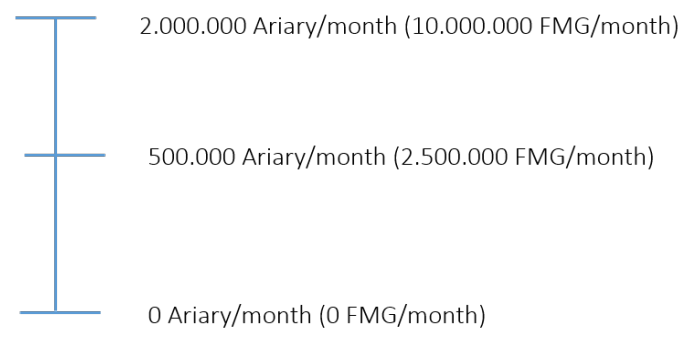


(a) What is the maximum level of average income per month that an average person in the city or village that you come from can have? (Ariary/month)

(b) What is the minimum level of average income per month that an average person in the city or village that you come from can have? (Ariary/month)

(c) What is your average income per month at the present? (Ariary/month)

(d) What is the level of average income per month you would like to achieve in your life? (goal/desire) (Ariary/month)

(e) What is the level of average income per month you expect to achieve in your life? (what you will probably achieve) (Ariary/month)

\section{Category 3. Social Status:}

1. To answer the following questions, please consider the ladder below. High social status means that your friends ask you regularly for your advice. No social status means that none of your friends asks you for your advice. You are free to report higher levels than those suggested. If you have questions please raise your hand.

Figure 4.7: Social Status Ladder

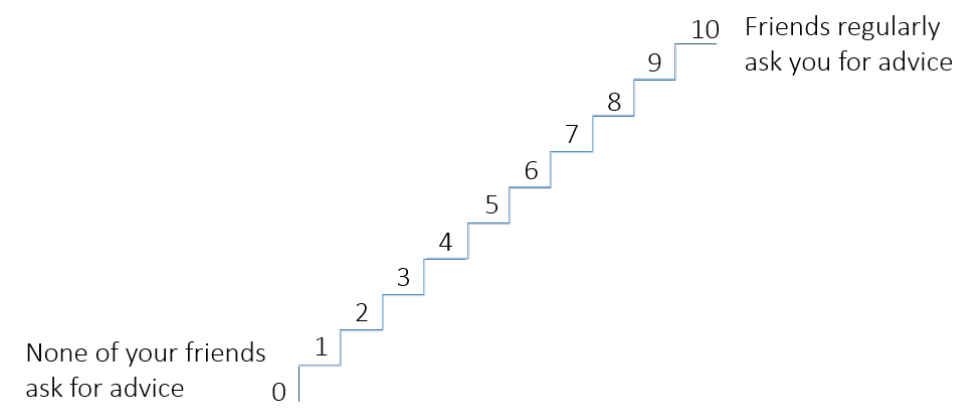

(a) What is the maximum level of social status that an average person in the city or village that you come from can have?

(b) What is the minimum level of social status that an average person in the city or village that you come from can have?

(c) What is the level of your social status at present?

(d) What is the level of social status you would like to achieve in your life? (goal/desire)

(e) What is the level of social status you expect to achieve in your life? (what you will probably achieve)

Category 4. Assets:

1. To answer the following questions, please consider the scale below. You are free to report higher levels than those suggested. If you have questions please raise your hand. 
Figure 4.8: Asset Scale

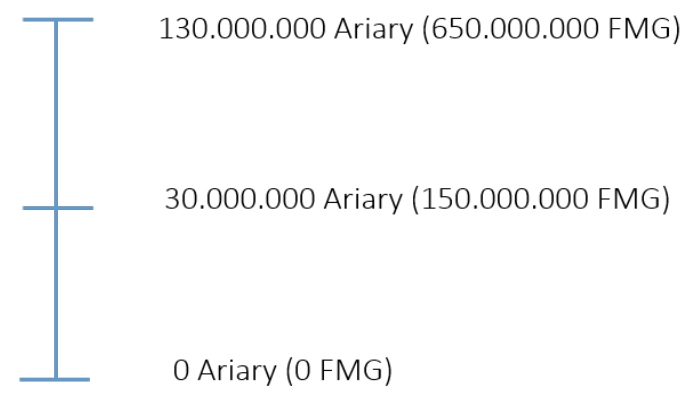

(a) What is the maximum level of assets (house and furniture, no other assets) an average person in the city or village that you come from can have? (Ariary)

(b) What is the minimum level of assets (house and furniture, no other assets) that an average person in the city or village that you come from can have? (Ariary)

(c) What is the level of assets (house and furniture, no other assets) you have at present? (Ariary)

(d) What is the level of assets (house and furniture, no other assets) you would like to achieve in your life? (goal/desire) (Ariary)

(e) What is the level of assets (house and furniture, no other assets) you expect to achieve in your life? (what you will probably achieve) (Ariary)

Now we would like you to tell us which of these four categories are the most important for you and to weight them accordingly. A small weight attributed to a category means that you do not attach any importance to it. A large weight in a category means that you attach a high importance to it.

You have 20 points that you can distribute among the categories according to the importance you attach to them.

\begin{tabular}{|l|c|}
\hline Category & Number of points (importance) \\
\hline Education & \\
\hline Income & \\
\hline Social Status & \\
\hline Assets & \\
\hline Total & $\mathbf{2 0}$ \\
\hline
\end{tabular}




\section{Activity Rhombus}

Instructor: Now we will start activity Rhombus. This activity has a total of 5 TASKs.

\section{What TASK will you be doing today?}

The TASK consists in circling and counting the 1's in matrices for 3 minutes. After you have finished counting the 1's in each matrix, you will have to write down the number of 1 's that you found. You can see this in the example.

Each one of you will receive the same pile of matrices. We will provide you with enough number of matrices so you will have the chance to solve as many as you can in the 3 minutes time, one after the other. To perform the TASK you have to start with Matrix 1 and continue with Matrix 2, 3, etc. Please follow the given order.

You will be paid according to your performance in correctly counting the 1's in the matrices. However, only one of your performances of the five TASKs will determine your earnings of this activity and it will be randomly chosen at the end of the workshop. If you still do not understand the task please raise your hand.

\section{TASK 1}

Instructor: Now, we will start TASK 1. If TASK 1 is randomly selected for payment at the end of the workshop, you will be paid 500 Ariary for each matrix that you solve correctly, meaning circling and finding the correct number of 1's in the matrix, during the 3 minutes time limit.

As you can see there are many matrices, and you have the chance to solve as many as you can, one after the other. Please start with Matrix 1 and continue with Matrix 2, 3, etc. Please follow the given order.

Once everybody has received the papers we will blow a whistle so you know that you can turn around the papers with the matrices and start the TASK. We will blow a whistle again for you to know that the time is up. Once the whistle sounds after the three minutes please put your pen aside. Please remain quiet and in your seat. Our enumerators will be collecting the papers. Do not discuss your performance with anyone else.

\section{- MATRICES-}

Instructor: Please stop counting and writing. Our enumerators will collect the TASK 1 now. Before continuing with TASK 2, please answer the question that our enumerators are distributing at the moment. 


\section{TASK 1-a}

Now please answer the following question. If your guess is correct you will be paid 1,000 Ariary.

How many matrices do think you have solved correctly during the 3 minutes time in this TASK 1 ?

\section{TASK 2}

Instructor: Now, we will start TASK 2. In this TASK you will be competing against the 3 persons who are sitting in the same row as you. This means that you will be in a group of 4 people. The person who solves more matrices correctly, meaning circling and finding the correct amount of 1's in the matrix, during the 3 minutes time will win the tournament. If TASK 2 is randomly selected for payment at the end of the workshop, the person who wins the tournament will be paid 2,000 Ariary per correct solved matrix. The persons who lose the tournament will receive nothing. If there is a tie for the first place, the winner will be selected randomly.

You will not know how many matrices your competitors have solved correctly. Therefore, you will not know whether you have won the tournament or not.

As you can see there are many matrices and you have the chance to solve as many as you can, one after the other. Please start with Matrix 1 and continue with Matrix 2, 3, etc. Please follow the given order.

Once everybody has received the papers we will blow a whistle so you know that you can turn around the papers with the matrices and start the TASK. We will blow a whistle again for you to know that the time is up. Once the whistle sounds after the three minutes please put your pen aside. Please remain quiet and in your seat. Our enumerators will be collecting the papers. Do not discuss your performance with anyone else.

\section{-MATRICES-}

Instructor: Please stop counting and writing. Our enumerators will collect the TASK 2 now. Before continuing with TASK 3, please answer the question that our enumerators are distributing at the moment.

\section{TASK 2-a}

Now please answer the following questions. If your guess is correct you will be paid 1,000 Ariary. 
How many matrices do think you have solved correctly during the 3 minutes time in this TASK 2 ?

\section{TASK 3}

Instructor: Now, will start TASK 3. In this TASK you will have the opportunity to choose the payment that you would like to have in case TASK 3 is randomly selected for payment at the end of the workshop. You can either decide to have an individual pay rate of 500 Ariary for each matrix that you solve correctly, or to enter into tournament against the persons in your group, the 3 persons sitting in the same row as you.

If you choose to enter into tournament and compete against the persons in your group, your performance in this TASK 3 will be compared with the number of matrices that each of the members of your group had solved correctly in TASK 2.

We will not provide you with the information of the scores that you have to beat. Before you make a decision, we will explain how each of the payment choices work:

Individual Pay: You will be paid 500 Ariary for each matrix that you solve correctly in TASK 3, meaning circling and finding the correct number of 1's in the matrix, during the 3 minutes time limit.

Tournament against the TASK 2 performances of the persons in your group: You will be competing against the performance the persons in your group had in TASK 2.

If in this TASK 3 you solve more matrices correctly than the persons in your group had in TASK 2, you will win the tournament and you will be paid 2,000 Ariary for each matrix that you solve correctly in this TASK. If you solve fewer matrices correctly than the persons in your group had in TASK 2, you will receive nothing.

You will not know how many matrices your competitors have solved correctly in TASK 2. Therefore, you will not know whether you have won the tournament or not. If there is a tie for the first place, the winner will be selected randomly.

Before performing the TASK you first have to decide which of the two payment choices you would prefer to have for this TASK. Please mark an X only in one of the options. Your decision will not influence the payoff of the other participants as you will compete against their past performance. Now, our enumerators will start distributing the decision sheet for the TASK 3. 


\section{Decision sheet TASK 3}

Now you will have the opportunity to choose the payment that you would like to have for this TASK 3. You can either decide to have an individual pay rate of 500 Ariary for each matrix that you solve correctly, or to enter into tournament against the persons in your group, the 3 persons sitting in the same row as you.

If you choose to enter into tournament and compete against the persons in your group, your performance in this TASK 3 will be compared with the number of matrices that each of the members of your group had solved correctly in TASK 2. We will not provide you with the information of the scores that you have to beat.

The payment choices are the following:

Individual Pay: You will be paid 500 Ariary for each matrix that you solve correctly in TASK 3, meaning circling and finding the correct number of 1's in the matrix, during the 3 minutes time limit.

Tournament against the TASK 2 performances of the persons in your group: You will be competing against the performance the persons in your group had in TASK 2.

If in this TASK 3 you solve correctly more matrices than the persons in your group had in TASK 2, you will win the tournament and you will be paid 2,000 Ariary for each matrix that you solve correctly in this TASK 3. If you solve fewer matrices correctly than the persons in your group had in TASK 2, you will receive nothing.

You will not know how many matrices your competitors have solved correctly in TASK 2. Therefore, you will not know whether you have won the tournament or not. If there is a tie for the first place, the winner will be selected randomly.

Which payment do you prefer for TASK 3? Please mark an X only in one of the options below. Your decision will not influence the payoff of the other participants as you will compete against their past performance.

\begin{tabular}{|c|l|c|}
\hline Option & \multicolumn{1}{|c|}{ Payment } & $\begin{array}{c}\text { Your decision } \\
\text { (mark an X in one option) }\end{array}$ \\
\hline Individual Pay & $\begin{array}{l}500 \text { Ariary for each correctly } \\
\text { solved matrix }\end{array}$ & \\
\hline $\begin{array}{c}\text { Tournament against the } \\
\text { performance of the people in } \\
\text { your group in TASK 2 }\end{array}$ & $\begin{array}{l}\text { If you win: 2,000 Ariary for each } \\
\text { correctly solved matrix } \\
\text { If you do not win: 0 Ariary }\end{array}$ & \\
\hline
\end{tabular}


Instructor: Now, our enumerators will start distributing the papers for TASK 3. In this TASK you chose already which payment option you would like to have for your performance in this TASK in case it is randomly selected for payment at the end of the workshop. As you can see there are many matrices [show pile of papers] and you have the chance to solve as many as you can, one after the other. Please start with Matrix 1 and continue with Matrix 2, 3, etc. Please follow the given order. Once everybody has received the papers we will blow a whistle so you know that you can turn around the papers with the matrices and start the TASK. We will blow a whistle again for you to know that the time is up. Once the whistle sounds after the three minutes please put your pen aside. Please remain quiet and in your seat. Our enumerators will be collecting the papers. Do not discuss your performance with anyone else.

\section{-MATRICES-}

Instructor: Please stop counting and writing. Our enumerators will collect the TASK 3 now. Before continuing with TASK 4, please answer the question that our enumerators are distributing at the moment.

\section{TASK 3-a}

Now please answer the following question. If your guess is correct you will be paid 1,000 Ariary.

How many matrices do think you have solved correctly during the 3 minutes time in this TASK 3 ?

\section{TASK 4}

Instructor: Now we will start TASK 4. In this TASK 4 you do not have to solve matrices. You only have to decide which payment you would like to receive for your performance in TASK 1. You can either decide to have an individual pay rate of 500 Ariary for each matrix that you solve correctly or to enter into tournament against the persons in your group, the 3 persons sitting in the same row as you.

If you choose to enter into tournament and compete against the persons in your group, your performance in this round will be compared with the number of matrices that each of the members of your group had solved correctly in TASK 1.

We will not provide you with the information of the scores that you have to beat. We will just remind you about the number of matrices that you believed you solved correctly in TASK 1. 
Before you make a decision, we will explain how each of the payment choices work:

Individual Pay: You will be paid 500 Ariary for each matrix that you solve correctly in TASK 1.

Tournament against the TASK 1 performances of the persons in your group: You will be competing against the performance the persons in your group had in TASK 1.

If in TASK 1 you solved more matrices correctly than the persons in your group had in TASK 1, you will win the tournament and you will be paid 2,000 Ariary for each matrix that you solved correctly in TASK 1 . If you solved fewer matrices correctly than the persons in your group had in TASK 1, you will receive nothing.

You will not know how many matrices your competitors have solved correctly in TASK 1. Therefore, you will not know whether you have won the tournament or not. If there is a tie for the first place, the winner will be selected randomly.

Now our enumerators will give back the paper where you stated your beliefs for TASK 1 in order to help you to make the decision for this TASK. 


\section{Decision sheet TASK 4}

In the paper you have just received, you will find your belief of the correct matrices that you have solved in TASK 1. Please have a look at it before answering the question below.

In this TASK 4 you will have the opportunity to choose the payment that you would like to have for TASK 1. You can either decide to have an individual pay rate of 500 Ariary per correctly solved matrix or to enter into tournament against the persons in your group, the 3 persons sitting in the same row as you.

If you choose to enter into tournament and compete against the persons in your group, your performance in TASK 1 will be compared with the number of matrices that each of the members of your group had solved correctly in TASK 1.

We will not provide you with the information of the scores that you have to beat. The payment choices are the following:

Individual Pay: You will be paid 500 Ariary for each matrix that you solved correctly in TASK 1 during the 3 minutes time limit.

Tournament against the TASK 1 performances of the persons in group: You will be competing against the performance the persons in your group had in TASK 1.

If in TASK 1 you solved more matrices correctly than the persons in your group had in TASK 1, you will win the tournament and you will be paid 2,000 Ariary for each matrix that you solved correctly in TASK 1.

You will not know how many matrices your competitors have solved correctly in TASK 1. Therefore, you will not know whether you have won the tournament or not. If there is a tie for the first place, the winner will be selected randomly.

Which payment would you like to receive for your performance in TASK 1 ?

Please mark an $\mathrm{X}$ only in one of the options below. Your decision will not influence the payoff of the other participants as you will compete against their past performance.

\begin{tabular}{|c|l|l|}
\hline Option & \multicolumn{1}{|c|}{ Payment } & $\begin{array}{c}\text { Your decision } \\
\text { (mark an X in one option) }\end{array}$ \\
\hline Individual Pay & $\begin{array}{l}\text { 500 Ariary for each correctly } \\
\text { solved matrix }\end{array}$ & \\
\hline $\begin{array}{c}\text { Tournament against the } \\
\text { performance of the people in } \\
\text { your group in TASK 1 }\end{array}$ & $\begin{array}{l}\text { If you win: 2,000 Ariary for each } \\
\text { correctly solved matrix } \\
\text { If you do not win: 0 Ariary }\end{array}$ & \\
\hline
\end{tabular}




\section{TASK 5}

Instructor: Now, will start TASK 5. In this TASK you will have the opportunity to choose the payment that you would like to have in case TASK 5 is randomly selected for payment at the end of the workshop. You can either decide to have an individual pay rate of 500 Ariary for each matrix that you solve correctly or to enter into tournament against yourself.

If you choose to enter into tournament against yourself, your performance in this TASK 5 will be compared with the number of matrices that you solved correctly in TASK 2 .

We will not provide you with the information of the score that you have to beat. We will just remind you about the number of matrices that you believed you solved correctly in TASK 2.

Before you make a decision, we will explain how each of the payment choices work:

Individual Pay: You will be paid 500 Ariary for each matrix that you solve correctly in this TASK 5, meaning circling and finding the correct number of 1 's in the matrix, during the 3 minutes time limit.

Tournament against your TASK 2 performance: You will be competing against yourself in a tournament. In TASK 2 you might have solved certain number of matrices correctly and in this tournament against yourself you will have the possibility to improve your score.

If you solve more correct matrices in TASK 5 than in TASK 2 you will win the tournament against yourself and therefore you will be paid 2,000 Ariary for each matrix that you solve correctly in this TASK 5. If you have the same or less correct matrices in TASK 5 than in TASK 2 you will not win the tournament against yourself and therefore you will receive nothing. Like in the tasks before, you will not know whether you have won the tournament or not.

Before performing the TASK you first have to decide which of the two payment choices you would prefer to have for this TASK. Please mark an X only in one of the options. Now, our enumerators will start distributing the decision sheet for the TASK 5. 


\section{Decision sheet TASK 5}

In the paper you have just received, you will find your belief of the correct matrices that you have solved in TASK 2. Please have a look at it before answering the question below.

Now you will have the opportunity to choose the payment that you would like to have for this TASK 5. You can either decide to have an individual pay rate of 500 Ariary for each matrix that you solve correctly in this task, or to enter into tournament against yourself.

If you choose to enter into tournament and compete against yourself, your performance in this TASK 5 will be compared with the number of matrices that you solved correctly in TASK 2.

We will not provide you with the information of the score that you have to beat. The payment choices are the following:

Individual Pay: You will be paid 500 Ariary for each matrix that you solve correctly in TASK 5, meaning circling and finding the correct number of 1's in the matrix, during the 3 minutes time limit.

Tournament against your TASK 2 performance: You will be competing against yourself in a tournament. In TASK 2 you might have solved certain number of matrices correctly and in this tournament against yourself you will have the possibility to improve your score.

If you solve more correct matrices in TASK 5 than in TASK 2 you will win the tournament against yourself and therefore you will be paid 2,000 Ariary for each matrix that you solve correctly in this TASK 5. If you have the same or less correct matrices in TASK 5 than in TASK 2 you will not win the tournament against yourself and therefore you will receive nothing. Like in the tasks before, you will not know whether you have won the tournament or not.

Which payment do you prefer for TASK 5? Please mark an X only in one of the options below.

\begin{tabular}{|c|l|l|}
\hline Option & \multicolumn{1}{|c|}{ Payment } & $\begin{array}{c}\text { Your decision } \\
\text { (mark an X in one option) }\end{array}$ \\
\hline Individual Pay & $\begin{array}{l}\text { 500 Ariary for each correctly } \\
\text { solved matrix }\end{array}$ & \\
\hline Tournament against yourself & $\begin{array}{l}\text { If you win: 2,000 Ariary for each } \\
\text { correctly solved matrix } \\
\text { If you do not win: 0 Ariary }\end{array}$ & \\
\hline
\end{tabular}


Instructor: Now, our enumerators will start distributing the papers for TASK 5 . In this TASK you chose already which payment option you would like to have for your performance in this TASK in case it is randomly selected for payment at the end of the workshop.

As you can see there are many matrices and you have the chance to solve as many as you can, one after the other. Please start with Matrix 1 and continue with Matrix 2, 3, etc. Please follow the given order.

Once everybody has received the papers we will blow a whistle so you know that you can turn around the papers with the matrices and start the TASK.

We will blow a whistle again for you to know that the time is up. Once the whistle sounds after the three minutes please put your pen aside. Please remain quiet and in your seat. Our enumerators will be collecting the papers. Do not discuss your performance with anyone else.

\section{- MATRICES-}

Instructor: Please stop counting and writing. Our enumerators will collect the TASK 5 now. Before continuing, please answer the question that our enumerators are distributing at the moment.

\section{TASK 5-a}

Now please answer the following question. If your guess is correct you will be paid 1,000 Ariary.

How many matrices do think you have solved correctly during the 3 minutes time in this TASK 5 ?

\section{- END OF TASKS-}

Instructor: Before finishing this activity, we will distribute some question to you now. With each question that you solve correctly you will earn 1,000 Ariary.

\section{Please answer the following questions. For each correct answer you are go- ing to be paid 1,000 Ariary.}

1. When you think of TASK 1 where you were payed for each correctly solved matrix 500 Ariary. Which rank do you believe you had in comparison to the other 3 people in your group? 1 is the best performing student in your group of 4 people and 4 is the worst performing student in the same group of people. 
I ranked - out of 4

2. When you think of TASK 2 where you competed against the other persons in your group. Which rank do you believe you had in comparison to the other 3 people in your group? 1 is the best performing student in your group of 4 people and 4 is the worst performing student in the same group of people.

I ranked - out of 4

3. On average, how many matrices do you think that the others in your session (all participants in the room) solved correctly in the different tasks?

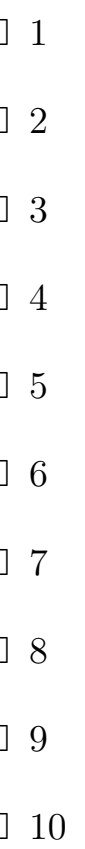

4. How many people in your group of 4 do you think chose to compete in TASK 3 ?

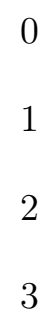




\section{End}

Instructor: Now, in order to select which activity will be used as your payment, one of you will take out one card of this non-transparent bag. According to the name written on the card we will pay each of you the earnings of that activity according to the decisions you made. For example if the name "Activity Triangle" comes up, we will pay you what you earned in that activity, if the name "Activity Rhombus" comes up, then we will pay what you earned in that activity. Same with "Activity Circle". As mentioned before, Activity Square will not be paid and thus will not be included in the bag.

If the result of the bag is Activity Rhombus, then we will use an extra bag to decide which TASK will be used to calculate the earnings of that activity. Remember that in Activity Rhombus we had 5 different TASKs; however, only one of them will be paid. Therefore, the same person that comes to the front will randomly select the TASK that we will be using to calculate your earnings. In this other bag there are 5 small and equal papers. Each paper has a number from 1 to 5 written on it. This will guarantee that only one TASK will be picked for the payment calculation of Activity Rhombus in case it is selected. Please remember that you can receive also nothing, for example, if the TASK selected is TASK 2 and you lost the competition in this TASK.

In addition to the amount you earn from the Activity selected, each of you will receive 2,000 Ariary as a bonus for your participation today. As we mentioned in the beginning, today you will receive the 2,000 Ariary and in one week we will come back to give you the money that you possibly earned in the Activity selected.

In the name of Diversity Turn, I want to thank you very much for your time and collaboration today.

While we prepare the bonus payment, please fill the questionnaire my colleagues are giving to you at the moment. Once you have finished you will receive the bonus payment for your participation today. 


\subsubsection{Survey}

\section{Participant No.}

Hello! We are researchers from the University of Goettingen and we are investigating about vanilla production and the decisions students make under different incentive schemes in the SAVA region. Today, we kindly ask for your cooperation by filling this questionnaire. The answers you will provide here are completely anonymous and will only be used for academic purposes. This means that neither your name, nor any other names, will be mentioned at any time. Nobody will be able to identify that you gave this information. This is not a test; therefore there are no right or wrong answers. The answers should only correspond to your reality or your opinion. In name of the University we thank you very much for your time and collaboration.

1. Did you have difficulties in answering one or more of the activities you did today? Please mark your answer with an X.

$$
\begin{aligned}
& \square \text { Yes } \\
& \square \text { No }
\end{aligned}
$$

If yes, in which one(s)?

2. Did you understand the instructions of the activity?

Please mark your answer with an X.

$$
\begin{aligned}
& \text { Yes } \\
& \text { No }
\end{aligned}
$$

3. Did you get exhausted as time in the experiment went by, so that you could concentrate less?

Please mark your answer with an X.
Yes
Yes, a little
No 
4. Which track are you studying?

Please mark your answer with an X.

$\square$ A1

$\square \mathrm{A} 2$

$\square \mathrm{C}$

$\square \mathrm{D}$

5. Which occupation do you want to have in the future? Please indicate:

6. In how many years do you expect you will achieve to work in your desired occupation? YEARS

7. How likely is it that you will work in your desired occupation?

Please mark your answer with an $\mathrm{X}$.

\begin{tabular}{|c|c|c|c|c|}
\hline 1 & 2 & 3 & 4 & 5 \\
Very unlikely & Unlikely & 50 percent likely & Likely & Very likely \\
\hline
\end{tabular}

8. How likely is it that you go to University?

Please mark your answer with an X.

\begin{tabular}{|c|c|c|c|c|}
\hline 1 & 2 & 3 & 4 & 5 \\
Very unlikely & Unlikely & 50 percent likely & Likely & Very likely \\
\hline
\end{tabular}

9. How likely is it that destiny, good or bad luck or other people affect your chances to work in your desired occupation?

Please mark your answer with an X.

\begin{tabular}{|c|c|c|c|c|}
\hline 1 & 2 & 3 & 4 & 5 \\
Very unlikely & Unlikely & 50 percent likely & Likely & Very likely \\
\hline
\end{tabular}

10. What is the highest school degree your mother has?

Please mark your answer with an X.

No education

Primary education

Secondary education

University degree 
11. What is the highest school degree your father has?

Please mark your answer with an X.

No education

$\square$ Primary education

Secondary education

$\square$ University degree

12. At which age would you like to get married?

YEARS

13. How often do you meet other people who are not at your school and who are not from your family?

Please mark your answer with an X.

\begin{tabular}{|c|c|c|c|c|}
\hline 1 & 2 & 3 & 4 & 5 \\
Never & Once a year & Once a month & Once a week & Every day \\
\hline
\end{tabular}

14. How often do you use a smartphone?

Please mark your answer with an X.

\begin{tabular}{|c|c|c|c|c|}
\hline 1 & 2 & 3 & 4 & 5 \\
Never & Once a year & Once a month & Once a week & Every day \\
\hline
\end{tabular}

15. Do you have a person you look up to?

Please mark your answer with an X.

$\square$ Yes

$\square$ No

(a) If yes, specify the gender: $\square$ Female $\quad \square$ Male

(b) If yes, specify the location where she/he lives:

(c) If no, go to question 16 .

16. On a scale from 1 to 5 , where 1 is strongly disagree and 5 is strongly agree, how much you agree or disagree with the following sentences. Please mark your answer with an $\mathrm{X}$.

(a) "To follow a career is more typical for men.

\begin{tabular}{|c|c|c|c|c|}
\hline 1 & 2 & 3 & 4 & 5 \\
Strongly disagree & Disagree & Neither agree nor disagree & Agree & Strongly agree \\
\hline
\end{tabular}

(b) "Women can generally achieve their occupational goals."

\begin{tabular}{|c|c|c|c|c|}
\hline 1 & 2 & 3 & 4 & 5 \\
Strongly disagree & Disagree & Neither agree nor disagree & Agree & Strongly agree \\
\hline
\end{tabular}


(c) "Men are typically performing better in competitive tasks."

\begin{tabular}{|c|c|c|c|c|}
\hline 1 & 2 & 3 & 4 & 5 \\
Strongly disagree & Disagree & Neither agree nor disagree & Agree & Strongly agree \\
\hline
\end{tabular}

(d) "Men are better at counting 1's in matrices."

\begin{tabular}{|c|c|c|c|c|}
\hline 1 & 2 & 3 & 4 & 5 \\
Strongly disagree & Disagree & Neither agree nor disagree & Agree & Strongly agree \\
\hline
\end{tabular}

(e) "Men believe that women are less able to count 1's in matrices."

\begin{tabular}{|c|c|c|c|c|}
\hline 1 & 2 & 3 & 4 & 5 \\
Strongly disagree & Disagree & Neither agree nor disagree & Agree & Strongly agree \\
\hline
\end{tabular}

(f) How do you like to be in competition with somebody else? Please tick a box on the scale, where the value 1 means: 'I do not like this' and the value 5 means: 'I like it very much':

\begin{tabular}{|c|c|c|c|c|}
\hline 1 & 2 & 3 & 4 & 5 \\
I do not like this & & & & I like it very much \\
\hline
\end{tabular}

17. Are you generally willing to take risks, or do you try to avoid risks? Please mark your answer with an X. In the scale the value 1 means: "Not willing to take a risk" and the value 10 means 'fully prepared to take risks'.

\begin{tabular}{|c|c|c|c|c|c|c|c|c|c|}
\hline $\begin{array}{c}1 \\
\text { Not willing } \\
\text { to take a risk }\end{array}$ & 2 & 3 & 4 & 5 & 6 & 7 & 8 & 9 & $\begin{array}{c}10 \\
\text { Fully prepare } \\
\text { to take risks }\end{array}$ \\
\hline
\end{tabular}

18. Suppose you were given the choice between receiving some money today or some money in one year. We will present to you three different situations. For each of these situations we would like to know which option you would choose. These situations are hypothetical. Please mark your answer with an X.

(a) Would you rather receive 100,000 Ariary today or 150,000 Ariary in 1 year?

$\square$ Today

$\square$ In one year

(b) Would you rather receive 100,000 Ariary today or 125,000 Ariary in 1 year?

Today

In one year

(c) Would you rather receive 100,000 Ariary today or 105,000 Ariary in 1 year?

Today

In one year 
19. Imagine a coin is flipped six times. Before each time, a lottery is offered to you and you could decide whether you want to accept or reject it. The amount that could be won is the same in all lotteries, while the amount that could be lost increases. Please decide whether you would accept or reject each of the following lotteries. As the amount that could be lost increases along the lotteries, you can only switch from "Accept" to "Reject" once. Please mark your answer with an X.

\begin{tabular}{|c|c|c|}
\hline Hypothetical Lottery & Accept & Reject \\
\hline $\begin{array}{l}\# 1 \text {. If the coin turns head up, then you would lose 1,000 Ariary; } \\
\text { if the coin turns up tails, you would win } 3,000 \text { Ariary }\end{array}$ & & \\
\hline $\begin{array}{l}\# 2 \text {. If the coin turns head up, then you would lose } 1,500 \text { Ariary; } \\
\text { if the coin turns up tails, you would win } 3,000 \text { Ariary }\end{array}$ & & \\
\hline $\begin{array}{l}\# 3 \text {. If the coin turns head up, then you would lose } 2,000 \text { Ariary; } \\
\text { if the coin turns up tails, you would win } 3,000 \text { Ariary }\end{array}$ & & \\
\hline $\begin{array}{l}\text { \#4. If the coin turns head up, then you would lose } 2,500 \text { Ariary; } \\
\text { if the coin turns up tails, you would win } 3,000 \text { Ariary }\end{array}$ & & \\
\hline $\begin{array}{l}\# 5 \text {. If the coin turns head up, then you would lose } 3,000 \text { Ariary; } \\
\text { if the coin turns up tails, you would win } 3,000 \text { Ariary }\end{array}$ & & \\
\hline $\begin{array}{l}\# 5 \text {. If the coin turns head up, then you would lose } 3,500 \text { Ariary; } \\
\text { if the coin turns up tails, you would win } 3,000 \text { Ariary }\end{array}$ & & \\
\hline
\end{tabular}

20. Rate your degree of confidence by writing down a number from 1 to 10 using the scale given below.

\begin{tabular}{|c|c|c|c|c|c|c|c|c|c|}
\hline $\begin{array}{c}1 \\
\begin{array}{c}\text { Cannot do } \\
\text { at all }\end{array}\end{array}$ & 2 & 3 & 4 & 5 & 6 & 7 & 8 & 9 & $\begin{array}{c}10 \\
\text { Highly certain } \\
\text { can do }\end{array}$ \\
\hline
\end{tabular}

Confidence (1-10)

a) Learn general mathematics

b) Learn biology

c) Learn reading, writing, and language skills

d) Learn to use computers

e) Learn science

f) Learn a foreign language

h) Learn social studies

21. Please rate the truthfulness of the following statements, according to how you see yourself. On the scale, 1 means 'not true of myself' and 5 means 'true of myself'. Please mark your answer with an $\mathrm{X}$.

(a) I can always manage to solve difficult problems if I try hard enough.

\begin{tabular}{|c|c|c|c|c|}
\hline 1 & 2 & 3 & 4 & 5 \\
Not true of myself & Slightly true of myself & Half true of myself & Mostly true of myself & True of myself \\
\hline
\end{tabular}


(b) If someone opposes me, I can find the means and ways to get what I want.

\begin{tabular}{|c|c|c|c|c|}
\hline 1 & 2 & 3 & 4 & 5 \\
Not true of myself & Slightly true of myself & Half true of myself & Mostly true of myself & True of myself \\
\hline
\end{tabular}

(c) It is easy for me to stick to my aims and accomplish my goals.

\begin{tabular}{|c|c|c|c|c|}
\hline 1 & 2 & 3 & 4 & 5 \\
Not true of myself & Slightly true of myself & Half true of myself & Mostly true of myself & True of myself \\
\hline
\end{tabular}

(d) I am confident that I could deal with unexpected events.

\begin{tabular}{|c|c|c|c|c|}
\hline 1 & 2 & 3 & 4 & 5 \\
Not true of myself & Slightly true of myself & Half true of myself & Mostly true of myself & True of myself \\
\hline
\end{tabular}

(e) Thanks to my resourcefulness, I know how to handle unforeseen situations.

\begin{tabular}{|c|c|c|c|c|}
\hline 1 & 2 & 3 & 4 & 5 \\
Not true of myself & Slightly true of myself & Half true of myself & Mostly true of myself & True of myself \\
\hline
\end{tabular}

(f) I can solve most problems if I invest the necessary effort.

\begin{tabular}{|c|c|c|c|c|}
\hline 1 & 2 & 3 & 4 & 5 \\
Not true of myself & Slightly true of myself & Half true of myself & Mostly true of myself & True of myself \\
\hline
\end{tabular}

(g) I can remain calm when facing difficulties because I can rely on my abilities to reduce stress.

\begin{tabular}{|c|c|c|c|c|}
\hline 1 & 2 & 3 & 4 & 5 \\
Not true of myself & Slightly true of myself & Half true of myself & Mostly true of myself & True of myself \\
\hline
\end{tabular}

(h) When I have problems, usually think of a solution.

\begin{tabular}{|c|c|c|c|c|}
\hline 1 & 2 & 3 & 4 & 5 \\
Not true of myself & Slightly true of myself & Half true of myself & Mostly true of myself & True of myself \\
\hline
\end{tabular}

(i) If I am in trouble, I can usually think of a solution.

\begin{tabular}{|c|c|c|c|c|}
\hline 1 & 2 & 3 & 4 & 5 \\
Not true of myself & Slightly true of myself & Half true of myself & Mostly true of myself & True of myself \\
\hline
\end{tabular}

(j) I can usually handle whatever comes on my way.

\begin{tabular}{|c|c|c|c|c|}
\hline 1 & 2 & 3 & 4 & 5 \\
Not true of myself & Slightly true of myself & Half true of myself & Mostly true of myself & True of myself \\
\hline
\end{tabular}

22. In the following you will be presented with a pair of two statements: A and B. Please state for each pair with which statement you agree most. Please mark your answer with an X. 
(a) A: Many of the unhappy things in people's lives are partly due to bad luck.

B: People's misfortunes result from the mistakes they make.

\begin{tabular}{|c|c|c|c|}
\hline 1 & 2 & 3 & 4 \\
I agree much more & I agree slightly more & I agree slightly more & I agree much more \\
with A & with A & with B & with B \\
\hline
\end{tabular}

(b) A: In the case of the well prepared student there is rarely if ever such a thing as an unfair test.

B: Many times exam questions tend to be so unrelated to course work that studying is really useless.

\begin{tabular}{|c|c|c|c|}
\hline 1 & 2 & 3 & 4 \\
I agree much more & I agree slightly more & I agree slightly more \\
with A & with A & with B & wree much more \\
\end{tabular}

(c) A: Becoming a success is a matter of hard work, luck has little or nothing to do with it.

B: Getting a good job depends mainly on being in the right place at the right time.

\begin{tabular}{|c|c|c|c|}
\hline 1 & 2 & 3 & 4 \\
I agree much more & I agree slightly more \\
with A & with A & I agree slightly more & I agree much more \\
with B & with B \\
\hline
\end{tabular}

(d) A: When I make plans, I am almost certain that I can make them work.

B: It is not always wise to plan too far ahead because many things turn out to be a matter of good or bad fortune anyhow.

\begin{tabular}{|c|c|c|c|}
\hline 1 & 2 & 3 & 4 \\
I agree much more & I agree slightly more \\
with A & with A & I agree slightly more & I agree much more \\
with B & with B \\
\hline
\end{tabular}

(e) A: Sometimes I can't understand how teachers arrive at the grades they give.

B: There is a direct connection between how hard I study and the grades I get.

\begin{tabular}{|c|c|c|c|}
\hline 1 & 2 & 3 & 4 \\
\hline $\begin{array}{l}\text { I agree much more } \\
\text { with A }\end{array}$ & $\begin{array}{c}\text { I agree slightly more } \\
\text { with A }\end{array}$ & $\begin{array}{c}\text { I agree slightly more } \\
\text { with B }\end{array}$ & $\begin{array}{c}\text { I agree much more } \\
\text { with B }\end{array}$ \\
\hline
\end{tabular}

(f) A: What happens to me is my own doing.

B: Sometimes I feel that I don't have enough control over the direction my life is taking.

\begin{tabular}{|c|c|c|c|}
\hline 1 & 2 & 3 & 4 \\
$\begin{array}{c}\text { I agree much more } \\
\text { with A }\end{array}$ & $\begin{array}{c}\text { I agree slightly more } \\
\text { with A }\end{array}$ & $\begin{array}{c}\text { I agree slightly more } \\
\text { with B }\end{array}$ & $\begin{array}{c}\text { I agree much more } \\
\text { with B }\end{array}$ \\
\hline
\end{tabular}


23. With how many people in your group are you friends with? Please mark your answer with an $\mathrm{X}$.
0
1
2
3

24. In which year were you born?

25. Where have you been raised? Please mark your answer with an X.

In a big city

In the rural area

26. What is your gender? Please mark your answer with an X. $\quad \square$ Female $\quad \square$ Male

27. How many brothers do you have? Please write how many.

28. How many sisters do you have? Please write how many.

29. Please indicate your economic situation on a scale from 1 to 5 , where 1 means 'poor' and 5 'wealthy'. Please mark your answer with an X.

\begin{tabular}{|c|c|c|c|c|}
\hline 1 & 2 & 3 & 4 & $\begin{array}{c}5 \\
\text { Wealthy }\end{array}$ \\
\hline
\end{tabular}

30. Do you have a job? Please mark your answer with an X.

$\square$ Yes

No

31. How many hours a week do you work? hours per week

32. Does your family cultivate vanilla? Please mark your answer with an X.

Yes

$\square$ No

33. How often do you go to the market to buy food? Please mark your answer with an X.

\begin{tabular}{|c|c|c|c|c|}
\hline 1 & 2 & 3 & 4 & 5 \\
Never & Once a year & Once a month & Once a week & Every day \\
\hline
\end{tabular}

34. What is your name:

Thank you very much for your participation! 


\subsubsection{Field Experiment Instructions - Job Announcement}

[Researcher enters the room and communicates the following:]

Thank you very much for your participation today! Before you go, I would like to share with you some information about a job opening in our research project. In my work I visit different villages from the SAVA region and I am in contact with vanilla farmers. For my next visit, I am looking for assistants and a coordinator to work with me. The job will be starting this year in October until December [starting next year in May until June]. In this paper that I will distribute to all of you, you can find more information about the jobs and application process. 


\section{$\underline{\text { JOB ANNOUNCEMENT }-P U B L I C \text { Decision Sheet }}$}

Before finishing the workshop of today, we would like to inform you about a job opening at our research project. Our project works with vanilla farmers in the SAVA region. We are looking for assistants and a coordinator who help us with our data collection starting this year in October until December [starting next year in May until June]. During the data collection we will do different workshops with the farmers. The job of the assistant consists in helping with the organization of the workshops and to fill in questionnaires with different farmers once the workshop is finished. The job of the coordinator is to visit the villages and plan the workshops in advance with the village chief. As the coordinator has more responsibilities than the assistant, the salary of the coordinator is 13 percent higher. The candidates for each position should be motivated to work in rural areas, be good team members and have good communications skills. Fluency in French or English is ideal but not a must.

If you are interested in applying for the job and want to know more about it please mark in the box below that you are interested. Once we have collected the decisions of all the people in the room we will call your name out loud to confirm that you are interested in applying for the job. If you mark that you are not interested, your name will not be called. Please remain in your seat and don't discuss your decision with the people around you.

Are you interested in applying for the job?

I am interested

I am not interested

If you are interested in the job, for which position exactly?

\section{Assistant}

\section{Coordinator}

For those who are interested, we will collect your name, E-Mail address and/or phone number and when we come back next week to give you your additional earnings of the workshop, you will have to fill in a job application. If you mark that you are not interested you will not have to fill in a job application next week. Your name, E-mail and/or telephone numbers will only be used for the job selection process. If you are interested in applying, please write down your name, E-Mail address/ telephone number here:

Name:

Email/Telephone number:

Your name, E-mail and/or telephone numbers will only be used for the job selection process. 


\section{JOB ANNOUNCEMENT - PRIVATE Decision Sheet}

Before finishing the workshop of today, we would like to inform you about a job opening at our research project. Our project works with vanilla farmers in the SAVA region. We are looking for assistants and a coordinator who help us with our data collection starting this year in October until December [starting next year in May until June]. During the data collection we will do different workshops with the farmers. The job of the assistant consists in helping with the organization of the workshops and to fill in questionnaires with different farmers once the workshop is finished. The job of the coordinator is to visit the villages and plan the workshops in advance with the village chief. As the coordinator has more responsibilities than the assistant, the salary of the coordinator is 13 percent higher. The candidates for each position should be motivated to work in rural areas, be good team members and have good communications skills. Fluency in French or English is ideal but not a must.

If you are interested in applying for the job and want to know more about it, please mark in the box below that you are interested. If you are not interested please mark in the box below that you are not interested. Your decision will not be shared with anybody in the room. Please remain in your seat and don't discuss your decision with the people around you.

Are you interested in applying for the job?

I am interested

I am not interested

If you are interested in the job, for which position exactly?

\section{Assistant}

\section{Coordinator}

For those who are interested, we will collect your name, E-Mail address and/or phone number and when we come back next week to give you your additional earnings of the workshop, you will have to fill in a job application. If you mark that you are not interested you will not have to fill in a job application next week. If you are interested in applying, please write down your name, E-Mail address/ telephone number here:

Name:

Email/Telephone number:

Your name, E-mail and/or telephone numbers will only be used for the job selection process. 
[After students have filled one of the decision sheets, the researcher tells them the following:]

Thank you for your time. As we mentioned before, in exactly one week we will be here at the same time to distribute the earnings of activity $\mathrm{X}$ [activity randomly selected for payment]. In addition, for those who expressed their interest in any of the job positions, we will bring the application forms on that day so you can fill them with your personal information. It is important that you bring one photo of you, as we will attached it to the application form. Please do not forget to bring the photo, otherwise your application will not be taken into account for the selection process. Now, please make a line at the front so each of you can receive the 2,000 Ariary for your participation today. 


\subsubsection{Job Application Form}

\section{Diversity Turn}

in Land Use Science

\begin{tabular}{|c|c|}
\hline Full Name: & \\
\hline Date of Birth: & \\
\hline Phone Number: & \\
\hline Email Address: & \\
\hline Where do you live? & \\
\hline $\begin{array}{l}\text { Would you be able to find accommodation } \\
\text { in Sambava for this job? }\end{array}$ & \\
\hline Date available to start: & \\
\hline Track of study: & \\
\hline Average grade Terminal (last year of school): & \\
\hline Lanouru skills. & English: $\square$ Very good $\quad \square$ Good $\quad \square$ So so $\quad \square$ Not good \\
\hline Language skills: & French: $\square$ Very good $\quad \square$ Good $\quad \square$ So so $\quad \square$ Not good \\
\hline $\begin{array}{l}\text { Did you hear about the project before we } \\
\text { visited you school? }\end{array}$ & $\square$ Yes $\quad \square$ No \\
\hline What are your salary expectations? & \\
\hline Do you like working in a team? & $\square$ Yes $\quad \square$ No \\
\hline $\begin{array}{l}\text { Do you have health problems that might } \\
\text { impede you to travel by car or moto? }\end{array}$ & $\begin{array}{l}\square \text { Yes } \quad \square \text { No } \\
\text { If yes, which ones? }\end{array}$ \\
\hline Have you worked in the past? & $\square$ Yes $\quad \square$ No \\
\hline Where have you worked before and for how long? & $\begin{array}{l}\text { Place: } \\
\text { Duration of work: }\end{array}$ \\
\hline & $\begin{array}{l}\text { Place: } \\
\text { Duration of work: }\end{array}$ \\
\hline Please list three references and their contract information & $\begin{array}{l}\text { Name: } \\
\text { Telephone number: } \\
\text { Relation to you: }\end{array}$ \\
\hline & $\begin{array}{l}\text { Name: } \\
\text { Telephone number: } \\
\text { Relation to you: }\end{array}$ \\
\hline & $\begin{array}{l}\text { Name: } \\
\text { Telephone number: } \\
\text { Relation to you: }\end{array}$ \\
\hline
\end{tabular}




\subsection{Appendix C - Video Scripts}

\subsubsection{Female Role Model Video}

Marie Rolande

Narrator: "This is Marie Rolande. She is 27 years old. Originally she is from Antsahanoro, but she has been living in Antalaha since 1991. Her goal was to become a research teacher of environmental conservation. At the moment she is teaching in CURSA (Centre Universitaire Régional de la SAVA) and at the same time she started her PhD with University of Mahajanga in cooperation with a University in Germany. Marie Rolande will tell us her story of how she achieved her goal:"

Marie Rolande: "During my Bachelor studies I always dreamed of becoming a research teacher, somebody who is important and respected by most of the people in the society I live in. I knew that in order to fulfill my goal, I have to exert a lot of effort by continuing my education. Working as a research teacher requires having minimum a Degree of Master2."

Narrator: "Acquiring a Master 2 Degree in Madagascar encompasses a long journey. People need to study for many years and in the first place they need to have the financial resources to fund it."

Marie Rolande: "My parents supported me for my studies during primary and secondary school. However, for my university studies their help was not enough. To fully fund my studies, I received help from the Malagasy government which was not easy to obtain as they support only the best students. But this did not keep me from trying. During the time of my studies I studied very hard, always giving my best to be able to get the financial aid"."

Narrator: "After 1 year of studying hard, Marie succeeded and received a grant from the government to fund her second and third year of her Bachelor studies."

Marie Rolande: "I was very happy and surprised when I received the news of my grant. Especially because I consider myself an average student and I knew many students, some way better than me, were applying for it. I think that what helped me to succeed was the commitment to my goal and my courage to keep going."

Narrator: "Apart from receiving a grant from the Malagasy government, Marie Rolande also found other sources of financial support that gave her the opportunity to start her Master 2 Degree Program. After she finished her Bachelor, Marie Rolande started searching for different international programs where she could obtain her Master2 Degree. She found a suitable program in Forest Management at the University of Kinshasa in Republic of Congo. It was a big step for Marie to do her Master2 abroad, especially coming from 
a country where it is not common that a woman her age keeps on studying instead of marrying, starting a family or cultivating vanilla. However, most of Marie Rolande's family did not understand why she kept studying so much and not focusing on having a family. Also, other people started questioning her decision on not cultivating vanilla and told her that studying for so long was not worth it. She has been feeling this pressure for 5 years now."

Marie Rolande: "I am aware that some people, especially in my village, don't agree with the decisions I have made in my life. But my dream of becoming a research teacher was my priority and having a family just didn't fit at that moment. I can still start a family or plant vanilla in the future but now I want to focus on my teaching and on my research."

Narrator: "After obtaining her Master2 Degree she was confident enough to apply for a research teacher position at CURSA. After some months of waiting, she finally got a positive response and got the dream job that she always wanted. Succeeding was not easy, it took her many years of studying and endurance until she was prepared to apply for the position."

Marie Rolande: "I am very happy to work for CURSA. Now I can finally focus on sharing the knowledge I have with my students and also doing research in my favorite field of study."

Narrator: "Besides achieving her goal, this job at CURSA has opened many doors for Marie. For example she started in 2016 a PhD with the University of Mahjanga in cooperation with a University in Germany. Furthermore, she has had the opportunity to work in other projects with international students that have visited the SAVA region."

Marie Rolande: "Becoming a research teacher at CURSA has opened me many doors and I am sure that there are more projects to come. Also, my family has played a key role in the last years. Especially, I wouldn't have achieved all this without the help of my mother and grandfather. They have been very important to me because they have supported me to continue my dreams all the time."

Mother of Marie Rolande: "I am very proud of my daughter and I know that with her commitment and strength she has a great future ahead. You know, she was like any other kid but as years passed by she started imaging something different for her life. I know how difficult it was for her and all the obstacles she had to face, but at the end she succeeded. Now, she can tell her story to others and help them to overcome their fears."

Narrator: "Some people think that she is losing her time with that job; however, her students and colleagues see her with other eyes. They see her as a person that follows her objectives and who is ready to make sacrifices along the way to achieve them."

Friend of Marie Rolande: "Some people in the village think that she should be doing 
something different, like having children and planting vanilla, but there are also people like me that see her life different and who admire her decision to keep on studying, to follow her dream. I was very happy when I got to know that she got the job at CURSA because I knew how much she wanted that job."

Colleague of Marie Rolande: "She is a great role model for all of our students. I have heard several times that they would like to be like her. She also tells her students that when she was young, she was like them and that if they want to succeed they need to have confidence in themselves and study hard."

Narrator: "The story of Marie Rolande shows that if one aims at doing something and works towards it, it is possible to achieve it. She imagined a different life than most of her friends and family have, and even though the journey was long and with many obstacles, she was able to make that imagination a reality." 


\subsubsection{Male Role Model Video}

\section{Fulgence}

Narrator: "This is Fulgence. He is 33 years old. Originally he is from from Antsahamanena but he has been living in Antalaha since 2015. His goal was to become a research teacher in zoology. At the moment he is teaching at CURSA (Centre Universitaire Régional de la SAVA) and at the same time he started his PhD with University of Antananarivo in cooperation with a University in Germany. Fulgence will tell us his story on how he achieved his goal:"

Fulgence: "During my Bachelor studies I always dreamed of becoming a research teacher, somebody who is important and respected by most of the people in the society I live in. I knew that in order to fulfill my goal, I have to exert a lot of effort by continuing my education. Working as a research teacher requires having minimum a Degree of Master."

Narrator: "Acquiring a Master 2 Degree in Madagascar encompasses a long journey. People need to study for many years and in the first place they need to have the financial resources to fund it."

Fulgence: "My family supported me for my studies during primary and secondary school. However, for my university studies their help was not enough. To fully fund my studies, I received help from the Malagasy government which was not easy to obtain as they support only the best students. But this did not keep me from trying. During the time of my studies I studied very hard, always giving my best to be able to get the financial aid."

Narrator: "After 1 year of studying hard, Fulgence succeeded and received a grant from the government to fund his second and third year of his Bachelor studies."

Fulgence: "I was very happy and surprised when I received the news of my grant. Especially because I consider myself an average student and I knew many students, some way better than me, were applying for it. I think that what helped me to succeed was the commitment to my goal and my courage to keep going."

Narrator: "Apart from receiving a grant from the Malagasy government, Fulgence got support from his older brother who decided to work in his place so that he could continue studying. After he finished his Bachelor, Fulgence started searching for different programs where he could obtain his Master2 Degree. He found a suitable program in Science at the University of Mahajanga. It was a big step for Fulgence to do his Master2 in another region of Madagascar, especially as he is coming from a rural area that is located far away from that University. However, some people from Fulgence family did not understand why he kept studying so much and not focus on cultivating vanilla instead. They think that 
studying for so long was not worth it."

Fulgence: "I am aware that some people, especially in my village, don't agree with the decisions I have made in my life. But my dream of becoming a research teacher was my priority and cultivating vanilla before just didn't fit at that moment. I can still plant vanilla in the future but now I want to focus on my teaching and on my research."

Narrator: "After obtaining his Master2 Degree he was confident enough to apply for a research teacher position at CURSA. After some months of waiting, he finally got a positive response and got the dream job that he always wanted. Succeeding was not easy, it took him many years of studying and endurance until he was prepared to apply for the position."

Fulgence: "I am very happy to work for CURSA. Now I can finally focus on sharing the knowledge I have with my students and also doing research in my favorite field of study."

Narrator: "Besides achieving his goal, this job at CURSA has opened many doors for Fulgence. For example he started in 2016 a PhD with the University of Tana in cooperation with a University in Germany. Furthermore, he has had the opportunity to get in contact with international researchers that have helped him to improve his research."

Fulgence: "Becoming a research teacher at CURSA has opened me many doors and I am sure that there are more projects to come. Also, my family has played a key role in the last years. Especially, I wouldn't have achieved all this without the help of my mother, my father and my aunt. They have been very important to me because they have supported me to continue my dreams all the time."

Mother of Fulgence: "I am very proud of my son and I know that with his commitment and strength he has a great future ahead. You know, he was like any other kid but as years passed by he started imaging something different for his life. I know how difficult it was for him and all the obstacles he had to face, but at the end he succeeded. Now, he can tell his story to others and help them to overcome their fears."

Narrator: "Some people think that he is losing his time with that job; however, his students and colleagues see him with other eyes. They see him as a person that follows his objectives and who is ready to make sacrifices along the way to achieve them."

Friend of Fulgence: "Some people in the village think that he should be doing something different, like planting vanilla, but there are also people like me that see his life different and who admire his decision to keep on studying, to follow his dream. I was very happy when I got to know that he got the job at CURSA because I knew how much he wanted that job." 
Colleague of Fulgence: "He is a great role model for all of our students. I have heard several times that they would like to be like him. He also tells his students that when he was young, he was like them and that if they want to succeed they need to have confidence in themselves and study hard."

Narrator: "The story of Fulgence shows that if one aims at doing something and works towards it, it is possible to achieve it. He imagined a different life than most of his friends and family have, and even though the journey was long and with many obstacles, he was able to make that imagination a reality." 


\subsubsection{Placebo Video}

\section{Rural and Urban Life in the Sava Region}

Narrator: "Life in cities is very attractive for young people. They often migrate to cities like Antalaha to find a job. There they find opportunities they do not have in the villages they come from. Marie Rolande is a young woman who left her village and came to the city to study and then work as a research teacher at CURSA, the Centre Universitaire Régional de la SAVA. Here she is teaching students in environmental conservation and at the same time she is doing her Phd with University of Mahajanga in cooperation with a University in Germany."

Marie: "Originally I am from Antsahanoro. However I have been living here in Antalaha since 1991. I think that the urban life is not the same as the life in villages. In the villages people mostly earn their living with farming. This also is reflected in their clothing. Farmers wear long shirts and trousers that protect them from injuries and mosquito bites. In the cities, clothing is different. Here people like to wear short clothes due to the warm climate."

Narrator: "Fulgence is a young man who lives in Antalaha. As Marie, he is also a research teacher at CURSA. He is teaching students in zoology. He is doing his $\mathrm{PhD}$ with University of Antananarivo in cooperation with a University in Germany, too."

Fulgence: "I have been living in bigger cities for the course of my studies. The life in a city like Antalaha is different than in rural areas. First the city is more developed as the rural area. Here you have more shops, markets; better infrastructure in general. Also lifestyle is different. Here people enjoy going out; watching films and dancing in discos. In the rural area this is different; there you have fewer opportunities even though some people have solar panels which enable them to watch videos."

Fulgence: "Not only rural and urban life differ in many aspects, but also the cities among each other. The first difference is the climate. Antalaha and Sambava have the same climate, but not Vohemar and Andapa. The second difference lies in the ethnicity. In Sambava for example we can find all ethnicities. Here in Antalaha the biggest ethnicity is the "Bezimzaraka."

Marie: "Some people of my family still live in Antsahanoro, where I come from. I visit them often; especially when there are traditional ceremonies in the village. For weddings for example, they invite not only the family of the woman and the man but all people in the village who want to come. And they prepare a big party for that: They kill a Zebu, they prepare a lot of rice and a lot of good things to eat, and they have beautiful music. City weddings are smaller; not so much people are invited." 
Narrator: "Rural and urban life is connected through farming and breeding livestock. Many occupations in the urban area depend on the cultivation that takes place in the rural area. Most products that are sold on markets in the city are usually from fields outside the cities, such as vanilla and rice. But there is also trade in the other direction. Products from Tana or from Tamatav are imported to the cities and sold in the rural areas."

Marie: "This is Antsahanoro. Here I spent many days of my life. Here, life is slower than in Antalaha and you know everybody in the village. When I am 60 years old, I will need some tranquility and a calm place, so I think I will return to the village. But, I am not really sure about the others, but me, I really like environment, nature."

Narrator: "Fulgence comes from Antsahamanena a village that is located in a remote area. The fastest way of reaching it, is to go by pirogue. Here most of the people cultivate vanilla. They spent most of their days in the field. As the do not have electricity there, they hear radio with batteries while they are working. The radio does not only serve as entertainment, but also as information source; so they know what is happening in the region."

Fulgence: "This is the village I come from. I really like coming here for traditional ceremonies, when we have Zebu meat. Here in the villages Zebu is more valuable than in the cities, so people are used to have Zebu for celebrations." Narrator: In Antalaha, if you don't have enough money, people just buy some meat or some chicken in the market, instead of having a Zebu. In Fulgence's family it is his mother who prepares the Zebu for traditional ceremonies, while Fulgence's father takes care of the vanilla."

Fulgence's mother: "Yes, Zebu is our traditional meal. Usually we eat it with rice and romazava. Everybody from our big family joins for special ceremonies, which means that I have to prepare a lot. Here in the villages it is normal for people to have very big families."

Marie's mother: "Families here are very big and they are getting bigger with every generation. But the land stays the same, so that there is often not enough land for young people. They need to move away into the big cities just to discover another way to conduct their lives. And maybe often they want to move away because they are just lazy to live like a farmer."

Narrator: "Most of the friends of Marie and Fulgence also did not want to become a farmer. At the moment they live in Antalaha and some are working as teachers, too. But as a teacher you do not necessarily have to live in the big city."

Fulgence's female friend: "I know many young people that try to find a job in the city. Most young people try to make it by working in the vanilla business. At the moment 
the vanilla prices are very high and this is very attractive for young people, but maybe in some years it will not be like that anymore."

Colleague of Marie: "Another difference between rural and urban areas is that only in big cities you can find public schools where students can finish their secondary education. Because of this, many students have to move to the cities to continue studying."

Narrator: "Living in the city has advantages and disadvantages, same as in the rural area. However, this diversity makes the Sava region a beautiful place to live." 


\section{Conclusion and Way Forward}

This thesis presents new evidence on the role of aspirations in development outcomes. It includes three studies that investigate four research objectives. The first research objective is to explore the relationship between aspirations that one has for one's community, defined as community aspirations, and cooperative behavior. We propose that community aspirations are an important determinant of collective action. In our study in chapter 2 we develop empirical measures for community aspirations and find evidence that our measure is positively related with contributions to a real public good as well as with a reported measure on participation in village work, but negatively related with reported measures that capture monetary contributions to village projects and general trust in the village. Since these results are based on correlations, future research should conduct causal analysis to understand the direction of causality. It could be that lower trust among villagers and unclear handling of village treasury contributions decreases community aspirations. The latter points to the importance to also understand how local institutions determine collective action through community aspirations. Also, future work should provide further tests on the validity and reliability of our proposed measure of community aspirations. With respect to validity the questions that could be addressed are: Do the dimensions of community aspirations reflect participants' definition of welfare? Can some dimension be relaxed, while another indicator should be included? In terms of reliability, future work is advised to test for consistency in respondents' answers over a specific time period and the role of participants' mood as well as anchoring effects of asking for the current level of achievements before the actual aspiration question (as Bernard \& Taffesse (2014) have done for their individual aspiration measure).

The second research objective of this thesis is to investigate the determinants of community aspirations. Chapter 2 and 3 both test the hypothesis that community role models presented in videos can widen the "aspiration window" and thereby raise community aspirations. Results of a natural field and a lab-in-the-field experiment conducted in the same area in rural Zambia provide similar results. We find that a video that uses a narrative frame 
in depicting the role models (village life video) is effective in increasing contributions to a public good, while a video that additionally includes prescriptive messages (collective action video) did not affect contributions in the lab-in-the-field, but in the natural field experiment.

The study in Chapter 3 addresses the third research objective, i.e. understanding how the design and content of the video intervention affects collective action. Comparing the effects of the two videos, the paper finds that while the village life video is effective at increasing contributions compared to the control, there are no significant differences in the level of conditional contributions between the different treatment videos. The finding that the narrative, and not the prescriptive video, is more effective at increasing contributions compared to the control is in line with theoretical literature on education entertainment that posits that the desirable behavior or the educational message should not be made too salient in order to prevent resistance among the viewers (Moyer-Gusé, 2008). ${ }^{1}$ Future work could test for participants' resistance by adding questions on their impression of behavioral change intentions of the experimenter. It could also be that participants do not relate with the characters in the collective action video. They might perceive the level of cooperation too far away from what they think they can achieve in their village and thus do not consider them to be a relevant reference group (Tankard \& Paluck, 2016). Even though 63 percent of the participants in the collective action video treatment rate the characters to be similar to them, most of the answers of those who do not agree indicate that they perceive the video characters to be more cooperative and more hard-working. Future interventions could collect control questions that explicitly target how participants rate the characters' success in collective action.

The increase in contributions to the public good among participants who saw the village life video, compared to participants in the no video condition, cannot be explained by an increase in community aspirations. In the lab-in-the-field experiment we find that the village life video has no effect on community aspirations and a negative effect on contributions in the natural field experiment. Instead, the mechanism seems to run through village efficacy and perceived norms of cooperation. The study in chapter 3 analyzes the latter by testing whether the expectation that the other group member saw the video influences contribution decisions. The study finds that unconditional and conditional contributions are higher in the village life video treatment if both participants of the group of two were shown the video compared to the no-video and one-person treatment. Thus, these results suggest that common knowledge in having seen the video is important and could be a potential mechanism. However, future research should analyze the joint role and interaction of village efficacy, perceived norms of cooperation and community aspirations in the decision to cooperate. Also, since we find no correlation of community aspirations with contribution decisions, but find that individual aspirations are negatively correlated with

\footnotetext{
${ }^{1}$ Both videos did not mention the public good used as an outcome measure in the natural field experiment (seed capital for newly formed savings groups) so that we can rule out that the effects are driven by the information provided in the treatment video.
} 
unconditional contributions in the lab-in-the-field experiment, future work could analyze the relative importance and interaction of community and individual aspirations. It could be that community aspirations conflict with individual goals to which participants attach greater importance.

The fourth and last research objective considers whether female's aspirations and willingness to apply to a competitive job can be affected through exposure to a role model video. The hypothesis is that female adolescents in developing countries lack female role models who can serve as reference points. This can trap them in a situation with low aspirations and low investments. Chapter 4 presents results of a field experiment conducted in Madagascar in which students in their last year of secondary school were randomly assigned to either a female, a male or a placebo video screening. After video exposure, we gave the students the opportunity to apply to an assistant or a coordinator position in a research project of one of the principal investigators. The results of the study provide evidence that female role models in videos are effective at increasing applications of female as well as male students to any of the two jobs. Moreover, the results suggest that the male role model video encourages female students to apply to the more competitive job, the coordinator position. As a result the gender gap in applications to this position, which is prevalent in the placebo group, shrinks. Whereas the decision to apply in the female video group can partly be explained by aspirations and current achievements, competitive preferences can explain the decision to apply to the coordinator position in the male video group. This chapter thus provides evidence that role models do not need to be of the same gender. Instead, our results suggest that the traits of the gender matter. Past research has argued that in general men are perceived more competitive compared to women (Blau \& Kahn, 2017). An extension could be to test for the importance of traits by asking control questions on the perceived competence of the role models in different domains and capture stereotypes on the abilities of men and women in the respective setting. In addition, this study does not provide a pure control group. The effects of the study are evaluated against a placebo group, which could also not be free of values and messages that could influence participants' behavior. Future work should therefore test whether another placebo video provides similar results.

The studies of this thesis only report the short-term results of a one-time video screening and thus cannot make any statements on the sustainability of the observed effects. An extension is to include the follow-up results of the paper in chapter 2 and 4 . Studying the long-term effects is important in order to understand how possible changes in aspirations due to role model interventions interact with external factors. This is especially relevant in contexts were there are not only internal but external constraints to the individual that diminish the possibility of realizing aspired outcomes. What happens if increased aspirations are not achieved? Especially in competitions that involve winners and also losers? Does this lead to the predicted frustration (Genicot \& Ray, 2017)? How does an individual develop after a goal has been reached? Does it aspire higher? We cannot tell for sure whether the video intervention gives false hope. Yet, we can claim that the role 
models in our videos are not fictional, but have a similar background as the viewers, and the stories about their success are real. As Bernard et al. (2014), the videos also do not provide information on the steps that are necessary to achieve a specific outcome that could prove to be misleading.

There are some limitations to the external validity of our findings. The treatment effects that we observe depend on our chosen role models. Different cultures might have a different understanding on what constitutes success and thus whether they perceive someone to be a role model. Also, the results on community aspirations could be different in other contexts, where communities have a peculiar understanding of community welfare. Moreover, the results might be different for people living in contexts with more access to information. The sample of our studies conducted in Zambia can be argued to have only limited access to media and information through mobile phones. Over half of the respondents in our studies of Chapter 2 and 3 report to never use a mobile phone or to watch television. Only about 10 percent of the respondents state to watch television or to use a mobile phone once or more than once a week. As television and mobile phones provide individuals with the opportunity to increase their "aspirations window", similar results can only be expected in contexts with comparable access to information.

On the basis of these results, several policy recommendations can be formulated. Yet, these should be backed by further evidence. First, initiatives that would like to promote collective action can show examples of the impacts of collective action instead of directly referring to the value and need of cooperation. Second, companies or organizations which would like to increase the share of applicants can use inspirational videos with characters that are similar to those of the participants. The advantage of videos is that, once produced, their use can be up-scaled at very low costs. Yet, these interventions should be combined with measures that lift external constraints of people. All in all, I hope that these studies inspire other researchers and policy makers to conduct further studies on how individuals and groups of people can be encouraged to increase their well-being by making the necessary investments, especially of those who do not have a vision for and belief in themselves. Could a soap opera displaying ecologically sustainable communities foster more climate action? I hope policy makers and researchers consider this idea in the quest of combating climate change. 


\section{Bibliography}

Abadie, A. (2006). Poverty, Political Freedom, and the Roots of Terrorism. American Economic Review, 96(2), 50-56.

Agrawal, A. (2001). Common Property Institutions and Sustainable Governance of Resources. World Development, 29(10), 1649-1672.

Alkire, S., \& Santos, M. E. (2014). Measuring Acute Poverty in the Developing World: Robustness and Scope of the Multidimensional Poverty Index. World Development, 59 , $251-274$

Anand, S., \& Sen, A. (1994). Human Development Index: Methodology and Measurement. (Human Development Report Office Occasional Papers). Human Development Report Office. Retrieved 2020-10-06, from https://ora.ox.ac.uk/objects/ uuid:98d15918-dca9-4df1-8653-60df6d0289dd/download_file?file_format= application/pdf\&safe_filename=HDI_methodology $\cdot$ pdf\&type_of_work=Report

Appadurai, A. (2004). The Capacity to Aspire: Culture and the Terms of Recognition. In V. Rao \& M. Walton (Eds.), Culture and Public Action (pp. 59-84). Stanford, California: Stanford University Press.

Arias, E. (2019). How Does Media Influence Social Norms? Experimental Evidence on the Role of Common Knowledge. Political Science Research and Methods, 7(3), 561-578.

Badaan, V., Jost, J. T., Fernando, J., \& Kashima, Y. (2020). Imagining better societies: A social psychological framework for the study of utopian thinking and collective action. Social and Personality Psychology Compass, 14(4), 1-14.

Balasubramanian, P., Ibañez Diaz, M., Khan, S., \& Sahoo, S. (2019). Does female economic empowerment promote development? (PEGNet Policy Brief No. 17/2019). Kiel: Kiel Institute for the World Economy (IfW), Poverty Reduction, Equity and Growth Network (PEGNet). Retrieved 2020-10-01, from https://www.pegnet.ifw-kiel.de/policy-briefs/ does-female-economic-empowerment-promote-development-13150/ 
Bandura, A. (1977). Social Learning Theory. Englewood Cliffs, NJ: Prentice-Hall.

Bandura, A. (1986). Observational Learning. In Social Foundations of Thought and Action (pp. 47 - 97). Englewood Cliffs, NJ: Prentice-Hall.

Bandura, A. (1997). Self-Efficacy: The Exercise of Control. New York: Freeman.

Bandura, A. (2004). Social cognitive theory for personal and social change by enabling media. In A. Singhal, M. J. Cody, E. M. Rogers, \& M. Sabdio (Eds.), EntertainmentEducation and Social Change: History, Research, and Practice (pp. 75-96). Mahwah, New Jersey: Lawrence Erlbaum Associates.

Bandura, A. (2006). Guide for Constructing Self-Efficacy Scales. In T. Urdan \& P. Frank (Eds.), Self-Efficacy Beliefs of Adolescents (Vol. 5, pp. 307-337). Greenwich, Conneticut: $\mathrm{CT}$ : Information Age Publishing.

Bandura, A. (2012). On the Functional Properties of Perceived Self-Efficacy Revisited. Journal of Management, 38(1), 9-44.

Banerjee, A., \& Duflo, E. (2009). The Experimental Approach to Development Economics. Annual Review of Economics, 1(1), 151-178.

Banerjee, A., \& Duflo, E. (2011). Poor Economics: A Radical Rethinking of the Way to Fight Global Poverty. New York, NY: PublicAffairs.

Banerjee, A., Ferrara, E. L., \& Orozco-Olvera, V. H. (2019). The Entertaining Way to Behavioral Change: Fighting HIV with MTV (NBER Working Paper Series No. 26096). Retrieved 2020-07-10, from http://www.nber.org/papers/w26096

Batista, C., \& Seither, J. (2019). Reference Points and Entrepreneurship (Working Paper). Retrieved 2020-10-07, from https://novafrica.org/wp-content/uploads/2019/05/ ReferencePointsEntrepreneurship_May2019.pdf

Beaman, L., Duflo, E., Pande, R., \& Topalova, P. (2012). Female Leadership Raises Aspirations and Educational Attainment for Girls: A Policy Experiment in India. Science, 335 (6068), 582-586.

Beaty, R. E., Silvia, P. J., Nusbaum, E. C., Jauk, E., \& Benedek, M. (2014). The roles of associative and executive processes in creative cognition. Memory \& Cognition, 42(7), 1186-1197.

Benedek, M., Jauk, E., Sommer, M., Arendasy, M., \& Neubauer, A. C. (2014). Intelligence, creativity, and cognitive control: The common and differential involvement of executive functions in intelligence and creativity. Intelligence, 46, 73-83.

Bernard, T., Dercon, S., Orkin, K., \& Taffesse, A. S. (2014). The Future in Mind: Aspirations and Forward-Looking Behaviour in Rural Ethiopia (Working Paper No. 10224). London, UK: Centre for Economic Policy Research. Retrieved 2020-07-10, from http: //www. ssrn . com/abstract $=2514590$ 
Bernard, T., Dercon, S., \& Taffesse, A. S. (2011). Beyond fatalism - an empirical exploration of self-efficacy and aspirations failure in Ethiopia. (Working Paper No. WPS/2017-13). Centre for the Study of African Economies, University of Oxford. Retrieved 2020-08-10, from https://ora.ox.ac.uk/objects/uuid:8568ecef-1412-4b3e $-\mathrm{a} 923-1 \mathrm{c} 70 \mathrm{cb} 2399 \mathrm{f} 2$

Bernard, T., \& Taffesse, A. (2014). Aspirations: An Approach to Measurement with Validation Using Ethiopian Data. Journal of African Economies, 23(2), 189-224.

Bertrand, M., Mullainathan, S., \& Shafir, E. (2004). A Behavioral-Economics View of Poverty. The American Economic Review, 94(2), 419-423.

Blair, G., Littman, R., \& Paluck, E. L. (2019). Motivating the adoption of new communityminded behaviors: An empirical test in Nigeria. Science Advances, 5(3), 1-8.

Blau, F. D., \& Kahn, L. (2017). The Gender Wage Gap: Extent, Trends, and Explanations. Journal of Economic Literature, 55(3), 789-865.

Bogliacino, F., \& Ortoleva, P. (2015). The Behavior of Other as a Reference Point (Documeno Escuela de Economía No. 67). Universidad Nacional de Colombia Sede Bogotá. Retrieved 2020-09-24, from http://www.ssrn. com/abstract=2653343

Bollen, K. A. (1986). Political rights and political liberties in nations: An evaluation of human rights measures, 1950 to 1984. Human Rights Quarterly, 8(4), 567-591.

Booth, A. L. (2009). Gender and competition. Labour Economics, 16(6), 599-606.

Bowles, S., \& Polanía-Reyes, S. (2012). Economic Incentives and Social Preferences: Substitutes or Complements? Journal of Economic Literature, 50 (2), 368-425.

Braithwaite, V. (2004). The Hope Process and Social Inclusion. The Annals of the American Academy of Political and Social Science,, 592(1), 128-151.

Breda, T., Grenet, J., Monnet, M., \& Van Effenterre, C. (2020). Do Female Role Models Reduce the Gender Gap in Science? Evidence from French High Schools (IZA DP No. 13163). IZA Institute of Labor Economics. Retrieved from http://ftp.iza.org/ dp13163.pdf

Brehm, J. W. (1966). A theory of psychological reactance. Oxford, England: Academic Press.

Brehm, S. S., \& Brehm, J. W. (1981). Psychological Reactance: A Theory of Freedom and Control. New York, NY: Academic Press.

Buser, T., Niederle, M., \& Oosterbeek, H. (2014). Gender, Competitiveness, and Career Choices. The Quarterly Journal of Economics, 129(3), 1409-1447. 
Buser, T., Niederle, M., \& Oosterbeek, H. (2020). Can Competitiveness Predict Education and Labor Market Outcomes? Evidence From Incentivized Choice and Survey Measures (NBER Working Paper Series). National Bureau of Economic Research. Retrieved 202009-30, from https://papers.ssrn.com/sol3/papers.cfm?abstract\{_\}id=3549354

Buser, T., Peter, N., \& Wolter, S. C. (2017). Gender, Competitiveness, and Study Choices in High School: Evidence from Switzerland. American Economic Review, 107(5), 125-130.

Caisse Nationale de Prévoyance Sociale Madagascar. (2015). Retrieved 2020-07-28, from http://www.cnaps.mg/en/index.php

Cardenas, J. C., \& Carpenter, J. (2008). Behavioural Development Economics: Lessons from Field Labs in the Developing World. The Journal of Development Studies, 44(3), $311-338$.

Carpenter, J., Frank, R., \& Huet-Vaughn, E. (2018). Gender differences in interpersonal and intrapersonal competitive behavior. Journal of Behavioral and Experimental Economics, $77,170-176$.

Central Statistical Office. (2016). 2015 Living Conditions Monitoring Survey (LCMS) Report (Tech. Rep.). Central Statistical Office Republic of Zambia. Retrieved 2020-0710, from https://www.zamstats.gov.zm/phocadownload/Living_Conditions/2015\% 20Living\%20Conditions\%20Monitoring\%20Survey\%20Report.pdf

Chong, A., \& La Ferrara, E. (2009). Television and Divorce: Evidence from Brazilian Novelas. Journal of the European Economic Association, 7(2-3), 458-468.

Cialdini, R. B. (2003). Crafting Normative Messages to Protect the Environment. Current Directions in Psychological Science, 12(4), 105-109.

Cobb-Clark, D. A. (2015). Locus of control and the labor market. IZA Journal of Labor Economics, 4(1), 1-19.

Coleman, J. S. (1988). Social Capital in the Creation of Human Capital. American Journal of Sociology, 94, S95-S120.

Croson, R., \& Gneezy, U. (2009). Gender Differences in Preferences. Journal of Economic Literature, 47(2), 448-474.

Dalton, P. S., Ghosal, S., \& Mani, A. (2016). Poverty and Aspirations Failure. The Economic Journal, 126(590), 165-188.

Dalton, P. S., Ruschenpöhler, J., \& Zia, B. (2018). Determinants and Dynamics of Business Aspirations: Evidence from Small-Scale Entrepreneurs in an Emerging Market (Policy Research Working Paper No. 8400). The World Bank. Retrieved 2020-09-24, from http://elibrary.worldbank. org/doi/book/10 .1596/1813-9450-8400 
Dercon, S. (Ed.). (2005). Insurance Against Poverty. New York, NY: Oxford University Press.

Duflo, E. (2003). Grandmothers and Granddaughters: Old-age Pensions and Intrahousehold Allocation in South Africa. The World Bank Economic Review, 17(1), 1-25.

Duflo, E. (2012). Human values and the design of the fight against poverty. Tanner Lecture at Harvard University. Retrieved 2018-02-26, from https://www.povertyactionlab.org/ sites/default/files/documents/TannerLectures_EstherDuflo_draft.pdf

Duflo, E., Glennerster, R., \& Kremer, M. (2007). Using Randomization in Development Economics Research: A Toolkit. In T. P. Schultz \& J. A. Strauss (Eds.), Handbook of Development Economics (Vol. 4, pp. 3895-3962). Elsevier.

Fafchamps, M. (2006). Development and Social Capital. The Journal of Development Studies, 42(7), 1180-1198.

Fehr, E., \& Fischbacher, U. (2003). The nature of human altruism. Nature, 425(6960), $785-791$

Feigenberg, B., Field, E., \& Pande, R. (2013). The Economic Returns to Social Interaction: Experimental Evidence from Microfinance. Review of Economic Studies, 80(4), 14591483.

Fernando, J. W., Burden, N., Ferguson, A., O’Brien, L. V., Judge, M., \& Kashima, Y. (2018). Functions of Utopia: How Utopian Thinking Motivates Societal Engagement. Personality and Social Psychology Bulletin, 44(5), 779-792.

Fernando, J. W., O’Brien, L. V., Burden, N. J., Judge, M., \& Kashima, Y. (2019). Greens or space invaders: Prominent utopian themes and effects on social change motivation. European Journal of Social Psychology, 50(2), 278-291.

Fischbacher, U., Gächter, S., \& Fehr, E. (2001). Are people conditionally cooperative? Evidence from a public goods experiment. Economics Letters, 71(3), 397-404.

Fischer, E., \& Qaim, M. (2012). Linking Smallholders to Markets: Determinants and Impacts of Farmer Collective Action in Kenya. World Development, 40(6), 1255-1268.

Flory, J. A., Leibbrandt, A., \& List, J. A. (2015). Do Competitive Workplaces Deter Female Workers? A Large-Scale Natural Field Experiment on Job Entry Decisions. The Review of Economic Studies, 82(1), 122-155.

Genicot, G., \& Ray, D. (2017). Aspirations and Inequality. Econometrica, 85(2), 489-519.

Genicot, G., \& Ray, D. (2020). Aspirations and Economic Behavior. Annual Review of Economics, 12(1), 715-746. 
Ginther, D. K., Currie, J. M., Blau, F. D., \& Croson, R. T. A. (2020). Can Mentoring Help Female Assistant Professors in Economics? An Evaluation by Randomized Trial. AEA Papers and Proceedings, 110, 205-209.

Glick, P., Handy, C., \& Sahn, D. E. (2015). Schooling, marriage, and age at first birth in Madagascar. Population Studies, 69(2), 219-236.

Gneezy, U., Niederle, M., \& Rustichini, A. (2003). Performance in Competitive Environments: Gender Differences. The Quarterly Journal of Economics, 118(3), 1049-1074.

Gomila, R. (2020). Logistic or linear? Estimating causal effects of experimental treatments on binary outcomes using regression analysis. Journal of Experimental Psychology: General. Retrieved 2020-10-01, from https://doi.org/10.1037/xge0000920 (Advance online publication)

Gottschalk, P. (2005). Can work alter welfare recipients' beliefs? Journal of Policy Analysis and Management, $24(3), 485-498$.

Goux, D., Gurgand, M., \& Maurin, E. (2017). Adjusting Your Dreams? High School Plans and Dropout Behaviour. The Economic Journal, 127(602), 1025-1046.

Gravel, N. (1994). Can a Ranking of Opportunity Sets Attach an Intrinsic Importance to Freedom of Choice? The American Economic Review, 84 (2), 454-458.

Greenaway, K. H., Cichocka, A., van Veelen, R., Likki, T., \& Branscombe, N. R. (2016). Feeling Hopeful Inspires Support for Social Change: Hope and Social Change. Political Psychology, 37(1), 89-107.

Grosse, N., Riener, G., \& Dertwinkel-Kalt, M. (2014). Explaining Gender Differences in Competitiveness: Testing a Theory on Gender-Task Stereotypes (Working Paper). Retrieved 2020-09-22, from http://www.ssrn. com/abstract=2551206

Harrison, G., \& List, J. (2004). Field experiments. Journal of Economic literature, 42(4), 1009-1055.

Herrera, C., Sahn, D. E., \& Villa, K. M. (2019). Teen Fertility and Female Employment Outcomes: Evidence from Madagascar. Journal of African Economies, 28(3), 277-303.

Herrera Almanza, C., Fred, A., Marchetta, F., Pelissier, A., Rajemison, H., Rakotomanana, F., ... Villa, K. (2017). Madagascar Young Adult Transitions Survey (GLM|LIC Working Paper No. 26). Growth in Labour Markets in Low Income Countries Programme. Retrieved 2020-09-22, from https://g2lm-lic.iza.org/wp-content/uploads/2017/ 04/glmlic-wp026.pdf

Ibañez, M., Khan, S., Minasyan, A., Sahoo, S., \& Balasubramanian, P. (2017). Women's economic empowerment on human development in low and middle-income countries. Campbell Systematic Reviews 2018. 
Ibañez, M., \& Riener, G. (2018). Sorting through Affirmative Action: Three Field Experiments in Colombia. Journal of Labor Economics, 36(2), 437-478.

ILO. (2020). World Employment and Social Outlook. Madagascar. Retrieved 2020-08-08, from https://www.ilo.org/wesodata

Janzen, S. A., Magnan, N., Sharma, S., \& Thompson, W. M. (2017). Aspirations failure and formation in rural Nepal. Journal of Economic Behavior $\& 3$ Organization, 139, 1-25.

Jensen, R. (2012). Do labor market opportunities affect young women's work and family decisions? Experimental evidence from India. Quarterly Journal of Economics, 127(2), $753-792$.

Jensen, R., \& Oster, E. (2009). The Power of TV: Cable Television and Women's Status in India. The Quarterly Journal of Economics, 124(3), 1057-1094.

Jerusalem, M., \& Schwarzer, R. (1995). Generalized Self-Efficacy scale. In J. Weinman, S. Wright, \& M. Johnston (Eds.), Measures in health psychology: A user's portfolio. causal and control beliefs (pp. 35-37). Windsor, UK: NFER-NELSON.

Kamas, L., \& Preston, A. (2015). Can social preferences explain gender differences in economic behavior? Journal of Economic Behavior and Organization, 116, 525-539.

Keser, C., \& Winden, F. V. (2000). Conditional Cooperation and Voluntary Contributions to Public Goods. The Scandinavian Journal of Economics, 102(1), 23-39.

Kleinjans, K. J. (2009). Do gender differences in preferences for competition matter for occupational expectations? Journal of Economic Psychology, 30(5), 701-710.

Knight, J., \& Gunatilaka, R. (2012). Income, aspirations and the Hedonic Treadmill in a poor society. Journal of Economic Behavior \& Organization, 82(1), 67-81. doi: $10.1016 /$ j.jebo.2011.12.005

Kocher, M. G., Cherry, T., Kroll, S., Netzer, R. J., \& Sutter, M. (2008). Conditional cooperation on three continents. Economics Letters, 101(3), 175-178.

Kolev, A., \& Sirven, N. (2010). Gender Disparities in Africa's Labor Markets: A CrossCountry Comparison Using Standardized Survey Data. In J. S. Arbache, A. Kolev, \& E. Filipiak (Eds.), Gender Disparities in Africa's Labor Market (chap. 1). The International Bank for Reconstruction and Development.

Krueger, A. B., \& Malečková, J. (2003). Education, Poverty and Terrorism: Is there a Causal Connection? Journal of Economic Perspectives, 17(4), 119-144.

La Ferrara, E. (2016). Mass Media and Social Change: Can We Use Television to Fight Poverty? Journal of the European Economic Association, 14(4), 791-827.

La Ferrara, E. (2019). Presidential Address: Aspirations, Social Norms, and Development. Journal of the European Economic Association, 17(6), 1687-1722. 
La Ferrara, E., Chong, A., \& Duryea, S. (2012). Soap Operas and Fertility: Evidence from Brazil. American Economic Journal: Applied Economics, 4(4), 1-31.

Lubega, P., Nakakawa, F., Narciso, G., Newman, C., \& Kityo, C. (2018). Inspiring women: Experimental evidence on sharing entrepreneurial skills in Uganda (Working Paper No. TRiSS-WPS-03-2018). Trinity College Dublin. Retrieved 2020-07-10, from https://www.tcd.ie/triss/assets/PDFs/wps/triss-wps-03-2018.pdf

Lybbert, T., \& Wydick, B. (2018). Poverty, Aspirations, and the Economics of Hope. Economic Development and Cultural Change, 66 (4), 709-753.

Lybbert, T., \& Wydick, B. (2019). Hope as Aspirations, Agency, and Pathways: Poverty Dynamics and Microfinance in Oaxaca, Mexico. In C. Barrett, M. Carter, \& J.-P. Chavas (Eds.), The Economics of Poverty Traps (pp. 153-177). Chicago, USA: University of Chicago Press.

Macours, K., \& Vakis, R. (2014). Changing Households' Investment Behaviour through Social Interactions with Local Leaders: Evidence from a Randomised Transfer Programme. The Economic Journal, 124(576), 607-633. doi: 10.1111/ecoj.12145

Martini, C., Ibañez Diaz, M., \& Khadjavi, M. (2020). Community Aspirations and Collective Action (Working Paper).

Martinsson, P., Pham-Khanh, N., \& Villegas-Palacio, C. (2013). Conditional cooperation and disclosure in developing countries. Journal of Economic Psychology, 34, 148-155.

Marx, D. M., \& Roman, J. S. (2002). Female Role Models: Protecting Women's Math Test Performance. Personality and Social Psychology, 28(9), 1183-1193.

McKelway, M. (2020). Women's Employment in India: Intra-Household and Intra-Personal Constraints (Working Paper). Retrieved 2020-09-22, from https://drive.google.com/ file/d/1Fi8Y8A0o4j-NwqOmROowAVOkLcuCC1Ai/view

Meier, K., Niessen-Ruenzi, A., \& Ruenzi, S. (2020). The Impact of Role Models on Women's Self-Selection in Competitive Environments (Working Paper). Retrieved 2020-09-22, from https://papers.ssrn.com/sol3/papers. cfm?abstract_id=3087862

Miller, T., Kim, A. B., \& Holmes, K. R. (2016). 2014 Index of Economic Freedom. Washington, DC: The Heritage Foundation and Dow Jones \& Company, Inc.

Mojo, D., Fischer, C., \& Degefa, T. (2016). Collective Action and Aspirations: The Impact of Cooperatives on Ethiopian Coffee Farmers' Aspirations. Annals of Public and Cooperative Economics, 87(2), 217-238.

Moyer-Gusé, E. (2008). Toward a Theory of Entertainment Persuasion: Explaining the Persuasive Effects of Entertainment-Education Messages. Communication Theory, 18(3), $407-425$. 
Mullainathan, S., \& Thaler, R. H. (2000). Behavioral Economics (NBER Working Paper No. 7948). National Bureau of Economic Research. Retrieved 2018-01-02, from http://www.nber.org/papers/w7948

Narayan, D., \& Pritchett, L. (2019). Cents and Sociability: Household Income and Social Capital in Rural Tanzania. Economic Development and Cultural Change, 47(4), 871-897.

Narciso, G., Newman, C., \& Tarp, F. (2018). Information, identification, or neither? Experimental evidence on role models in Viet Nam (Working Paper No. 2018/185). United Nations University World Institute for Development Economics Research. Retrieved 2020-07-10, from https://www.wider.unu.edu/sites/default/files/Publications/ Working-paper/PDF/wp2018-185.pdf

Nguyen, T. (2008). Information, Role Models and Perceived Returns to Education: Experimental Evidence from Madagascar (Working Paper). Retrieved 2020-09-22, from https: // www . povertyactionlab.org/sites/default/files/documents/Nguyen\%202008. pdf

Niederle, M., Segal, C., \& Vesterlund, L. (2013). How Costly Is Diversity? Affirmative Action in Light of Gender Differences in Competitiveness. Management Science, 59(1), $1-16$.

Niederle, M., \& Vesterlund, L. (2007). Do Women Shy Away From Competition? Do Men Compete Too Much? The Quarterly Journal of Economics, 122(3), 1067-1101.

Niederle, M., \& Vesterlund, L. (2011). Gender and Competition. Annual Review of Economics, 3(1), 601-630.

Nordman, C. J., Rakotomanana, F., \& Robilliard, A.-S. (2010). Gender Disparities in the Malagasy Labor Market. In J. S. Arbache, A. Kolev, \& E. Filipiak (Eds.), Gender Disparities in Africa's Labor Market (pp. 87-144). The International Bank for Reconstruction and Development.

Ostrom, E. (1990). Governing the Commons: The Evolution of Institutions for Collective Action. Cambridge University Press.

Ostrom, E. (2000). Reformulating the Commons. Swiss Political Science Review, 6(1), $29-52$.

Paluck, E. L. (2009). Reducing Intergroup Prejudice and Conflict Using the Media: A Field Experiment in Rwanda. Journal of Personality and Social Psychology, 96 (3), 574-587.

Paluck, E. L., \& Green, D. P. (2009). Deference, Dissent, and Dispute Resolution: An Experimental Intervention Using Mass Media to Change Norms and Behavior in Rwanda. American Political Science Review, 103(4), 622-644.

Pasquier-Doumer, L., \& Risso Brandon, F. (2015). Aspiration Failure: A Poverty Trap for Indigenous Children in Peru? World Development, 72, 208-223. 
Pattanaik, P. K., \& Xu, Y. (1998). On Preference and Freedom. Theory and Decision, $44(2), 173-198$.

Platteau, J.-P. (1997). Mutual insurance as an elusive concept in traditional rural communities. The Journal of Development Studies, 33(6), 764-796.

Porter, C., \& Serra, D. (2020). Gender Differences in the Choice of Major: The Importance of Female Role Models. American Economic Journal: Applied Economics, 12(3), 226-254.

Puppe, C. (1996). An Axiomatic Approach to "Preference for Freedom of Choice". Journal of Economic Theory, 68(1), 174-199.

Qian, N. (2008). Missing Women and the Price of Tea in China: The Effect of Sex-Specific Earnings on Sex Imbalance. Quarterly Journal of Economics, 123(3), 1251-1285.

Ray, D. (2006). Aspirations, Poverty, and Economic Change. In A. V. Banerjee, R. Benabou, \& D. Mookherjee (Eds.), Understanding Poverty (pp. 409-421). New York, NY: Oxford University Press.

Riley, E. (2018). Role models in movies: the impact of Queen of Katwe on students' educational attainment (Working Paper No. WPS/2017-13). Centre for the Study of African Economies, University of Oxford. Retrieved 2020-07-20, from https://www . csae .ox.ac.uk/materials/papers/csae-wps-2017-13.pdf

Robb, C. (1998). Can the Poor Influence Policy? Participatory Poverty Assessments in the Developing World, Second Edition. Washington, DC: World Bank. Retrieved 2019-09-22, from https://elibrary.worldbank.org/doi/abs/10.1596/0-8213-5000-5

Rotter, J. (1966). Generalized expectancies for internal and external locus of reinforcement. Psychological Monographs: General and Applied, 80(1), 1-28.

Roy, S., Morton, M., \& Bhattacharya, S. (2018). Hidden human capital: Self-efficacy, aspirations and achievements of adolescent and young women in India. World Development, $111,161-180$.

Schier, U. K. (2020). Female and male role models and competitiveness. Journal of Economic Behavior and Organization, 173, 55-67.

Sen, A. (1991). Welfare, preference and freedom. Journal of Econometrics, 50(1-2), 15-29.

Sen, A. (2001). Development as Freedom. Oxford, UK: Oxford University Press.

Serneels, P., \& Dercon, S. (2020). Aspirations, Poverty and Education: Evidence from India (IZA DP No. 13697). IZA Institute of Labor Economics. Retrieved 2020-0921, from https://www.iza.org/publications/dp/13697/aspirations-poverty-and -education-evidence-from-india

Silvia, P. J. (2015). Intelligence and Creativity Are Pretty Similar After All. Educational Psychology Review, 27(4), 599-606. 
Singhal, A., \& Rogers, E. M. (2003). The Status of Entertainment-Education Worldwide. In A. Singhal, M. J. Cody, E. M. Rogers, \& M. Sabido (Eds.), Entertainment-Education and Social Change: History, Research, and Practice. Routledge.

Skjortnes, M., \& Zachariassen, H. H. (2010). 'Even with higher education you remain a woman': a gender perspective on higher education and social change in the Toliara region of Madagascar. Gender and Education, 22(2), 193-207.

Smith, R. W., \& Schwarz, N. (2012). When promoting a charity can hurt charitable giving: A metacognitive analysis. Journal of Consumer Psychology, 22(4), 558-564.

Stifel, D., \& Rakotomanana, F. H. (2007). Assessing Labor Market Conditions in Madagascar, 2001-2005 (Africa Region Working Paper Series No. 105). World Bank Group. Retrieved 2020-09-22, from http://documents1.worldbank.org/curated/en/ 207511468270305133/pdf/418910MG0LaborOmarkets0wp10501PUBLIC1 .pdf

Stout, J. G., Dasgupta, N., Hunsinger, M., \& McManus, M. A. (2011). STEMing the Tide: Using Ingroup Experts to Inoculate Women's Self-Concept in Science, Technology, Engineering, and Mathematics (STEM). Journal of Personality and Social Psychology, $100(2), 255-270$.

Stutzer, A. (2004). The role of income aspirations in individual happiness. Journal of Economic Behavior \& Organization, 54 (1), 89-109.

Tankard, M. E., \& Paluck, E. L. (2016). Norm Perception as a Vehicle for Social Change. Social Issues and Policy Review, 10(1), 181-211.

The Nobel Prize. (2019). The Sveriges Riksbank Prize in Economic Sciences in Memory of Alfred Nobel 2019. Retrieved 2020-09-29, from https://www.nobelprize.org/prizes/ economic-sciences/2019/press-release/

The Psychologist (Ed.). (2009). Social cognitive theory goes global (6th ed., Vol. 22). Talk for the British Psychological Society's London and Home Counties Branch at Friends House, London. Retrieved 2020-09-17, from https://thepsychologist.bps.org.uk/ volume-22/edition-6/social-cognitive-theory-goes-global

Todd, P. (2013). How to Improve Women's Employability and Quality of Work in Developing and Transition Economies (Working Paper). Retrieved 2020-1001, from http://www.womeneconroadmap.org/sites/default/files/Todd_Improve\% 20Women $\% 20$ Employability $\% 20$ and $\% 20$ Quality $\% 20$ of $\% 20$ Work.pdf

UNESCO. (2020). Madagascar Education and Literacy. Retrieved 2020-04-16, from http://uis. unesco.org/en/country/mg

UNFPA. (2015). Madagascar sees a new generation of women leaders. Retrieved 202004-16, from https://www.unfpa.org/news/madagascar-sees-new-generation-women -leaders 
UNICEF. (2020). Early childhood development - development status. Retrieved 2020-07-29, from https://data. unicef .org/resources/dataset/early-childhood-development -development-status/

UNICEF Madagascar. (2018). Challenges and opportunities for children in Madagascar (Tech. Rep.). United Nations Children's Fund. Retrieved 2020-09-22, from https://www. unicef .org/madagascar/en/reports/challenges-and -opportunities-children-madagascar

Valentinov, V. (2007). Why are cooperatives important in agriculture? An organizational economics perspective. Journal of Institutional Economics, 3(1), 55-69. doi: 10.1017/ S1744137406000555

Vélez, M. A., Robalino, J., Cardenas, J. C., Paz, A., \& Pacay, E. (2020). Is collective titling enough to protect forests? Evidence from Afro-descendant communities in the Colombian Pacific region. World Development, 128, 104837.

Wollni, M., \& Zeller, M. (2007). Do farmers benefit from participating in specialty markets and cooperatives? The case of coffee marketing in Costa Rica. Agricultural Economics, $37(2-3), 243-248$.

World Bank. (2015). World Development Report 2015: Mind, Society, and Behavior (Tech. Rep.). Retrieved 2020-09-29, from https://www.worldbank.org/en/publication/ wdr2015

World Bank. (2019). World Development Indicators. Retrieved 2019-09-10, from https:// data. worldbank. org

World Economic Forum. (2019). The Global Gender Gap Report (Tech. Rep.). Cologny/Geneva, Switzerland: World Economic Forum. Retrieved 2020-09-22, from https://www. weforum.org/reports/gender-gap-2020-report-100-years-pay -equality

World Food Programme. (2020). Democratic Republic of the Congo. Retrieved 2020-07-10, from https://www.wfp.org/countries/democratic-republic-congo

Wozniak, D., Harbaugh, W. T., \& Mayr, U. (2014). The Menstrual Cycle and Performance Feedback Alter Gender Differences in Competitive Choices. Journal of Labor Economics, 32(1), 161-198.

Wuepper, D., \& Lybbert, T. J. (2017). Perceived Self-Efficacy, Poverty, and Economic Development. Annual Review of Resource Economics, 9(1), 383-404.

Wydick, B., Glewwe, P., \& Rutledge, L. (2013). Does International Child Sponsorship Work? A Six-Country Study of Impacts on Adult Life Outcomes. Journal of Political Economy, 121(2), 393-436. 
Zelmer, J. (2003). Linear Public Goods Experiments: A Meta-Analysis. Experimental Economics, 6(3), 299-310. 